Portland State University

PDXScholar

$1-1-2012$

\title{
Intimate Partner Violence During the Transition from Prison to the Community: An Ecological Analysis
}

Margaret Joy Freeland Braun

Portland State University

Follow this and additional works at: https://pdxscholar.library.pdx.edu/open_access_etds

Let us know how access to this document benefits you.

\section{Recommended Citation}

Freeland Braun, Margaret Joy, "Intimate Partner Violence During the Transition from Prison to the Community: An Ecological Analysis" (2012). Dissertations and Theses. Paper 511.

https://doi.org/10.15760/etd.511

This Dissertation is brought to you for free and open access. It has been accepted for inclusion in Dissertations and Theses by an authorized administrator of PDXScholar. Please contact us if we can make this document more accessible: pdxscholar@pdx.edu. 
Intimate Partner Violence During the Transition from Prison to the Community:

An Ecological Analysis

by

Margaret Joy Freeland Braun

A dissertation submitted in partial fulfillment of the requirements for the degree of

Doctor of Philosophy

in

Applied Psychology

Dissertation Committee:

Eric S. Mankowski, Chair

Paul T. Bellatty

Todd Bodner

Kris Henning

Katherine McDonald

Portland State University

(C)2012 


\begin{abstract}
While extensive research has been conducted on the causes of intimate partner violence in the community, very little is known about rates and predictors of domestic violence perpetrated by offenders who have recently been incarcerated. Some evidence suggests that formerly incarcerated individuals may be at an increased risk to perpetrate intimate partner violence during the transition from prison to the community (e.g., Hairston \& Oliver 2006; Hilton, Harris, Popham, \& Lang, 2010; Oliver \& Hairston, 2008). The primary goal of this dissertation was to examine the extent to which former inmates engage in domestic violence during the transition from prison to the community. A second goal of this dissertation was to determine the independent and interactive effects of selected individual, situational, and socialstructural factors on post-prison domestic violence. The current dissertation project involved a retrospective study of data collected from $n=1,137$ formerly-incarcerated male offenders who were released from state prison between 2004 and 2009. Data regarding individual-level factors of borderline and antisocial personality characteristics and exposure to family-of-origin violence were extracted from institutional records. Additional individual-level demographic characteristics including offenders' age, ethnicity, education need, marital status, number of children, crime of conviction, length of incarceration, and participation in correctional rehabilitation programs extracted from institutional records were also considered. The situational-level factor of offenders' employment after prison release
\end{abstract}


was also collected from institutional records; and the social-structural factor of neighborhood disadvantage was collected from information available in offenders' community supervision records and Census tract-level data. The outcome measure of post-prison domestic violence was gathered from local law enforcement records. Data were entered into statistical models to predict post-prison domestic violence. Main effects on post-prison domestic violence were examined for each of the individuallevel demographic characteristics, borderline and antisocial personality features, exposure to family-of-origin violence, employment, and neighborhood disadvantage. Interactive effects on post-prison domestic violence were examined between borderline and antisocial personality characteristics, exposure to family-of-origin violence, employment, and neighborhood disadvantage. Significant predicted main effects on post-prison domestic violence included age, ethnicity, education need, number of children, violent criminal history, attendance of substance abuse treatment in prison, witnessing interparental violence as a child, and neighborhood disadvantage. Significant predicted interaction effects on post-prison domestic violence included the interaction between physical abuse as a child and neighborhood disadvantage. Implications for policies regarding post-prison supervision sentencing, housing, and the advancement of programming to prevent intimate partner violence during the transition from prison to the community are discussed. Contributions to the literature on intimate partner violence, environmental transition theory, and ecological theoretical frameworks are also addressed. 


\section{Dedication}

My dissertation is dedicated to my dad, Stephen J. Freeland, $\mathrm{PhD}$ (Colorado State University, 1981). Da, I still have the "Round Tuit" that Pop gave to you while you were writing your dissertation. I am honored that you passed it down to me while I was writing mine. Your achievement of a $\mathrm{PhD}$ was the biggest motivator for me to follow in the same path (even if mine is not in a "real" science - ha ha). You have no idea how wonderful it has been to be able to share my struggles during this process with someone who knows them only too well. I never would have begun this journey without your support, and I never would have finished without your perpetual encouragement. I love you. 


\section{Table of Contents}

Abstract........................................................ i

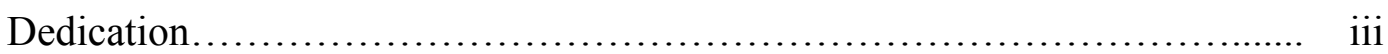

List of Tables................................................ v

List of Figures................................................... vii

Chapter 1

Introduction and Overview.......................................... 1

Chapter 2

Conceptual Model.................................................. 13

Chapter 3

The Experience of Incarceration for Inmates and Partners and the Effect on Intimate Relationships and Partner Violence during Reentry.

Chapter 4

Research Questions

Chapter 5

Method................................................................ 116

Chapter 6

Analysis.

Chapter 7

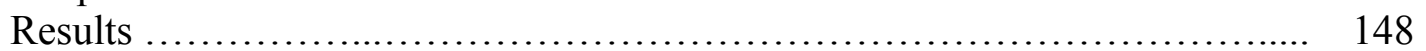

Chapter 8

Discussion, Contributions, and Limitations.............................. 206

References...................................................... 268 


\section{List of Tables}

Table 1

Interactions tested in Research Question Two.

Table 2

Demographic characteristics of the study sample and study population who were released from prison to Multnomah county and the population of offenders released to the entire state between January 1, 2004 and December $31,2009$.

Table 3

List of measured variables with corresponding data sources

Table 4

Dummy variables created to represent categorical demographic constructs.......

Table 5

Interaction terms created for Research Question Two.

Table 6

Descriptive statistics for individual, situational, and social-structural level variables $(n=1137)$.

Table 7

Descriptive statistics for additional individual-level demographic characteristics $(n=1137)$....

Table 8

Correlation coefficients between each non-categorical construct $(n=1137) \ldots \ldots . .$.

Table 9

One-way analysis of variance showing differences in continuous variables by the categorical variable of ethnicity $(n=1137)$.

Table 10

One-way analysis of variance showing differences in continuous variables by the categorical variable of marital status $(n=1137)$.

Table 11

One-way analysis of variance showing differences in continuous variables by the categorical variable of education need $(n=1137)$. 
Table 12

Chi-square tests showing differences in categorical variables by ethnicity $(n=1137)$

Table 13

Chi-square tests showing differences in categorical variables by marital status $(n=1137)$

Table 14

Chi-square tests showing differences in categorical variables by education need $(n=1137)$.

Table 15

Step one of the Cox regression model predicting any post-prison domestic violence incident $(n=1137)$.

Table 16

Step two of the Cox regression model predicting any post-prison domestic violence incident $(n=1137)$.

Table 17

Step one of the Cox regression model predicting severe post-prison domestic violence $(n=1137)$

Table 18

Step two of the Cox regression model predicting severe post-prison domestic violence $(n=1137)$.

Table 19

Summary of main effects

Table 20

Summary of interaction effects. 


\section{List of Figures}

\section{Figure 1}

Ecological models of intimate partner violence proposed by Carlson (1984) (a) and Heise (1998) (b)

Figure 2

Ecological models of intimate partner violence (a) and the transition from prison to the community (b)

Figure 3

Ecological model combining intimate partner violence and the transition from prison to the community.

Figure 4

Areas where the study sample is decreased due to missing data on specific measures

Figure 5

Estimated survival function for any post-prison domestic violence incident

Figure 6

Estimated hazard function for any post-prison domestic violence incident

Figure 7

Estimated survival function for severe post-prison domestic violence.

Figure 8

Estimated hazard function for severe post-prison domestic violence.

176

Figure 9

Survival rate to any post-prison domestic violence incident at the means of the predictors and interactions

Figure 10

Interaction between witnessing interparental violence and percentage of quarters worked on any post-prison domestic violence incident

Figure 11

Interaction between antisocial personality characteristics and percentage of quarters worked on any post-prison domestic violence incident. 
Figure 12

Interaction between borderline personality characteristics and percentage of

quarters worked on any post-prison domestic violence incident

Figure 13

Survival rate to severe post-prison domestic violence at the means of the predictors and interactions

Figure 14

Interaction between physical abuse during childhood and percentage of quarters

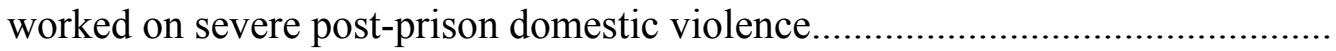

Figure 15

Interaction between physical abuse during childhood and neighborhood disadvantage on severe post-prison domestic violence

Figure 16

Interaction between neighborhood disadvantage and percentage of quarters worked on severe post-prison domestic violence.

Figure 17

Interaction between physical abuse during childhood and borderline personality on severe post-prison domestic violence

Figure 18

Interaction between witnessing interparental violence and percentage of quarters worked on severe post-prison domestic violence. 


\section{Chapter 1: Introduction and Overview}

Incarceration rates in the United States (US) are exceptionally high. With more than 730 per 100,000 US residents housed in prisons and local jails, current incarceration rates have surpassed those of any other time in US history and those of all other Western European countries (Gottschalk, 2009; Raphael, 2009; Tonry, 1999). While the growth in US incarceration rates initially corresponded with increasing violent crime in the $1980 \mathrm{~s}$, an overall decrease in violent crime in the 1990s was not followed by a reciprocal decrease in incarceration (Tonry, 1999; Warren, Gelb, Horowitz, \& Riordan, 2008). Violent crime - with the exception of gun violence-is no higher in the US than in other Western European countries (e.g., Germany and Finland) where the rate of incarceration has stabilized or decreased since the early 1970s (Tonry, 1999). In contrast, the incarceration rate in the US has nearly quadrupled over the same period of time (Raphael, 2009).

Most individuals who are incarcerated in the US will eventually be released back into the community when their sentences end. In fact, the number of people who are released from prison each year is nearly identical to the number of people who are admitted. More than 735,000 individuals were released from US prisons in 2008-a figure almost equal to the number of new inmates during the same year (Sabol, West, $\&$ Cooper, 2009). Because of the high rate of inmate release, some scholars have distinguished current reentry trends from those at any other time in history. In other 
words, the number of inmates releasing back into the community today is the largest it has ever been (Petersilia, 2001).

\section{The Transition from Prison to the Community}

The transition from one environment to another is a phenomenon that has been studied by scholars in community psychology over the past several decades (e.g., Felner, Aber, Primavera \& Cauce, 1985; Felner, Ginter, \& Primavera, 1982; Felner, Primavera, \& Cauce, 1981). In general, transitions between environments present challenges in relation to coping with and adjusting to the new environment. Individuals undergoing transitions such as getting married, retirement, or transferring between schools are faced with navigating new social roles and expectations which may cause stress in the form of role strain (Fenzel, 1989). Unfortunately, evidence suggests that the kind of stress experienced during the transition from one environment to another can cause some individuals to adjust to the new environment in maladaptive ways (Felner et al., 1982). More generally, some individuals appear to be susceptible to maladaptive changes in adjustment during significant life transitions. Based on these principles, it is reasonable to imagine that former inmates are susceptible to stress during the significant life event of transitioning from prison back into the community; and that some may experience challenges when adjusting to their new environment.

During the transition from prison to the community, former inmates are tasked with engaging in activities that contribute meaningfully to their new environment and 
reduce the risk that they will recidivate and go back to prison. Toward that end, exinmates face several different challenges. These challenges may include finding employment, resisting drugs and alcohol, disassociating from criminal peers, and engaging in community-based therapeutic services that address mental health, addiction, and behavioral issues (Andrews \& Bonta, 2010; Bahr, Armstrong, Gibbs, Harris, \& Fisher, 2005; Harding, 2003; Oliver \& Hairston, 2008; Travis \& Petersilia, 2001). In addition, many former inmates reestablish interpersonal relationships they had before prison and reintegrate back into their families (Gadsen, 2003; Harman, Smith, \& Egan, 2007; Nelson, Deess, \& Allen, 1999; Oliver \& Hairston, 2008; Petersilia, 2001).

The transition and the family. Research regarding transitions from one environment to another indicates that perceived social support from friends and family buffers individuals' experiences of stress during the transition and decreases the chance of maladaptive adjustment to the new environment (Felner et al., 1982; Fenzel, 1989). The same appears to be true for former inmates engaging in the transition between prison and the community. Specifically, a growing body of literature suggests that maintaining strong family connections and social support throughout an inmate's incarceration and during reentry to the community can significantly decrease the risk of recidivism and increase former inmates' overall success after prison (Draine \& Wolff, 2009; Herman-Stahl, Kan, \& McKay, 2008; Hughes, 1998; Mills \& Codd, 2008; Rose \& Clear, 2003). For example, in a 
qualitative study of 49 offenders' post-prison experiences, Nelson and colleagues (1999) found that those with strong and supportive family connections were more likely to engage in other activities that reduced their risk of recidivism including finding a job, establishing permanent housing, and abstaining from drugs and alcohol. To illustrate, a third of participants with supportive families found employment within the first month after release, and 82 percent were living with their families in what they perceived as a permanent arrangement. In addition, study participants with substance abuse problems who had strong families that supported their efforts to stay sober were less likely to relapse during the first month after release. The seven participants in the study who did relapse shared only one characteristic in common: they all reported tenuous family relationships (Nelson et al., 1999).

In an ideal world, all inmates who release from prison could reunite with strong and supportive families during reentry and succeed to the same degree as the offenders in Nelson et al.'s (1999) research. However, reconciliation with family members after prison is difficult. Former inmates struggle to reinitiate interpersonal relationships because of problems or conflict that may have existed before the incarceration or developed as a result of the incarceration (Fishman, 1990). Imprisonment not only impacts the individual in custody but can also have serious consequences for the inmate's family, spouse, and/or children. Inmates' families face their own difficult challenges during the incarceration like coping with physical separation, lack of income, absent parenting, and stigmatization by the community 
(Bakker, Morris, \& Janus, 1978; Carlson \& Cervera, 1991; Codd, 2007; Harman et al., 2007; Petersilia, 2001, 2009; Showalter \& Williams-Jones, 1980; Zamble \& Porporino, 1990). Families and spouses experience intense emotional reactions such as anger toward the inmate for committing crime and resentment because they cannot contribute to the family or share childcare responsibilities when they are incarcerated (Bakker et al., 1980; Dallao, 1997; Hannon, Martin, \& Martin, 1984; Harman et al, 2007; Nelson et al., 1999; Oliver \& Hairston, 2008; Tripp, 2003). The residual effects of such intense emotions, coupled with the stress of the offender's transition back into the community and the family, may lead to conflict—particularly conflict between former inmates and their intimate partners (Hairston \& Oliver, 2006; Harman et al., 2007; Oliver \& Hairston, 2008; Tripp, 2003).

The transition and intimate partner violence. Although difficulties reuniting with intimate partners are surely encountered by both male and female former inmates, much of the current literature concerning intimate partner conflict during the transition from prison to the community concentrates on male inmates returning to female intimate partners (e.g., Hairston \& Oliver, 2006; Oliver \& Hairston, 2008; Oliver, Williams, Hairston, \& Crowder, 2004). Given that men are incarcerated at 14 times the rate of women (Sabol et al., 2009), the concentration on male former inmates returning to female partners within the literature is not surprising. Due in part to the high rate of male former inmates returning home to female partners, a selection of scholars have recently begun to consider whether 
partner conflict that may occur within the context of male former inmates' transition to the community could develop into male-to-female intimate partner violence (e.g., Hairston \& Oliver, 2006; Oliver \& Hairston, 2008; Oliver et al., 2004).

Intimate partner violence is a serious problem that impacts a variety of individuals, families, and communities throughout the US. Though partner violence can occur in all types of intimate relationships (e.g., heterosexual and homosexual) and both women and men can be victimized, perpetrators are significantly more likely to be men (Healey, Smith, \& O’Sullivan, 1998). Despite significant social and political advances such as the battered women's movement (Dobash \& Dobash, 1979) and the Violence against Women Act of 1994, the physical, sexual, and psychological victimization of women continues to be a widespread issue. For example, a national survey of families in the US showed that nearly 22 percent of female respondents had been physically assaulted, raped, or stalked by an intimate partner at sometime in their lives (Tjaden \& Thoennes, 2000). Psychological violence in the form of threats and intimidation is also common. Of the national survey respondents who had been victimized, 33 percent reported that their partner threatened to kill them and 45 percent indicated they feared they or someone close to them would be severely harmed or killed during their most recent physical assault (Tjaden \& Thoennes, 2000). In addition, domestic violence is the most common cause of injury to women between the ages of 15 and 44 (Marin \& Russo, 1999) and 
is a frequent reason for seeking medical care reported by women visiting emergency rooms (Tjaden \& Thoennes, 2000).

Some of the more recent research on domestic violence is focused on how intimate partner violence is perpetrated within a variety of specific contexts (i.e., the workplace; see Versola-Russo \& Russo, 2009, for a review). Intimate partner violence that occurs during former inmates' transition from prison to the community is one context that warrants more investigation. Currently, research in this area is still developing and is mostly exploratory. For example, Oliver and Hairston (2008) conducted focus groups with former inmates wherein participants described circumstances in which domestic violence could result from the stressors associated with the transition from prison to the community. Several participants reported that they would feel justified expressing their frustration with family dynamics through displays of aggression and violence against their partners. Other participants reported that they would feel justified engaging in violence if they believed their partner was unfaithful during the incarceration or if she challenged the former inmate's authority in the family (Hairston \& Oliver, 2006; Oliver \& Hairston, 2008). Similarly, focus groups conducted with female intimate partners of incarcerated men revealed that some women anticipate abuse during the transition from prison either because of past violent experiences or threats communicated during the incarceration (Hairston \& Oliver, 2006). 
Beyond the findings of this exploratory research, data regarding the actual occurrence of partner violence perpetrated by ex-inmates during reentry is limited. In addition, many known individual, situational, social-structural, and sociocultural correlates of domestic violence (e.g., demographic variables, personality characteristics, family history, violent and/or delinquent peer associations, substance abuse, employment, and neighborhood disadvantage; Benson \& Fox, 2004;

Dekeseredy \& Kelly, 1993; Dutton \& Hart, 1992; Jennings \& Murphy, 2000; Logan, Walker, Staton, \& Leukefeld, 2001; O’Neil, 2008; White, Gondolf, Robertson, Goodwin, \& Caraveo, 2002; see also Schumacher, Feldbau-Kohn, Smith Slep, \& Heyman, 2000 and Stith, Smith, Penn, Ward, \& Tritt, 2004 for reviews) have received limited attention within the current research on intimate partner violence during former inmates' transition from prison to the community.

\section{Purpose of Study}

The primary goal of this dissertation was to build upon the current literature with an examination of formerly incarcerated offenders' perpetration of domestic violence during the transition from prison to the community. The limited literature already suggests that the risk for intimate partner violence may be high during this time (e.g., Hairston \& Oliver, 2006; Oliver \& Hairston, 2008; Oliver et al., 2004); however knowledge regarding the actual prevalence of intimate partner violence during the transition from prison to the community is missing. A second purpose of this dissertation was to determine whether selected individual, situational, and social- 
structural factors independently and interactively predicted intimate partner violence perpetrated by former inmates after their release from prison. Beyond focus group participants' reports of issues that may 'trigger' domestic violence (e.g., evidence of infidelity and feelings of powerlessness; Hairston \& Oliver, 2006; Oliver \& Hairston, 2008), knowledge regarding other specific factors that may increase the risk for domestic violence during reentry is absent. More knowledge regarding (1) the extent to which domestic violence occurs during formerly incarcerated offenders' transition from prison to the community; and (2) the individual, situational, and socialstructural factors that contribute to domestic violence perpetration during this time may help correctional departments better assess and address offenders' risk of engaging in post-prison domestic violence. Other significant life transitions have been targeted by community psychologists for primary prevention, including the transition from elementary or middle school to high school and the transition some children undergo when parents divorce (e.g., Felner et al., 1982). If evidence indicates that formerly incarcerated offenders are at risk to perpetrate intimate partner violence after being released from prison, prevention efforts could be targeted on soon-to-be-released inmates and their families that could help to reduce that risk.

The organization of this dissertation. I begin by situating the topic of intimate partner violence during the transition from prison to the community within an ecological theoretical framework. I describe the ecological framework as it exists both in developmental and community psychology, and then apply the framework to 
the study of intimate partner violence during formerly incarcerated offenders' transition from prison to the community. I then examine the impact of incarceration on inmates and their partners, focusing specifically on the effects of imprisonment on intimate relationships. Drawing from Bronfenbrenner's (1977) ecological theory of human development, I argue that inmates and partners encounter different developmental experiences (i.e., proximal processes) and that each person develops incompatible beliefs, attitudes, and behaviors as a result of these separate experiences (Harman et al., 2007). I then focus on the deleterious effects of incarceration for inmates, emphasizing how inmates' adaptation to prison life (i.e., 'prisonization'; Clemmer, 1940) can have detrimental consequences for their intimate relationships during reentry. I draw from theories of gender role socialization to argue that inmates' adaptation to prison life involves adopting standards of stereotypical and often extreme masculinity that are modeled in the prison environment (Rose, 2001; Seymour, 2003). Tenets of stereotypical masculinity may encourage inmates to take on attitudes and values like power and control, dominance, and aggression—qualities that not only contribute to masculine gender role conflict at the individual level but may also contribute to relationship problems and interpersonal violence (Braithwaite \& Daly, 1994; Kimmel, 1994; O’Neil, 2008).

Upon establishing that the experience of incarceration can have significant negative consequences for both inmates and their partners, I transition into a review of the limited literature on intimate partner violence perpetrated during the transition 
from prison to the community and among incarcerated populations in general. Although research on the occurrence of partner violence during reentry is limited, data from focus groups conducted with male inmates and female partners of incarcerated men suggests that both parties anticipate difficulty upon the ex-inmate's homecoming. Moreover, both inmates and partners are able to identify specific circumstances and challenges during reentry that will most likely lead to domestic violence (i.e., evidence of infidelity, shifts in gender role dynamics, and struggles for power and control; Hairston \& Oliver, 2006; Oliver \& Hairston, 2008). Furthermore, many female partners of inmates anticipate domestic violence during reentry because they experienced abuse before their partner's incarceration began (Hairston \& Oliver, 2006) or in some cases during their partner's incarceration (Riesch Toepell \& Greaves, 2001).

In addition, evidence from a number of studies indicates that some male inmates report perpetrating intimate partner violence before being sent to prison (Cook, 2002; Dutton \& Hart, 1992; Robertson \& Murachver, 2007; White et al., 2002). In a study of men's self-reported domestic violence behavior, White and colleagues (2002) found that one third of surveyed inmates physically assaulted their partner in the year prior to their incarceration. Similarly, findings from Dutton and Hart's (1992) review of nearly 600 inmate files indicate that 30 percent engaged in violence against a family member before entering prison. Also, in a comparison of incarcerated and non-incarcerated samples, Robertson and Murachver (2007) 
discovered that male inmates report perpetrating significantly more physical and psychological violence against their partners and inflict substantially more injury than non-incarcerated controls. It is reasonable to speculate that men who perpetrated violence before being sent to prison may continue to engage in the same kinds of behaviors once they are released.

Finally, I report the results of a study that tested a model of intimate partner violence predictors during the transition from prison to the community. I conducted a retrospective study of data collected from institutional and community supervision records of formerly incarcerated male offenders who were released from state prison between 2004 and 2009. Institutional and community supervision records were paired with data from law enforcement reports of domestic violence perpetrated by these offenders in the community after prison release. 


\section{Chapter 2: Conceptual Model}

All too often academic research, theory, and public policy attempt to attribute complex social issues to a limited number of causal factors. For example, numerous lines of inquiry have attempted to isolate the causes of intimate partner violence within a limited number of contextual levels. To illustrate, some research and theory focus almost exclusively on individual qualities of abusive men such as personality characteristics (e.g., Dutton, 1994, 1998; Holtzworth-Munroe \& Stuart, 1992) and physiological abnormalities (e.g., head injury; Rosenbaum, Hoge, Adelman, Warnken, Fletcher, \& Kane, 1994). Other theories promote similarly limited explanations of intimate partner violence, asserting that all violence against women is caused by men's need for power and control and the societal undervaluing of women (e.g., Pence \& Paymar, 1993).

The rapidly growing body of research concerning intimate partner violence risk assessment is an example of the tendency to restrict the explanation of domestic violence to one or two levels of behavioral analysis. Much of the research on domestic violence risk has been dedicated to the identification of individual risk factors, the development of risk assessment tools based on those factors, and the validation of these tools across a variety of samples and research contexts. The most well known risk assessment tools include the Ontario Domestic Assault Risk Assessment (ODARA, Hilton, Harris, Rice, Lang, \& Cormier, 2004), the Danger Assessment (DA; Campbell, 1995), the Domestic Violence Screening Inventory 
(DVSI; Williams \& Houghton, 2004), the Spousal Assault Risk Assessment Guide (SARA; Kropp, Hart, Webster, \& Eaves, 1995, 1999), and the Violence Risk Appraisal Guide (VRAG; Harris, Rice, \& Quinsey, 1993). A recent meta-analysis (Hanson, Helmus, \& Bourgon, 2007) indicates each of these risk assessments show small to moderate associations with domestic violence recidivism; however most of these tools limit the scope of assessment to individual-level characteristics of perpetrators.

To illustrate, the VRAG only measures static perpetrator characteristics such as childhood history, criminal history, and psychiatric variables (Harris et al., 1993). The scope of risk factors measured by the DA, SARA, and DVSI is slightly broader in that each measure considers perpetrators' employment status and relationship problems in addition to individual characteristics (Campbell, 1995; Kropp et al., 1995, 1999; Williams \& Houghton, 2004). In an effort to improve and facilitate the 'comprehensive' measurement of intimate partner violence risk, Kropp (2009) outlined ten factors that should always be considered in risk assessment. These include (1) past physical or sexual violence in relationships; (2) violent threats, ideation, or intent; (3) escalation of violence; (4) violations of civil or criminal court orders; (5) attitudes supporting domestic violence; (6) other criminality; (7) relationship problems; (8) employment and/or financial problems; (9) substance abuse; and (10) mental disorder or illness. Notably, nine out of ten of these factors are located exclusively at the individual level of behavioral analysis. Limiting the scope 
of measurement to individual-level characteristics alone hardly advances the 'comprehensive' measurement of domestic violence risk. Risk factors within the situational, social-structural, and sociocultural contextual levels are virtually ignored. Restricting the focus of scholarly inquiry to a limited number of contextual levels may facilitate the accumulation of scientific knowledge by making research and theory-building more manageable; however such an approach inherently implies that complex social issues can be explained by a handful of individual factors. Certainly not all occurrences of intimate partner violence can be explained by individual characteristics like attitudes, personality, mental health, or criminal history alone. Rather, complex social issues like intimate partner violence are more likely to be caused by the interaction of multiple factors that exist simultaneously across a variety of contextual levels. These interactions are the focus of ecological theoretical frameworks.

Research and theory-building that is informed by the ecological perspective consider that human behavior and social phenomena are the result of interdependent factors that exist simultaneously at multiple levels: individual/ontogenic, situational, social-structural, cultural, and historical. In addition to seeking out and isolating the effects of single factors, ecological researchers also focus on principal main effects that are caused by interactions (Bronfenbrenner, 1977). This perspective can be applied to the topic of this dissertation - the occurrence of intimate partner violence during the transition from prison to the community. There are no doubt multiple 
features of contexts impinging on the lives of men transitioning from prison back into the community, including searching for employment, reconnecting with their children, and desisting from crime (Petersilia, 2001). Certain behaviors like partner conflict and domestic violence that may occur during this transition are likely caused by the interaction of these multiple contextual features and not by any one of them alone.

The following chapter introduces the ecological perspective and summarizes its applicability within the context of this dissertation. I begin with a description of the ecological perspective and review its use within the fields of developmental and community psychology. I then describe how the ecological perspective has been applied to the understanding of intimate partner violence in the current literature. I also conceptualize criminal risk during the transition from prison to the community within an ecological framework, despite the limited application of the framework to this social issue in the literature. Finally, I highlight the significant overlap between ecological frameworks of intimate partner violence and criminal risk during former inmates' transition from prison to the community and propose an integrated conceptual model that this dissertation explored.

\section{Bronfenbrenner's Ecological Model of Human Development}

Bronfenbrenner's (1977, 1994; Bronfenbrenner \& Morris, 1998) ecological model of human development was first introduced in the 1970s in reaction to researchers studying individual behavior within virtual social "vacuums". 
Specifically, Bronfenbrenner (1977) observed that the majority of research in the field of human development was conducted in sterile, unnatural situations devoid of real life consequences and contextual cues (i.e., the laboratory). Bronfenbrenner (1977) argued that findings derived from these kinds of investigations had limited applicability to reality, and that in order to understand human development one must consider the entire ecological system in which growth occurs (Bronfenbrenner, 1994, p. 37).

Bronfenbrenner's ecological perspective (1977, 1994; Bronfenbrenner \& Morris, 1998) began almost exclusively as a theory within the field of developmental psychology and has since expanded into a model that can be applied almost universally to the analysis of human behavior. The model asserts that individuals develop within nested levels of context that interact with one another to shape attitudes, beliefs, and behaviors. These levels, from innermost to outermost, are the microsystem, mesosystem, exosystem, and macrosystem. Nested levels assume the effect each level has on the other as well as the all-encompassing nature of the largest, most abstract level (i.e., the macrosystem). As the levels progress toward the center of the system they more closely represent the literal interactions of the individual with his immediate environment.

The innermost level, the microsystem, represents an individual's immediate environment and incorporates the interactions that the person engages in directly with other people, objects, and symbols in that environment. These enduring, 
progressively more complex and reciprocal interactions - called proximal processes - are units of development. Proximal processes cumulatively shape individuals' attitudes, beliefs, and behaviors over time. Individuals participate in multiple microsystems simultaneously, and interactions that occur in one microsystem impact interactions that occur in others. These interrelationships between multiple microsystems are represented by the next level in the ecological framework, the mesosystem. Interactions that occur beyond the mesosystem which indirectly influence the developing individual are the focus of the exosystem. The exosystem represents interactions in which others engage that have an eventual impact on the individual's immediate situation (Belsky, 1980; Edleson \& Tolman, 1992). Finally, the macrosystem represents higher level cultural components that operate through their influence on factors that exist within the lower levels of analysis.

Bronfenbrenner's (1977, 1994; Bronfenbrenner \& Morris, 1998) ecological model applies to the developmental experiences of an offender making the transition from prison to the community after being released. Many inmates who are released from prison return home to spouses and children who all participate in the offender's family microsystem. Within the family microsystem the offender regularly engages in reciprocal interactions (i.e., proximal processes) with his spouse that, as the relationship continues, become progressively more complex. For example, the couple may have more children, change their housing situation, support one another in going 
back to school, or engage in other joint ventures that will shape the kinds of proximal processes they have and, as a result, their development. The offender also participates in other microsystems with friends, coworkers, and community groups. Mesosystems are formed by the interrelationships between, say, the offender's family microsystem and friends microsystem. Interactions that the offender has within the family will influence interactions he has with his friends, and vice versa. Interactions that occur within the offender's community corrections supervision team represent the exosystem. For instance, community corrections staff make decisions about the offender's course of supervision and rehabilitation which impact his immediate environment (e.g., where he lives, what kind of therapeutic services he receives, and his daily activities). Finally, macrosystem factors such as community perceptions of criminal offenders or cultural beliefs about family will impact the offender's development through their influence on neighborhood environments, family dynamics, and interpersonal interactions.

\section{Community Psychology and the Ecological Approach}

While Bronfenbrenner's model of human development (1977, 1994; Bronfenbrenner \& Morris, 1998) is likely the most recognized articulation of the ecological perspective, interpretations of the theory exist in other disciplines as well. Specifically, Kelly and colleagues' ecological analogy (1966, 1968; Trickett, 1984, 1995, 1996; Trickett \& Birman, 1986; Trickett, Kelly, \& Todd, 1972; Trickett, Kelly, \& Vincent, 1985) was developed in the 1960s when community psychology began to 
spread to the US. Community psychology emerged in the US partially in response to paradigms such as clinical psychology which tended to minimize and ignore the ways that context, history, and culture shape human behavior (Trickett, 1995). In opposition to clinical psychology's inclination toward isolating human behavior as separate from the environment, the goal of community psychology is to understand individual behavior within the environment. While clinical psychologists focus the majority of their attention at the individual level of behavior analysis, community psychologists focus on the person-in-context level of analysis and argue that the functions of individuals and environments are interdependent (Kelly, 1968). Individual behavior is therefore analyzed within the context of the immediate environment, which is shaped by social, cultural, and historical factors (Kelly, 1966, 1968; Trickett, 1984, 1996; Trickett \& Birman, 1986; Trickett et al., 1972; Trickett et al., 1985)

Kelly and colleagues' ecological analogy (1966, 1968; Trickett, 1984, 1996; Trickett \& Birman, 1986; Trickett et al., 1972) both aligns with and is different from Bronfenbrenner's (1977, 1994; Bronfenbrenner \& Morris, 1998) ecological framework in a number of ways. Like Bronfenbrenner, Kelly (1966) maintains the basic assumption that ecology is useful for the interpretation of individual behavior in social situations. However, while Bronfenbrenner's model (1977, 1994; Bronfenbrenner \& Morris, 1998) focuses on the role of the individual developing person at the center of the framework, Kelly's $(1966,1968)$ model tends to 
emphasize the developmental dynamics of communities and provides ideas for interpreting different components of the ecological contexts themselves (Trickett \& Buchanan, 2001). The two models are also structurally distinctive. Instead of organizing the model around specified nested levels of analysis, Kelly $(1966,1968)$ proposes four principles (derived from field biology) that pertain to the study of social ecosystems: adaptation, cycling of resources, interdependence, and succession. These principles provide conceptual language for understanding and describing behavior at the person-in-context level of analysis (Trickett, 1995).

The adaptation principle refers to the cultural context of human communities. This context includes traditions, norms, processes, structures, and polices which together create environmental conditions to which individuals and groups adapt in varying ways (Trickett $\&$ Birman, 1989). Individual behavior is shaped by the particular adaptive requirements of the community, and individuals draw upon resources present in the environment in order to adapt to and function within that environment. The extent to which individuals are able to adapt depends upon the cycling of resources within their environment. Resources that are available for problem-solving and community development will help individuals meet the adaptive requirements of the community, and a lack of resources will make adaptation more difficult (Trickett, 1995; Trickett \& Buchanan, 2001).

The interdependence principle is identical to Bronfenbrenner's assumption (1977, 1994; Bronfenbrenner \& Morris, 1998) that components of the ecological 
system are interdependent. Changes made to one feature of the system produce a ripple effect of change throughout its other features, and the functioning of each part of the system is influenced by the functioning of its other parts (Kelly, 1968; Trickett, 1995; Trickett \& Birman, 1989). For example, behavior that is adaptive in one environment may be maladaptive in another because individual behavior and context depend upon each other (Trickett, 1995). Much of an individual's behavior varies from setting to setting, and therefore the greatest explanatory power is gained by considering the characteristics of persons and settings jointly (Trickett \& Todd, 1972).

Finally, the succession principle emphasizes the time dimension or the historical factors that shape the adaptation of individuals and communities over time (Kelly, 1968; Trickett, 1995). The historical past is in itself a characteristic of individual and community contexts and must be considered when interpreting behavior. At the individual level the succession principle highlights the historical, economic, social, and cultural contexts that individuals have experienced over time and how these contexts have shaped individuals' world views. This principle also draws attention to the impact individuals' world views have on their future goals and aspirations (Trickett, 1995; Trickett \& Birman, 1989; Trickett \& Buchanan, 2001).

As with Bronfenbrenner's framework (1977, 1994; Bronfenbrenner \& Morris, 1998), the ecological analogy articulated by Kelly and colleagues (1966, 1968; Trickett, 1984, 1996; Trickett \& Birman, 1986; Trickett et al., 1972) is best illustrated 
through an example. For instance, the ecological analogy can be used to describe how the dynamics of an offender's intimate relationship and family life influence their behavior shortly after being released from prison. The adaptive requirements of family life such as parental responsibilities and the expectations of the spouse shape former inmates' attitudes, beliefs, and behavior in regard to their spouse, children, and general family life. The extent to which ex-inmates meet such adaptive requirements is influenced by the availability and cycling of resources. For example, certain interpersonal and parenting skills may help an offender relate to and care for their children. The offender's education, job skills, and his ability to maintain employment will help him fulfill expectations his spouse may have regarding staying out of trouble and providing for the family. Social support provided by the spouse may also help the offender successfully follow through with his responsibilities and expectations. The interdependence of individual behavior and environmental circumstances is demonstrated through variations in the behavior of the former inmate following, say, an argument with their spouse. Offenders may become frustrated by their partner's expectations and their limited ability to fulfill those expectations, which may increase the risk that they will engage in criminal or otherwise negative behavior (e.g., abusing drugs or alcohol). Lastly, succession is represented by the historical, economic, social, and cultural surroundings that have shaped the former inmate's world view over time. For example, past experiences with his spouse and children will influence former inmates' attitudes, beliefs, and 
behaviors regarding his current family life and relationship dynamics (Trickett \& Todd, 1972).

\section{The Ecological Framework of Intimate Partner Violence}

As political and social awareness of intimate partner violence expanded in the late 1970s, so too did academic discourse regarding its causes, correlates, and potential solutions (Harway \& O’Neil, 1999). From this discourse, a number of theories have emerged proposing a diverse assortment of factors that are associated with and may cause male violence against female intimate partners. Although disagreements among scholars regarding certain causes of partner violence continue to exist (see Dutton \& Corvo, 2006, 2007 and Gondolf, 2007 for one example), many researchers generally argue that (1) there are multiple, varied causes of intimate partner violence that interact and overlap with each other in complex ways; (2) intimate partner violence is caused by diverse contextual, situational, cultural, historical, and individual characteristics; and (3) there is no "one size fits all" theoretical model that explains all occurrences of intimate partner violence across all situations (Carlson, 1984; Cunningham, Jaffe, Baker, Dick, Malla, Mazaheri, \& Poisson, 1998; Dutton \& Corvo, 2006; Gondolf, 2002; Harway \& O’Neil, 1999; Heise, 1998).

For these reasons, the study of intimate partner violence fits well within the context of an ecological analytical framework. The ecological perspective is appropriate for conceptualizing intimate partner violence in that it allows for the 
consideration of multiple, interdependent related factors that exist simultaneously at the personal, situational, social-structural, and sociocultural levels (Heise, 1998). Figure 1 illustrates two of the strongest ecological analyses of intimate partner violence, authored by Carlson (1984) and Heise (1998). Both authors analyze the correlates, potential causes, and maintenance of intimate partner violence from the perspective of Bronfenbrenner's ecological framework (1977, 1994; Bronfenbrenner $\&$ Morris, 1998) using slightly different, more applied nomenclature to describe the various levels of analysis. Carlson (1984) and Heise (1998) integrate findings from accumulated research on intimate partner violence and provide evidence for correlated and potentially causal factors that exist on each contextual level of analysis. The following sections are a summary and expansion of current articulations of intimate partner violence (e.g., Carlson, 1984; Harway \& O’Neil, 1999; Heise, 1998; Stith et al., 2004) through the lens of Bronfenbrenner's ecological framework (1977, 1994; Bronfenbrenner \& Morris, 1998). In some cases, Bronfenbrenner's original labels for each level of contextual analysis are replaced with the language proposed by Carlson (1984) and Heise (1998).

Individual/Ontogenic. Although representations of the ecological framework do not always include the individual or ontogenic level of behavior analysis, Carlson (1984) and Heise (1998) identify several potential causes of intimate partner violence at this level. Analysis at this level focuses on what the perpetrator brings with him to the relationship from his past experiences and individual development. Generally, this 

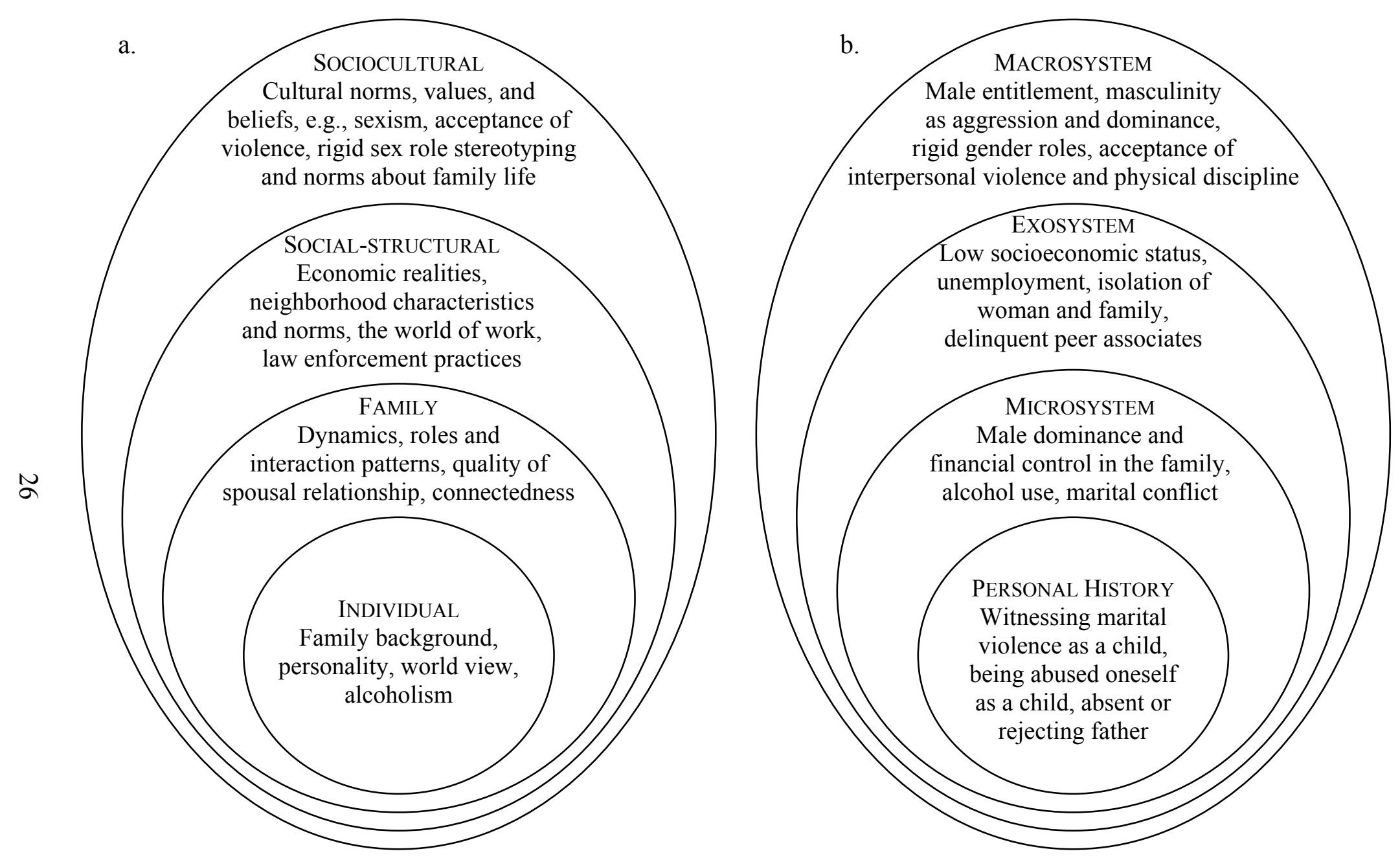

Figure 1. Ecological models of intimate partner violence proposed by Carlson (1984) (a) and Heise (1998) (b). 
may include individual characteristics like attitudes, values, and beliefs learned in one's family of origin or through past experiences; personal resources and skills; and perceptions of reality or beliefs about the world (Carlson, 1984).

Exposure to family-of-origin violence. A significant amount of evidence suggests that exposure to family-of-origin violence during childhood plays a role in the perpetration of abuse as an adult (Delsol \& Margolin, 2004). Early home experiences, parent-child interactions, and observations of parents' behavior lay the foundation for enduring cognitive, emotional, and behavioral patterns (Malamuth, Sockloskie, Koss, \& Tanaka, 1991). Therefore, early developmental experiences such as witnessing violence between parents and experiencing physical or sexual abuse oneself may encourage the transmission of attitudes and behavioral patterns that are marked by aggression and violence.

Indeed, many studies of intimate partner violence indicate that male perpetrators often report growing up in violent environments characterized by interparental violence and personal victimization (Carlson, 1984; Delsol \& Margolin, 2004; Heise, 1998; Malamuth et al., 1991; see also Stith, Rosen, Middleton, Busch, Lundeberg, \& Carlton, 2000 for a review). In a meta-analysis of research on the intergenerational transmission of violence, Stith and colleagues (2000) found significant moderate associations $(r=.21)$ between witnessing interparental domestic violence during childhood and perpetrating intimate partner violence in adulthood. The authors also found evidence supporting a relationship between abusive men's 
own childhood victimization and perpetrating partner abuse as an adult $(r=.19$; Stith et al., 2000). Of course, not all men who witness and/or are victims of abuse during childhood will engage in partner violence as adults; however the demonstrated relationship between witnessing and perpetrating abuse is worth considering within an ecological analysis of intimate partner violence.

Personality. Personality characteristics that are related to engaging in domestic violence also exist at the individual/ontogenic level of behavioral analysis (Carlson, 1984; Heise, 1998). There is substantial evidence to support the notion that some men who perpetrate relationship violence exhibit personality characteristics reflective of borderline, anti-social, and dependent/compulsive personality disorders (Dutton, 1994, 1995, 1998; Dutton \& Hart, 1992; Hamberger \& Hastings, 1986; Holtzworth-Munroe \& Stuart, 1994). Dutton (1994, 1998) actually proposes a specific "abusive personality" that closely mirrors borderline personality disorder. Men who exhibit Dutton's (1998) abusive personality are chronic abusers whose violence is unpredictable and directed only toward the family. Dutton (1998) describes these men as highly emotional, anxious, and depressed, and that they cycle through periods of mounting tension and explosive violence. Dutton (1998) argues that some men with abusive personalities likely developed fearful attachment styles during childhood and were rejected by their mothers and abused by their fathers. Personality characteristics inline with antisocial and narcissistic personality disorders 
are also apparent among domestically violent men (e.g., Dutton \& Hart, 1992; White et al., 2002).

In addition to Dutton's $(1994,1998)$ abusive personality theory, other researchers have proposed typologies of abusive men that are derived from personality characteristics and accompanying patterns of behavior (e.g., Hamberger \& Hastings, 1986; Holtzworth-Munroe \& Stuart, 1994). To illustrate, HoltzworthMunroe and Stuart (1994) assert that there are three subtypes of domestically violent men who consistently differ on three dimensions: personality characteristics, severity of abuse, and pattern of abusive behavior. "Family-only" abusive men are those whose violent behavior is mostly physical (i.e., not sexual or psychological), less severe, and perpetrated within the family exclusively. Men within the family-only subtype exhibit either passive-dependent personality disorder or no disordered personality characteristics whatsoever. Holtzworth-Munroe and Stuart (1994) estimate that up to 50 percent of domestically violent men fall within the family-only subtype. The second subtype, “dysphoric/borderline," includes abusive men whose violence is moderate to severe and manifests physically, psychologically, and sexually. The family is the primary target for this subtype's abusive behavior, but they may also be violent outside the family and likely evidence related problems with the law. Just as the label suggests, the dysphoric/borderline subtype is more likely to exhibit borderline or schizoid personality characteristics along with psychological distress, emotional instability, and problems with drugs and alcohol. Lastly, the 
“generally violent/antisocial" subtype represents men who engage in moderate to severe physical, psychological, and sexual abuse both within and outside the family. Because of their pattern of more frequent extrafamilial violence, men within the generally violent/antisocial subtype are more likely to have extensive histories of criminal behavior and problems with the law. These men may exhibit antisocial personality disorder or psychopathy, and are the most likely subtype to have severe problems with substance abuse. Holtzworth-Munroe and Stuart (1994) estimate that the dysphoric/borderline and generally violent/antisocial subtypes each account for 25 percent of abusive men.

Substance abuse. Many perpetrators of intimate partner violence also report substance abuse problems, which arguably exist at the individual level of behavioral analysis as well (Carlson, 1984; see also Heise, 1998, who positions substance abuse at the microsystem level of analysis). A large amount of evidence indicates that both alcohol and illicit drug use are significantly related to intimate partner violence (Bennett \& Williams, 2003; Carlson, 1984; Hilton \& Harris, 2005; Hotaling \& Sugarman, 1986; Kaufman-Kantor \& Straus, 2003; Stith et al., 2004; White et al., 2002). For example, Bennett, Tolman, Rogalski, and Srinivasaraghavan (1994) found that perpetration of domestic violence is significantly related to early onset of substance abuse problems and history of illicit drug use, particularly cocaine. More recently, O'Leary and Schumacher (2003) found both linear and threshold effects for the association between alcohol use and domestic violence. In two large national 
samples the authors found a linear relationship between quantity and frequency of alcohol use and intimate partner violence. They also discovered that the relationship between substance abuse and domestic violence was stronger for heavy drinkers and binge drinkers, indicating a threshold effect (O'Leary \& Schumacher, 2003). In addition, a recent meta-analysis indicated an overall moderate to strong relationship between perpetrating physical abuse against an intimate partner and substance abuse across 85 studies ( $r=.31$; Stith et al., 2004). To clarify, current evidence does not allow researchers to conclude that the association between substance abuse and intimate partner violence is causal; however it does suggest that drugs and alcohol significantly impact individuals' inhibitions and behavior patterns which, for some men, increases the likelihood that they will engage in intimate partner violence (Bennett \& Williams, 2003; Carlson, 1984; Gelles \& Straus, 1979a).

Masculine gender role conflict. When examining the association between masculinity and intimate partner violence it is necessary to reflect on the ways in which the relationship is conceptualized. In other words, one must consider the processes and mechanisms by which masculinity shapes men's perpetration of intimate partner violence (see Moore \& Stuart, 2005, for a review). Prior literature has focused heavily on gender role socialization and how the processes of masculine socialization influence how men express their emotions during times of distress (e.g., Harway \& O’Neil, 1999). For example, masculine-socialized men are taught that vulnerability and emotionality are signs of weakness and that one of the only 
acceptable emotions to express while maintaining one's masculine persona is anger. From this perspective, masculinity is associated with intimate partner violence in that masculine socialization processes encourage men to express anger at times when they are feeling sad or vulnerable. This anger may then lead to partner violence (Lisak, Hopper, \& Song, 1996).

Other scholars have suggested that domestic violence may not only be a consequence of masculine socialization processes that support anger and violence, but that it may also be a product of gender role conflict or the psychological state of men who are trying to adhere to dysfunctional gender role expectations (e.g., O'Neil, Helms, Gable, David, \& Wrightsman, 1986; O’Neil, 2008; Pleck, 1995). To illustrate, many of the masculine gender role expectations that are promoted by conventional Western society have negative consequences for men who follow them. For example, stereotypical masculine behaviors in which men are socialized to engage include emotional inexpressiveness, aggression, authoritativeness, and restricted affectionate behavior. Reinforcement and subsequent internalization of these behaviors restricts the range of coping mechanisms men are able to use when managing daily life events (e.g., expressing emotion or seeking help), thus diminishing their ability to cope effectively and relate to others (O’Neil et al., 1986; O’Neil \& Nadeau, 1999). In addition, gender role conflict theory asserts that men who resist adhering to stereotypical masculine gender role expectations also face negative psychological consequences because of cultural pressure to abide by accepted gender norms (Moore 
\& Stuart, 1995). In effect, masculine-socialized men face a double-edged sword regarding their masculinity in that both adhering to and resisting the processes of masculine gender role socialization can cause negative psychological consequences and may lead some men to engage in dysfunctional behaviors to meet gender role expectations (O’Neil et al., 1995; O’Neil \& Nadeau, 1999; Pleck, 1995).

Intimate partner violence is one dysfunctional behavior in which men experiencing masculine gender role conflict may engage in order to meet masculine gender role expectations (Moore \& Stuart, 2005; O’Neil \& Nadeau, 1999). Much of the research on masculine gender role conflict and intimate partner violence is based on the notion that challenges to masculine gender role expectations and the ensuing stress men feel may lead to intimate partner violence (Moore \& Stuart, 2005). In other words, the more stress or conflict felt by a man who perceives masculine gender role norms being challenged, the more likely that man is to engage in dysfunctional behaviors (e.g., violence) to diminish the threat to their masculine gender role. Moderate to large correlations between measures of gender role conflict and selfreported abusive behavior can be found in the literature $(r=.44$; Copenhaver, Lash, \& Eisler, 2000); and additional research indicates that gender role conflict significantly predicts dating violence, even when income and masculine ideology are statistically controlled (Jakupcak, Lisak, \& Roemer, 2002).

Parrott and Zeichner (2003) also found empirical support for the relationship between gender role conflict and violence against women through the examination of 
aggressive acts perpetrated by male college students against female confederates. The authors engaged male participants with female 'opponents' on a competitive task measuring reaction speed and accuracy. In order to measure aggression, male participants were informed that they could deliver electric shocks to their female opponent as frequently as they liked, or not at all, throughout the competition. This scenario created an environment where male participants faced the threat of 'losing to a girl' and were given the choice to reaffirm their masculine gender role through engaging in an aggressive act against a woman. Parrott and Zeichner (2003) found that the majority of male participants who shocked the female opponent the most were more likely to have abused an intimate partner at least once in their lifetime. Moreover, the same participants scored higher on measures of 'hypermasculinity,' indicating a tendency to overcompensate for their masculine gender role through exhibiting an exceedingly masculine personality. Although the authors did not use an instrument that measured masculine gender role conflict explicitly, the conditions of the experiment created a threat to male participants' gender role expectations to which some men - arguably those who experienced more stress and conflict in the face of the threat—responded with aggression.

Hostile attitudes toward women. Generally negative and hostile attitudes toward women (Check, Malamuth, Elias, \& Barton, 1985) including attitudes endorsing the abuse of women are also correlates of abusive behavior that can be placed within the individual level of ecological analysis (Eisikovits, Edleson, 
Guttman, \& Sela-Amit, 1991; Sugarman \& Frankel, 1996; Stith et al., 2004). Such attitudes may be learned in the home during early development, from peers, or from values perceived at the cultural level (Holtzworth-Munroe \& Stuart, 1994; Malamuth et al., 1991). Malamuth and colleagues (1991) conjecture that physical and sexual aggression against women are ways that some men "act out" hostile attitudes toward women.

Indeed, evidence indicates that hostile attitudes toward women are significantly associated with the perpetration of physical and sexual violence against women. In a study of nearly 3,000 male college students, Malamuth and colleagues (1991) found that participants' hostile attitudes toward women accounted for a significant proportion of the variance in self-reported physical and sexual aggression perpetrated against women. Studies comparing groups of domestically violent and non-violent men also indicate that violent men score significantly higher on measures of hostile attitudes toward women compared to non-violent men (Holtzworth-Munroe et al. 2000). Moreover, wives' reports of their male partners' hostile attitudes toward women differ significantly based on the severity of the male partners' abusive behavior (Holtzworth-Munroe et al., 2000).

In addition, evidence indicates that there may be within-group differences among men who engage in domestic violence in terms of their hostile attitudes toward women. For example, men's hostile attitudes toward women account for a significant portion of the variance among the three "batterer" subtypes proposed by 
Holtzworth-Munroe and Stuart (1994; Holtzworth-Munroe, 2000; HoltzworthMunroe, Meehan, Herron, Rehman, \& Stuart, 2000). In a study of domestically violent men and their wives, Holtzworth-Munroe and colleagues (2000) found that men who were classified within the "dysphoric/borderline" and "generally violent/antisocial" subtypes were more likely to exhibit hostile attitudes toward women relative to men in the "family only" subtype.

Previous domestically violent behavior. Although neither Carlson (1984) nor Heise (1998) explicitly identify men's previous perpetration of domestic violence as a factor that fits within their ecological models of intimate partner violence, evidence from two large meta-analyses indicates that past perpetration of physical, sexual, and psychological violence significantly predicts current reports of domestic violence perpetration (Schumacher et al., 2001; Stith et al., 2004). Both meta-analyses found that the magnitude of the effect of previous partner violence on current domestic violence ranged from moderate $(r=.24)$ to large $(r=.49)$. The magnitude of the effect of previous psychological abuse on current physical abuse appears to be the largest $(r=.49)$; followed by the effect of previous sexual abuse $(r=.45)$ and previous physical abuse ( $r=.24$; Stith et al., 2004). Given this evidence, it is reasonable to identify past perpetration of domestic violence as a predictor within the individual/ontogenic level of the ecological analysis of intimate partner violence.

Situational/Microsystem. Many factors that are known to be associated with men's perpetration of intimate partner violence are present within the 
situational/microsystem level of behavioral analysis (Carlson, 1984; Heise, 1998). To review, the situational/microsystem level represents an individuals' immediate environment and incorporates the interactions (i.e., proximal processes) that the person engages in directly with other people, objects, and symbols in that environment. Within the discussion of intimate partner violence, the family is a critically relevant situational/microsystem factor. Factors present within the family microsystem interact significantly with family background and personal variables located within the individual/ontogenic level of analysis (Carlson, 1984).

Family gender role dynamics. Heise (1998) and Carlson (1984) identify a number of factors at the microsystem level of analysis that contribute to the occurrence of intimate partner violence, including male and female gender role dynamics within the family. While men's sense of masculine gender role conflict was identified within the individual/ontogenic level of behavioral analysis, the way this conflict may play out within the family falls within the situational/microsystem level.

Family dynamics that threaten or challenge the traditional, dominant male role appear to contribute to the occurrence of intimate partner violence. To illustrate, stereotypical Western conceptualizations of the ideal family include the male fulfilling the role of the sole provider and the female as dependent on the male for protection, shelter, and resources. Female employment outside of the home and financial independence represent threats to this traditional family model, and as a result appear to be associated with partner abuse (Swanberg, Logan, \& Macke, 2005). 
Indeed, evidence indicates that some men who are angered or frustrated by their spouses' employment will use abuse tactics in order to prevent her from arriving at work and maintaining her job. For example, perpetrators may disrupt their partner's ability to work by physically assaulting them before they leave for work or threatening to hurt the children during their absence (Swanberg et al., 2005). Many victims of domestic violence also report being harassed or stalked at work, and some have been physically assaulted in the workplace by their male partners (Moe \& Bell, 2004; Swanberg et al., 2005).

While women's employment and financial independence may be related to intimate partner violent to the extent that they represent a challenge to family gender role dynamics, women's lack of employment and financial dependence on men may help maintain patterns of domestic violence once they have begun (Heise, 1998). In other words, there is evidence to indicate that going against traditional family gender role dynamics and adhering to those gender role dynamics are both related to intimate partner violence. For example, Moe and Bell's (2004) qualitative analysis of women living in domestic violence shelters revealed that many women attributed their experience of partner abuse in part to their lack of employment and financial dependence on their abuser. One woman in the study reported that her boyfriend manipulated her into becoming completely dependent on him for money and housing by hiring her to work for his company and then refusing to pay her a salary so she could support herself and her child. As a result the woman lost her apartment and had 
no other choice but to move in with him. Once they were living together, the woman's boyfriend moved them to a new house 45 minutes outside of town and hid her driver's license so that she could not leave to find a paying job (Moe \& Bell, 2004). This woman's experience illustrates how the maintenance of traditional family gender role dynamics, albeit to an extreme degree, contributed to her victimization in the form of isolation, dominance, and control.

Employment. There are additional situational/microsystem variables located outside the family microsystem that impact men's perpetration of intimate partner violence. Like all individuals, men who engage in intimate partner violence participate in a variety of microsystems and are therefore influenced by many different situational factors. One such situational/microsystem variable that is associated with men's perpetration of intimate partner violence is men's employment. Evidence indicates that men who are unemployed or underemployed are more likely to engage in partner abuse than men who are employed (Hampton \& Gelles, 1994; Sherman, Smith, Schmidt, \& Rogan, 1992; Stith et al., 2004). One explanation for this link is that unemployment may cause men to feel inadequate in terms of their masculine gender role. As discussed previously, Western cultural models of masculinity dictate standards to which men feel they must adhere such as financial stability, status, and the ability to provide for one's family (Kilmartin, 2000). Men who are unemployed, have a low income, and are ultimately unable to provide for their family to the culturally expected degree may feel stress about not being able to 
meet key masculine gender role expectations. This stress and conflict over feelings of inadequacy may lead to partner abuse as a way of fulfilling masculine gender role expectations (Gelles, 1999; Goldstein \& Rosenbaum, 1985).

Another possible explanation for the link between men's unemployment and perpetration of intimate partner violence can be found in the theoretical literature regarding informal social control and stake in conformity (e.g., Sherman et al., 1992). Employment offers a source of informal social control for most individuals and the benefits derived from employment (e.g., income, a social network, recognition, and status) increase one's stake in conformity. Individuals who have higher stake in conformity will be more likely to desist from engaging in behaviors that jeopardize the maintenance of their status. From this perspective, men who are employed are less likely to perpetrate intimate partner violence because they do not want to lose their jobs. In contrast, men who are unemployed may be more likely to engage in partner abuse because they have less to lose in terms of social status (Sherman et al., 1992).

Violent and/or delinquent peers. Another indicator of intimate partner violence stems from situational/microsystem linkages between the individual and delinquent or violent peers (Heise, 1998). Specifically, sexual aggression and partnerabusive behavior perpetrated by one's friends appears to be related to one's own endorsement of similarly violent actions (DeKeseredy \& Kelly, 1993; Malamuth et al., 1991). For example, Malamuth and colleagues (1991) found that delinquent peer 
associations were significantly related to male university students' self-reported coerciveness toward women. Others have found evidence that college-aged men in dating relationships are significantly more likely to perpetrate psychological, sexual, and physical abuse against their girlfriends if they have other male friends who support and justify violence against women (DeKeseredy \& Kelly, 1993). More recently, Casey and Beadnell (2010) found that men whose peer networks were comprised of a small number of highly delinquent male friends reported higher rates of domestic violence perpetration than men whose peer groups were larger and comprised of both male and female friends. Perceived pressure from friends to engage in abusive behavior and peers' patriarchal attitudes are both significant indicators of men's perpetration of intimate partner violence (DeKeseredy \& Kelly, 1993).

Partner conflict. Scholars also identify intimate partner conflict at the situational/microsystem level within ecological analyses of intimate partner violence (Carlson, 1984; Heise, 1998; Stith et al., 2000). In a national survey of families in the US, Straus, Gelles, and Steinmetz (1980) found a direct relationship between the amount of marital conflict in couples and the likelihood of physical violence. Hotaling and Sugarman $(1986,1990)$ report that marital conflict and verbal arguments are strongly associated with intimate partner abuse, even after controlling for other variables such as socioeconomic status and stress. Marital disagreements are caused by a variety of factors, but conflict that most frequently leads to partner abuse 
typically involves children, the division of household labor, money, and discrepancies in partners' educational attainment (Carlson, 1984; Hotaling \& Sugarman, 1990; Straus et al., 1980). The impact of conflict appears to be cumulative, such that more frequent conflict dramatically increases the likelihood of intimate partner violence within the couple (Straus et al., 1980).

Social-structural/Exosystem. Various factors at the socialstructural/exosystem level of behavioral analysis are also linked to intimate partner violence. To review, the social-structural/exosystem level of the ecological perspective reflects social structures that have an eventual impact on an individual's immediate situation (Belsky, 1980; Edleson \& Tolman, 1992). In the following paragraphs I review two social structures that indirectly influence the immediate contexts of intimate partner violence perpetrators and their victims.

Personal and neighborhood disadvantage. Gelles and Straus (1979b) argue that social imbalance causes economic deprivation and stress to be differentially distributed across groups, and that families who are low in socioeconomic status lead more stressful and deprived lives as a result. Some evidence indicates that affluent families are less likely to experience intimate partner violence compared to poorer families (Benson \& Fox, 2004; Straus et al., 1980); however one cannot conclude that being poor causes intimate partner violence since not all poor families experience partner abuse (Carlson, 1984). Rather, Gelles and Straus' (1979b) theory regarding unequal distribution of resources, stress, and deprivation suggests that socioeconomic 
status is likely associated with intimate partner violence in that it creates severe stress and tension which, for some couples, leads to physical abuse (Benson \& Fox, 2004; Carlson, 1984).

In addition, the degree of social and economic deprivation at the community or neighborhood level also appears to impact the rate of intimate partner violence in those communities. Some research indicates that partner abuse is related to community-level rates of unemployment and poverty in urban neighborhoods (Benson \& Fox, 2004; Heise, 1998). This association adds to Gelles and Straus' (1979b) idea that unequal distribution of resources between groups (i.e., employment opportunities) leads to increased stress, deprivation, and in some cases, domestic violence.

Community response to intimate partner violence. Community attitudes regarding partner abuse and violence against women are also present at the socialstructural/exosystem level of behavioral analysis. Carlson (1984) argues that communities often contribute to the level of intimate partner violence through local norms, laws, and rules, and through their response to the problem when it occurs. Laws and customs dictating the reaction of law enforcement to domestic violence reports and the overall criminal justice response may certainly influence the degree to which some men engage in partner abuse and may also shape victims' willingness to report the abuse (Buzawa \& Buzawa, 2003). For example, evidence indicates some domestic violence victims report negative interactions with the police including 
failure to arrest the perpetrator, mistaking the victim as the primary aggressor, trivializing the situation, or persecuting the victim because of socioeconomic status, ethnicity, or immigrant status (see Liang, Goodman, Tummala-Narra, \& Weintraub, 2005, for a review). Laws such as mandatory arrest and "no drop" prosecution policies that are meant in part to encourage victims to report abuse actually appear to increase the likelihood of further victimization over time (Buzawa \& Buzawa, 2003; Epstein, Bell, \& Goodman, 2003). Finally, a dearth of appropriate victim resources in the community may prevent women from obtaining necessary services and may also convey the message that the community does not care about domestic violence survivors (Liang et al., 2005). Lacking adequate access to advocacy, victim support, and criminal justice resources may isolate victims further and increase the probability that intimate partner violence will continue (Carlson, 1984; Liang et al., 2005).

Sociocultural/Macrosystem. Finally, there are a number of various correlates and factors related to intimate partner violence that exist within the overall culture or macrosystem. To review, sociocultural/macrosystem factors operate through their influence on structures present within the lower levels of the ecological framework (Heise, 1998). The feminist theoretical approach to explaining and describing intimate partner violence strongly advocates for the cultural analysis of intimate partner violence relative to other single-level theoretical models. The nested ecological perspective considers cultural factors within the macrosystem level, and provides the opportunity to theorize about the ways such cultural indicators of 
intimate partner violence interact with factors present in other levels of the ecological model (Heise, 1998).

Culturally idealized masculinity. Men's individual attitudes and beliefs regarding masculinity and masculine gender role expectations and their effects on abusive behavior were discussed within the individual/ontogenic level of behavioral analysis. More broadly, factors that influence men's perceptions of masculine gender role expectations and dictate appropriate ways to fulfill those expectations are present within the macrosystem. Specifically, culturally idealized models of gender in Western culture promote expectations for the masculine gender role that are linked to dominance, power, toughness, honor, and superiority of men relative to women (Heise, 1998; Kaufman, 1994; Kilmartin, 2000; Messerschmidt, 2005; Seymour, 2003). Broader cultural expectations regarding the masculine gender role are arguably linked to men's perpetration of domestic violence to the extent that they encourage men to engage in dysfunctional behaviors in order to meet gender role expectations. Later chapters will provide a more in-depth analysis of masculinity and hypermasculinity, and how they may influence men's experience of gender role conflict and subsequent enactment of dysfunctional behaviors such as domestic violence. For now, culturally idealized masculinity is introduced briefly as a correlate of intimate partner violence that exists at the sociocultural/macrosystem level of behavioral analysis. 
Sexism. Overall, persistent cultural trends of sexism and male superiority over women also influence the prevalence of violence against women in certain cultures (Carlson, 1984; Heise, 1998). Carlson (1984) argues that rampant sexism is present throughout Western culture, and that this sexism—although it may not be directly present in the family — contributes to intimate partner violence in both obvious and indirect ways. For example, sexism in the job market is manifested through unequal wages for women and job discrimination (Carlson, 1984). Sexism is also present in the ways that boys and girls are socialized as children (e.g., Chodorow, 1978). In general, Chodorow (1978) argues that young girls are primarily socialized to be nurturing, considerate, passive, and dependent, whereas boys are more likely to be encouraged to be independent, aggressive, and dominant.

Cultural tolerance of violence. Finally, intimate partner violence is likely influenced by the general cultural acceptance or tolerance of violence (Carlson, 1984; Heise, 1998). More specifically, people are over exposed to violence each and every day. Images of violence are rampant throughout popular movies, television, and other media. Aggression and violence are glorified through contact sports like American football, wrestling, and boxing. Violence, it seems, is a perfectly acceptable tool to be used to settle disputes and display dominance or power (Heise, 1998). Such a general acceptance, tolerance, and even glorification of violence surely influences individual behavior. Indeed, data from a sample of nearly 3,000 college-aged men in the US 
indicates that attitudes accepting of interpersonal violence are strongly related to men's perpetration of sexual violence against women (Koss \& Dinero, 1989).

\section{The Ecological Framework of Criminal Risk during the Transition from Prison to the Community}

After most adult offenders are released from state prison they are typically required to maintain contact with the criminal justice system through some sort of post-prison supervision or parole. Offenders are required to meet with community corrections officers who help them create plans to transition back into the community successfully and desist from crime. Offenders' conditions of post-prison supervision often include requirements to seek and maintain stable employment, engage in substance abuse treatment, or participate in mental health services if necessary.

In many states, guidance provided by community corrections officers is dictated in part by an assessment of the offender's risk of criminal recidivism or “criminal risk" (see Andrews \& Bonta, 2010, and Gendreau, Little, \& Goggin, 1996, for reviews). Post-prison supervision and transition programming are based on the notion that decreasing offenders' criminal risk will increase the probability that they will successfully transition back into the community and not return to prison. Conceptually, criminal risk is comprised of personal and behavioral factors (i.e., ‘criminal risk factors'; Andrews \& Bonta, 2010) which evidence indicates predict recidivism (Andrews \& Bonta, 2010; Gendreau et al., 1996). Certain combinations of these risk factors either increase or decrease an offender's criminal risk. The more 
risk factors that are present within an offender's life the higher his criminal risk. Higher criminal risk indicates an increased likelihood of recidivism and the chance that the offender will return to prison (Andrews \& Bonta, 2010). From an ecological perspective, many criminal risk factors that have been identified by scholars fall within one or more levels of behavioral analysis. Before situating these factors within an ecological model, a brief description of criminal risk factors is warranted.

Criminal risk factors can be either static or dynamic (Andrews \& Bonta, 2010). Static criminal risk factors are elements of an offenders' background that are unchangeable, such as the offender's age or number of previous criminal convictions (Andrews \& Bonta, 2010). For example, younger individuals are more likely to recidivate than older individuals; and therefore a younger offender's criminal risk will naturally be higher than that of an older offender (Andrews \& Bonta, 2010; Laub \& Sampson, 2003). Other static factors also appear to be related to individuals' risk of criminal recidivism, such as having a delinquent biological parent. A few studies of criminal adults who were adopted as children have shown that many had at least one biological parent who was also a criminal (e.g., Rowe \& Osgood, 1984).

In contrast, dynamic risk factors or what Andrews and Bonta (2010) call 'criminogenic needs' are criminal risk factors that can be mitigated by therapeutic services targeted at those factors (e.g., correctional rehabilitation programs). Criminogenic needs include antisocial emotionality, positive attitudes toward crime, substance abuse, social supports for criminality (e.g., friends who are also criminals), 
problems in the school/work context, lack of employment and education, and negative family/marital circumstances (Andrews \& Bonta, 2010). Of course, there are additional dynamic factors associated with criminal behavior that are considered important in sociological and pathological theories of crime (e.g., personal distress, poor self-esteem, history of victimization, and anxiety; Andrews \& Bonta, 2010). However, these factors are considered noncriminogenic because targeting these factors is not empirically proven to significantly reduce offenders' risk to engage in criminal behavior (Andrews \& Bonta, 2010; Andrews, Bonta, \& Hoge, 1990). Criminogenic needs are factors that are significantly related to reductions in criminal behavior when targeted with appropriate treatment services (Andrews \& Bonta, 2010). Some benefit may of course be derived from targeting noncriminogenic factors (e.g., reducing offenders' personal distress); however targeting these factors will not significantly impact criminal behavior (Andrews \& Bonta, 2010).

Criminogenic needs and selected static criminal risk factors are not often conceptualized within an ecological framework in the current literature, despite some scholars' discussion of the correlates of criminal conduct within multiple levels of behavioral analysis (i.e., biological, personal, interpersonal, familial, political, and cultural; Andrews, 1995). The following paragraphs are an attempt to strengthen this area of the literature through a brief ecological analysis of criminal risk factors that are characteristic of former inmates who are transitioning from prison back in to the 
community. Below is a description of criminogenic needs and a selection of additional important risk factors situated within the levels of ecological analysis.

Individual/Ontogenic. To review, analysis at the individual level focuses on what the individual brings from his past experiences to his current circumstances. The individual/ontogenic level of behavioral analysis consists of factors like attitudes, values, beliefs, and skills that have been developed throughout an individual's life (Carlson, 1984). Several criminogenic needs arguably fall within the individual/ontogenic level of analysis. Namely, antisocial personality characteristics, positive attitudes toward crime, and substance abuse problems are issues that shape transitioning offenders' immediate circumstances and, therefore, the risk that they will engage in criminal behavior.

Antisocial personality characteristics and behavior patterns. Antisocial personality characteristics include impulsivity, generalized interpersonal trouble, aggressive tendencies, disregard for others, and adventurous pleasure-seeking (Andrews \& Bonta, 2010). Antisocial behavior patterns are reflected through past involvement in antisocial activities including being arrested at a young age, and having a long history of prior criminal offenses and violations while on post-prison supervision (Andrews \& Bonta, 2010). A history of antisocial personality characteristics and corresponding behavior are strongly related to criminal behavior. Many individuals who are incarcerated evidence antisocial personality characteristics, and some are even diagnosed with antisocial personality disorder. For example, in a 
review of surveys conducted with approximately 14,000 inmates across 12 different countries, Fazel and Danesh (2002) found that nearly 47 percent of incarcerated males and 21 percent of incarcerated females were diagnosed with antisocial personality disorder. Fazel and Danesh (2002) estimate that the prevalence of antisocial personality disorder among incarcerated individuals is 10 times the rate found within the US general population. Other research estimates that the prevalence of antisocial personality disorder among inmates is in the range of 50 to 80 percent (Ogloff, 2006).

In terms of criminal recidivism, evidence from a retrospective study of former federal inmates indicates a moderate relationship between antisocial behavior patterns and both general recidivism $(r=.33)$ and violent recidivism $(r=.22$; Glover, Nicholson, Hemmati, Bernfeld, \& Quinsey, 2002). Furthermore, the authors found statistically significant differences between former inmates who recidivated and those who did not recidivate on measures of antisocial behavior patterns and conduct disorder - a diagnosis that often precedes antisocial personality disorder (Glover et al., 2002). Finally, in their meta-analysis of eight other meta-analyses Andrews and Bonta (2010) found small to moderate overall associations between antisocial personality characteristics and criminal conduct $(r=.12-.33)$ and antisocial behavior patterns and criminal conduct $(r=.16-.38)$.

Positive attitudes toward crime. In general, an attitude represents a relatively enduring tendency to respond to an object or symbol in a way that reflects a positive 
or negative evaluation of that symbol. Attitudes are reflected in individuals' cognitive (i.e., beliefs), affective, (i.e., emotions) and behavioral tendencies (Manstead, 1996). Individuals generally strive to behave in accordance with their attitudes when the immediate situation is amenable to the given behavior. When one's behavior does not align with one's attitudes, negative psychological consequences may result (i.e., cognitive dissonance). Alleviating this negative psychological state often involves changing attitudes to correspond with behaviors (Manstead, 1996).

Given the relationship between attitudes and behavior in general, one would expect there to be a relationship between individuals' attitudes toward crime and their criminal behavior. Indeed, evidence regarding the relationship between attitudes and criminal behavior indicates that many offenders exhibit beliefs, values, and attitudes that are favorable to criminal activity (Andrews \& Bonta, 2010; Simourd \& Olver, 2002). These positive attitudes toward crime include the tendency to rationalize and justify criminal behavior, identification with a criminal lifestyle, negative attitudes toward law enforcement and the justice system, and a belief that crime will pay off (Andrews \& Bonta, 2010; Simourd \& Olver, 2002). Researchers have found that positive attitudes toward crime are significantly related to both self-reported criminal conduct (Andrews \& Wormith, 1984) and official records of crime (Simourd \& Olver, 2002). In their study of nearly 400 former inmates, Simourd and Olver (2002) found significant relationships between offenders' positive attitudes toward crime and post-prison recidivism including rearrest for violent crime, rearrest in general, parole 
violations, and reincarceration. In addition, at least eight different meta-analyses indicate that attitudes in support of crime are positively related to criminal behavior $(r$ $=.15-.48 ;$ Andrews \& Bonta, 2010).

Cognitive-behavioral treatment programs are offered in many correctional institutions in an attempt to change and redirect inmates' positive attitudes toward crime so that they will be more likely to desist from crime when they return to the community (Andrews \& Bonta, 2010). Cognitive-behavioral treatment programs are based on the notion that behavior (e.g., criminal conduct) is influenced by attitudes (e.g., positive attitudes toward crime) and behavior change is caused by changing attitudes (e.g., changing positive attitudes toward crime into negative attitudes toward crime). However, the link between attitudes and behavior is shaped by circumstances in the immediate environment (Manstead, 1996). Behavior is not determined solely by attitudes, but rather by a combination of attitudes and environmental circumstances and the effect each has on the decision to act (Andrews \& Bonta, 2010; Manstead, 1996). Therefore, anti-criminal sentiments and prosocial behavior patterns that inmates learn in prison-based treatment programs may be thwarted by the stressful and potentially overwhelming experience of transitioning back into the community, and they may readopt the tendency to rationalize crime as a means to a desired end.

Substance abuse. Another individual/ontogenic factor within the ecological model of criminal behavior is substance abuse. The link between criminal conduct 
and substance abuse is evidenced in part by the significantly higher prevalence of both alcohol abuse and illegal drug use among criminal offenders relative to nonoffender populations. Estimates of alcohol abuse among offenders who are incarcerated and those on community supervision range from 13 to 30 percent for males and 10 to 24 percent for females (Andrews \& Bonta, 2010; Fazel, Bains, \& Doll, 2006). Reports on the prevalence of illegal drug use among offenders in prison and on supervision are slightly higher and more varied (i.e., $10-48 \%$ in males and $30-$ $60 \%$ in females). In comparison, national surveys of US households have found that 10 percent of male respondents and four percent of female respondents meet the diagnostic criteria for alcohol abuse (Harford, Grant, Yi, \& Chen, 2005), and eight percent reported using illegal drugs during the month prior to the survey (Substance Abuse and Mental Health Services Administration, 2005).

Prior research indicates that both acute alcohol use and chronic drug and alcohol abuse are related to criminal behavior. For example, several national surveys conducted with offenders in jail, prison, and on probation show that almost 40 percent reported they were drinking or intoxicated at the time of their offense (Greenfeld \& Henneberg, 2001). Among surveyed offenders whose convictions were for violent crime, 50 percent reported using alcohol directly prior to committing their crime. In addition, Zhang's (2003) study of nearly 200,000 recently arrested offenders indicated that almost 10 percent of males tested positive for alcohol within 48 hours of their arrest and nearly 30 percent were determined to be at risk for 
alcohol dependence. In addition, 70 percent of male arrestees tested positive for illegal drug use and almost 40 percent were determined to be at risk for drug dependence. Among arrested female offenders in the same study, a remarkable 86 percent tested positive for alcohol and 73 percent were positive for illegal drugs within 48 hours of their arrest. Twenty-three percent of female offenders were determined to be at risk for alcohol dependence, and 40 percent were at risk for drug dependence (Zhang, 2003).

Evidence regarding the association between substance abuse and criminal behavior does not permit researchers to conclude that the relationship is causal (Lipsey, Wilson, Cohen, \& Derzon, 1997). Rather, substance abuse is likely related to criminal behavior indirectly. Specifically, alcohol use is theorized to be related to criminal conduct through its effects on individuals' inhibitions, impulsivity, and aggressive tendencies (Kazemain \& LeBlanc, 2004). Separately, researchers assert that illegal drug use may in part be related to criminal behavior because it places individuals in direct contact with other criminals, who may exert pressure to engage in other illegal activities in order to buy drugs (Andrews \& Bonta, 2010).

Situational/microsystem. Individual/ontogenic characteristics and background variables shape the ways that offenders interact with and respond to factors in their immediate environment. In the ecological model, this immediate environment is represented in the situational/microsystem level of behavioral analysis. To review, the situational/microsystem level incorporates interactions (i.e., 
proximal processes) that the person engages in directly with other people, objects, and symbols in their immediate environment. A number of crucial situational/microsystem factors influence adult offenders' risk to engage in criminal behavior, particularly during the transition from prison to the community.

Delinquent peers and social support for criminality. Individuals who are involved in personal relationships with delinquent peers are much more likely to engage in criminal behavior themselves (Andrews \& Bonta, 2010). In fact, Andrews and Bonta's (2010) review of eight meta-analyses indicates that having criminal associates who are supportive of delinquency is one of the strongest correlates of criminal behavior relative to most other criminogenic needs $(r=.21-.37)$. In addition, associating with delinquent peers and engaging in criminal behavior tends to isolate individuals from anti-criminal, prosocial peers who might moderate the negative influences of criminal friends and procriminal attitudes (Andrews \& Bonta, 2010). Offenders who are transitioning from prison back into the community are at particularly high risk to reconnect with delinquent peers they associated with before going to prison. Specifically, many former inmates are released back into the same county, city, and community where they committed their incarcerating offense. Therefore, the opportunity to reestablish former relationships with delinquent friends who live in the same neighborhood is present. These offenders may also maintain relationships with delinquent peers that are still incarcerated, or connect with other former inmates on the outside because of the shared experience of going to prison. 
Family/Marital circumstances. The quality of interpersonal relationships is another important risk factor for criminal behavior that is also located within the situational/microsystem level of behavioral analysis. Specifically, the quality of an offender's marriage or intimate partnership is related to the risk of criminal conduct (Andrews \& Bonta, 2010). A relationship that is characterized by mutual respect, caring, interest, and anti-criminal expectations is a protective factor that prevents offenders from engaging in criminal behavior (Laub \& Sampson, 2003). In fact, evidence from longitudinal studies of lifetime offenders indicates that high quality intimate partnerships are significantly associated with long-term desistance from crime (Laub \& Sampson, 2003). In contrast, an intimate partnership that is of poor quality and marked with neutral expectations regarding crime or even procriminal expectations increases the likelihood that an offender will engage in crime (Andrews \& Bonta, 2010). Multiple meta-analyses indicate a moderate to strong relationship between marital/family circumstances and criminal behavior $(r=.10-.33)$. This criminogenic need is particularly important within the context of this dissertation which will explore characteristics of intimate partnerships and the occurrence of domestic violence during the transition from prison to the community.

Unstable employment and low education. Lacking education, minimal vocational achievement, and an unstable employment record are other important predictors of criminal behavior that are located in the situational/microsystem level of behavioral analysis. Evidence suggests that criminal behavior systematically 
increases with multiple, frequent periods of unemployment (Andrews \& Bonta, 2010). Results from Andrews and Bonta's (2010) review of eight meta-analyses indicate correlations ranging up to $r=.28$ between unstable employment/low education and criminal behavior. In contrast, data from longitudinal studies indicate that obtaining stable employment and engaging in long-term education programs are both related to desistance from crime in the life course of frequent and serious criminals (Laub \& Sampson, 2003). Much of the theory regarding this link asserts that long-term employment and education act as sources of informal social control and increase offenders' stake in conformity (Andrews \& Bonta, 2010; Laub \& Sampson, 2003; Sherman et al., 1992). The longer one is employed in a job or engaged in an education program the more committed they feel, and the more they have to lose if they are caught committing crime. Unfortunately, finding employment is a significant obstacle for offenders who are transitioning from prison back into the community (Waldfogel, 2001; Western, Kling, \& Weiman, 2001). Therefore, these offenders may not be as likely to experience the positive impact of employment or long-term education on criminal conduct.

Similarly, problems within the school and/or work situational contexts are also associated with increased risk of criminal activity (Andrews \& Bonta, 2010). Andrews and Bonta (2010) highlight the importance of school/work context in terms of interpersonal relationships that are established in those settings. Qualities of school and/or work contexts that are associated with increases in criminal risk include low 
levels of performance and involvement, low satisfaction, and few rewards (Andrews \& Bonta, 2010).

Social-structural/Exosystem. Social-structural/exosystem variables are also linked to offenders' risk of engaging in criminal behavior during the transition from prison into the community. To review, the social-structural/exosystem level of the ecological perspective reflects social structures that do not involve the individual directly but have an eventual impact on their immediate context.

Neighborhood disadvantage. The notion that crime can be attributed in part to the quality of the neighborhood environment stems from social disorganization theory, which asserts that crime and disorder are caused by impaired local controls at the neighborhood level (Rose \& Clear, 1998). Socially disadvantaged, high-crime neighborhoods influence criminal behavior in that they provide many opportunities to engage in crime and lack local sources of social control (i.e., strong family and community structures). Neighborhood characteristics influence factors present within other levels of ecological analysis (e.g., presence of delinquent peers, family/marital circumstances, and availability of prosocial activities like employment, high quality public education, and community fellowship) and therefore have an eventual impact on individual criminal behavior (Andrews \& Bonta, 2010). In other words, disadvantaged and disorganized neighborhoods may not directly cause inhabitants to engage in criminal behavior but they may exacerbate the delinquent behavior of individuals who are already high risk (Andrews \& Bonta, 2010). For example, 
evidence indicates that antisocial personality characteristics more strongly predict criminal behavior among individuals who live in socially disadvantaged neighborhoods. Lynam, Caspi, Moffitt, and Wikström (2000) found that individuals exhibiting antisocial characteristics like impulsivity were more likely to engage in criminal behavior if they lived in impoverished neighborhoods with minimal social controls relative to similarly impulsive individuals living in affluent neighborhoods with strong social controls. Therefore, the neighborhood environment where former inmates live during the transition from prison to the community may certainly impact their ability to desist from crime given that their delinquent histories automatically place them at a higher risk to reoffend.

Sociocultural/Macrosystem. Many theories of crime tend to focus on the causes of criminal behavior that exist at the individual/ontogenic and situational/microsystem levels of behavioral analysis. Few theories concentrate on cultural correlates of criminal behavior beyond neighborhood and community characteristics, which this analysis locates within the social-structural/exosystem level. The following paragraphs briefly summarize two such cultural correlates of crime, namely social class and masculinity. From an ecological perspective, social class and the social construction of masculinity (sociocultural/macrosystem factors) interact with structures present within lower levels of the framework (e.g., neighborhoods and positive attitudes toward crime) to influence criminal behavior (Heise, 1998). 
Social class of origin. Many classic sociological theories of crime argue that social class of origin is a major source of variation in illegal conduct (e.g. anomie/strain theory, subcultural theory, and labeling theory; see Andrews \& Bonta, 2010 for a review). For example, anomie/strain theory asserts that delinquency occurs when conventional aspirations exceed the levels of achievement that are possible by way of legitimate behavior. Criminal behavior is therefore conceptualized as an innovative route to the same rewards that conventional employment would bring if only legitimate channels were available (Andrews \& Bonta, 2010).

However, some scholars have found evidence that the relationship between social class of origin and criminal behavior is moderate at best. In a review of 35 studies regarding the association between social class and crime, Tittle, Villimez, and Smith (1978) found an average effect size of $r=-.09$ indicating a relatively weak relationship between social class and crime. Although some theorists have continued to tout the relationship between social class and crime (e.g., Braithewaite, 1981), further reviews of research corroborate the findings of Tittle and colleagues (e.g., Andrews \& Bonta, 2010; Gendreau et al., 1996). From an ecological perspective, it is possible that social class does not have a direct and independent effect on criminal behavior but rather that social class interacts with and exacerbates factors within other levels of the ecological system (e.g., neighborhood quality and exposure to criminal associates) to increase the risk of crime. 
Culturally idealized masculinity. Social constructions of gender-masculinity in particular - are important to consider within the context of criminal behavior. In general, men and boys are significantly more likely to commit crime than girls and women. Early criminologists attributed differences in criminal behavior among men and women to biological characteristics (Messerschmidt, 1993); however more recent analyses of criminality from a gendered perspective tend to focus on the relationship between cultural constructions of masculinity and criminal behavior (e.g., Messerschmidt, 2005). Messerschmidt (2005) argues that "gender must be viewed as structured action, or what people do under specific social-structural constraints" (p. 197). Men "do gender" or demonstrate that they are male in different social situations, and these expressions of "maleness" vary according to the social-structural constraints of the immediate circumstances. More specifically, men demonstrate their gender according to the culturally idealized form of masculinity present in a given social setting (Messerschmidt, 2005).

In the previous section describing the ecological model of intimate partner violence, I introduced the individual experience of masculine gender role conflict as a correlate. Western cultural models of gender equate masculinity with dominance, power, toughness, honor, and superiority of men relative to women (Heise, 1998; Kaufman, 1994; Kilmartin, 2000; Kimmel, 1994; Messerschmidt, 2005; Seymour, 2003); and gender role conflict may motivate some men to engage in dysfunctional and/or dangerous behaviors in order to meet these gender role expectations (O'Neil et 
al., 1986). Therefore, broader socially constructed definitions of masculinity are inherently linked with engaging in criminal behavior to the extent that they cause masculine gender role conflict and lead men to engage in dysfunctional (i.e., criminal) behavior to meet gender role expectations (Messerschmidt, 1993, 2005). Specifically, committing crime is a way of expressing dominance, power, toughness, and superiority, and therefore "maleness". I echo the assertions of previous scholars who argue that committing crime is a way of "doing" masculinity within the constraints of socially constructed definitions of manhood (Messerschmidt, 1993, 2005; Seymour 2003).

\section{An Ecological Model of Intimate Partner Violence during the Transition from Prison to the Community}

In this chapter I have described important factors underlying the correlates and potential causes of intimate partner violence and the experiences of formerly incarcerated offenders transitioning from prison to the community from an ecological perspective. For each phenomenon I illustrated variables that operate at the individual/ontogenic, situational/microsystem, social-structural/exosystem, and sociocultural/macrosystem levels. The ecological perspective suggests that each of these variables may operate independently of and interactively with each other between the different levels of analysis to influence behavior.

When the ecological frameworks of inmate reentry and domestic violence reviewed here are compared side by side, one notices that they are strikingly similar 
(see Figure 2). Many of the issues that increase the risk of criminal behavior and therefore plague successful transitions from prison to the community are also known correlates of intimate partner violence in the community. For example, substantial evidence indicates that partner violence is more common within couples where the male partner exhibits antisocial or borderline personality characteristics (Dutton, 1998; Dutton \& Hart, 1992), abuses drugs and alcohol (Bennett et al., 1994; Coker, Smith, McKeown, \& King, 2000) and is unemployed (Gelles \& Straus, 1979a; Sherman et al., 1992)—characteristics that also increase the chance of criminal recidivism among former inmates transitioning from prison to the community (Andrews \& Bonta, 2010; Petersilia, 2001).

Given the commonalities between the correlates of partner abuse and the risk factors of individuals transitioning from prison to the community, it is logical to consider that the potential for domestic violence is heightened for formerly incarcerated male offenders and their intimate partners shortly after prison release. I therefore tested a hybrid of these two ecological models within a sample of formerlyincarcerated male offenders after their release from prison (see Figure 3).

One of the most fundamental principles of the ecological theoretical perspective is that human behavior and social phenomena are the result of the independent and interdependent operations of factors that exist simultaneously at multiple contextual levels (Bronfenbrenner, 1977). Therefore, theoretically speaking, 

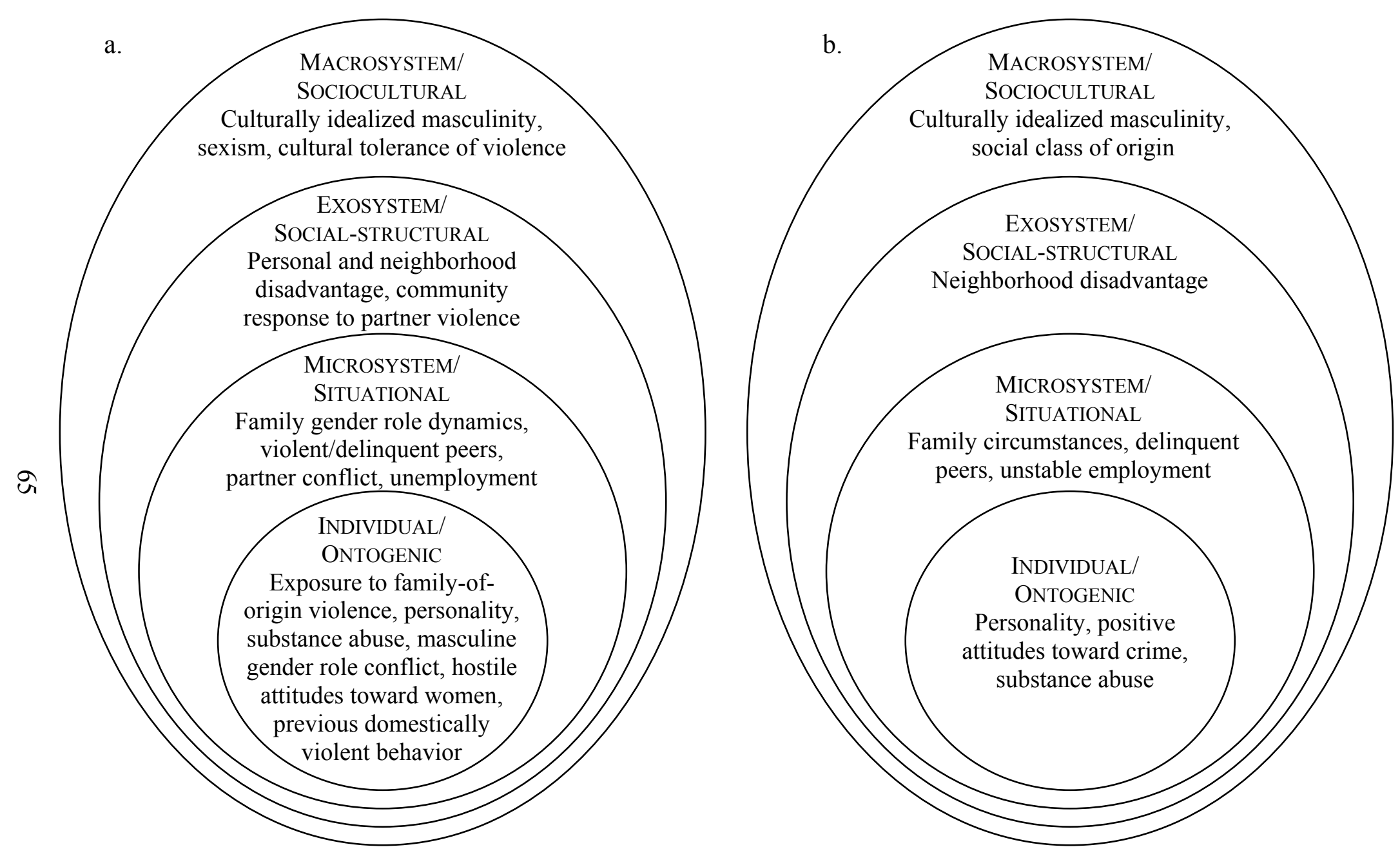

Figure 2. Ecological models of intimate partner violence (a) and the transition from prison to the community (b). 


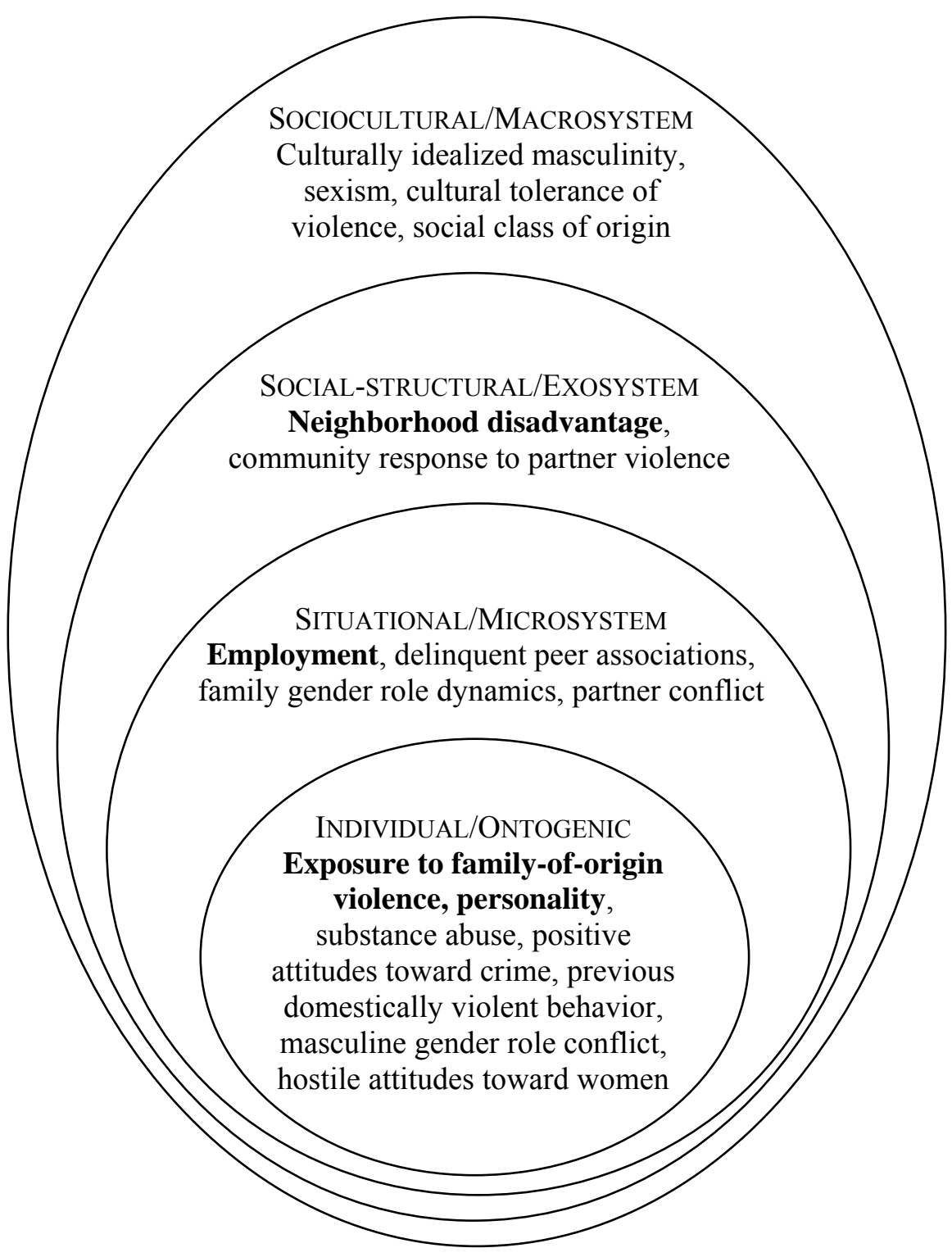

Figure 3. Ecological model combining intimate partner violence and the transition from prison to the community. Factors that were within the focus of data collection and analysis appear in bold type. 
independent effects and interactions between every factor existing at every level of an ecological model should account for at least part of the variance in any behavioral outcome of study. In other words, ecological theory suggests that both the main effects of and interactions between each of the individual, situational, socialstructural, and sociocultural predictors in my ecological model should be evaluated. Ideally, with an unlimited number of observations, one could test each and every factor existing within every level of an ecological model as well as all of the withinlevel and cross-level interactions between them. However, within the constraints of applied research and limited sample sizes, one must be selective about the main effects and interactions one chooses to test.

One way that a researcher can make these choices is to consult existing literature and select factors that appear to be more important relative to others in the prediction of the phenomenon of study. Limiting the number of tested independent factors also allows the researcher to test a more manageable number of interactions. Based on this line of reasoning, I focused the empirical analysis of my ecological model presented in Figure 3 on a selection of factors within each of the three innermost levels of the model. More specifically, the individual/ontogenic, situational/microsystem, and social-structural/exosystem levels of the ecological model were represented in my analysis by one to two variables that were chosen based on their predictive validity in prior literature. Testing a limited number of factors within each level allowed me to maintain parsimony within the empirical 
model while preserving the model's ecological theoretical structure. To clarify, not testing all theorized factors and all levels of analysis does not mean that I chose to ignore their influence. Rather, I considered the influence of these factors through their operation on other variables and levels. So while I acknowledge that the factors I selected to test interact with other individual/ontogenic, situational/microsystem, social-structural/exosystem, and sociocultural/macrosystem factors, the specific measurement focus of this dissertation was on a limited number of factors within each of the three innermost levels alone.

Individual/Ontogenic. In my empirical analysis, the individual/ontogenic level of my conceptual model was represented by two factors: offenders' antisocial and borderline personality characteristics and offenders' exposure to family-of-origin violence. As reviewed earlier, exposure to family-of-origin violence and perpetrators' personality characteristics are two of the most consistent correlates of intimate partner violence throughout the literature (Schumacher et al., 2001; Stith et al., 2004). Antisocial personality characteristics are also strongly associated with general criminal behavior (Andrews \& Bonta, 2010). Meta-analyses indicate that effect sizes range from small to medium $(r=.14-.44)$ for the relationship between domestic violence perpetration and exposure to family-of-origin violence (Schumacher et al., 2001). Effect sizes for the relationships between domestic violence perpetration and both borderline and antisocial personality characteristics range from medium to large $(r=.27-.56$ for borderline and $r=.31-.56$ for antisocial; Schumacher et al., 2001). 
Finally, meta-analyses of general criminal risk factors indicate that the magnitude of the effect of antisocial personality characteristics on general criminal behavior ranges from small to medium ( $r=.16-.33$; Andrews \& Bonta, 2010).

The majority of prior research regarding the relationships between partner abuse, exposure to family-of-origin violence, and antisocial and borderline personality characteristics has been conducted with offenders in the community (Schumacher et al., 2000; Stith et al., 2000); and evidence regarding these relationships among formerly incarcerated perpetrators of intimate partner violence is lacking. Only a handful of scholars who have investigated partner violence among incarcerated offenders have looked at antisocial and borderline personality characteristics (i.e., Dutton \& Hart, 1992; White et al., 2002), and only one study has examined the relationship between exposure to family-of-origin violence and partner abuse among incarcerated offenders (i.e., Dutton \& Hart, 1992). Notably, in their study of incarcerated domestic violence perpetrators, Dutton and Hart (1992) suggest that the presence of borderline personality characteristics in conjunction with a history of family-of-origin violence should be "sufficient to put someone at moderate risk for wife assault" (p. 110). These findings suggest that the relationships between partner abuse, exposure to family-of-origin violence, and borderline and/or antisocial personality characteristics should be explored further in populations with a history of incarceration. Moreover, Dutton and Hart's (1992) assertion suggests that the interaction between certain personality characteristics and exposure to family-of- 
origin violence should be investigated in this population. Therefore, in my analysis of post-prison domestic violence perpetrated by formerly incarcerated offenders I examined the main effects of exposure to family-of-origin violence, antisocial personality characteristics, and borderline personality characteristics, as well as the interactions between them.

Additional individual-level demographic considerations. As indicated in the previous section, I selected personality characteristics and exposure to family-oforigin violence to represent the individual-level of the ecological model of domestic violence that I tested among formerly incarcerated male offenders. Both factors are important predictors within ecological models of intimate partner violence (Carlson, 1982; Heise, 1998) and within models of general criminal risk (Andrews \& Bonta, 2010). However, other evidence suggests that there are a variety of additional correlates of domestic violence and general criminal conduct whose influence at the individual-level of analysis should be considered.

Specifically, meta-analyses suggest that perpetration of intimate partner violence and criminal conduct in general are significantly associated with younger age (Andrews \& Bonta, 2010; Laub \& Sampson, 2003; Stith et al., 2004) and limited education (Andrews \& Bonta, 2010; Hotaling \& Sugarman, 1986; Stith et al., 2004). Other findings indicate that both intimate partner violence and criminal conduct vary by ethnicity such that ethnic minorities may be at a higher risk for both (Caetano, Cunradi, Schafer, \& Clark, 2000; Gendreau et al., 1996; Schumacher et al., 2001). 
Perpetration of domestic violence is also related to marital status such that married couples have a lower incidence of violence relative to divorced, separated, cohabiting, and reconstituted couples (Hotaling \& Sugarman, 1986). Similarly, married individuals are less likely to engage in crime in general (Laub \& Sampson, 2003). Still more evidence suggests that perpetration of intimate partner violence may be positively related to the number of children a couple has (Hotaling \& Sugarman, 1986; Szinovacz \& Egley, 1995). Having many children has been shown to decrease couples' marital satisfaction (Twenge, Campbell, \& Foster, 2003), which increases the incidence of partner violence (Stith, Green, Smith, \& Ward, 2008).

For formerly incarcerated individuals in particular, the length of their incarceration, crime of conviction, and participation in correctional rehabilitation programs are associated with post-prison criminal conduct. In general, meta-analyses indicate that increases in length of incarceration correspond with small but consistent increases in post-prison criminal recidivism (Gendreau, Goggin, \& Cullen 1999). Also, offenders with criminal histories that include violent offenses (i.e., crimes against other people) are more likely to perpetrate further violent crime in the future (Rice, 1997). Finally, incarcerated offenders' participation in correctional rehabilitation programs (e.g., cognitive-behavioral therapy) is associated with decreases in post-prison criminal recidivism (Andrews, Zinger, Hoge, Bonta, Gendreau, \& Cullen, 1990). In their meta-analysis, Andrews and colleagues (1990) found small to moderate effect sizes for the relationship between correctional 
program participation and reductions in recidivism $(\mathrm{phi}=.13-.30)$. In contrast, no exposure to correctional rehabilitation programs is associated with increases in postprison recidivism (phi = -.07; Andrews et al., 1990).

Clearly prior literature has established that there are significant associations between each of these demographic characteristics and either intimate partner violence, general criminal conduct, or both. For this reason, formerly incarcerated male offenders' age, education, ethnicity, marital status, number of children, length of incarceration period, crime of conviction, and correctional program participation were considered as additional individual-level demographic characteristics within the ecological model I tested. In my analysis, I only considered the main effects each of these additional individual-level demographic variables had on post-prison domestic violence perpetrated by formerly incarcerated offenders.

Situational/Microsystem. The situational/microsystem level of the model I tested was represented by offenders' post-prison employment. To summarize my earlier review, prior literature indicates that offenders' employment significantly influences patterns of both domestic violence perpetration (Schumacher et al., 2001; Stith et al., 2004) and general criminal conduct (Andrews \& Bonta, 2010). Effect sizes derived from meta-analyses indicate employment has small but significant negative main effects on domestic violence perpetration $(r=-.10, p<.001$; Stith et al., 2004). Similarly, lacking employment is significantly associated with general criminal conduct ( $r=.28$; Andrews \& Bonta, 2010). The impact of employment on 
domestic violence perpetrated by formerly incarcerated male offenders has not been considered in prior research. Given the importance of the relationship between employment and both intimate partner violence and general criminal conduct, and given that the relationship between employment and domestic violence has not been considered within a formerly incarcerated sample, post-prison employment represented the situational level of the model I tested. In my analysis I examined the main effects of employment as well as its interactions with offenders' exposure to family-of-origin violence, antisocial personality characteristics, and borderline personality characteristics.

Social-structural/Exosystem. Finally, the social-structural/exosystem level of the model I tested was represented by the social and economic characteristics of neighborhoods where offenders lived after their release from prison (i.e., neighborhood disadvantage). To recap, neighborhood-level social and economic disadvantage is associated with both criminal conduct in general (Andrews \& Bonta, 2010) and perpetration of domestic violence (Benson \& Fox, 2004). In addition, some evidence suggests that neighborhood disadvantage exacerbates certain individuallevel characteristics such as antisocial personality to influence criminal behavior (Lynam et al., 2000). The interaction between neighborhood disadvantage at the social-structural level and employment at the situational level represents a broader picture of socioeconomic context, a factor that is also related to both domestic violence (Gelles \& Straus, 1979b) and criminal conduct in general (Andrews \& 
Bonta, 2010). Therefore, in my analysis of post-prison domestic violence perpetrated by formerly incarcerated offenders I examined the main effects of neighborhood disadvantage as well as its interactions with exposure to family-of-origin violence, antisocial personality characteristics, borderline personality characteristics, and postprison employment. 


\section{Chapter 3: The Experience of Incarceration for Inmates and Partners and the Effect on Intimate Relationships and Partner Violence during Reentry}

In the previous chapter, I examined the social phenomena of intimate partner violence and criminal risk through the lens of an ecological theoretical framework. I compared and contrasted the ecological conceptualizations of each phenomenon and demonstrated that they are more similar to each other than they are different. Many of the criminal risk factors or "criminogenic needs" that have been identified by scholars (e.g., Andrews \& Bonta, 2010) fit within one or more levels of an ecological framework. Moreover, many general criminal risk factors and known correlates of intimate partner violence are identical. Given the overlap between general criminal risk factors and correlates of intimate partner violence, I proposed a new model combining the ecological conceptualizations of both phenomena within the context of former inmates transitioning from prison to the community.

In the following chapter I continue with a more detailed discussion of the intersection between incarceration, intimate partnerships, and intimate partner violence during the transition from prison to the community. I describe the experience of incarceration for offenders and their intimate partners and how these experiences shape their relationship and may contribute to the risk of intimate partner violence. I also review the limited literature on domestic violence perpetrated during the transition from prison to the community and the prevalence of domestic violence among incarcerated populations in general. 


\section{Incarceration and Intimate Relationships}

Within the fields of criminal justice and correctional rehabilitation, literature regarding the transition from prison to the community concentrates predominantly on the importance of reentry activities that address selected criminogenic needs like finding a job and staying sober (e.g., Andrews, 1995; Maruna, 2001; Maruna \& Immarigeon, 2004; Petersilia, 2001, 2009; Travis \& Petersilia, 2001). The majority of the literature fails to address more personal issues within the context of reentry such as former inmates' family circumstances and intimate relationships. Evidence suggests that healthy family relationships during and after incarceration positively impact offenders' experiences within prison and significantly reduce the risk of recidivism after release (Andrews \& Bonta, 2010; Carlson \& Cervera, 1991; Codd, 2007; Draine \& Wolff, 2009; Gottfredson, 1970; Mills \& Codd, 2008; Nelson et al., 1999; Rose \& Clear, 2003; Tripp, 2003). Some theorists note the separate but equal importance of inmates' intimate relationships in facilitating successful transitions from prison and propose that returning home to a satisfying, high-quality intimate partnership is an important predictor of post-prison success (Freedman \& Rice, 1977).

Unfortunately, a large amount of evidence suggests that former inmates often return home to relationships that are weakened by the incarceration. The limited privacy and general atmosphere in prison may significantly deplete couples' capacity for intimacy and can lead to breakdowns in mutual trust (Carlson \& Cervera, 1991; 
Hairston \& Oliver, 2006; Harman et al., 2007; Oliver \& Hairston, 2008). Inmates are separated physically from their partners and their communication is also restricted to such a degree that family contact and partner involvement with the inmate is virtually prohibited (Day, Acock, Bahr, \& Arditti, 2005; Hairston \& Oliver, 2006; Nurse, 2002). Inmates are limited to infrequent collect telephone calls that are expensive for partners to accept and letters that are read by correctional staff prior to being mailed or delivered. Visiting with inmates may require partners and families to travel long distances, and physical contact (e.g., embracing or holding hands) is not permitted (Bates, Lawrence-Wills, \& Hairston, 2003; Carlson \& Cervera, 1991; Comfort, 2003; Hairston \& Oliver, 2006; Riesch-Toepell \& Greaves, 2001). Such limited contact and intimacy as well as the tension associated with imprisonment in general can create new challenges for inmates and their partners and/or exacerbate relationship difficulties that existed before the incarceration (Carlson \& Cervera, 1991; Hairston \& Oliver, 2006). As a result, many inmates' intimate relationships are either significantly damaged or terminated by the time the inmate is released (Carlson \& Cervera, 1991).

\section{Competing Social Ecologies}

Because of the nature of incarceration and the separation of the inmate from the outside world, it may seem obvious that inmates struggle to maintain relationships with their intimate partners. However, some scholars theorize that relationship problems between inmates and their partners are not so much a result of the 
separation as they are a product of the different life experiences each individual goes through during the incarceration. To illustrate, the relationship between an inmate and his partner exists between two competing social ecologies (i.e., prison and the free world; Bronfenbrenner, 1977, 1994; Bronfenbrenner \& Morris, 1998). Consequently, each person is shaped by different individual, situational, social-structural, and sociocultural factors.

Like most couples, the inmate and his partner participate in interactions and contexts at the situational/microsystem level that function outside of the relationship context (e.g., with co-workers, immediate family, etc.). However, unlike most couples the distinction between the nature of an inmate's immediate context and that of his partner is more severe. For example, the inmate's partner may participate in a neighborhood context where day to day interactions (i.e., proximal processes) with neighbors (e.g., discussing the weather or sharing childcare) shape her attitudes, beliefs, and behaviors. In contrast, the inmate participates in an institutional housing unit context where he interacts with his cell mate, other inmates in the unit, and correctional staff. Depending on the demographic of the housing unit residents (e.g., gang members or violent offenders), the inmate's crime of conviction, and the nature of his relationship with staff, day to day interactions might be characterized by intimidation, confrontation, or even aggression and violence (e.g., Seymour, 2003). Such interactions within the immediate prison environment are no doubt distressing for inmates, and like other interactions they will cumulatively shape their attitudes, 
beliefs, and behaviors over time (Bronfenbrenner, 1977, 1994; Bronfenbrenner \& Morris, 1998). Given the distinction between inmates' and partners' immediate contexts, the different behaviors, attitudes, and beliefs that each develops over time may significantly impact the way they relate to each other upon the inmate's release.

Interrupted versus continuing development. The fundamental differences between inmates' and partners' daily proximal processes and the implications for their intimate relationship have been highlighted by a number of scholars. Harman et al. (2007) and Zamble and Porporino (1990) have identified particular ways in which the proximal processes of a man who is incarcerated differ from those of his partner. For example, female partners of incarcerated men interviewed by Harman and colleagues' (2007) reported that they assumed new roles and responsibilities, such as the provider and sole caretaker of children, while their husbands were in prison. Some participants entered the workforce for the first time and others elected to further their education so they could find a better job (Harman et al., 2007). As a result of their expanding roles, most research indicates that female partners of male inmates report an overall sense of increased (albeit forced) independence and newfound authority within the family (Hairston \& Oliver, 2006; Harman et al., 2007; Oliver \& Hairston, 2008). Partners' new roles and experiences foster new and diverse contexts and interactions, thereby contributing to their continued growth and natural development. This notion is consistent with social psychological theory regarding 
complex role sets, which asserts that accumulating various complex roles develops one's personality through exposure to new information (Coser, 1990).

In contrast to their partners who continue to develop and grow on the outside, Zamble and Porporino (1990) argue that inmates experience a behavioral "deep freeze" while they are incarcerated (p. 62). In their longitudinal study of inmate behavior and coping skills, Zamble and Porporino (1990) found that inmates' cognitive, behavioral, and social capacities remained largely unchanged from the beginning of their sentence until they were released. In addition, inmate ability to cope effectively with the circumstances of imprisonment was inversely related to the number of times they had been incarcerated. In other words, the more times an inmate had been incarcerated the less able he was to cope effectively with his immediate environment (Zamble \& Porporino, 1990). These findings suggest that, in opposition to inmates' partners who may continue to develop naturally outside of prison, inmates' course of development may either be interrupted or depleted during incarceration. From an ecological perspective, it is possible that the rigidity and control which characterizes the sociocultural environment of the prison (i.e., macrosystem) limits the ability to engage in new and diverse interactions (i.e., proximal processes) that would be available on the outside. These limitations therefore inhibit the availability of new contexts and information that might enrich inmates' social and behavioral development (e.g., Coser, 1990). 
Evidence confirms that inmates' and their partners' participation in different social and developmental contexts during the incarceration can create problems within their relationship during the transition from prison to the community (e.g., Harman et al., 2007). Perhaps due in part to their developmental "deep freeze" (Zamble \& Porporino, 1990), many inmates return home expecting their friends, family, relationships, and lives in general to be the same as when they left (Oliver \& Hairston, 2008; Horowitz, 2010). Instead, many inmates find their partners have expanded their caretaker and provider roles to accommodate the loss of shared responsibility and income that occurred because of his incarceration (Hairston \& Oliver, 2006; Harman et al., 2007). As a result, Oliver and Hairston (2008) observe that some former inmates experience feelings of powerlessness and frustration regarding their perceived role within the family and status as the provider. As discussed in chapter two, pressure to modify gender role dynamics within the family can be frustrating for men who have traditional attitudes about the social roles of men and women (Carlson, 1984; Hotaling \& Sugarman, 1986; Yllö \& Straus, 1990). Both inmates and partners report that the tension created by differences in development, conflicting attitudes about gender roles, and changes in expectations frequently lead to relationship problems and conflict during the transition from prison to the community (Hairston \& Oliver, 2006; Oliver \& Hairston, 2008).

Interrupted development during incarceration is also identified elsewhere in the literature as a major detriment to former inmates' ability to fulfill adult roles and 
obligations upon their release from prison. For example, female partners of formerly incarcerated men indicate that prison relieves them of adult responsibilities (e.g., managing finances and supporting the family) and therefore fosters a childlike dependency on others (Hairston \& Oliver, 2006, p. 14). Partners report that men find excuses (e.g., lack of skill or education) to avoid participating in adult tasks such as finding a job and contributing to the household upon their release from prison. Although partners acknowledge that finding a job with adequate pay may be difficult for former inmates because of their criminal record, partners feel that men use the excuse that no one will hire them to avoid changing their delinquent lifestyles and accepting responsibility (Hairston \& Oliver, 2006). Many partners in Hairston and Oliver's (2006) research report that instead of finding a job and contributing to the household their formerly incarcerated spouses reinitiate the same attitudes and risky behaviors that sent them to prison in the first place (e.g., gambling and spending time with delinquent friends; Hairston \& Oliver, 2006; Harman et al., 2007). Former inmates" reengagement in "street life" along with their inability to find stable employment are two of the most frequent causes of relationship conflict mentioned by partners in a number of studies (Hairston \& Oliver, 2006; Harman et al., 2007; Oliver \& Hairston, 2008).

Tension created by former inmates' reengagement with street life may be exacerbated if they made promises to their partners to "do right" upon releasing from prison. Hairston and Oliver (2006) found that many inmates make promises to their 
partners while they are incarcerated regarding their future together as a couple and their plans to desist from crime and delinquency. Inmates often promise to improve their marital and family circumstances and obtain a legitimate job (Hairston \& Oliver, 2006). However, partners feel that inmates make promises in order to maintain the relationship throughout the incarceration while all the while intending to return to life on the streets (Hairston \& Oliver, 2006; Oliver \& Hairston, 2008). This can lead to significant relationship conflict particularly if the partner feels they were strung along by promises that inmates never in reality intended to fulfill (Hairston \& Oliver, 2006; Oliver \& Hairston, 2008).

Prisonization. Related to Zamble and Porporino's (1990) findings that inmate development is interrupted during incarceration, others have observed that inmates endure deleterious developmental experiences by virtue of their incarceration. More specifically, some theorists (e.g., Clemmer, 1940) suggest that inmates adapt to life in prison by adopting certain cognitive characteristics and patterns of behavior that, while facilitating survival in a prison environment, may negatively impact life on the outside and consequently with their partners. These 'prisonization' or 'institutionalization' theories claim that the prison environment resocializes inmates to be antagonistic and violent through adoption of the "inmate subculture" and social scripts such as the "inmate code" (Clemmer, 1940; Gillespie, 2004; Haney, 2008; Lerman, 2009; Terry, 2003). The inmate subculture encourages attitudes and behaviors characterized by violence, strength, predation, and exploitation; and is in 
direct opposition to paradigms of social organization in the free world (Gillespie, 2004; Haney 2008). Through compliance with the inmate subculture and adoption of the inmate code, inmates may experience deep-seated behavior change ranging from social and emotional withdrawal to extreme aggression and violence (Haney, 2008; Porporino, 1990). Such characteristics are not conducive to smooth transitions from prison to the community let alone to the health of an intimate partnership.

Two dominant perspectives exist regarding the causes of prisonization. First, the importation perspective claims that pre-prison socialization and individual characteristics shape the extent to which inmates become "prisonized". This perspective suggests that the adoption of the inmate subculture is linked to individual factors such as prior convictions, arrests, offense type, and endorsement of delinquent attitudes and values (Paterline \& Petersen, 1999). Second, the deprivation model emphasizes the negative attributes of the prison environment that contribute to experiences of prisonization. Proponents of this perspective claim that prisonization is an adaptive process that inmates use to cope with the social and physical deprivations of imprisonment (Paterline \& Petersen, 1999). Some data indicate that each model independently determines prisonization (e.g., Dhami, Ayton, \& Loewenstein, 2007) while other evidence suggests that the two models explain more variance in the occurrence of prisonization together than either model does alone (e.g., Paterline \& Petersen, 1999). From an ecological perspective it is logical to consider that pre-incarceration individual characteristics as well as prison 
environmental factors both contribute to inmates' experiences of prisonization.

Proximal processes that occur in select microsystems/situations (i.e., before prison) certainly impact those in other microsystems/situations (i.e., in prison;

Bronfenbrenner \& Morris, 1998); therefore it is reasonable to assert that inmates' individual characteristics which likely led them to prison in the first place carry over into the institution (i.e., importation model) and are solidified or exacerbated by the harsh environmental conditions (i.e., deprivation model).

Female partners of current and former male inmates confirm that inmates become overly accustomed to prison life (i.e., "prisonized") and that such adaptation to the controlled environment negatively impacts their lives on the outside (Comfort, 2002; Hairston \& Oliver, 2006). Women in Hairston and Oliver's (2006) study note that this "prison mentality" impairs former inmates' ability to be "good husbands and fathers when they return home" (p. 14), and encourages behavior that is not conducive to the well-being of the family. A number of researchers expand on Hairston and Oliver's (2006) participants' reports, stating that the experience of prisonization sometimes motivates inmates to distance themselves from family and intimate partners (Hannon et al., 1984; Porporino, 1990; Tripp, 2003) and in some cases cut off all social ties with the outside world (Nurse, 2002). As a result of this isolation, former inmates' relationship and parenting skills may appear depleted once they return to the family and general community (Tripp, 2003). 
Prisonization or the 'prison mentality' (Hairston \& Oliver, 2006) may also decrease an ex-inmate's ability to effectively cope with difficult situations that arise with other people, including their intimate partners. For example, Freedman and Rice (1977) and Harman et al. (2007) report that inmates often cope with challenges in prison through either avoidance and denial of the problem or by acting out in frustration and anger. Given inmates' limited options and lack of autonomy within correctional institutions, such an avoidant style of coping may actually be effective to the extent it allows inmates to manage stress in the controlled environment (e.g., Lazarus, 2006). However, avoidant coping strategies are not likely to be effective in the context of intimate relationships outside of prison where more control and opportunity to engage in active coping is possible. Indeed, Zamble and Porporino (1990) found that former inmates have little ability to actively cope with difficult situations during the transition from prison to the community, and that small problems are often made worse by the tendency to cope ineffectively. For example, ex-inmates in Zamble and Porporino's (1990) study reported coping with financial difficulties by spending all available money on drugs instead of actively pursuing a way to improve their financial situation. Similarly, former inmates coped with intimate relationship problems either through infidelity or via physical confrontation and aggression against their partners (Zamble \& Porporino, 1990). Conversely, an inmate's partner's ability to actively cope with day-to-day challenges may actually be enhanced by virtue of the additional responsibilities she had to juggle while he was 
incarcerated (i.e., increased independence and responsibility; Hairston \& Oliver, 2006; Harman et al., 2007; Oliver \& Hairston, 2008). Discrepancies between inmates' and partners' use of active versus avoidant coping strategies may have serious implications for their emotional well-being (Lazarus, 2006) and could lead to significant conflict during the transition from prison back into the community and family.

Extreme masculinity: A Different kind of prisonization. Much of the inmate subculture to which inmates adapt revolves around patterns of gendered behavior that are dictated by sociocultural definitions of masculinity. Therefore, a more detailed examination of masculine prison culture is relevant to the analysis of the 'prison mentality' that some inmates adopt during their incarceration and to the notion that experiences in prison can complicate former inmates' transition back into the family.

To begin, masculinity and femininity are not driven exclusively by biological sex but by cultural agents of gendered socialization (e.g., Chodorow, 1978; Kilmartin 2000; Lutze \& Murphy, 1999). In other words, men and women are not born masculine or feminine; rather they learn how to be masculine or feminine through particular agents (e.g., parents and peers) and processes of socialization (Kilmartin, 2000). Of course, conceptualizations of masculinity and femininity vary according to culture, social class, race, sexuality, and physical ability (Cowburn, 1998). However, some scholars claim that there is a dominant, culturally idealized or 'hegemonic' 
form of masculinity present within Western culture to which the great majority of men are constantly exposed and expected to adhere (e.g., Cowburn, 1998; Seymour, 2003).

Chodorow (1978) provides one possible framework to conceptualize the processes of hegemonic masculine socialization in Western culture. This modern psychoanalytic perspective suggests that there are significant distinctions between the processes through which boys learn to be masculine and the processes through which girls learn to be feminine. Chodorow (1978) asserts that, with the role of primary caregiver almost exclusively belonging to the mother, both boys and girls initially grow up with the same feminine object of identification (i.e., their mother). Throughout early development, girls are encouraged to identify with their mothers and mimic the nurturing and caring qualities that she models through her caregiver role. In sharp contrast, boys' are expected to disengage from their initial identification with their mothers so that a separate masculine identity can develop. This disruption of boys' initial identification with their mothers is facilitated by agents of socialization (e.g., parents and peers) who reinforce behaviors that conform to social scripts of masculinity and punish behaviors that deviate from it. Chodorow (1978) argues that the developmental path toward manhood is therefore shaped by the understanding that masculine behavior (i.e., what boys do) is the exact opposite of feminine behavior (i.e., what girls do). In other words, masculinity is equivalent to anti-femininity. 
Threads of anti-femininity that are woven into men's social development have resulted in masculinity being defined by what it is not rather than by what it is (Kilmartin, 2000). For example, traditional symbols of femininity include the tendency to be submissive and dependent, emotionally expressive, affectionate, caring, supportive, and nurturing. In direct opposition, symbols of traditional masculinity include dominance and authority, power, aggression, emotional guardedness, and independence (Kite, Deaux, \& Haines, 2008). Adherence to such strict definitions of gender can actually cause psychological harm, and indeed a large developing body of research focuses on the negative effects of socialized gender roles or 'gender role conflict' (O’Neil et al., 1986; O’Neil, 2008). Gender role conflict is a psychological state wherein traditional attitudes about gender roles have negative consequences including the restriction of the person's ability to actualize their human potential (O’Neil et al., 1986). Scholars argue that certain aspects of gender roles, particularly the masculine gender role, are psychologically dysfunctional and that both the acts of fulfilling and violating the masculine gender role can lead to negative psychological consequences for an individual (Pleck, 1995).

Like parents and peers who shape boys' understanding of what it means to be 'a man,' prisons act as additional agents of masculine socialization for men who are incarcerated (Lutze \& Murphy, 1999; Seymour, 2003; Sim, 1994). The prison environment encourages the same types of anti-feminine attitudes and behaviors that guide masculine socialization throughout Western society-however some scholars 
argue that the version of masculinity present in correctional institutions is more extreme (Cowburn, 1998; Lutze \& Murphy, 1999; Seymour, 2003; Sim, 1994). For example, prison staff and the inmate population are overwhelmingly male (Cowburn, 1998; Seymour, 2003). Interpersonal communication in prison is confrontational and significant emphasis is placed on the importance of traditional masculine qualities like physical strength (Seymour, 2003). Prison masculinity is defined as exclusively heterosexual and in direct opposition to femininity (Cowburn, 1998). In other words, prisons are categorically masculine environments that reinforce and strengthen stereotypical masculine qualities such as power, dominance, hierarchy, misogyny, aggression, and violence (Cowburn, 1994; Lutze \& Murphy, 1999; Rose, 2001; Seymour, 2003; Sim, 1994; Snider, 1998).

Some theorists argue that an exaggerated form of hegemonic masculinity is displayed in prisons because other more traditional methods of 'doing masculinity' are not available to inmates. Specifically, Sykes (1958) and Scully (1990) argue that in the absence of the ability to have sexual intercourse with women, men must prove their heterosexual manhood both for themselves and for others through expressions of other traditional masculine gestures. As a result, in the prison environment "manhood is validated through physical strength and aggression" (Scully, 1990, p. 9). Similarly, Seymour (2003) argues that the use and expression of violence is basic to the construction and demonstration of masculinity in prison. Social psychological theories of the masculine gender role corroborate these assertions, claiming that 
extreme versions of masculinity encourage attitudes and values that are fundamental to interpersonal violence (Braithwaite \& Daly, 1994; Kimmel, 1994). Kimmel (1994) notes that men fear that "other men will unmask us, reveal to us and the world that we do not measure up, that we are not real men", and that this fear triggers feelings of powerlessness and vulnerability which some men disguise with violence (Kimmel, 1994, p. 131). Lutze and Murphy (1999) support the notions of Scully (1990), Seymour (2003), Sykes (1958) and Kimmel (1994) with evidence that extreme masculinity within the prison environment is significantly related to inmate reports of aggressive interactions. Specifically, Lutze and Murphy (1999) found that inmates who perceive the prison culture as more masculine report more frequent aggressive interactions, stress, and conflict with other inmates and staff (Lutze \& Murphy, 1999).

Exposure to the misogynistic, confrontational, aggressive, and violent form of masculinity within prisons may certainly impact inmates' attitudes and behavior during their incarceration. More importantly, potential orientation toward or adoption of these exaggerated masculine qualities could significantly impact former inmates' relationships with female partners during the transition back into the family. To illustrate, Oliver and Hairston's (2008) research shows that former inmates' masculine gender role expectations shape their attitudes about traditional family dynamics, often leading to relationship conflict. Former inmates reported feeling angry upon finding that their female partners' role within the family and their 
intimate relationship changed during the incarceration. Specifically, many female partners of former inmates adopted the traditionally masculine role of family provider by obtaining jobs and controlling the household finances while the inmate was in prison (Oliver \& Hairston, 2008). Cultural norms of masculine socialization dictate that it is the man's role to provide all necessary resources for the family-therefore the notion of female partners providing for the family is arguably a threat to former inmates' masculine identity (Oliver \& Hairston, 2008; O’Neil et al., 1986). In general, evidence shows that situations which threaten men's masculine selfperceptions are associated with decreases in men's marital satisfaction and increases in marital conflict (Faulkner, Davey, \& Davey, 2005; Harrell, 1990). Indeed, former inmates in Oliver and Hairston's (2008) study reported significant conflict with their female partners because of shifts in family role dynamics and in response to feeling that the female partner "wears the pants" in the relationship (p. 264).

By no means is it certain that all inmates will experience prisonization or adopt an exaggerated masculine identity wrought with violent and aggressive tendencies in prison; however frameworks of social learning theory (e.g., Bandura, 1974, 1977) and cultural psychology (e.g., Fiske, Kitayama, Markus, \& Nisbett, 1998) would suggest it is highly probable that most inmates will experience prisonization at least to some extent. For example, social learning theory asserts that individual behavior is influenced by observing the actions of others and the consequences associated with those actions (Bandura, 1974, 1977). Individuals are 
likely to learn and imitate certain behaviors if they observe that the behavior is reinforced with a valued reward and less likely to do so if the behavior is punished (Bandura, 1974, 1977). Conceptualizations of prison hierarchies propose a direct association between masculinity and status among inmates (Dumond, 1992); therefore, inmates are likely to observe that exaggerated masculine behaviors like aggression, physicality, and violence are rewarded through the acquisition of status and power within the institutional hierarchy (Dumond, 1992). Likewise, inmates who are perceived as weak and submissive (i.e., feminine) are punished and isolated at the bottom of the hierarchy. Evidence indicates that inmates who do not exhibit an exaggerated masculine identity are also more likely to be targets of physical and sexual victimization within the institution (e.g., Chonco, 1989; Hensley, Koscheski, \& Tewksbury, 2005; Hensley, Tewksbury, \& Castle, 2003; Toch, 1977). Therefore from a social learning perspective, inmates are likely to imitate behaviors that are rewarded with a place at the top of the hierarchy (i.e., aggression, physicality, and confrontation) and avoid behaviors that are punished with isolation and potential victimization (i.e., caring, consideration, and sensitivity). Such behavior that is learned and reinforced in prison could carry over into former inmates' lives after release and influence their transition back into the community and family.

Cultural psychology offers another framework that may explain inmates' experiences of prisonization and the extent to which they will adopt the kinds of qualities that are associated with the 'prison mentality'. Cultural psychology posits 
that individuals tend to adopt the world view of their immediate social context (i.e., acculturation; Fiske et al., 1998). This process is necessary in order to maintain normal functioning within potentially new and different social contexts (Fiske et al., 1998). From this perspective, it is reasonable to assert that individuals who are removed from their usual social context (i.e., free society) and placed in prisons will adopt the world view of the prison culture to the extent that it facilitates their functioning and survival within the institution. In other words, some inmates will adopt a world view that values hierarchy, confrontation, physicality, aggression, and violence in order to survive prison (Cowburn, 1994; Dumond, 1992; Lutze \& Murphy, 1999; Rose, 2001; Seymour, 2003; Sim, 1994). Unfortunately, this perspective implies that even if an individual is not violent, aggressive, or confrontational when they enter prison as an inmate, they may be at risk to develop these tendencies as a natural consequence of their incarceration (Haney, 2008; Snider, 1998; Terry, 2003).

\section{Intimate Partner Violence during the Transition from Prison to the Community}

The previous section demonstrated that incarceration can have significant consequences for the developmental progress of inmates and their partners and for their intimate relationship in general. To summarize, inmates and their partners encounter different social and developmental experiences during the inmate's incarceration. Partners' day-to-day context provides the opportunity to grow naturally while the prison environment severely limits' inmates' ability to progress socially, 
behaviorally, and developmentally (Harman et al., 2007; Zamble \& Porporino, 1990). Inmates are also likely to experience other growth-inhibiting and destabilizing forces in prison, including adopting what partners call a 'prison mentality' (i.e., prisonization) and subscribing to the inmate subculture of hierarchy, dominance, aggression, and violence (Clemmer, 1940; Hairston \& Oliver, 2006; Haney, 2008). Prisonization is related to tenets of masculine socialization — and the categorically masculine environment of prison encourages male inmates' adherence to exaggerated versions of masculinity (Seymour, 2003). Such differences in development, experiences of prisonization, and the potential adoption of an exaggerated masculine identity may contribute to difficulty in reestablishing intimate partnerships during inmate reentry. These challenges are reflected in frequent reports from ex-inmates and their partners that relationship conflict is prevalent during the ex-inmate's transition back into the family (Hairston \& Oliver, 2008; Harman et al., 2007; Oliver \& Hairston, 2008; Tripp, 2003; Zamble \& Porporino, 1990).

Because of the challenges of inmate reentry in general (e.g., finding a job and staying sober; Maruna, 2001; Maruna \& Immarigeon, 2004) and relationship conflict that is reportedly associated with former inmate-partner reunification (Harman et al., 2007; Tripp, 2003; Zamble \& Porporino, 1990), scholars have begun to explore whether former inmates are at an increased risk for perpetrating domestic violence during the transition from prison to the community (e.g., Hairston \& Oliver, 2006; Oliver \& Hairston, 2008; Oliver et al., 2004). The following section summarizes 
current research findings regarding the overlap between incarceration, inmate reentry, and intimate partner violence. Although this body of literature is small, early indicators suggest that there may be a connection between these three social phenomena.

Inmates and partners anticipate violence during reentry. Although it is limited, the majority of research on domestic violence during the transition from prison to the community originates from the Safe Return Initiative-a US Office of Violence Against Women technical assistance project that addresses the intersection of inmate reentry and intimate partner violence in the African American community (Institute on Domestic Violence in the African American Community [IDVAAC], 2008; Oliver \& Hairston, 2008). The Initiative's focus on the African American community is motivated by two factors. One, African American men and women are disproportionately represented among perpetrators and victims of domestic violence relative to other ethnic groups (Tjaden \& Thoennes, 2000); and two, the incarceration rate of African American males is nearly 10 times that of Caucasian males (Harrison $\&$ Beck, 2003). For these reasons, the African American community has been identified as a high risk group for domestic violence following a period of imprisonment (Oliver \& Hairston, 2008).

Findings from the Safe Return Initiative indicate overall that indeed, African American former inmates may be at risk for physically and psychologically abusing their female partners upon returning home from prison (Hairston \& Oliver, 2006; 
Oliver \& Hairston, 2008; Oliver et al., 2004). Although the actual prevalence of domestic violence during inmate reentry has not been examined, focus group data indicates that incarcerated men and their partners at least acknowledge that domestic abuse, including physical assault, is a strong possibility following a period of incarceration (e.g., Hairston \& Oliver, 2006; Harman et al., 2007; Oliver \& Hairston, 2008; Oliver et al., 2004). For example, Oliver and Hairston (2008) found that incarcerated men identified specific issues they believed would lead to relationship conflict and, in many cases, physical assault of their partner during reentry. Among these issues were men's perceived lack of authority in the household and economic pressure; as well as partners' criticism of men's ability to provide for the family which, as argued in previous chapters, may create conflict to the extent men perceive that their masculine identity is threatened. Some former inmates also reported that discovering their partners had engaged in an intimate relationship with another man would lead to physical abuse. One former inmate indicated that if he discovered his partner had become pregnant by another man during his incarceration, her infidelity would lead to "a beat down” (Oliver \& Hairston, 2008, p. 265). Data from female partners of incarcerated men corroborate men's reports that questions and rumors about a woman's fidelity during the man's incarceration can often lead to retaliatory abuse after prison (Hairston \& Oliver, 2006).

Still other data indicate that sometimes incarcerated men will attempt to monitor their partners' behavior and faithfulness from inside prison by asking his 
friends or family members to keep tabs on her during his absence (Freedman \& Rice, 1977; Hairston \& Oliver, 2006; Riesch Toeppell \& Greaves, 2001). Relationship conflict and psychological abuse can often arise if the inmates' informants report that she has been unfaithful regardless of whether the report is true (Freedman \& Rice, 1977; Hairston \& Oliver, 2006). For example, one female participant in Hairston and Oliver's (2006) research indicated that despite sending love letters and money and frequently visiting her incarcerated husband, he would accuse her of infidelity if a friend reported that she was "talking to someone else" on the outside (p. 13). Similarly, Riesch Toeppell and Greaves (2001) found that some male inmates in Canadian prisons coerce their partners into making frequent institutional visits and accepting expensive collect calls from prison. These inmates also attempt to control who their partners associate with on the outside and make them account for all of their time not spent visiting the institution. Some inmates even expected their partners to relocate in order to be closer to the correctional facility, which required partners to give up jobs, find new housing, and take their children out of school (Riesch Toeppell \& Greaves, 2001). The kind of psychological control and coercion described by participants in these studies clearly falls within the spectrum of intimate partner violence (Pence \& Paymar, 1993).

Other researchers have gathered similar reports of psychological abuse from ex-inmates and their female partners. For example, Harman and colleagues (2007) report that men returning home from prison are often jealous and controlling of their 
partners and that struggles for authority within the family create serious conflict for the couple. Some female partners report that their formerly incarcerated spouses become jealous and verbally abusive for any reason, such as when his phone calls to her are not answered at the first ring or if she takes too long to check the mailbox (Harman et al., 2007). Some of Harman and colleagues' (2007) participants reported that their husbands became angry and jealous if they stayed in their nightgowns while at home and accused them of waiting for another man to come over (p. 804).

Most importantly, many female partners of former and current inmates acknowledge that they comply with the offenders' demands to visit frequently, relocate, or limit associations with other people in order to avoid retaliation in the form of physical assault or verbal abuse (Harman et al., 2007). Some partners also indicate that they stay in the intimate relationship only to avoid this abuse. In fact, Harman and colleagues (2007) found that the threat of verbal, emotional, or physical abuse was so severe that many partners of former inmates felt the only way the relationship would end is if the offender went back to prison or was killed on the streets. Overall, Harman et al. (2007) conclude that many relationships between exinmates and their partners are characterized by an ongoing struggle for power and control which, according to most feminist perspectives of intimate partner violence, is the basis for all acts of violence against women (e.g., Pence \& Paymar, 1993).

Partners report violence before and during the incarceration. The findings summarized above indicate that incarcerated men and their female partners 
actually anticipate intimate partner violence during reentry (Hairston \& Oliver, 2006; Harman et al., 2007; Oliver et al., 2004; Oliver \& Hairston, 2008). Former inmates and their partners can identify circumstances in which they believe physical assault could occur (Hairston \& Oliver, 2008); and female partners of ex-inmates report that they behave in ways that prevent this violence, including staying in the relationship indefinitely (Harman et al., 2007).

In addition, other evidence suggests that female partners of incarcerated men may anticipate domestic violence during reentry because they were victimized by their partners before and sometimes during the incarceration (Hairston \& Oliver, 2006; Riesch Toepell \& Greaves, 2001). Some partners of incarcerated men in Hairston and Oliver's (2006) research reported being verbally, emotionally, physically, and even sexually abused by their partners before the incarceration began; and many believed that the same abusive patterns might happen again during his reentry into the community. Similar findings from other studies further indicate that female partners of male inmates often experienced isolation, manipulation, and coercion in addition to physical, sexual, and verbal abuse before their partner was sent to prison (Riesch Toepell \& Greaves, 2001).

Reports of intimate partner violence occurring before the inmates' incarceration may be limited by some women's conceptualizations of domestic violence behavior. Specifically, Riesch Toepell and Greaves (2001) found that some women in their research had limited insight regarding which of their partners' pre- 
incarceration behaviors could be considered 'abusive'. For example, one woman whose partner was incarcerated reported that before going to prison he would lock her in a bedroom for days at a time; however she did not believe his behavior was abusive because he "never left any physical marks" (Riesch Toepell \& Greaves, 2001, p. 87). The authors noted that several women in their research failed to identify non-physical abuse (e.g., control, manipulation, coercion, and confinement) as falling within the scope of domestic violence (Riesch Toepell \& Greaves, 2001). Therefore, the actual prevalence of physical, sexual, and psychological abuse perpetrated before some women's partners were sent to prison may be greater than current findings suggest.

In addition to abuse perpetrated prior to the incarceration, some female partners of male inmates are physically abused during their partner's incarceration. In a study of family visiting programs in Canadian prisons, Riesch Toepell and Greaves (2001) found that at least one female partner of a male inmate experienced physical abuse during a conjugal visit with her husband, and that many more feared for their safety during such visits. Although only one person revealed to researchers that her partner had been violent during a conjugal visit, all women in the study were aware that "bad" conjugal visits_-visits during which the inmate becomes violent or abusive - could and did occur. In fact, most participants had heard of at least one incident where a woman had been physically abused by her partner during a conjugal visit and was forced to wait seven hours in the locked conjugal visiting residence with 
her violent spouse until correctional staff arrived to let her out. Participants also reported regularly seeing women leave the prison with visible bruises and knew of others who were removed from conjugal visiting residences before the visit was over because the inmate became physically abusive (Riesch Toepell \& Greaves, 2001).

Some scholars argue that the process of participating in conjugal visits in itself is abusive and is perceived by many women as manipulative and coercive. Riesch Toepell and Greaves' (2001) analysis of the visiting arrangement in Canadian prisons revealed a system that places most of the control in the hands of the inmates and removes the female partner's choice to participate or not. To illustrate, it is primarily the inmate who initiates the approval process for conjugal visits while they are incarcerated. Inmates obtain the necessary forms, fill out the paperwork, and then tell their female partner to indicate she is willing to participate by signing the consent form. Under this system, there is no effective way for female partners to resist participating in conjugal visits without angering their incarcerated partner, incriminating him further, or suffering the loss of private time. For example, if the partner decides not to consent to conjugal visits, she risks retaliation from the inmate that could take the form of violence and abuse after his release. Furthermore, if she refuses to participate in conjugal visits because she fears being abused when she and her partner are alone, the reason for her refusal could be noted in the inmate's institutional file and consequently affect his institutional privileges or release eligibility. On the other hand, if she does not participate she risks not being able to 
spend time with her partner which, even if she fears he may abuse her, is "more than what she has living in isolation without support or him outside prison" (RieschToepell \& Greaves, 2001, p. 90). With the removal of choice and threat of severe consequences, it would seem that the process of participating in conjugal visits further perpetuates the cycle of abusive behavior and puts some women at risk for experiencing physical, sexual, and emotional violence.

Inmates report perpetrating violence before incarceration. In addition to women's reports of victimization before and during their partners' incarceration, several researchers have found that inmates themselves report having engaged in partner abuse before they were incarcerated. For example, Robertson and Murachver (2007) found that incarcerated men acknowledge perpetrating frequent physical and psychological abuse against their partners prior to being sent to prison. These incarcerated men were more than twice as likely to report perpetrating physical and psychological violence in their lifetime relative to a non-incarcerated control group (Robertson \& Murachver, 2007). Similarly, in a study focused on risk markers for intimate partner violence, Dutton and Hart (1992) found "evidence of extreme risk for wife assault" (p. 109) among federally incarcerated men. The elevated risk identified by Dutton and Hart (1992) was especially pronounced among inmates with certain individual characteristics including violent criminal records, witnessing abuse as a child, and narcissistic and borderline personality disorders. Data from Logan et al. (2001) and White and colleagues (2002) confirm these findings, adding that 
inmates in their studies who reported perpetrating domestic violence before their incarceration also had severe problems with substance abuse.

Other researchers have found that many inmates have histories of domestic violence prior to their incarceration regardless of their current conviction or custody level. For example, Cook (2002) found that a variety of incarcerated men reported histories of perpetrating physical, emotional, verbal, and sexual abuse against a female partner regardless of their crime of conviction. In other words, these men revealed that they had been violent and abusive toward a female intimate partner even if they had no record of convictions for crimes related to partner abuse (e.g., assault, harassment, or stalking). Similarly, a study by Logan et al. (2001) regarding the intersection of partner violence, substance abuse, and incarceration showed that 42 percent of participating inmates reported perpetrating moderate violence against an intimate partner (e.g., pushing or slapping) in the year prior to their incarceration. Eleven percent of participants reported more severe forms of partner abuse including kicking, beating, and using a knife or gun against their partners before coming to prison (Logan et al., 2001). Similar patterns of self-reported domestic violence among male inmates were found by White and colleagues (2002). A third of participants in White et al.'s (2002) sample reported engaging in minor to moderate partner abuse and 10 percent reported severe abuse during the year before entering prison. White and colleagues (2002) only sampled offenders who were housed in low-security correctional facilities, which are typically designated for non-violent offenders. This 
indicates that histories of violence involving inmates' partners may not be considered when they are assigned to particular housing units. More likely, inmates' histories of intimate partner violence are unknown.

The preceding sections have focused predominantly on the impact of incarceration on male-female intimate relationships and the risk of domestic violence during the transition from prison to the community. Evidence and theory summarized above indicate that incarceration can create problems for inmates and their intimate partners and that partner conflict and potentially domestic violence may occur during the transition from prison to the community. In spite of this evidence, it is not an absolute certainty that all intimate relationships will be damaged as a result of incarceration. Many relationships are unchanged by incarceration and there is even some evidence to suggest that relationships can be positively influenced by incarceration (Codd, 2007; Comfort, 2002). For example, Comfort's (2002) research with partners of incarcerated men showed that partners felt their relationship improved as a result of the man's imprisonment. Comfort's (2002) participants noted that prison forced their male partners to abstain from drugs and alcohol, and that their sobriety enhanced the closeness and intimacy of their relationship (Comfort, 2002). In addition, Codd (2007) notes that the incarceration of a family member can be beneficial if the person being sent to prison is abusive toward the rest of the family. Therefore, while one of the goals of this dissertation is to measure the extent to which 
former inmates perpetrate intimate partner violence during reentry, I do not claim that such behavior is an absolute certainty for every inmate released from prison. 


\section{Chapter 4: Research Questions}

To reiterate, the primary goal of this dissertation was to examine the extent to which formerly incarcerated offenders engage in domestic violence after they are released from prison during their transition to the community. Previous literature has established that the potential for intimate partner violence exists during this environmental transition (e.g., Fishman, 1990; Hairston \& Oliver, 2006; Oliver \& Hairston, 2008; Oliver et al., 2004); however measurement of the actual prevalence of intimate partner violence perpetrated by former inmates is lacking. A second purpose of this dissertation was to test the independent and interactive effects of selected individual, situational, and social-structural factors on post-prison intimate partner violence within a sample of former inmates during the transition from prison to the community. Selected factors are based on a blended ecological model of intimate partner violence and criminal risk during the transition from prison to the community. To fulfill these goals, the following research questions were evaluated.

\section{Research Question One}

To date, studies regarding the occurrence of intimate partner violence during the transition from prison to the community have been predominantly qualitative and exploratory (e.g., Hairston \& Oliver, 2006; Oliver \& Hairston, 2008), which limits the capacity to quantify the scope of the problem. In an effort to build upon this preliminary research, my first research question asked: what is the prevalence of postprison domestic violence perpetrated by former inmates after their release from 
prison? Measuring the prevalence of intimate partner violence during the transition from prison to the community provides the opportunity to quantify and understand the scope of the problem to an enhanced degree.

\section{Research Question Two}

My second research question addressed the second goal of this dissertation, which was to determine the independent and interactive effects of selected individual, situational, and social-structural variables on former inmates' perpetration of postprison domestic violence. More specifically, Research Question Two asked: what combination of individual, situational, and social-structural variables extracted from a blended ecological model of intimate partner violence and criminal risk during the transition from prison to the community most accurately predict former inmates' perpetration of post-prison domestic violence?

To address Research Question Two I tested the conceptual model presented in Figure 3 predicting former inmates' perpetration of post-prison domestic violence from selected individual, situational, and social-structural predictors and the interactions between them. In Chapter Two I stated that theoretically speaking, independent effects and interactions between every factor existing at each level of an ecological model should account for at least part of the variance in any behavioral outcome of study. In other words, ecological theory suggests that both the main effects of and interactions between each of the individual, situational, and socialstructural predictors in my ecological model should be evaluated. However, within 
the constraints of an applied research project and a limited sample size, I restricted the number of independent factors and interactions that I tested and chose one or two predictors to represent each of the three ecological levels in my analysis.

Main effects. Main effects on post-prison domestic violence were examined for the individual-level predictors of exposure to family-of-origin violence, antisocial personality characteristics, and borderline personality characteristics. Main effects on post-prison domestic violence were also examined for the individual-level demographic characteristics of age, ethnicity, education need, marital status, number of children, crime of conviction, length of incarceration, and correctional program participation. The main effects of the situational-level of employment and the socialstructural level of neighborhood disadvantage were also examined. The direction of hypothesized main effects are listed below.

Individual-level main effects. I anticipated a positive main effect of familyof-origin violence on post-prison domestic violence such that offenders who reported family-of-origin violence would be more likely to perpetrate post-prison domestic violence. In accordance with prior literature (Schumacher et al., 2001; Stith et al., 2004), I predicted that sampled offenders who reported a history of childhood sexual or physical victimization and those who reported witnessing spouse abuse as a child would be more likely to engage in post-prison domestic violence compared to those who reported no family-of-origin violence. 
I predicted that there would be a positive main effect of borderline and antisocial personality characteristics on the odds that formerly-incarcerated offenders would engage in post-prison domestic. Based on the findings of Dutton and Hart (1992) and White et al., (2002), I anticipated that offenders who exhibited borderline and/or antisocial personality features would be more likely to perpetrate post-prison domestic violence during the transition from prison to the community.

Among the individual-level demographic variables, I anticipated positive main effects on post-prison domestic violence for number of children, crime of conviction, length of incarceration, and education need. In line with the work of Szinovacz and Egley (1995), I predicted that offenders who reported having more children would be more likely to perpetrate post-prison domestic violence. Based on the findings of Rice (1997), I hypothesized that offenders who were incarcerated for violent crime (i.e., person crime) would be more likely to perpetrate post-prison domestic violence relative to offenders who were incarcerated for non-violent crime (i.e., property and statutory crime). In accordance with theory regarding prisonization and its effects on general recidivism (i.e., Clemmer, 1940), I predicted that the length of time offenders were incarcerated would be positively related to perpetrating postprison domestic violence. In line with the findings of Andrews and Bonta (2010) and Stith et al. (2004), I predicted that offenders with more need for education would be more likely to perpetrate post-prison domestic violence. 
I anticipated negative main effects on post-prison domestic violence for the individual-level demographic variables of age, and correctional program participation. Based on the meta-anlayses of Andrews and Bonta (2010) and Stith et al. (2004), I predicted that older offenders would be less likely to perpetrate postprison domestic violence. In accordance with Andrews and colleagues (1991), I predicted that offenders who participated in correctional rehabilitation programs (e.g., cognitive-behavioral therapy) during their incarceration would be less likely to perpetrate post-prison domestic violence.

I also anticipated main effects on post-prison domestic violence for the individual-level demographic variables of ethnicity and marital status. In line with prior literature (e.g., Schumacher et al., 2001), I anticipated that offenders who are ethnic minorities would be more likely to perpetrate post-prison domestic violence. Based on evidence provided by Laub and Sampson (2003), I also anticipated that married offenders would be less likely to perpetrate post-prison domestic violence relative to separated or divorced offenders.

Situational-level main effect. I anticipated a negative main effect of employment on post-prison domestic violence during the transition from prison to the community. In line with prior literature (e.g., Andrews \& Bonta, 2010; Schumacher et al., 2001; Stith et al., 2004), I predicted that employment would serve as a protective factor such that offenders who were employed and earned income after prison release would be less likely to engage in post-prison domestic violence. 
Social-structural level main effect. I predicted that there would be a positive main effect of neighborhood disadvantage on offenders' perpetration of post-prison domestic violence. Based on evidence from previous research (e.g., Andrews \& Bonta, 2010; Benson \& Fox, 2004), I hypothesized that sampled offenders who resided in more economically and socially disadvantaged neighborhoods would be more likely to engage in post-prison domestic violence during the transition from prison to the community.

Interactions. As stated earlier, research that is informed by an ecological theoretical perspective is not only concerned with identifying the main effects of independent variables on an outcome of interest, but it is also concerned with indentifying effects that are caused by interactions. To quote Bronfenbrenner (1977), "In ecological research, the principal main effects are likely to be interactions" (p. 518). Based on this assertion, one could argue that statistically significant interaction effects provide support for ecological models. To determine whether this study supported supports the my ecological model of post-prison domestic violence, I tested interactions between predictors that I selected to represent each level of my ecological model.

Interactions were entered into the same statistical model for Research Question Two containing tests of main effects. I tested interactions between the individual-level predictors of exposure to family-of-origin violence and antisocial and borderline personality characteristics, the situational-level predictor of employment, 
and the social-structural predictor of neighborhood disadvantage. The only level of analysis that contained more than one selected predictor was the individual level, therefore I only tested within-level interaction effects at this level (i.e., between family-of-origin violence and personality characteristics). All other tested interactions were across levels of analysis simply because the remaining levels were represented by one predictor each. Tests of interactions between predictors that exist at different levels of my ecological conceptual model allowed me to explore the effect each level of behavioral analysis has on the others; and to conjecture about the interdependent nature of one's personal characteristics, immediate environment, and broader social indicators. All tested interactions appear in Table 1. Predictions concerning the effect of each interaction on the outcome are described below.

I expected exposure to family-of-origin violence to moderate the effects of borderline and antisocial personality characteristics on post-prison domestic violence. Based on the theoretical work and findings of Delsol and Margolin (2004), I predicted that the positive main effects of borderline and antisocial personality characteristics would be stronger for offenders who reported witnessing interparental violence and/or being personally victimized as a child.

I predicted that employment would moderate the effects of each individuallevel predictor on post-prison domestic violence. In accordance with prior literature (e.g., Laub \& Sampson, 2003), I anticipated that the positive main effects of exposure to family-of-origin violence, antisocial personality characteristics, and borderline 
Table 1.

Interactions tested in Research Question Two.

\begin{tabular}{lccc}
\hline & $\begin{array}{c}\text { Borderline and } \\
\text { antisocial personality } \\
\text { characteristics }\end{array}$ & Employment & $\begin{array}{c}\text { Neighborhood } \\
\text { disadvantage }\end{array}$ \\
\hline Family-of-origin violence & $\mathrm{X}$ & $\mathrm{X}$ & $\mathrm{X}$ \\
$\begin{array}{l}\text { Borderline and antisocial } \\
\text { personality characteristics }\end{array}$ & $\mathrm{X}$ & $\mathrm{X}$ \\
& & $\mathrm{X}$ \\
\hline
\end{tabular}


personality characteristics would be weaker for offenders who were employed and earned income after prison release.

Finally, I predicted that neighborhood disadvantage would moderate the effects of exposure to family-of-origin violence, antisocial personality characteristics, borderline personality characteristics, and post-prison employment on post-prison domestic violence. Based on prior literature (e.g., Andrews \& Bonta, 2010; Benson et al., 2004; Lynam et al., 2000), I anticipated that the positive main effects of exposure to family-of-origin violence, antisocial personality characteristics, and borderline personality characteristics would be stronger for offenders who resided in more economically and socially disadvantaged neighborhoods after prison release. I anticipated that the negative main effect of employment on post-prison domestic violence would be weaker for offenders who resided in economically and socially disadvantaged neighborhoods after prison release. 


\section{Chapter 5: Method}

A retrospective study of intimate partner violence perpetrated by formerly incarcerated male offenders after their release from state correctional institutions run by the Oregon Department of Corrections (DOC) was conducted. Data for the current retrospective study were collected from institutional and community supervision records of formerly incarcerated male offenders who were released from prison between 2004 and 2009 and followed for an average of 4.4 years in the community (range $=1.3$ 7.3 years). These records were paired with data from law enforcement reports of domestic violence perpetrated by sampled offenders in the community during the follow-up period.

\section{Sample}

A sample $(n=1,223)$ of offenders whose records contained complete data on the measured variables that I selected to represent each level of the ecological model I proposed (hereafter, the "study sample") was extracted from a pool of 5,378 adult male inmates who were released from prison to the Portland area (i.e., Multnomah county) between January 1, 2004 and December 31, 2009. Demographic characteristics of the study sample are presented in Table 2 . The majority of the study sample is Caucasian (72\%); followed by $23 \%$ African American, two percent Latino, two percent Native American, and one percent Asian. Age at the time of prison release ranged from 18 to 78 years with an average age of $37(S D=9.8)$. At the time of prison release, $11 \%$ of the were between the ages of 18 and 24, 21\% were between 25 and 30, 48\% were between 31 and 45, 19\% were between 46 and 60, and one percent were 61 and older. 
Table 2.

Demographic characteristics of the study sample and study population who were released from prison to Multnomah county and the population of offenders released to the entire state between January 1, 2004 and December 31, 2009.

\begin{tabular}{|c|c|c|c|}
\hline & $\begin{array}{c}\text { Study } \\
\text { Sample } \\
(n=1,223)\end{array}$ & $\begin{array}{c}\text { Study } \\
\text { Population } \\
(n=5,378)\end{array}$ & $\begin{array}{c}\text { State } \\
\text { Population } \\
(n=21,359)\end{array}$ \\
\hline \multicolumn{4}{|l|}{ Ethnicity } \\
\hline Caucasian & $72 \%$ & $62 \%$ & $76 \%$ \\
\hline African American & $23 \%$ & $25 \%$ & $9 \%$ \\
\hline Latino & $2 \%$ & $9 \%$ & $12 \%$ \\
\hline Native American & $2 \%$ & $2 \%$ & $2 \%$ \\
\hline Asian & $1 \%$ & $2 \%$ & $1 \%$ \\
\hline \multicolumn{4}{|l|}{ Age (in years) } \\
\hline Mean (SD) & $37(9.8)$ & $35(12)$ & $36(11)$ \\
\hline Range & $18-78$ & $16-81$ & $16-87$ \\
\hline 17 and under & $0 \%$ & $1 \%$ & $1 \%$ \\
\hline $18-24$ years & $11 \%$ & $16 \%$ & $17 \%$ \\
\hline $25-30$ years & $21 \%$ & $19 \%$ & $22 \%$ \\
\hline $31-45$ years & $48 \%$ & $46 \%$ & $42 \%$ \\
\hline $46-60$ years & $19 \%$ & $16 \%$ & $16 \%$ \\
\hline 61 and older & $1 \%$ & $2 \%$ & $2 \%$ \\
\hline \multicolumn{4}{|l|}{ Crime type } \\
\hline Person & $40 \%$ & $48 \%$ & $46 \%$ \\
\hline Property & $38 \%$ & $32 \%$ & $29 \%$ \\
\hline Statutory & $22 \%$ & $20 \%$ & $25 \%$ \\
\hline \multicolumn{4}{|c|}{ Length of most recent incarceration (in years) } \\
\hline Mean $(S D)$ & $2.1(1.6)$ & $2.7(3.1)$ & $2.6(2.9)$ \\
\hline Range & $0.2-9.6$ & $0.01-32$ & $0.03-32$ \\
\hline One year or less & $28 \%$ & $29 \%$ & $29 \%$ \\
\hline One to three years & $49 \%$ & $43 \%$ & $44 \%$ \\
\hline Three to five years & $13 \%$ & $10 \%$ & $9 \%$ \\
\hline Five to ten years & $9 \%$ & $14 \%$ & $14 \%$ \\
\hline Ten to twenty years & $0 \%$ & $3 \%$ & $2 \%$ \\
\hline Twenty years or more & $0 \%$ & $1 \%$ & $1 \%$ \\
\hline \multicolumn{4}{|c|}{ Risk of post-prison felony reconviction } \\
\hline Low & $32 \%$ & $41 \%$ & $46 \%$ \\
\hline Moderate & $53 \%$ & $47 \%$ & $44 \%$ \\
\hline High & $15 \%$ & $12 \%$ & $10 \%$ \\
\hline
\end{tabular}


The majority of offenders within the study sample were released from prison after serving sentences for person-related crime (40\%). Thirty-eight percent were released after serving time for property crime, and about $22 \%$ served sentences for statutory crime. Offenders in the study sample served sentences ranging from less than six months to nearly 10 years with an average of 2.1 years ( $S D=1.6$ years). Twentyeight percent of offenders in the study sample were incarcerated for one year or less, $49 \%$ were in prison for one to three years, $13 \%$ for three to five years, and $9 \%$ for five to 10 years. At the time of their incarceration, most offenders in the study sample were determined by DOC to be at moderate risk for felony reconviction (53\%). Thirty-two percent were determined to be at low risk for felony reconviction, and $15 \%$ were determined to be at high risk.

To reiterate, the study sample is comprised only of offenders whose records contained complete data on the measured variables that I selected to represent each level of the ecological model I tested. More specifically, the study sample includes all offenders who were released from prison to Multnomah county between January 1, 2004 and December 31, 2009 and whose records contained data on their exposure to family-of-origin violence, personality characteristics, post-prison employment, and neighborhood disadvantage. While there were 5,378 offenders released to Multnomah county between January 1, 2004 and December 31, 2009, only 1,223 offenders completed measures during their incarceration for the variables in the model I tested.

There are a number of reasons why some offenders completed these measures and others did not. First, the measures of exposure to family-of-origin violence and 
personality characteristics are only offered in English. Therefore, offenders who were not proficient in English did not complete these measures. Second, completion of each measure requires a certain level of literacy, albeit minimal. Offenders whose reading and comprehension ability were below $6^{\text {th }}$ grade proficiency levels were not given the opportunity to complete the personality measure and were therefore not included in the study sample. Third, in order to collect post-prison employment records DOC must obtain offenders' consent to use their social security numbers. Offenders who did not give DOC permission to use their social security numbers to obtain post-prison employment records were not included in the study sample. Finally, zip codes associated with neighborhoods where offenders lived after prison release were required to compute the index of neighborhood disadvantage, which will be described in this chapter. Fortunately, all offender records that contained data for exposure to family-oforigin violence, personality characteristics, and post-prison employment also contained the zip codes of their post-prison neighborhoods. Therefore, sample size was not decreased because of missing data required to compute the index of neighborhood disadvantage. Figure 4 provides an illustration of areas where the study sample decreased due to missing data on specific measures.

Given that the study sample was not a random sample of all offenders who were released to Multnomah county during the specified dates, it is important to consider the possibility that there are differences between offenders in the study sample and the pool of 5,378 offenders who were released to Multnomah county between January 1, 2004 and December 31, 2009 from which the study sample was drawn (hereafter, the "study 


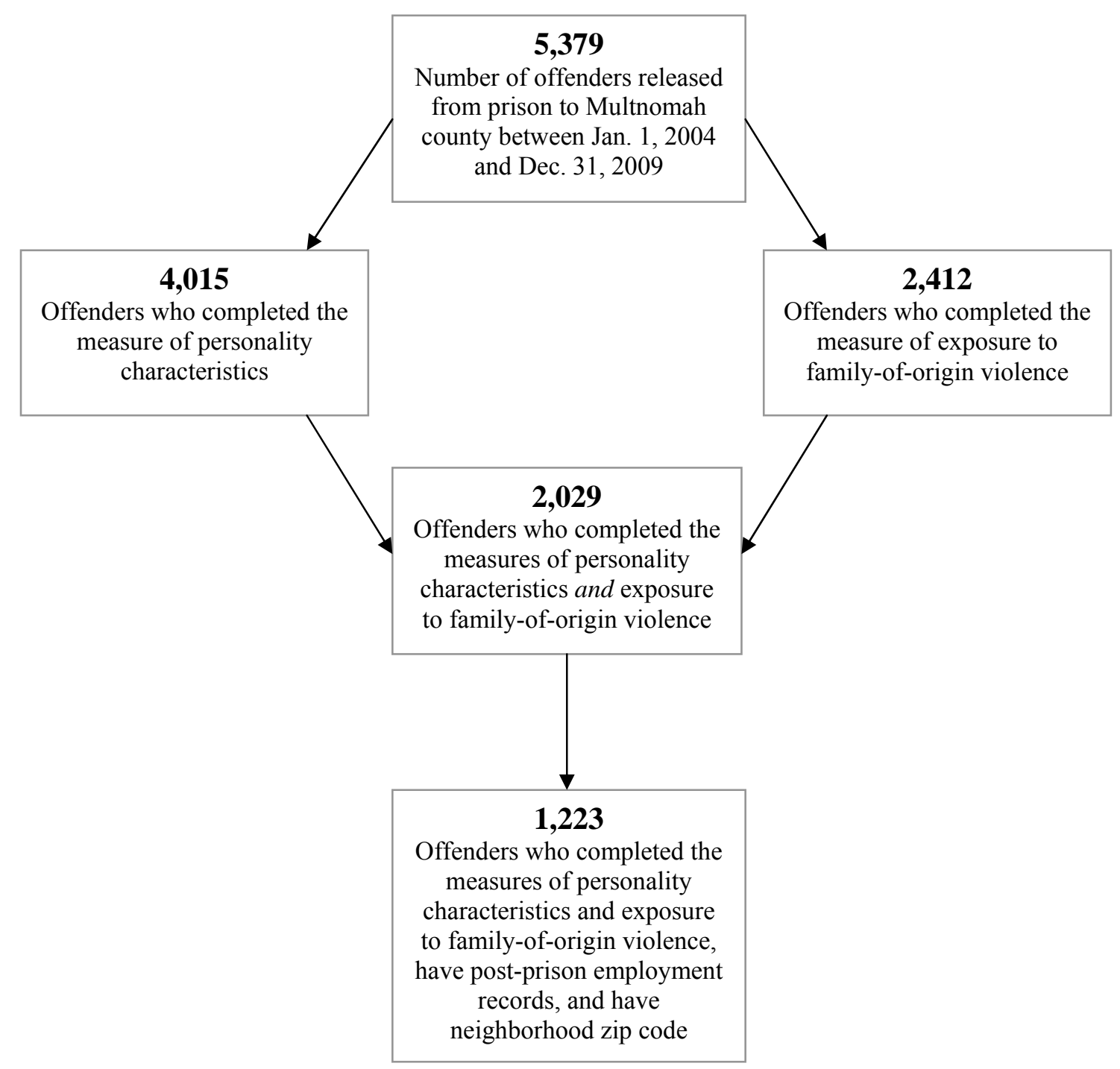

Figure 4. Areas where the study sample is decreased due to missing data on specific measures. 
population"). If the study sample is significantly different from the study population, generalizability of the findings is restricted. Indeed, Table 2 indicates that there were a few key differences between the study sample and the study population. In terms of ethnicity, the study sample contained a higher proportion of Caucasian offenders (72\%) relative to the study population (62\%), and a lower proportion of Latino offenders ( $2 \%)$ relative to the study population (9\%). This underrepresentation of Latino offenders in the study sample may be due to language barriers surrounding the personality and family-of-origin violence measures that are only offered in English. Regarding crime type, property crime offenders were more heavily represented within the study sample (38\%) than in the study population (32\%); and the proportion of offenders convicted of person crime in the study sample (40\%) was smaller than that of the study population (48\%). In addition, the length of the most recent incarceration for offenders in the study sample was slightly shorter than that of the study population by about half a year (2.1 years vs. 2.7 years). Finally, a slightly larger proportion of offenders in the study sample were classified as moderate or high risk to be reconvicted of a felony (68\%) relative to offenders in the study population (59\%).

The larger number of moderate and high risk offenders in the study sample relative to the study population partially explains the demographic differences between the two groups. Specifically, moderate and high risk offenders in Oregon are generally more likely to be younger, non-Latino, and commit property-related offenses relative to low risk offenders (DOC, 2011). In addition, moderate and high risk offenders in Oregon generally serve shorter prison sentences than low risk offenders (DOC, 2011). 
As demonstrated in Table 2, the study sample was younger in age, mostly non-Latino, more likely to have committed property crime, and served shorter sentences than the study population. However, while it is possible that the study sample may be somewhat representative of moderate and high risk offenders in Oregon, I reiterate that the study sample is not a random selection of former inmates and my ability to generalize my findings to a broader offender population is limited.

To further situate the study sample within the demographic context of the state of Oregon, Table 2 also presents the demographic characteristics of all male offenders who were released throughout the state between January 1, 2004 and December 31, 2009 (hereafter, the "state population"). The most salient difference between the study sample/population and the state population is ethnicity. Over $20 \%$ of both the study sample and study population is African American relative to nine percent of the state population. The larger representation of African American inmates in the study sample and study population reflects the larger general population of African Americans who reside in Multnomah county relative to all other counties in Oregon. African Americans represent six percent of the total population in Multnomah county and only two percent of the Oregon population overall (US Census Bureau, 2008). Since incarcerated individuals are usually released into the same county where they were convicted of their crime, one would expect a larger percentage of African American offenders to be released to Multnomah county compared to the other counties in Oregon. In addition, the larger representation of African Americans in the study sample and study population is reflective of the significantly higher incarceration rate of African Americans (2.3\%) 
relative to Caucasians $(0.4 \%)$ both in Oregon and throughout the United States (Mauer \& King, 2007).

\section{Procedure and Variables}

Offenders who are incarcerated in Oregon are evaluated by DOC on a number of different domains when they enter prison and again when they are due to be released (e.g., mental health, substance abuse, treatment needs, cognitive capacity, educational attainment, and changes in criminal risk) in order to create plans for their rehabilitation and treatment. Measures and risk assessments that are administered by DOC staff that were used to address the current research questions are described below. Data for each measure and assessment were collected from electronic DOC records for all offenders in the study sample. A list of all measured variables with corresponding data sources are presented in Table 3.

Individual level: Exposure to family-of-origin violence. Exposure to familyof-origin violence including each offender's own victimization and witnessing of partner violence as a child is assessed by DOC with a series of three questions. These questions are: "Were you ever physically abused as a child", "were you ever sexually abused as a child", and "when you were growing up, did you ever see the people who raised you hit or strike one another?" Offenders respond to the questions using either "yes" or "no".

For purposes of the current research, three dummy variables were created to indicate offenders' responses to the exposure to family-of-origin violence questions: Physical Abuse Victim, Sexual Abuse Victim, and Witnessed Abuse. Offenders who 
Table 3.

List of measured variables with corresponding data sources.

\begin{tabular}{|c|c|c|c|}
\hline Level of Analysis & Measured Variable & Source of Data & $\begin{array}{r}\text { Time of Data } \\
\text { Collection } \\
\end{array}$ \\
\hline \multirow[t]{3}{*}{ Individual } & $\begin{array}{l}\text { Family-of-origin } \\
\text { violence }\end{array}$ & DOC Records & Prison Intake \\
\hline & $\begin{array}{l}\text { Antisocial \& borderline } \\
\text { personality } \\
\text { characteristics }\end{array}$ & DOC Records & Prison Intake \\
\hline & $\begin{array}{l}\text { Demographic } \\
\text { characteristics }\end{array}$ & DOC Records & Prison Intake \\
\hline Situational & Employment & $\begin{array}{l}\text { DOC Records and } \\
\text { Oregon Employment } \\
\text { Department }\end{array}$ & After prison release \\
\hline Social-structural & $\begin{array}{l}\text { Neighborhood } \\
\text { disadvantage }\end{array}$ & $\begin{array}{l}\text { DOC Records } \\
\text { (address) \& Online } \\
\text { Census tract data }\end{array}$ & After prison release \\
\hline Outcome & $\begin{array}{l}\text { Post-prison } \\
\text { domestic violence }\end{array}$ & Portland Police Bureau & After prison release \\
\hline
\end{tabular}


answered "yes" to the question regarding experiences of childhood physical abuse received a 1 on the Physical Abuse Victim dummy variable and those who answered "no" received a 0. Offenders who answered "yes" to the question regarding experiences of childhood sexual abuse received a 1 on the Sexual Abuse Victim dummy variable and those who answered "no" received a 0 . Offenders who answered "yes" to the question about witnessing abuse between their caregivers received a 1 on the Witnessed Abuse dummy variable and those who answered "no" received a 0 .

Individual level: Personality characteristics. The current study focuses on borderline and antisocial personality characteristics, which have been identified as correlates of self-reported domestic violence among both incarcerated and nonincarcerated samples in partner violence research (Dutton, 1995; Dutton \& Hart, 1992; Edwards, Scott, Yarvis, Paizis, \& Panizzon, 2003; White et al., 2002). Borderline and antisocial personality characteristics were measured with the Personality Assessment Inventory (PAI; Morey, 1991, 2007) which is administered by DOC to all offenders at the beginning of their incarceration in order to identify areas of risk and route them to appropriate treatment services.

The PAI is a 344-item self-administered assessment that contains 22 separate scales organized into 4 categories: Interpersonal, Clinical, Treatment, and Validity. Respondents rate each of the 344 statements using a four-point Likert scale ranging from "false, not at all true" to "very true." Total scores on two subscales within the Clinical scale—Borderline Features and Antisocial Features—-were collected from each sampled offender's DOC record and included in the analyses. The 24-item Borderline 
Features subscale (BOR) was created to assess core features of borderline personality disorder as it is defined in the Diagnostic and Statistical Manual of Mental Disorders (DSM; American Psychiatric Association, 1994). Specifically, BOR items assess affective instability, identity problems, negative relationships, and selfharm/impulsivity. The 24-item Antisocial Features subscale (ANT) assesses core features of antisocial personality disorder as defined in the DSM, including conduct problems and criminality, self-centered and remorseless behavior, and thrill seeking tendencies (Morey, 1991, 2007). The BOR and ANT subscales are scored so that higher total scores indicate more severe borderline and antisocial personality characteristics, respectively. Scores of 70 and higher on each scale suggest the presence of either borderline or antisocial personality disorder (Morey, 1991, 2007). Within the current sample, approximately 19 percent had scores of 70 and above on the BOR subscale and 25 percent had scores of 70 and above on the ANT subscale.

Use of the PAI in domestic violence research is rare compared to the widespread use of personality measures like the Minnesota Multiphasic Personality Inventory (MMPI; Hathaway \& McKinley, 1943) and the Millon Clinical Multiaxial Inventory (MCMI; Millon, 1983). Both the MMPI and MCMI are used frequently to assess the personality characteristics of domestically violent men, however recent criticisms suggest that the PAI may be equally if not more appropriate to use within this population (Chambers \& Wilson, 2007). Specifically, the MCMI has been found to over diagnose personality disorders (Wetzler, 1990) and some have argued that the MCMI and MMPI are overly sensitive to pathological characteristics (Groth-Marnat, 1997). 
Chambers and Wilson (2007) assert that a personality measurement tool which is sensitive to nonpathological characteristics as well as pathological characteristics is crucial to use when studying perpetrators of intimate partner violence given that the majority are not pathological (Hamberger, Lohr, Bonge, \& Tolin, 1996; HoltzworthMunroe \& Stuart, 1994; Saunders, 1992; Waltz, Babcock, Jacobson, \& Gottman, 2000). A handful of studies confirm that the PAI is an adequate measure of domestic violence perpetrators' personality characteristics. For example, the PAI has been used to replicate Holtzworth-Munroe and Stuart's (1994) original "batterer typology” model that was established and has been validated using the MMPI almost exclusively (Chambers \& Wilson, 2007; Delsol, Margolin, \& John, 2003). In addition, the BOR and ANT subscales of the PAI have been used to classify domestically violent men in terms of the severity of self-reported violence (Edwards et al., 2003).

The PAI is also gaining notoriety as a useful personality measurement tool in correctional settings (Edens, Cruise, \& Buffington-Vollum, 2001; Piotrowski, 2000). Correctional institution counselors and psychologists may use the PAI to assist in the management and treatment of incarcerated offenders (Edens \& Ruiz, 2005). The PAI is also suitable for use within a correctional setting due to its ease of use. Specifically, the PAI can be completed by an individual with a fourth grade reading ability — a quality which makes it practical for incarcerated offenders who often have limited educational achievement. In addition, the PAI is significantly shorter (344 items) than other, more popular personality assessment instruments such as the MMPI (nearly 600 items; Edens et al., 2001). 
Validation studies on the PAI have been conducted with normative communitydwelling adults, college students, and incarcerated samples (Morey, 1991, 2007). Overall, psychometric properties of the PAI Clinical scales (which include the BOR and ANT) are relatively good. Within a combined sample of community-dwelling adults and college students, test-retest reliability of the clinical scales is high $(r=.79-.92)$ and internal consistency is excellent (Cronbach's alpha $\geq .82$; Morey, 1991, 2007). Internal consistency is also good for each of the individual subscales included in the current study among community and college samples. Cronbach's alpha values found in previous literature for the ANT subscale range up to .84 (Morey, 1991) and Cronbach's alpha for the BOR subscale has been slightly higher at .88 (Boone, 1998). Internal consistency estimates for the Clinical scales in corrections samples range from .82 to .92, and PAI scale scores demonstrate significant relationships with institutional misconduct and general aggression (Edens \& Ruiz, 2005). Also, studies comparing the PAI to other personality assessments (i.e., the MMPI) indicate high convergent validity between measures ( $r>.50$; see Edens et al., 2001 for a review). Internal consistency for the ANT subscale in the current sample is acceptable (Cronbach's alpha $=.76)$ and internal consistency for the BOR subscale is good (Cronbach's alpha $=.85)$.

Individual level: Demographic variables. Additional individual-level demographic variables that were collected from offenders' DOC records include age at prison release, number of children, length of incarceration, ethnicity, marital status at the time of their arrest, type of crime for which they were incarcerated, the type(s) of correctional program(s) in which they participated during their incarceration (i.e., 
substance abuse treatment, cognitive-behavioral therapy, religious services programming, or domestic violence intervention programming), and education need.

Continuous demographic variables included age at prison release, number of children, and length of incarceration. The variable of age at prison release was represented in years. Number of children and length of incarceration period were also treated as continuous, with length of incarceration reflecting the number of years that elapsed between prison admission and release dates.

All remaining demographic constructs were treated as categorical. Table 4 displays dummy variables that were created to represent the categorical demographic constructs of ethnicity, marital status, type of crime, correctional program participation, and education need. A single dummy variable was created to represent five ethnic group categories including Caucasian, African American, Latino, Asian, and Native American. Another dummy variable was created to represent five marital status categories including single (never married), married, separated, divorced, and widowed. A dummy variable was created to signify whether the type of crime for which an offender was incarcerated was violent or non-violent. Offenders who were incarcerated for person-related crime received a score of "1" on the dummy variable and offenders who were incarcerated for property or statutory crime received a score of "0" on the dummy variable. Dummy variables were also created to signify the types of correctional programs in which offenders participated. Specifically, one dummy variable each was created to represent participation in substance abuse treatment, cognitive-behavioral treatment, religious services programming, and domestic violence intervention 
Table 4.

Dummy variables created to represent categorical demographic constructs.

\begin{tabular}{|c|c|c|c|}
\hline $\begin{array}{l}\text { Dummy } \\
\text { variable }\end{array}$ & Score & Category & Definition \\
\hline \multirow[t]{5}{*}{ Ethnic group } & 1 & Asian & Offender is Asian \\
\hline & 2 & African American & Offender is African American \\
\hline & 3 & Latino & Offender is Latino \\
\hline & 4 & Native American & Offender is Native American \\
\hline & 5 & Caucasian & Offender is Caucasian \\
\hline \multirow[t]{5}{*}{ Marital status } & 0 & Single & Offender was single (i.e., never married) at arrest \\
\hline & 1 & Separated & Offender was separated at arrest \\
\hline & 2 & Divorced & Offender was divorced at arrest \\
\hline & 3 & Widowed & Offender was widowed at arrest \\
\hline & 4 & Married & Offender was married at arrest \\
\hline \multirow[t]{2}{*}{ Type of crime } & 0 & Non-violent crime & Offender was in prison for a non-violent crime \\
\hline & 1 & Violent crime & Offender was in prison for a violent crime \\
\hline \multirow{2}{*}{$\begin{array}{l}\text { Substance } \\
\text { treatment }\end{array}$} & 0 & Did not participate & Offender did not participate in substance abuse treatment \\
\hline & 1 & Participated & Offender participated in substance abuse treatment \\
\hline \multirow{2}{*}{$\begin{array}{l}\text { Cognitive } \\
\text { treatment }\end{array}$} & 0 & Did not participate & Offender did not participate in cognitive programs \\
\hline & 1 & Participated & Offender participated in cognitive programs \\
\hline \multirow{2}{*}{$\begin{array}{l}\text { Religious } \\
\text { programs }\end{array}$} & 0 & Did not participate & Offender did not participate in religious programming \\
\hline & 1 & Participated & Offender participated in religious programming \\
\hline \multirow{2}{*}{$\begin{array}{l}\text { Domestic } \\
\text { violence (DV) }\end{array}$} & 0 & Did not participate & Offender did not participate in DV programming \\
\hline & 1 & Participated & Offender participated in DV programming \\
\hline \multirow[t]{5}{*}{$\begin{array}{l}\text { Education } \\
\text { need }\end{array}$} & 1 & $\begin{array}{l}\text { Most education } \\
\text { need }\end{array}$ & $\begin{array}{l}\text { Offender did not have a high school degree and could no } \\
\text { read at } 7^{\text {th }} \text { grade level }\end{array}$ \\
\hline & 2 & $\begin{array}{l}\text { Moderate } \\
\text { education need }\end{array}$ & $\begin{array}{l}\text { Offender did not have a high school degree and could no } \\
\text { read at } 9^{\text {th }} \text { grade level }\end{array}$ \\
\hline & 3 & $\begin{array}{l}\text { Some education } \\
\text { need }\end{array}$ & $\begin{array}{l}\text { Offender did not have a high school degree but could } \\
\text { read at } 9^{\text {th }} \text { grade level and conduct math at } 6^{\text {th }} \text { grade level }\end{array}$ \\
\hline & 4 & $\begin{array}{l}\text { Minimal education } \\
\text { need }\end{array}$ & $\begin{array}{l}\text { Offender had at least a high school degree and could reac } \\
\text { at } 7^{\text {th }} \text { grade level }\end{array}$ \\
\hline & 5 & No education need & $\begin{array}{l}\text { Offender had at least a high school degree and could read } \\
\text { at } 10^{\text {th }} \text { grade level and conduct math at } 11^{\text {th }} \text { grade level }\end{array}$ \\
\hline
\end{tabular}


programming. Offenders who participated in any one of these correctional programs during their incarceration received a score of " 1 " on the corresponding program's dummy variable. No participation in a given program resulted in a score of " 0 " on the corresponding program's dummy variable.

DOC determines all incarcerated offenders' need for education services and eligibility for prison-based work programs (i.e., education need) through a review of degree(s) earned and educational testing. Offenders are then categorized on an ordinal scale ranging from most education need to no education need. Because the differences between points on DOC's scale of education need are not equal, a dummy variable was created to represent the education need of offenders in the current sample at the time of their release from prison. The "Most education need" category included offenders who did not have a high school degree and could not read at the seventh grade level at the time of their release from prison. Offenders in the "Moderate education need" category did not have a high school degree and could not read at the ninth grade level at the time of their prison release. The "Some education need" category included offenders who did not have a high school degree but could read at the ninth grade level and conduct math at the sixth grade level when they were released from prison. The "Minimal education need" category included offenders who had at least a high school degree and could read at the seventh grade level when they were released. Finally, the "No education need" category included sampled offenders who had at least a high school degree, a tenth grade reading level, and an eleventh grade math level at prison release. 
Situational level: Employment. Data regarding sampled offenders' employment after prison release was collected from records maintained by the Oregon Employment Department (OED). Employment data is reported by OED on a quarterly basis. Two variables were extracted from OED reports to measure offenders' employment after prison release: wages earned per calendar quarter worked and the number of calendar quarters worked. For each offender, average wages earned per year and the percentage of quarters worked were calculated for the entirety of the follow-up period. Average wages earned per year was calculated by first calculating the average wages earned per quarter worked. Average wages per quarter worked was computed by taking the total amount of wages an offender earned between his prison release date and his study exit date and dividing it by the number of quarters during which he was employed. Average wages per quarter worked was then collapsed into categories representing average wages earned per year. Percentage of quarters worked was calculated by taking the number of quarters during which the offender was employed and dividing it by the number of quarters that were available to work between his prison release date and study exit date. For example, an offender who was released from prison on December 1, 2006 and engaged in post-prison domestic violence on July 20, 2010 (i.e., his study exit date) had 15 calendar quarters available to work. If the offender worked during two quarters out of the 15 available, his percentage of quarters worked was $13 \%$.

Social-structural level: Neighborhood disadvantage. Characteristics of the neighborhood(s) in which sampled offenders lived after their release from prison were 
collected via tract-level data from the 2000 Census. Tract-level data from the 2010 Census was not available at the time of analysis. Neighborhoods in which sampled offenders lived after prison release were determined from their home addresses, which were gathered from DOC community supervision records. Offenders' addresses were matched to the appropriate census tract, and a selection of neighborhood factors were collected from each tract to represent an index of neighborhood disadvantage.

The index of neighborhood disadvantage was modeled on the work of Benson and colleagues (Benson \& Fox, 2004; Benson, Fox, DeMaris, \& Van Wyk, 2003; Fox, Benson, DeMaris, \& Van Wyk, 2002); and was defined by the following five census tract items: percent of single parents, percent of families on public assistance, percent below the poverty line, percent non-White, and percent unemployed. To create the neighborhood disadvantage index, each of the five census items were transformed into a $Z$ score. To create the $Z$ score, distribution means $(\mu)$ and standard deviations $(\sigma)$ for each item were derived from averages found across the surrounding four counties (i.e., Multnomah, Washington, Clackamas, and Clark counties). Specifically, the average percent of single parents across Multnomah, Washington, Clackamas, and Clark counties was entered into an equation to transform each offenders' neighborhood tractlevel single parent data into $Z$ scores. The same steps were followed to compute $Z$ scores for the percent of families on public assistance, percent below the poverty level, and so on. $Z$ scores obtained for each offender's neighborhood indicators were then summed and divided by the number of indicators (i.e., five) to form the continuous index of neighborhood disadvantage. Following the $Z$ distribution, positive scores above 
zero on the neighborhood disadvantage index indicate above average neighborhood disadvantage. Negative scores below zero indicate below average neighborhood disadvantage. Fox et al. (2004) report excellent internal consistency (Cronbach's alpha $=.92-.93)$ for the index of neighborhood disadvantage from census tract data collected on a sample of 4,940 couples who responded to a national survey of US households. Internal consistency among the neighborhood disadvantage index indicators within the current sample was lower but still acceptable (Cronbach's alpha $=.75$ ).

The vast majority of offenders in the sample had records listing multiple addresses between their prison release date and study exit date. In many cases, each address was associated with a different index of neighborhood disadvantage. In order to establish a single score for each offender on the neighborhood disadvantage index, I averaged each offenders' neighborhood disadvantage scores and weighted each score by the number of years spent living at the address. I chose to create a weighted average of the neighborhood disadvantage index because the amount of time an offender lived at each address varied widely. For example, an offender may have spent many years at one address with a certain neighborhood disadvantage index and only four months at another address with a different neighborhood disadvantage index. By computing a weighted average of each offender's neighborhood disadvantage index scores, I was able to account for the amount of time the offender was "exposed" to each level of neighborhood disadvantage.

Outcome: Post-prison domestic violence. Sampled offenders' perpetration of post-prison domestic violence was measured from Portland Police Bureau records of 
officer responses to domestic violence calls in the community collected in April of 2011. As a part of their regular law enforcement report-writing process, the Portland Police Bureau (PPB) engages in special procedures to "flag" reports that are related to domestic violence in the Portland area. For example, say a PPB officer responds to a police call from a citizen whose car tires have been slashed. When the officer arrives at the scene of the crime and begins to collect information about the incident, the citizen (a woman) states that she thinks her estranged husband may have slashed her tires after an argument that they had the night before. After talking for a while the woman decides not to bring criminal charges against her husband and the officer leaves. Later in the day, the officer writes up a report concerning the incident and delivers it to a data entry clerk. Upon reading the officer's narrative, the data entry clerk determines the various offense codes that apply to the incident (e.g., criminal mischief in this example), "flags" the incident as a domestic violence-related offense, and lists the woman's husband as a suspect in the crime. This process creates a record indicating the woman's husband as a suspect in a police report involving domestic violence. If the officer had arrested the woman's husband and charged him with criminal mischief for slashing his wife's tires, the officer would flag the case report as an offense that falls within the scope of domestic violence and indicate that the woman's husband was taken into custody as a result of the crime.

PPB's domestic violence incident report "flagging” system allows law enforcement to look up any offender to examine whether he or she was a suspect or taken into custody for a case involving intimate partner violence regardless of whether 
the offender was convicted of a crime. This system of data collection is unique in that law enforcement contact that does not result in an official sanction (e.g., charges and/or an arrest) is still identified or "flagged" as a domestic violence incident if evidence suggests the offender was a suspect. Given that police responses to domestic violence calls do not always result in an official sanction, PPB data allowed for a broader operational definition of domestic violence recidivism relative to other studies which are often limited to data present in public and/or legal records. The only limitation to the data is that the exact nature of the familial relationship between the offender and victim is not recorded by PPB, making it impossible to determine whether the victim was an offender's intimate partner or other family member. However, recent findings indicate that out of a random sample of PPB cases flagged as domestic violence incidents, nearly $80 \%$ involved heterosexual intimate partners (K. Henning, personal communication, March, 2012). Therefore, it can be assumed that the overwhelming majority of domestic violence events in the current study involved sample offenders' intimate partners.

Per the recommendation of Cook (personal communication, August 2010) and in accordance with similar research (i.e., Harris et al., 1993; Hilton et al., 2010), postprison domestic violence was treated dichotomously. Two dichotomous post-prison domestic violence variables were created: one to represent any post-prison domestic violence incident and a second to represent severe post-prison domestic violence. Any post-prison domestic violence incident was defined as any occurrence wherein the offender was either a suspect or taken into custody for their role in a disturbance that involved a domestic relationship (e.g., domestic problems, family disturbance, and 
offense versus the family). Severe post-prison domestic violence was defined as an event wherein the offender was either a suspect or taken into custody for engaging in criminal action (e.g., assault, violation of a court order, threats, and robbery) against an intimate partner or other family member. Offenders whose PPB records contained one or more indicators that they were either a suspect or taken into custody for their role in a disturbance that involved a domestic relationship received a score of " 1 " on the dichotomous variable representing any post-prison domestic violence incident. Offenders whose records indicated that they were neither a suspect nor taken into custody for their role in a disturbance that involved a domestic relationship received a score of " 0 " on the variable representing any post-prison domestic violence incident. Offenders whose PPB records indicated that they were either a suspect or taken into custody for engaging in criminal action against an intimate partner or other family member received a score of " 1 " on the dichotomous variable representing severe postprison domestic violence. Offenders whose records indicated that they were neither a suspect nor taken into custody for engaging in criminal action against an intimate partner or other family member received a score of " 0 " on the variable representing severe post-prison domestic violence. PPB records were coded by law enforcement to clearly indicate whether a given report should be classified as any domestic violence incident or severe domestic violence. The status of the offender in relation to the incident (i.e., suspect, taken into custody, or neither) was also clearly noted by law enforcement. Because this system of flagging and coding was implemented by law 
enforcement before data were delivered, further coding beyond the development of the dichotomous post-prison domestic violence variables was not necessary. 


\section{Chapter 6: Analysis}

Once data were obtained, appropriate data screening procedures were implemented including estimating the extent and pattern of missing data, checking for normality, and searching for univariate and multivariate outliers (Tabachnick \& Fidell, 2001). Descriptive statistics (i.e., mean, standard deviation, and range) for each variable were also computed. Variable distributions were checked to ensure that all values were within range and that all means and standard deviations were plausible. In addition, correlation matrices were scrutinized for inflated or deflated correlations and signs of multicollinearity among the predictors (Tabachnick \& Fidell, 2001).

Conducting these screening procedures allowed me to identify areas where the data needed to be cleaned or otherwise modified (e.g., deleted, imputed, or transformed) so that the data met the assumptions of my statistical procedures and allowed me to conduct an "honest analysis of the data" (Tabachnick \& Fidell, 2001, p. 56). After data were thoroughly screened, cleaned, and organized, I proceeded to test my research questions.

\section{Research Question One}

My first research question concerned the prevalence of post-prison domestic violence perpetrated by formerly incarcerated offenders during the transition from prison to the community. Traditionally, researchers describe time-to-event or duration data like these in two different ways (Luke, 1993). First, a researcher may report the percentage of a sample for which the event of interest has occurred by a particular point in time (e.g., the end of the study). If I chose this approach in my analysis of the 
prevalence of post-prison domestic violence, I would report the percentage of sampled offenders who engaged in any post-prison domestic violence incident and/or severe post-prison domestic violence event during the follow-up period. Second, a researcher may report the average length of time to the event of interest for the sample. If I chose this approach, I would report the average length of time that elapsed between sampled offenders' release from prison and commission of any post-prison domestic violence incident and/or severe post-prison domestic violence event. However, both of these descriptions of time-to-event data are problematic. If I applied the first descriptive method, I would be reporting the proportion of sampled offenders who engaged in postprison domestic violence while ignoring the timing of these events. If I used the second descriptive method, I would be reporting the timing of post-prison domestic violence without indicating how many of the sampled offenders recidivated. Furthermore, neither descriptive method would account for sampled offenders who do not appear to have engaged in post-prison domestic violence because they did not recidivate before the end of the follow-up period (i.e., censored cases; Luke, 1993).

Survival analysis is one analytic method that allows for the exploration of both the proportion of a sample for which the event of interest has occurred and the timing of the event of interest while correcting for biases in estimates that are caused by censored cases (Luke, 1993). Therefore, I conducted a survival analysis to address my first research question concerning the prevalence of post-prison domestic violence perpetrated by sampled offenders after prison release. Two separate survival analyses 
were conducted to predict any post-prison domestic violence incident and severe postprison domestic violence.

To conduct a survival analysis, I first expanded my dependent variable of postprison domestic violence to reflect event time and event status for each sampled offender (Luke, 1993). In the current analysis, event time reflects the number of months that elapsed between each offender's prison release and either a post-prison domestic violence event (for non-censored cases) or the end of the offender's specific follow-up period (for right-censored cases). Event status is reflected by the dichotomous postprison domestic violence variables indicating that the event has either occurred (i.e., signified by a score of "1" on each of the dichotomous post-prison domestic violence variables) or not occurred, thereby representing a censored case (i.e., signified by a score of "0").

A significant degree of care and consideration was taken during the calculation of the event time variable for the current analysis. For many offenders, event time was calculated as the number of months that elapsed between their release from prison and either the end of the study or their first post-prison domestic violence event. However, detailed examination of post-prison address and community supervision records indicated that many sampled offenders exited the study for a variety of other reasons. For example, some offenders were readmitted to state or federal prison for unknown reasons, other offenders were deported or moved to a different state, and a small number of offenders died. Naturally, the calculation of event time for each sampled offender varied according to the way in which they exited the study. 
For those offenders who engaged in any post-prison domestic violence incident, including severe post-prison domestic violence $(n=280)$, event time was calculated as the number of months that elapsed between their prison release date and the date associated with the post-prison domestic violence event. For offenders who were readmitted to state or federal prison for unknown reasons $(n=36)$, event time was calculated as the number of months that elapsed between their prison release date and the date they became reincarcerated. Event time for offenders who were deported to another country $(\mathrm{n}=2)$ was calculated as the number of months between their prison release date and the date of deportation. For offenders who moved to another state $(\mathrm{n}=$ 12), event time was calculated as the number of months that elapsed between their prison release date and the date associated with the first out-of-state address listed in their community supervision records. Five sampled offenders passed away during the study follow-up period, therefore event time for these cases was calculated as the number of months that elapsed between their prison release date and the date of their death. Finally, for sampled offenders who survived until the end of the study without exiting for any of the above reasons $(n=802)$, event time was calculated as the number of months that elapsed between their prison release date and the end of the study follow-up period (i.e., April 20, 2011).

After event status and event time were calculated for each sampled offender, I estimated the overall survival and hazard curves using the actuarial method for calculating life tables. Survival analysis using life tables is the desired approach when one has a large sample size and large enough time intervals that can be split into smaller 
units (Luke, 1993). One month time intervals were used in the analyses for Research Question One. Examining the survival and hazard curves allowed me to interpret the general pattern of survival times and the rate of event occurrence for my sample as a whole. I observed the slope of the survival curve to determine the overall length of survival time and estimated survival time at the $25^{\text {th }}$ percentile for my sample. I observed the shape of the hazard curve to estimate changes in the rate of event occurrence over time and determine event risk for any particular offender at a given point in time. Event risk represents the probability that the event of interest will occur at a given point in time, given that the event has not occurred up until that point (Luke, 1993). This allowed me to conjecture about whether sampled offenders were at more or less risk to engage in post-prison domestic violence at certain points in time after their release from prison.

\section{Research Question Two}

My second research question addressed the extent to which individual, situational, and social-structural predictors independently and interactively predicted domestic violence perpetrated by formerly incarcerated offenders after their release from prison. To address this research question I conducted a survival analysis using Cox's proportional hazards technique, also known as Cox regression (Cox, 1972). The proportional hazards technique models the effects of predictors on the event rate. If a predictor is related to the event, then changes in this predictor are associated with changes in the overall level of the hazard function, resulting in either a shift up or down in the hazard curve (Luke, 1993). Regression coefficients signify the relative effect of 
each predictor on the curve (Tabachnick \& Fidell, 2001). Similar to the analysis for Research Question One, two separate Cox regression survival analyses were conducted for Research Question Two - one to predict any post-prison domestic violence incident and a second to predict severe post-prison domestic violence.

For each model, predictors whose main effects were tested were the group of individual-level demographic variables as well as the individual-level predictors of exposure to family-of-origin violence, borderline personality characteristics, and antisocial personality characteristics; the situational-level predictor of post-prison employment; and the social-structural predictor of post-prison neighborhood disadvantage. Interactions that were tested were: exposure to family-of-origin violence*personality characteristics, exposure to family-of-origin violence*employment, exposure to family-of-origin violence*neighborhood disadvantage, personality characteristics*employment, personality characteristics*neighborhood disadvantage, and employment*neighborhood disadvantage (see Table 1).

Before running Cox regression survival analyses I centered each of the individual, situational, and social-structural predictors by subtracting the mean score of each construct measure from each offender's data-point on the respective measure. To illustrate, the sample mean for each of the three dichotomous family-of-origin violence dummy variables was subtracted from each offender's data-point on the respective dummy variable. The sample means for the BOR and ANT subscales were subtracted from each offender's BOR and ANT data-points. The sample means for wages earned 
and percentage of quarters worked were subtracted from each offender's corresponding data-point. Finally, the sample mean on the measure of neighborhood disadvantage was subtracted from each offender's corresponding data-point. After all predictors were centered I created interaction terms by multiplying the appropriate centered predictors together. Some of the measured constructs were represented by dummy variables (i.e., exposure to family-of-origin violence) and/or multiple variables (i.e., employment; see Table 5).

Once all predictors were centered and interaction terms created, I conducted a sequential Cox regression survival analysis predicting post-prison domestic violence from the specified individual, situational, and social-structural predictors and interactions. Each of the individual-level, situational-level, and social-structural level predictors were entered simultaneously as a block into the first step of the model to test the main effects of each on the prediction of post-prison domestic violence. All interaction terms were entered simultaneously into the second and final step of the model. Interaction terms were entered into the model in the last step to determine their importance to the prediction of survival over and above the main effects of the other predictors. Entering the interaction terms last also permitted a likelihood-ratio test of the effect of the interactions after controlling for the other predictors.

Evaluation of the model involved determining the relative importance of each main effect and interaction to the prediction of survival time to any post-prison domestic violence incident and severe post-prison domestic violence. Regression coefficients (i.e., Beta values), p values, and odds ratios associated with each main 
Table 5

Interaction terms created for Research Question Two.

\begin{tabular}{|c|c|c|c|c|c|c|}
\hline & & \multicolumn{2}{|c|}{ Personality } & \multicolumn{2}{|c|}{ Employment } & \multirow{2}{*}{$\begin{array}{c}\frac{\text { Neighborhood }}{\text { Disadvantage }} \\
N D\end{array}$} \\
\hline & & ANT & BOR & EMP: Quarters & EMP: Wages & \\
\hline \multirow{3}{*}{$\begin{array}{l}\text { Family of } \\
\text { origin } \\
\text { violence }\end{array}$} & Victim: & $\begin{array}{c}\text { ANT* } \\
\text { Victim.Phycis }\end{array}$ & $\begin{array}{c}\text { BOR* } \\
\end{array}$ & EMP:Quarters* & EMP:Wages* & $\begin{array}{c}\text { ND* } \\
\text { Victim.Pbyisol }\end{array}$ \\
\hline & $\begin{array}{l}\text { Victim: } \\
\text { Sexual }\end{array}$ & $\begin{array}{c}\text { ANT* } \\
\text { Victim:Sexual }\end{array}$ & $\begin{array}{c}\text { BOR* } \\
\text { Victim:Sexual }\end{array}$ & $\begin{array}{c}\text { EMP:Quarters* } \\
\text { Victim:Sexual }\end{array}$ & $\begin{array}{l}\text { EMP:Wages* } \\
\text { Victim:Sexual }\end{array}$ & $\begin{array}{c}\text { ND* } \\
\text { Victim:Sexual }\end{array}$ \\
\hline & Witnessed & $\begin{array}{c}\text { ANT* } \\
\text { Witnessed }\end{array}$ & $\begin{array}{c}\text { BOR* } \\
\text { Witnessed }\end{array}$ & $\begin{array}{c}\text { EMP:Quarters* } \\
\text { Witnessed }\end{array}$ & $\begin{array}{c}\text { EMP:Wages* } \\
\text { Witnessed }\end{array}$ & $\begin{array}{c}\text { ND* } \\
\text { Witnessed }\end{array}$ \\
\hline \multirow[t]{2}{*}{ Personality } & ANT & & & $\begin{array}{c}\text { EMP:Quarters* } \\
\text { ANT }\end{array}$ & $\begin{array}{c}\text { EMP: Wages* } \\
\text { ANT }\end{array}$ & ND*ANT \\
\hline & BOR & & & $\begin{array}{c}\text { EMP:Quarters* } \\
\text { BOR }\end{array}$ & $\begin{array}{c}\text { EMP: Wages* } \\
\text { BOR }\end{array}$ & $\mathrm{ND} * \mathrm{BOR}$ \\
\hline \multirow[t]{2}{*}{ Employment } & $\begin{array}{l}\text { EMP: } \\
\text { Quarters }\end{array}$ & & & & & $\begin{array}{c}\text { ND* }^{*} \\
\text { EMP:Quarters }\end{array}$ \\
\hline & $\begin{array}{l}\text { EMP: } \\
\text { Quarters }\end{array}$ & & & & & $\begin{array}{c}\text { ND* } \\
\text { EMP:Wages }\end{array}$ \\
\hline
\end{tabular}


effect and interaction term were examined to verify which predictors and interactions were significantly associated with survival time to a post-prison domestic violence event. In addition, the calculated log-likelihood of the model was inspected at each step and compared to the calculated log-likelihood of the model at the previous step. Specifically, the calculated log-likelihood of the model at the first step containing all individual-level, situational-level, and social-structural level predictors was examined to determine whether they, as a set, reliably predicted survival time to a post-prison domestic violence event. Strength of the association between the set of predictors at step 1 and survival time was assessed by calculating $R^{2}$ (Allison, 1995). Finally, the calculated log-likelihood of the model at step 2 containing all individual, situational, and social-structural predictors and interactions was compared to the calculated loglikelihood of the model at step 1 to assess whether inclusion of interactions contributes significantly to the prediction of survival time to a post-prison domestic violence event. Significance of the interactions entered at step 2 was determined by examining the Chisquare statistic associated with the change from the previous step and the calculation of $R^{2}$ 


\section{Chapter 7: Results}

The following chapter addresses preliminary and descriptive analyses including data cleaning and organization. In addition, each research question is addressed using the plan for analysis detailed in Chapter 6 as a guide. All analyses were performed using either SPSS version 19.0 or SAS analytic software programs for Windows PC.

\section{Preliminary Analyses}

All data from DOC institutional records, community supervision records, and PPB were delivered in separate electronic files and merged together by a DOC research analyst. Before data were merged and delivered to me, the research analyst checked a random selection of $10 \%$ of cases obtained from PPB against the DOC institutional and community supervision records to ensure that the information provided by PPB was correctly matched to the appropriate offender. DOC and PPB records were examined for matching on sampled offenders' first and last name, date of birth, and ethnicity. Upon confirming that all $10 \%$ of the randomly selected cases matched on all criteria, the research analyst merged the data files from each source together and stripped the merged file of all identifiers. The de-identified data file was then securely delivered to me for analysis.

Preliminary data analyses involved screening for missing data among variables representing demographic constructs only, as no data were missing among variables chosen to represent my ecological model. All demographic and ecological model constructs were screened for univariate and multivariate outliers, normality, linearity, homoscedasticity, and absence of multicollinearity. Survival analysis does not require 
that all of these assumptions be met; however, doing so often increases statistical power (Tabachnick \& Fidell, 2001). Screening for missing data through examination of frequency tables indicated that information regarding post-prison domestic violence was missing entirely for 41 offenders or $3 \%$ of the sample. Small proportions of missing data (i.e., 2-3\%) were also found within the marital status, number of children, and neighborhood disadvantage index variables. Separate independent samples t-tests comparing offenders with missing data to offenders with complete data on all key predictor variables and demographic variables suggested no systematic differences between groups. Therefore, because missing values appeared random and less than 5\% of values were missing from variables of interest (Tabachnick \& Fidell, 2001), cases that were missing post-prison domestic violence outcome variables and/or the categorical marital status variable were deleted (reducing the sample size to $n=1,147$ ). Missing values on the continuous number of children variable and neighborhood disadvantage index variable were replaced by the sample mean.

Traditionally, substituting the mean is considered a conservative approach to estimating missing values since the overall mean does not change by inserting the mean value for a case (Mertler \& Vannatta, 2005; Tabachnick \& Fidell, 2001). However, substituting the mean as a method of estimating missing values has been the target of some recent criticism (e.g., Howell, 2009). Specifically, Howell (2009) argues that substituting the mean for missing values decreases variability by increasing sample size without adding any new information to the data. In order to determine the extent to which the variability of constructs with missing values in the current study was reduced 
by substituting the mean, I compared the descriptive statistics of the number of children and neighborhood disadvantage variables with and without substituted missing values. For each construct, substituting the mean reduced the standard deviation by a negligible amount; therefore all remaining analyses containing these constructs were conducted with the sample mean in place of previously missing values.

Univariate outliers were identified through examination of standardized $Z$ scores computed for each variable of interest. Standardized scores were examined to ensure all cases fell within \pm 4.00 , the range recommended by Stevens (1992) for sample sizes larger than 100. Several cases had scores on two variables, neighborhood disadvantage index and participation in prison-based domestic violence intervention programming, that fell well above the positive 4.00 cutoff. To reduce the influence of outliers, the variable representing neighborhood disadvantage index was transformed so that scores for the outlying cases remained deviant, but not as deviant as they were originally (Tabachnick \& Fidell, 2001). Specifically, outlying cases were assigned a raw score on the neighborhood disadvantage index variable of five, or one unit larger than the next most extreme score in the distribution (i.e., four). Tabachnick and Fidell (2001) argue that this simple method of transformation is "an attractive alternative to reduce the impact of a univariate outlier" (p. 71).

Further investigation of the data indicated that only seven offenders or $0.6 \%$ of the entire sample participated in domestic violence intervention programming during their incarceration. Rummel (1970) recommends deletion of dichotomous variables with extreme splits (i.e., 90/10) because cases in the small category disproportionately 
influence future analyses relative to cases in the larger category. In the case of the current analysis, the seven offenders in the sample who participated in domestic violence intervention programming during their incarceration would have a disproportionate influence on the analysis of post-prison domestic violence relative to the other $99.4 \%$ of offenders who did not participate in domestic violence intervention programming. Therefore, in accordance with Rummel's (1970) suggestion the variable representing participation in domestic violence intervention in prison was not included in further analyses.

Multivariate outliers were identified by calculating Mahalanobis distances and examining those that exceeded the critical $\chi^{2}$ at $p<.001$. Ten cases were identified as multivariate outliers based on this criteria. Stepwise regression was used to identify the combination of variables on which each of the ten cases deviated from the remaining sample. Dummy variables were created to distinguish each outlying case from the rest of the sample, and each dummy variable was entered into its own stepwise regression analysis as the dependent variable. The remaining variables of interest were entered as independent variables. Findings indicated that six out of seven cases were outliers because of the combination of scores on two variables: average wages earned per year and percentage of quarters worked. Examination of raw scores on these variables indicated that each case scored very high on the wages variable and moderate to very low on the percentage of quarters worked variable. In other words, these seven cases appeared to be offenders who may have worked for short periods of time in relatively high-paying jobs. The final case was an outlier on the combination of average wages 
earned per quarter and ethnicity. Raw scores indicated that this case was an African American offender who scored very high on the wages variable. Because survival analysis is particularly sensitive to large correlations among predictors (Tabachnick \& Fidell, 2001), all ten outlying cases were deleted reducing the sample size to $\mathrm{n}=1,137$. Since these cases will not be included in subsequent analyses, there will be some uncertainty regarding the generalizability of findings to offenders who are employed for short periods of time in high-paying jobs and to African American offenders who earn relatively high wages.

Analysis of univariate normality through normal probability plots indicated adequate normal distribution for each study variable. Examination of plots comparing standardized residuals to the predicted values of the dependent variable also indicated sufficient normality, linearity, and homoscedasticity to proceed with analyses.

Finally, data were screened for two additional assumptions that are particularly important for Cox regression: multicollinearity and proportionality of hazards. Cox regression is sensitive to high correlations among predictors and it is often recommended that predictors with squared multiple correlation coefficients in excess of .90 be deleted (Tabachnick \& Fidell, 2001). I took a more conservative approach in accordance with Cohen's (1992) conventions, and inspected squared multiple correlation coefficients for values in excess of .50. Analyses indicated squared multiple correlation coefficients of .597 for the variable representing average wages earned per year and .596 for percentage of quarters worked. Not wanting to delete both of the variables I selected to represent the situational level of my ecological model, I chose to 
delete the variable associated with the higher squared multiple correlation coefficient (i.e., average wages earned per year). Average wages earned per year was therefore not included in any further analyses. Remaining predictors' squared multiple correlation coefficients were reanalyzed and found to be below .50; therefore deletion of other redundant predictors was not necessary.

The proportionality of hazards assumption states that the shape of the survival functions are the same between all levels of a given predictor over time. Specifically, survival to the event of interest may be different between groups at different levels of a predictor, but it is assumed that the failure rate is the same for all groups once it begins (Tabachnick \& Fidell, 2001). Violation of this assumption is signified by interactions between time and the levels of each predictor. Following the recommendation of Tabachnick and Fidell (2001), proportionality of hazards was assessed by testing the significance of the interactions between each predictor and the natural logarithm of the event time variable. A Bonferroni adjustment was made to determine significance of the time*predictor interactions $(p<.003)$. The Bonferroni adjustment corrects for inflated Type I error brought on by multiple comparisons through the use of a more stringent significance value. The corrected significance value is calculated by dividing the target significance value (i.e., $p<.05$ ) by the number of comparisons that will be made. In the case of the current analysis, 17 time*predictor interactions were made; therefore the adjusted significance value is $.05 / 17=.003$. Analyses indicated that none of the time*predictor interactions were statistically significant at $p<.003$; therefore the proportionality of hazards assumption was met. 
Descriptive statistics. Descriptive statistics for the individual, situational, and social-structural level variables that were selected to represent the levels of my ecological model of post-prison domestic violence appear in Table 6. Descriptive statistics for length of time within the study follow-up period (i.e., between participants' prison release date and study exit date) are also listed in Table 6. Descriptive statistics for the group of additional individual-level demographic characteristics that were considered are displayed in Table 7. Correlation coefficients between each noncategorical construct are displayed in Table 8.

A number of significant bivariate relationships were found among variables within each level of analysis and among variables existing at different levels. At the individual-level of my ecological model there were significant positive relationships among reports of physical abuse, sexual abuse, and witnessing abuse as a child; suggesting that offenders who experienced any one form of abuse were likely to have experienced other forms of abuse as well. In addition, physical abuse, sexual abuse, and witnessing abuse were all significantly positively correlated with antisocial and borderline personality characteristics.

There were additional significant bivariate relationships between variables at the individual level and variables within other levels of my ecological model. Specifically, offenders who were sexually abused were significantly more likely to have committed a violent crime. Offenders who were sexually abused and/or witnessed abuse during childhood were more likely to have participated in religious services programming in prison. Offenders who witnessed interparental abuse were also more likely to have 
Table 6.

Descriptive statistics for individual, situational, and social-structural level variables (n=1137).

\begin{tabular}{|c|c|c|c|c|}
\hline Variable & $\%$ & $M$ & $S D$ & Range \\
\hline \multicolumn{5}{|l|}{$\begin{array}{l}\text { Individual/Ontogenic Level: } \\
\text { Exposure to family-of-origin violence }\end{array}$} \\
\hline \multicolumn{5}{|l|}{ Physically abused as a child } \\
\hline Yes & $26 \%$ & & & \\
\hline No & $74 \%$ & & & \\
\hline \multicolumn{5}{|l|}{ Sexually abused as a child } \\
\hline Yes & $14 \%$ & & & \\
\hline No & $86 \%$ & & & \\
\hline \multicolumn{5}{|l|}{ Witnessed interparental violence } \\
\hline Yes & $41 \%$ & & & \\
\hline No & $59 \%$ & & & \\
\hline \multicolumn{5}{|l|}{ Personality } \\
\hline Antisocial personality characteristics & & 63 & 11 & $38-103$ \\
\hline Borderline personality characteristics & & 58 & 13 & $32-102$ \\
\hline \multicolumn{5}{|l|}{ Situational/Microsystem Level: } \\
\hline Percent of quarters worked & & $32 \%$ & $34 \%$ & $0-100 \%$ \\
\hline \multicolumn{5}{|l|}{$\begin{array}{l}\text { Social-situational/Exosystem Level: } \\
\text { Neighborhood disadvantage }\end{array}$} \\
\hline Neighborhood disadvantage index & & 1.9 & 1.6 & $-2.9-5$ \\
\hline Length of study follow-up period (in years) & & 3.7 & 2 & $.003-7.3$ \\
\hline
\end{tabular}


Table 7.

Descriptive statistics for additional individual-level demographic characteristics ( $n=1137)$.

\begin{tabular}{|c|c|c|c|c|}
\hline Variable & $\%$ & $M$ & $S D$ & Range \\
\hline \multicolumn{5}{|l|}{ Individual Level: Demographics } \\
\hline Age at release & & 37 & 9.5 & $18-69$ \\
\hline $18-24$ years & $10 \%$ & & & \\
\hline $25-30$ years & $20 \%$ & & & \\
\hline $31-45$ years & $50 \%$ & & & \\
\hline 46-69 years & $20 \%$ & & & \\
\hline \multicolumn{5}{|l|}{ Ethnicity } \\
\hline Caucasian & $72 \%$ & & & \\
\hline African American & $23 \%$ & & & \\
\hline Native American & $2 \%$ & & & \\
\hline Latino & $2 \%$ & & & \\
\hline Asian & $1 \%$ & & & \\
\hline \multicolumn{5}{|l|}{ Education level } \\
\hline Most education need & $7 \%$ & & & \\
\hline Moderate education need & $9 \%$ & & & \\
\hline Some education need & $6 \%$ & & & \\
\hline Minimal education need & $52 \%$ & & & \\
\hline No education need & $26 \%$ & & & \\
\hline \multicolumn{5}{|l|}{ Marital status } \\
\hline Never married & $62 \%$ & & & \\
\hline Divorced & $17 \%$ & & & \\
\hline Married & $14 \%$ & & & \\
\hline Separated & $6 \%$ & & & \\
\hline Widowed & $1 \%$ & & & \\
\hline Number of children & & 1.5 & 1.4 & $0-4$ \\
\hline No children & $35 \%$ & & & \\
\hline One child & $20 \%$ & & & \\
\hline Two children & $18 \%$ & & & \\
\hline Three children & $13 \%$ & & & \\
\hline Four or more children & $14 \%$ & & & \\
\hline \multicolumn{5}{|l|}{ Crime of conviction } \\
\hline Violent & $38 \%$ & & & \\
\hline Non-violent & $62 \%$ & & & \\
\hline Length of incarceration in years & & 2.1 & 1.6 & $.02-9.6$ \\
\hline Less than 1 year & $29 \%$ & & & \\
\hline $1-3$ years & $50 \%$ & & & \\
\hline $3-5$ years & $13 \%$ & & & \\
\hline $5-10$ years & $8 \%$ & & & \\
\hline \multicolumn{5}{|l|}{ Substance abuse treatment } \\
\hline Yes & $25 \%$ & & & \\
\hline No & $75 \%$ & & & \\
\hline \multicolumn{5}{|l|}{ Cognitive behavioral treatment } \\
\hline Yes & $57 \%$ & & & \\
\hline No & $43 \%$ & & & \\
\hline \multicolumn{5}{|l|}{ Religious services programming } \\
\hline Yes & $62 \%$ & & & \\
\hline No & $38 \%$ & & & \\
\hline
\end{tabular}


Table 8.

Correlation coefficients between each non-categorical construct ( $n=1137)$.

\begin{tabular}{|c|c|c|c|c|c|c|c|c|c|c|c|c|c|}
\hline \multirow{2}{*}{$\begin{array}{l}\text { Variable } \\
\text { Individual Level }\end{array}$} & 1 & 2 & 3 & 4 & 5 & 6 & 7 & 8 & 9 & 10 & 11 & 12 & 13 \\
\hline & & & & & & & & & & & & & \\
\hline 1. Physically abused (1=Yes) & - & & & & & & & & & & & & \\
\hline 2. Sexually abused (1=Yes) & $.50^{\mathrm{b}}$ & - & & & & & & & & & & & \\
\hline 3. Witnessed abuse (1=Yes) & $.41^{\mathrm{b}}$ & $.22^{\mathrm{b}}$ & - & & & & & & & & & & \\
\hline 4. Antisocial personality & $.17^{\mathrm{b}}$ & $.10^{\mathrm{b}}$ & $.13^{\mathrm{b}}$ & - & & & & & & & & & \\
\hline 5. Borderline personality & $.27^{\mathrm{b}}$ & $.19^{\mathrm{b}}$ & $.24^{\mathrm{b}}$ & $.63^{\mathrm{b}}$ & - & & & & & & & & \\
\hline Individual Level: Demographics & & & & & & & & & & & & & \\
\hline 6. Age at release & -.01 & .01 & .05 & $-.19^{b}$ & $-.10^{\mathrm{b}}$ & - & & & & & & & \\
\hline 7. Number of children & .00 & .02 & $.09^{\mathrm{b}}$ & $-.12^{\mathrm{b}}$ & -.04 & $.29^{\mathrm{b}}$ & - & & & & & & \\
\hline 8. Violent crime (1=Yes) & $.01^{\mathrm{a}}$ & $.12^{\mathrm{b}}$ & $.06^{\mathrm{a}}$ & $-.18^{\mathrm{b}}$ & -.05 & $-.11^{\mathrm{b}}$ & .03 & - & & & & & \\
\hline 9. Length of incarceration & $.07^{\mathrm{a}}$ & .03 & $.07^{\mathrm{a}}$ & $-.10^{\mathrm{b}}$ & -.02 & .02 & .04 & $.45^{\mathrm{b}}$ & - & & & & \\
\hline 10. Substance treatment (1=Yes) & .00 & -.02 & $.07^{\mathrm{a}}$ & .03 & .03 & -.04 & .03 & -.01 & $.15^{\mathrm{b}}$ & - & & & \\
\hline 11. Cognitive treatment (1=Yes) & .00 & .01 & .01 & .00 & .03 & $-.07^{\mathrm{a}}$ & .02 & $.08^{\mathrm{a}}$ & $.27^{\mathrm{b}}$ & $.15^{\mathrm{b}}$ & - & & \\
\hline 12. Religious programs (1=Yes) & .04 & $.06^{\mathrm{a}}$ & $.06^{\mathrm{a}}$ & -.05 & .06 & -.03 & .05 & $.15^{\mathrm{b}}$ & $.29^{\mathrm{b}}$ & $.22^{\mathrm{b}}$ & $.13^{\mathrm{b}}$ & - & \\
\hline $\begin{array}{l}\text { Situational Level } \\
\text { 13. Percent of quarters worked }\end{array}$ & -.01 & .00 & -.03 & -.05 & -.04 & $-.12^{b}$ & -.03 & .03 & .02 & $.07^{\mathrm{a}}$ & -.05 & $.06^{\mathrm{a}}$ & - \\
\hline $\begin{array}{l}\text { Social-structural Level } \\
\text { 14. Neighborhood disadvantage }\end{array}$ & -.04 & .00 & .02 & .02 & .02 & $-.06^{\mathrm{a}}$ & .05 & .03 & .04 & -.05 & -.01 & -.01 & $-.13^{\mathrm{b}}$ \\
\hline
\end{tabular}

${ }^{\mathrm{a}} p<.05 ;{ }^{\mathrm{b}} p<.01$ 
committed a violent crime and to have served longer prison sentences. Witnessing interparental abuse was also significantly related to having more children and to participating in substance abuse treatment. Offenders exhibiting antisocial personality characteristics were more likely to exhibit borderline personality characteristics as well; and antisocial and borderline personality characteristics were significantly related to younger age. Offenders exhibiting antisocial personality characteristics also served significantly shorter prison sentences, had fewer children, and were more likely to have committed a nonviolent offense.

Among the individual-level demographic variables, correlation coefficients indicated that older offenders had more children and were less likely to have committed a violent crime. Older offenders were also less likely to have participated in cognitivebehavioral treatment in prison. Offenders who served longer periods of incarceration were more likely to have a violent crime conviction and to have participated in substance abuse treatment, cognitive-behavioral treatment, and religious services programming. Significant positive relationships were found among all three variables representing participation in prison-based treatment programs (i.e., substance abuse treatment, cognitive-behavioral treatment, and religious services programming).

A few significant bivariate relationships were also found between individuallevel demographic variables and variables within the situational and social-structural levels of analysis. For example, older offenders worked less and lived in less socially and economically disadvantaged neighborhoods. Offenders who participated in substance abuse treatment and religious services programming worked more, and 
offenders who worked more lived in more economically and socially advantaged neighborhoods.

Relationships between the categorical variables of ethnicity, marital status, and education need and all continuous variables were examined by conducting one-way analyses of variance (ANOVA). Table 9 shows that significant differences were detected in the ANOVA for ethnicity. Post-hoc analyses indicated significant differences between ethnic groups regarding antisocial personality characteristics $(F[4,1132]=6.24, p<.001)$. Caucasian offenders $(M=63.64)$ were significantly more likely than African American $(M=59.97)$ and Asian offenders $(M=56.81)$ to exhibit antisocial personality characteristics. Caucasian offenders were significantly older at prison release $(M=38.07)$ compared to African American offenders $(M=35.90$; $F[4,1132]=3.36, p<.05)$. African American offenders served significantly longer prison sentences $(M=28.62$ months $)$ than Caucasian offenders $(M=23.73$ months; $F[4,1132]=3.52, p<.01)$. Caucasian offenders had a significantly higher percentage of quarters worked during the study follow-up period $(M=.35)$ compared to Native American $(M=.20)$ and African American offenders $(M=.22 ; F[4,1132]=7.99, p<$ .001). Caucasian offenders also lived in significantly more socially and economically advantaged neighborhoods $(M=1.72)$ relative to all other groups except Asian offenders $(M=1.53 ; F[4,1132]=15.95, p<.001)$.

Table 10 shows that significant differences were also detected in the ANOVA for marital status. Post-hoc analyses indicated that married offenders were less likely to exhibit antisocial personality characteristics $(M=58.91)$ than all other groups except 
Table 9.

One-way analysis of variance showing differences in continuous variables by the categorical variable of ethnicity ( $n=1137)$.

\begin{tabular}{|c|c|c|c|c|c|c|c|c|c|c|c|}
\hline \multirow[b]{2}{*}{ Variable } & \multicolumn{2}{|c|}{ Asian } & \multicolumn{2}{|c|}{$\begin{array}{c}\text { African } \\
\text { American }\end{array}$} & \multicolumn{2}{|c|}{ Latino } & \multicolumn{2}{|c|}{$\begin{array}{c}\text { Native } \\
\text { American }\end{array}$} & \multicolumn{2}{|c|}{ Caucasian } & \multirow[b]{2}{*}{$p$} \\
\hline & $M$ & $S D$ & $M$ & $S D$ & $M$ & $S D$ & $M$ & $S D$ & $M$ & $S D$ & \\
\hline $\begin{array}{l}\text { Individual Level } \\
\text { Antisocial personality }\end{array}$ & 56.81 & 8.65 & 59.97 & 9.41 & 60.61 & 11.26 & 62.52 & 8.48 & 63.64 & 11.79 & $.00^{\mathrm{c}}$ \\
\hline Borderline personality & 51.91 & 6.84 & 56.31 & 11.83 & 57.19 & 13.35 & 57.88 & 12.90 & 57.94 & 13.27 & .09 \\
\hline $\begin{array}{l}\text { Individual Level: Demographics } \\
\text { Age at release }\end{array}$ & 35.04 & 10.10 & 35.90 & 10.02 & 35.19 & 11.01 & 35.44 & 8.18 & 38.07 & 9.55 & $.10^{\mathrm{a}}$ \\
\hline Number of children & 1.59 & 1.49 & 1.86 & 1.52 & 1.54 & 1.32 & 1.24 & 1.42 & 1.40 & 1.37 & $.00^{\mathrm{c}}$ \\
\hline Length of incarceration (in months) & 29.87 & 23.56 & 28.62 & 23.02 & 24.03 & 14.76 & 28.72 & 24.24 & 23.73 & 18.15 & $.01^{\mathrm{b}}$ \\
\hline $\begin{array}{l}\text { Situational Level } \\
\text { Percent of quarters worked }\end{array}$ & .29 & .39 & .22 & .29 & .34 & .32 & .20 & .31 & .35 & .34 & $.00^{c}$ \\
\hline $\begin{array}{l}\text { Social-structural Level } \\
\text { Neighborhood disadvantage }\end{array}$ & 1.53 & 1.38 & 2.53 & 1.54 & 2.67 & 1.70 & 2.39 & 1.39 & 1.72 & 1.53 & $.00^{\mathrm{c}}$ \\
\hline
\end{tabular}

${ }^{\mathrm{a}} p<.05 ;{ }^{\mathrm{b}} p<.01 ;{ }^{\mathrm{c}} p<.001$ 
Table 10.

One-way analysis of variance showing differences in continuous variables by the categorical variable of marital status ( $n=1137)$.

\begin{tabular}{|c|c|c|c|c|c|c|c|c|c|c|c|}
\hline \multirow[b]{2}{*}{ Variable } & \multicolumn{2}{|c|}{$\underline{\underline{\text { Never }}}$} & \multicolumn{2}{|c|}{ Separated } & \multicolumn{2}{|c|}{ Divorced } & \multicolumn{2}{|c|}{ Widowed } & \multicolumn{3}{|c|}{ Married } \\
\hline & $M$ & $S D$ & $M$ & $S D$ & $M$ & $S D$ & $M$ & $S D$ & $M$ & $S D$ & $p$ \\
\hline $\begin{array}{l}\text { Individual Level } \\
\text { Antisocial personality }\end{array}$ & 63.75 & 11.11 & 62.09 & 11.00 & 61.71 & 11.63 & 66.12 & 16.48 & 58.91 & 10.74 & $.00^{\mathrm{c}}$ \\
\hline Borderline personality & 58.07 & 13.22 & 58.75 & 13.60 & 57.92 & 13.57 & 59.50 & 11.69 & 56.91 & 13.12 & .85 \\
\hline $\begin{array}{l}\text { Individual Level: Demographics } \\
\text { Age at release }\end{array}$ & 34.16 & 8.45 & 42.30 & 8.91 & 43.74 & 8.22 & 43.98 & 7.53 & 42.05 & 9.32 & $.00^{\mathrm{c}}$ \\
\hline Number of children & 1.08 & 1.29 & 2.51 & 1.33 & 2.02 & 1.35 & 2.31 & 1.43 & 2.30 & 1.30 & $.00^{\mathrm{c}}$ \\
\hline Length of incarceration (in months) & 24.36 & 19.17 & 28.28 & 21.61 & 24.13 & 19.86 & 15.29 & 8.00 & 28.05 & 20.28 & .06 \\
\hline $\begin{array}{l}\text { Situational Level } \\
\quad \text { Percent of quarters worked }\end{array}$ & .31 & .33 & .31 & .33 & .33 & .31 & .07 & .10 & .31 & .33 & .30 \\
\hline $\begin{array}{l}\text { Social-structural Level } \\
\text { Neighborhood disadvantage }\end{array}$ & 1.94 & 1.56 & 2.00 & 1.58 & 1.88 & 1.65 & 2.70 & 1.27 & 1.92 & 1.54 & .69 \\
\hline
\end{tabular}

${ }^{\mathrm{a}} p<.05 ;{ }^{\mathrm{b}} p<.01 ;{ }^{\mathrm{c}} p<.001$ 
widowed offenders $(M=66.12 ; F[4,1132]=6.65, p<.001)$. Offenders who were never married were significantly younger $(M=34.16 ; F[4,1132]=69.89, p<.001)$ and less likely to have children $(M=1.08 ; F[4,1132]=52.44, p<.001)$ compared to all other marital status groups.

Significant differences found in the ANOVA for education need are displayed in Table 11. Post-hoc analyses indicated that offenders with no education need served significantly longer prison sentences $(M=27.48$ months $)$ than all groups except offenders with minimal education need $(M=25.76$ months; $F[4,1132]=5.24, p<$ $.001)$. Offenders with the most education need worked significantly less $(M=.12)$ than all other groups, and offenders with no education need worked significantly more than all other groups $(M=.39 ; F[4,1132]=12.41, p<.001)$. Finally, offenders with the most education need $(M=2.16)$ and offenders with minimal education need $(M=2.03)$ lived in significantly more disadvantaged neighborhoods relative to offenders with some education need $(M=1.59)$ and offenders with no education need $(M=1.74$; $F[4,1132]=2.85, p<.05)$

Chi-square tests of independence were performed to examine the relationships between ethnicity, marital status, education need, and all remaining categorical variables. Table 12 shows that significant differences were detected in the chi-square test for ethnicity. A higher proportion of Caucasian and Native American offenders experienced physical abuse during childhood relative to African American offenders $\chi^{2}(4, N=1137)=31.12, p<.001$. Similarly, a higher proportion of Caucasian offenders experienced sexual abuse during childhood compared to African American offenders 
Table 11.

One-way analysis of variance showing differences in continuous variables by the categorical variable of education need ( $n=1137)$.

\begin{tabular}{|c|c|c|c|c|c|c|c|c|c|c|c|}
\hline \multirow[b]{2}{*}{ Variable } & \multicolumn{2}{|c|}{$\begin{array}{c}\text { Most } \\
\text { education } \\
\text { need }\end{array}$} & \multicolumn{2}{|c|}{$\begin{array}{c}\text { Moderate } \\
\text { education } \\
\text { need }\end{array}$} & \multicolumn{2}{|c|}{$\begin{array}{l}\text { Some } \\
\text { education } \\
\text { need }\end{array}$} & \multicolumn{2}{|c|}{$\begin{array}{c}\text { Minimal } \\
\text { education } \\
\text { need }\end{array}$} & \multicolumn{3}{|c|}{$\begin{array}{c}\text { No } \\
\text { education } \\
\text { need }\end{array}$} \\
\hline & $M$ & $S D$ & $M$ & $S D$ & $M$ & $S D$ & $M$ & $S D$ & $M$ & $S D$ & $p$ \\
\hline $\begin{array}{l}\text { Individual Level } \\
\text { Antisocial personality }\end{array}$ & 61.29 & 9.30 & 62.34 & 10.20 & 62.40 & 10.70 & 62.79 & 11.01 & 62.92 & 12.75 & .81 \\
\hline Borderline personality & 57.53 & 11.11 & 58.76 & 13.62 & 58.77 & 13.81 & 57.73 & 12.88 & 58.02 & 14.39 & .93 \\
\hline $\begin{array}{l}\text { Individual Level: Demographics } \\
\text { Age at release }\end{array}$ & 38.96 & 11.22 & 35.67 & 9.64 & 36.67 & 9.85 & 37.86 & 9.23 & 36.92 & 9.50 & .09 \\
\hline Number of children & 1.38 & 1.51 & 1.40 & 1.32 & 1.44 & 1.40 & 1.60 & 1.44 & 1.39 & 1.38 & .21 \\
\hline Length of incarceration (in months) & 19.90 & 17.92 & 19.51 & 13.99 & 21.94 & 19.15 & 25.76 & 19.89 & 27.48 & 20.58 & $.00^{\mathrm{c}}$ \\
\hline $\begin{array}{l}\text { Situational Level } \\
\text { Percent of quarters worked }\end{array}$ & .12 & .22 & .25 & .30 & .29 & .31 & .32 & .33 & .39 & .35 & $.00^{\mathrm{c}}$ \\
\hline $\begin{array}{l}\text { Social-structural Level } \\
\text { Neighborhood disadvantage }\end{array}$ & 2.16 & 1.47 & 1.96 & 1.44 & 1.59 & 1.50 & 2.03 & 1.61 & 1.74 & 1.54 & $.02^{\mathrm{a}}$ \\
\hline
\end{tabular}

${ }^{\mathrm{a}} p<.05 ;{ }^{\mathrm{b}} p<.01 ;{ }^{\mathrm{c}} p<.001$ 
Table 12.

Chi-square tests showing differences in categorical variables by ethnicity ( $n=1137)$.

\begin{tabular}{|c|c|c|c|c|c|c|c|}
\hline Variable & & $\frac{\text { Asian }}{\%}$ & $\begin{array}{c}\text { Affican } \\
\text { American } \\
\%\end{array}$ & $\frac{\text { Latino }}{\%}$ & $\begin{array}{c}\begin{array}{c}\text { Native } \\
\text { American }\end{array} \\
\frac{\%}{\%}\end{array}$ & $\frac{\text { Caucasian }}{\%}$ & $\chi^{2}$ \\
\hline \multicolumn{8}{|l|}{ Individual Level } \\
\hline \multirow[t]{2}{*}{ Physically abused } & Yes & 0 & 15 & 19 & 44 & 29 & $31.12^{\mathrm{c}}$ \\
\hline & No & 100 & 85 & 81 & 56 & 71 & \\
\hline \multirow[t]{2}{*}{ Sexually abused } & Yes & 0 & 6 & 10 & 20 & 16 & $19.79^{\mathrm{b}}$ \\
\hline & No & 100 & 94 & 90 & 80 & 84 & \\
\hline \multirow[t]{2}{*}{ Witnessed abuse } & Yes & 9 & 38 & 38 & 52 & 42 & 7.02 \\
\hline & No & 91 & 62 & 62 & 48 & 58 & \\
\hline \multicolumn{8}{|c|}{ Individual Level: Demographics } \\
\hline \multirow[t]{5}{*}{ Marital status } & Never married & 64 & 69 & 52 & 72 & 60 & $26.82^{\mathrm{a}}$ \\
\hline & Separated & 9 & 8 & 10 & 0 & 6 & \\
\hline & Divorced & 9 & 10 & 5 & 16 & 19 & \\
\hline & Widowed & 0 & 0 & 5 & 0 & 1 & \\
\hline & Married & 18 & 12 & 29 & 12 & 14 & \\
\hline \multirow[t]{5}{*}{ Education need } & Most & 0 & 14 & 24 & 20 & 5 & $87.41^{\mathrm{c}}$ \\
\hline & Moderate & 0 & 15 & 14 & 4 & 7 & \\
\hline & Some & 9 & 5 & 10 & 4 & 6 & \\
\hline & Minimal & 46 & 55 & 38 & 40 & 52 & \\
\hline & None & 46 & 11 & 14 & 32 & 31 & \\
\hline \multirow[t]{2}{*}{ Violent crime } & Yes & 36 & 49 & 48 & 48 & 34 & $19.87^{\mathrm{c}}$ \\
\hline & No & 64 & 51 & 52 & 52 & 66 & \\
\hline \multirow{2}{*}{$\begin{array}{l}\text { Substance } \\
\text { treatment }\end{array}$} & Yes & 18 & 20 & 24 & 16 & 27 & 6.31 \\
\hline & No & 82 & 80 & 76 & 84 & 73 & \\
\hline \multirow{2}{*}{$\begin{array}{l}\text { Cognitive } \\
\text { treatment }\end{array}$} & Yes & 54 & 58 & 62 & 60 & 56 & .99 \\
\hline & No & 46 & 42 & 38 & 40 & 44 & \\
\hline \multirow{2}{*}{$\begin{array}{l}\text { Religious } \\
\text { programs }\end{array}$} & Yes & 82 & 62 & 62 & 92 & 61 & $11.75^{\mathrm{a}}$ \\
\hline & No & 18 & 38 & 38 & 8 & 39 & \\
\hline
\end{tabular}


$\chi^{2}(4, N=1137)=19.79, p<.01$. No Asian offenders experienced physical or sexual abuse during childhood. In terms of marital status, Caucasian offenders were overrepresented in the divorced category relative to African American offenders $\chi^{2}(4$, $N=1137)=26.82, p<.05$. With regard to education need, a smaller proportion of Caucasian offenders fell within the Most education need category relative to all other ethnic groups except Asian offenders $\chi^{2}(4, N=1137)=87.41, p<.001$. In addition, African American and Latino offenders were underrepresented in the No education need categories relative to Caucasian, Asian, and Native American offenders. African American offenders were also overrepresented in the violent crime category relative to Caucasian offenders $\chi^{2}(4, N=1137)=19.87, p<.01$. Finally, a higher proportion of Native American offenders participated in religious services programming compared to African American and Caucasian offenders $\chi^{2}(4, N=1137)=11.75, p<.05$.

In addition to the differences in martial status and education need by ethnicity described in the previous paragraph, Tables 13 and 14 show that there were also significant differences in violent crime by marital status and differences in childhood sexual abuse by education need. Table 13 shows that a higher proportion of married offenders were incarcerated for committing violent crime relative to divorced offenders $\chi^{2}(4, N=1137)=10.08, p<.05$. Table 14 shows that a larger proportion of offenders with No education need experienced sexual abuse during childhood compared to offenders with Minimal education need $\chi^{2}(4, N=1137)=12.15, p<.05$. No other significant differences were found in the chi-square tests for marital status and education need. 
Table 13

Chi-square tests showing differences in categorical variables by marital status $(n=1137)$.

\begin{tabular}{|c|c|c|c|c|c|c|c|}
\hline Variable & & $\begin{array}{c}\text { Never } \\
\text { maried } \\
\%\end{array}$ & $\frac{\text { Separated }}{\%}$ & $\frac{\text { Divorced }}{\%}$ & $\frac{\text { Widowed }}{\%}$ & $\frac{\text { Married }}{\%}$ & $\chi^{2}$ \\
\hline \multicolumn{8}{|l|}{ Individual Level } \\
\hline \multirow[t]{2}{*}{ Physically abused } & Yes & 26 & 23 & 24 & 38 & 29 & 1.84 \\
\hline & No & 74 & 77 & 76 & 62 & 71 & \\
\hline \multirow[t]{2}{*}{ Sexually abused } & Yes & 13 & 19 & 14 & 12 & 16 & 3.05 \\
\hline & No & 87 & 81 & 86 & 88 & 84 & \\
\hline \multirow[t]{2}{*}{ Witnessed abuse } & Yes & 40 & 38 & 41 & 75 & 46 & 6.67 \\
\hline & No & 60 & 62 & 59 & 25 & 54 & \\
\hline \multicolumn{8}{|c|}{ Individual Level: Demographics } \\
\hline \multirow[t]{5}{*}{ Ethnicity } & Asian & 1 & 1 & 1 & 0 & 1 & $26.82^{\mathrm{a}}$ \\
\hline & African American & 25 & 28 & 14 & 13 & 21 & \\
\hline & Latino & 2 & 3 & 1 & 13 & 4 & \\
\hline & Native American & 3 & 0 & 2 & 0 & 2 & \\
\hline & Caucasian & 70 & 68 & 83 & 75 & 72 & \\
\hline \multirow[t]{5}{*}{ Education need } & Most & 8 & 7 & 5 & 13 & 7 & 13.12 \\
\hline & Moderate & 9 & 11 & 9 & 0 & 6 & \\
\hline & Some & 5 & 5 & 5 & 25 & 5 & \\
\hline & Minimal & 53 & 53 & 52 & 38 & 51 & \\
\hline & None & 25 & 24 & 29 & 25 & 31 & \\
\hline \multirow[t]{2}{*}{ Violent crime } & Yes & 39 & 38 & 31 & 25 & 47 & $10.08^{\mathrm{a}}$ \\
\hline & No & 61 & 62 & 69 & 75 & 53 & \\
\hline \multirow{2}{*}{$\begin{array}{l}\text { Substance } \\
\text { treatment }\end{array}$} & Yes & 25 & 27 & 22 & 25 & 26 & .61 \\
\hline & No & 75 & 73 & 78 & 75 & 74 & \\
\hline \multirow{2}{*}{$\begin{array}{l}\text { Cognitive } \\
\text { treatment }\end{array}$} & Yes & 55 & 61 & 58 & 37 & 59 & 2.52 \\
\hline & No & 45 & 39 & 42 & 63 & 41 & \\
\hline \multirow{2}{*}{$\begin{array}{l}\text { Religious } \\
\text { programs }\end{array}$} & Yes & 60 & 65 & 67 & 50 & 63 & 3.70 \\
\hline & No & 40 & 35 & 33 & 50 & 37 & \\
\hline
\end{tabular}


Table 14.

Chi-square tests showing differences in categorical variables by education need ( $n=1137)$.

\begin{tabular}{|c|c|c|c|c|c|c|c|}
\hline Variable & & $\begin{array}{c}\text { Most } \\
\text { education } \\
\frac{\text { need }}{\%}\end{array}$ & $\begin{array}{c}\text { Moderate } \\
\text { education } \\
\frac{\text { need }}{\%}\end{array}$ & $\begin{array}{c}\text { Some } \\
\text { education } \\
\frac{\text { need }}{\%}\end{array}$ & $\begin{array}{c}\text { Minimal } \\
\text { education } \\
\frac{\text { need }}{\%}\end{array}$ & $\begin{array}{l}\text { No education } \\
\frac{\text { need }}{\%}\end{array}$ & $\chi^{2}$ \\
\hline \multicolumn{8}{|l|}{ Individual Level } \\
\hline \multirow[t]{2}{*}{ Physically abused } & Yes & 21 & 25 & 18 & 27 & 28 & 3.44 \\
\hline & No & 79 & 75 & 82 & 73 & 72 & \\
\hline \multirow[t]{2}{*}{ Sexually abused } & Yes & 8 & 12 & 12 & 12 & 9 & $12.15^{\mathrm{a}}$ \\
\hline & No & 92 & 88 & 88 & 88 & 81 & \\
\hline \multirow[t]{2}{*}{ Witnessed abuse } & Yes & 36 & 50 & 31 & 42 & 38 & 8.68 \\
\hline & No & 64 & 50 & 69 & 58 & 62 & \\
\hline \multicolumn{8}{|c|}{ Individual Level: Demographics } \\
\hline \multirow[t]{5}{*}{ Ethnicity } & Asian & 0 & 0 & 2 & 1 & 2 & $87.41^{\mathrm{c}}$ \\
\hline & African American & 42 & 40 & 20 & 24 & 10 & \\
\hline & Latino & 6 & 3 & 3 & 1 & 1 & \\
\hline & Native American & 6 & 1 & 2 & 2 & 3 & \\
\hline & Caucasian & 46 & 56 & 74 & 72 & 85 & \\
\hline \multirow[t]{5}{*}{ Marital status } & Never married & 68 & 66 & 62 & 63 & 59 & 13.12 \\
\hline & Separated & 6 & 8 & 7 & 7 & 6 & \\
\hline & Divorced & 12 & 16 & 16 & 16 & 18 & \\
\hline & Widowed & 1 & 0 & 3 & 1 & 1 & \\
\hline & Married & 13 & 10 & 12 & 13 & 16 & \\
\hline \multirow[t]{2}{*}{ Violent crime } & Yes & 29 & 32 & 36 & 39 & 43 & 7.64 \\
\hline & No & 71 & 68 & 64 & 61 & 57 & \\
\hline \multirow{2}{*}{$\begin{array}{l}\text { Substance } \\
\text { treatment }\end{array}$} & Yes & 20 & 16 & 21 & 27 & 26 & 6.96 \\
\hline & No & 80 & 84 & 79 & 73 & 74 & \\
\hline \multirow{2}{*}{$\begin{array}{l}\text { Cognitive } \\
\text { treatment }\end{array}$} & Yes & 56 & 54 & 49 & 57 & 58 & 2.06 \\
\hline & No & 44 & 46 & 51 & 43 & 42 & \\
\hline \multirow{2}{*}{$\begin{array}{l}\text { Religious } \\
\text { programs }\end{array}$} & Yes & 61 & 57 & 49 & 63 & 64 & 6.55 \\
\hline & No & 39 & 43 & 51 & 37 & 36 & \\
\hline
\end{tabular}




\section{Research Question One}

My first research question concerned the prevalence of post-prison domestic violence perpetrated by formerly incarcerated offenders during the transition from prison to the community. In order to explore both the proportion of sampled offenders who engaged in post-prison domestic violence as well as the timing of these events, I performed a survival analysis using life tables. Two separate survival analyses were conducted to predict any post-prison domestic violence incident and severe post-prison domestic violence.

Any post-prison domestic violence incident. To review, any post-prison domestic violence incident was defined as any occurrence wherein the offender was either a suspect or taken into custody for their role in a disturbance that involved a domestic relationship (e.g., domestic problems, family disturbance, and offense versus the family). Out of the sample of 1,137 offenders, 280 (25\%) engaged in a post-prison domestic violence incident between the time of their release from prison and the end of the study follow-up period. The average time that elapsed between an offender's prison release date and either censorship or any post-prison domestic violence incident (i.e., mean survival time) was 47 months ( $S D=23$ months). Survival time to any post-prison domestic violence incident ranged from five days to nearly seven years.

Figure 5 presents a graph of the estimated survival curve for any post-prison domestic violence incident. The survival curve represents the proportion of offenders who "survived" to a given point in time without engaging in any post-prison domestic violence incident. As is evident, the shallow slope of the survival curve suggests that 
sampled offenders averaged somewhat long survival times relative to the duration of the study follow-up period. The steady decline of the curve indicates that there were no sudden shifts in the probability of survival at any given point in time (Luke, 1993). In other words, the flatness of the survival curve suggests that the rate of engaging in any post-prison domestic violence incident remained steady throughout sampled offenders' transition from prison to the community.

In survival analysis, median survival time is a useful summary statistic that can be interpreted as the point where any given member of the sample has a $50 \%$ chance of engaging in the event of interest (Hamilton, 2009). Estimating the median time to any post-prison domestic violence incident was not possible within the current sample given that the cumulative survival function did not reach 0.5 or the $50^{\text {th }}$ percentile of survival time. The survival function estimated the $25^{\text {th }}$ percentile between 51 and 52 months, indicating that sampled offenders had a $25 \%$ chance of engaging in any post-prison domestic violence incident within 51.5 months (4.3 years) of their release from prison. Figure 6 displays the graph of the estimated hazard function for any domestic violence incident. Each point on the hazard function symbolizes the hazard rate for a particular one month interval. The hazard rate is interpreted as event risk, or the probability of engaging in any post-prison domestic violence incident in a given time interval provided that the offense did not occur in a previous interval. The greater the hazard rate, the more likely it is that any post-prison domestic violence incident will occur during the specified time interval (i.e., the greater the event risk). 


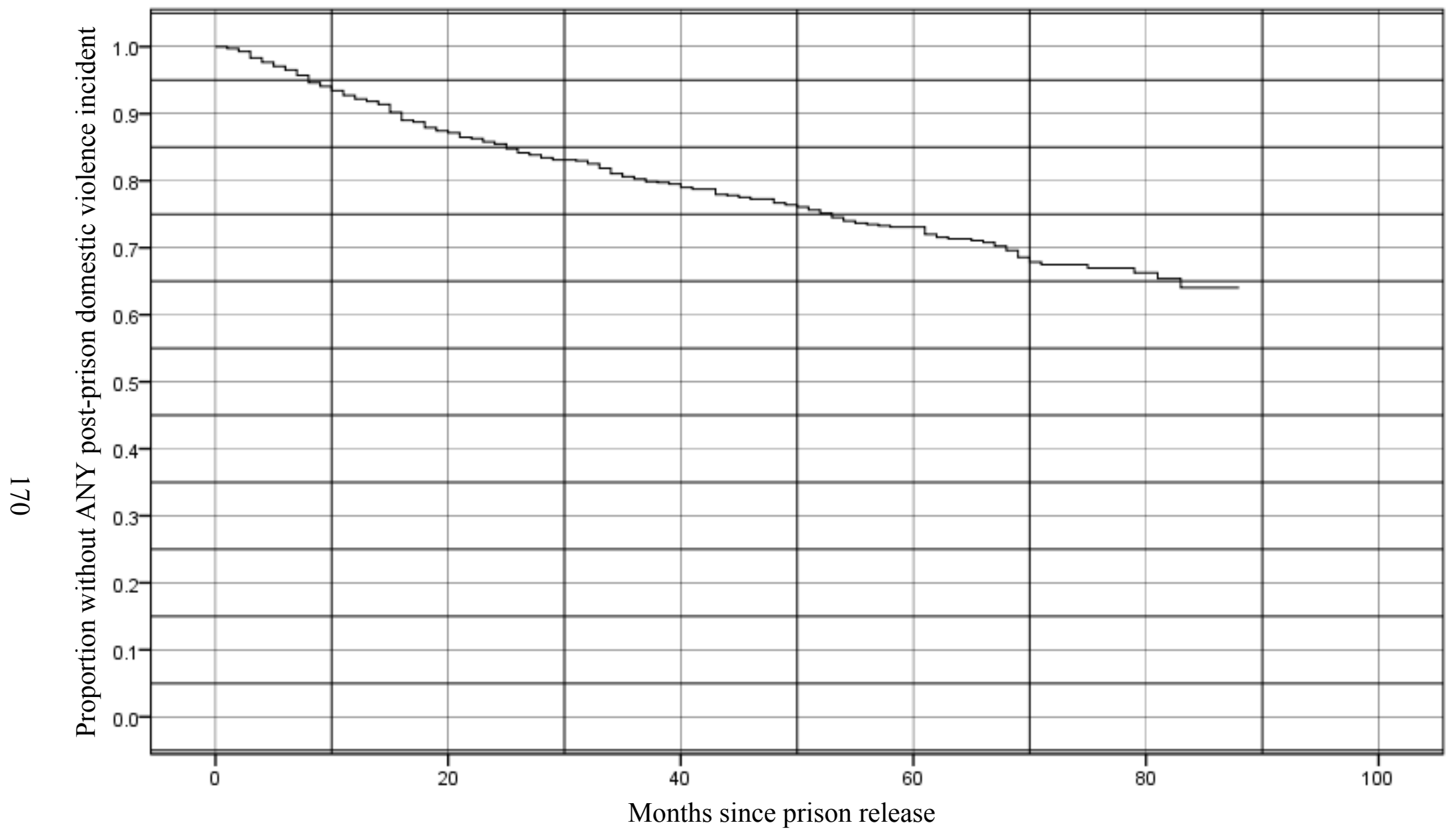

Figure 5. Estimated survival function for any post-prison domestic violence incident. 
As is evident in Figure 6, the hazard function for any post-prison domestic violence incident is virtually flat for the duration of the study follow-up period. It shows that the risk of engaging in any post-prison domestic violence incident is low and constant over the first 12 months after prison release_-ranging from .003 to .011 . There is a very slight increase in event risk at months 14 and 15 , where the hazard rate reaches .013. Event risk then drops and remains consistently low until 60 months, after which the pattern increases and decreases several times until month 82. Afterward, the hazard rate drops to zero through the end of the last monthly interval. Despite these slight variations in the hazard rate of any post-prison domestic violence incident over time, event risk remains relatively stable and never rises above .021 throughout the entire study follow-up period. The flatness of the hazard function suggests that there was no particular point in time during the follow-up period where it was significantly more likely for a sampled offender to be considered a suspect or taken into custody for any post-prison domestic violence incident.

Severe post-prison domestic violence. To review, severe post-prison domestic violence was defined as an event wherein the offender was either a suspect or taken into custody for engaging in criminal action (e.g., assault, violation of a court order, threats, and robbery) against an intimate partner. One hundred sixty one offenders or $14 \%$ of the sample engaged in severe post-prison domestic violence between the time of their release from prison and the end of the study follow-up period. Mean survival time to either censorship or severe post-prison domestic violence was 46 months $(S D=23$ 


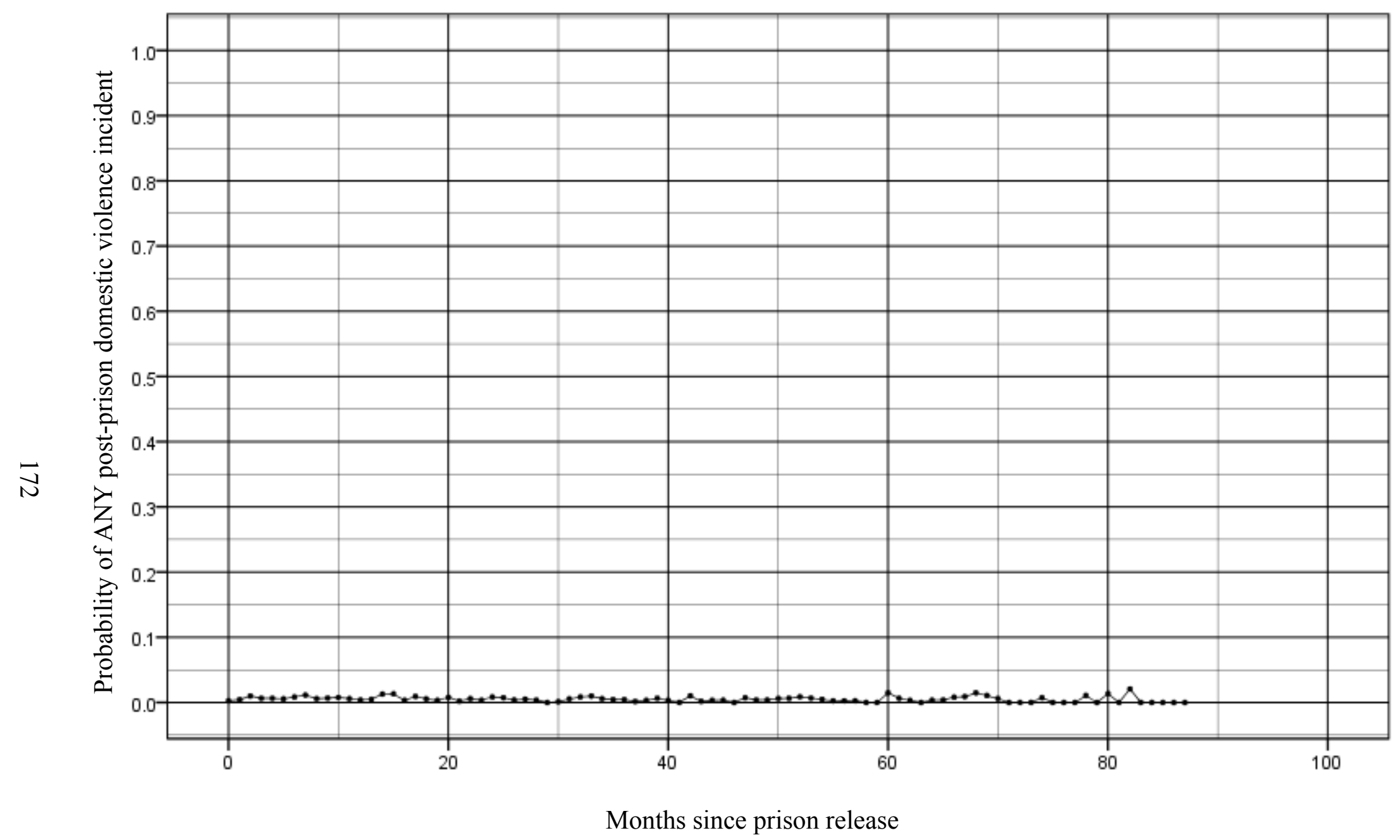

Figure 6. Estimated hazard function for any post-prison domestic violence incident. 
months). Survival time to severe post-prison domestic violence ranged from five days to 6.8 years.

The estimated survival curve for severe post-prison domestic violence is displayed in Figure 7. Nearly identical to the survival curve for any post-prison domestic violence incident, the curve for severe post-prison domestic violence is shallow and shows a steady decline in the proportion of offenders who survived to a given point in time without engaging in severe post-prison domestic violence. These attributes of the survival function indicate that offenders averaged somewhat long survival times to severe post-prison domestic violence relative to the length of the study follow-up period; and that the probability of survival did not vary significantly over time. Similar to the case of any post-prison domestic violence incident, the flatness of the survival curve in Figure 7 suggests that the risk of engaging in severe post-prison domestic violence was relatively consistent throughout sampled offenders' transition from prison to the community.

Estimates of both the $50^{\text {th }}$ and the $25^{\text {th }}$ percentile of survival to severe postprison domestic violence were not possible since the cumulative survival function only reached .76 . The survival function estimated the $10^{\text {th }}$ percentile at 27 months, indicating that sampled offenders had a $10 \%$ chance of engaging in severe post-prison domestic violence within 2.25 years of their release from prison. The $20^{\text {th }}$ percentile was estimated at 69 months, suggesting that sampled offenders had a $20 \%$ chance of engaging in severe post-prison domestic violence within 5.75 years of their release from prison. 


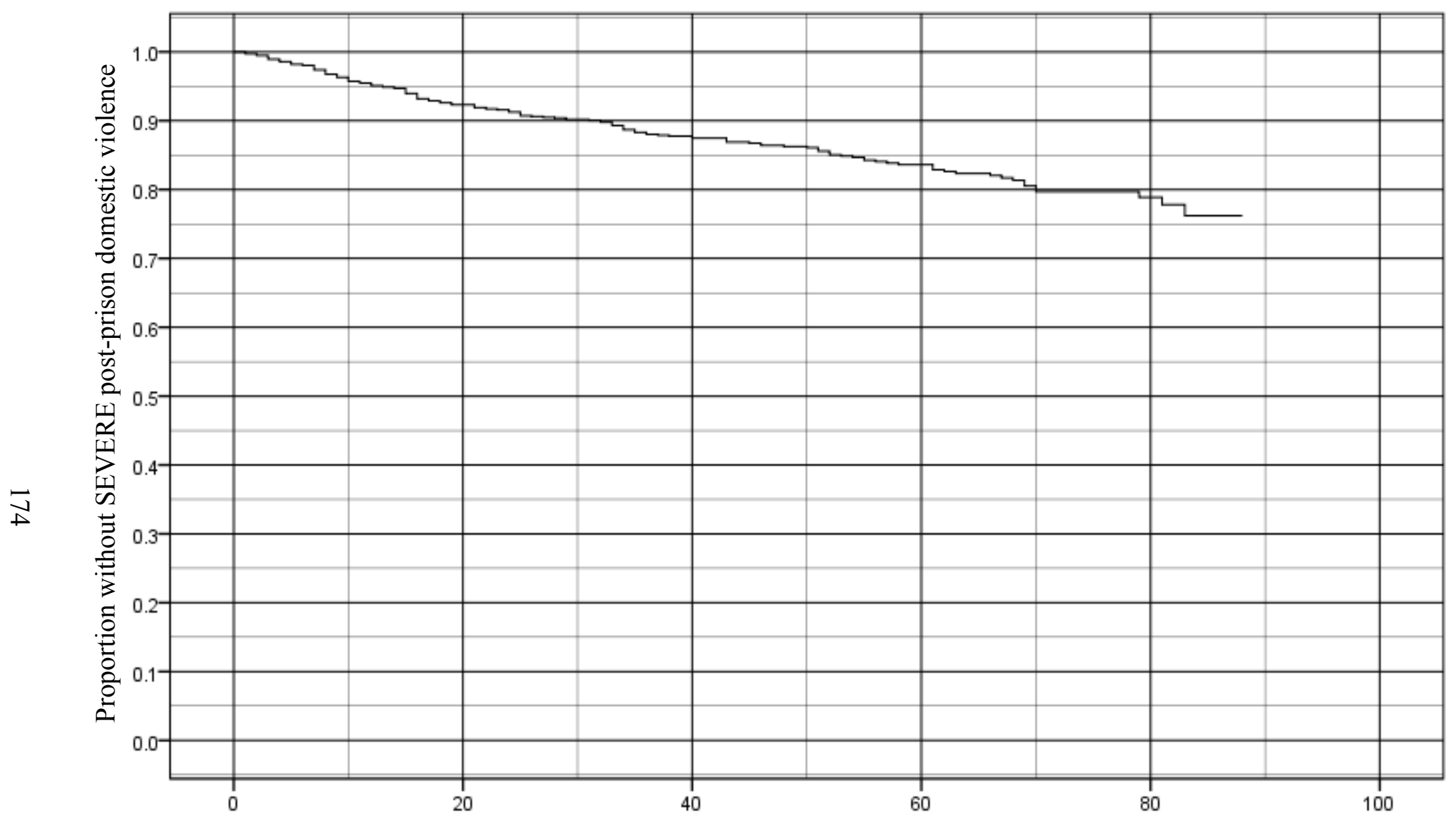

Months since prison release

Figure 7. Estimated survival function for severe post-prison domestic violence. 
Figure 8 displays the graph of the estimated hazard function for severe postprison domestic violence. Similar to the hazard function for any domestic violence incident, the hazard function for severe post-prison domestic violence is virtually flat. For the period of 51 months or 4.25 years after prison release, the hazard rate remains consistently low and ranges from 0 to .008 . There is a minor increase in event risk at month 69 , where the hazard rate reaches .011 . Event risk then drops and stays at 0 for the remainder of the study follow-up period except for three separate jumps at month 78 to .011 , month 80 to .013 , and month 82 to .021 . Overall, the hazard rate of severe postprison domestic violence is comparable to the hazard rate of any post-prison domestic violence incident in that it remained relatively stable over the duration of the follow-up period, rising no higher than .021 . Similarly, the hazard function for severe post-prison domestic violence also suggested that the likelihood of engaging in severe post-prison domestic violence was stable over time.

\section{Research Question Two}

My second research question concerned the extent to which selected individual, situational, and social-structural predictors independently and interactively predicted post-prison domestic violence. Two separate Cox regression survival analyses were conducted to model the effects of predictors and their interactions on the rate of any post-prison domestic violence incident and severe post-prison domestic violence.

Initial Cox regression analyses regressing post-prison domestic violence on all selected individual, demographic, situational, and social-structural predictors produced an error message indicating that the specified model could not be run because one or 


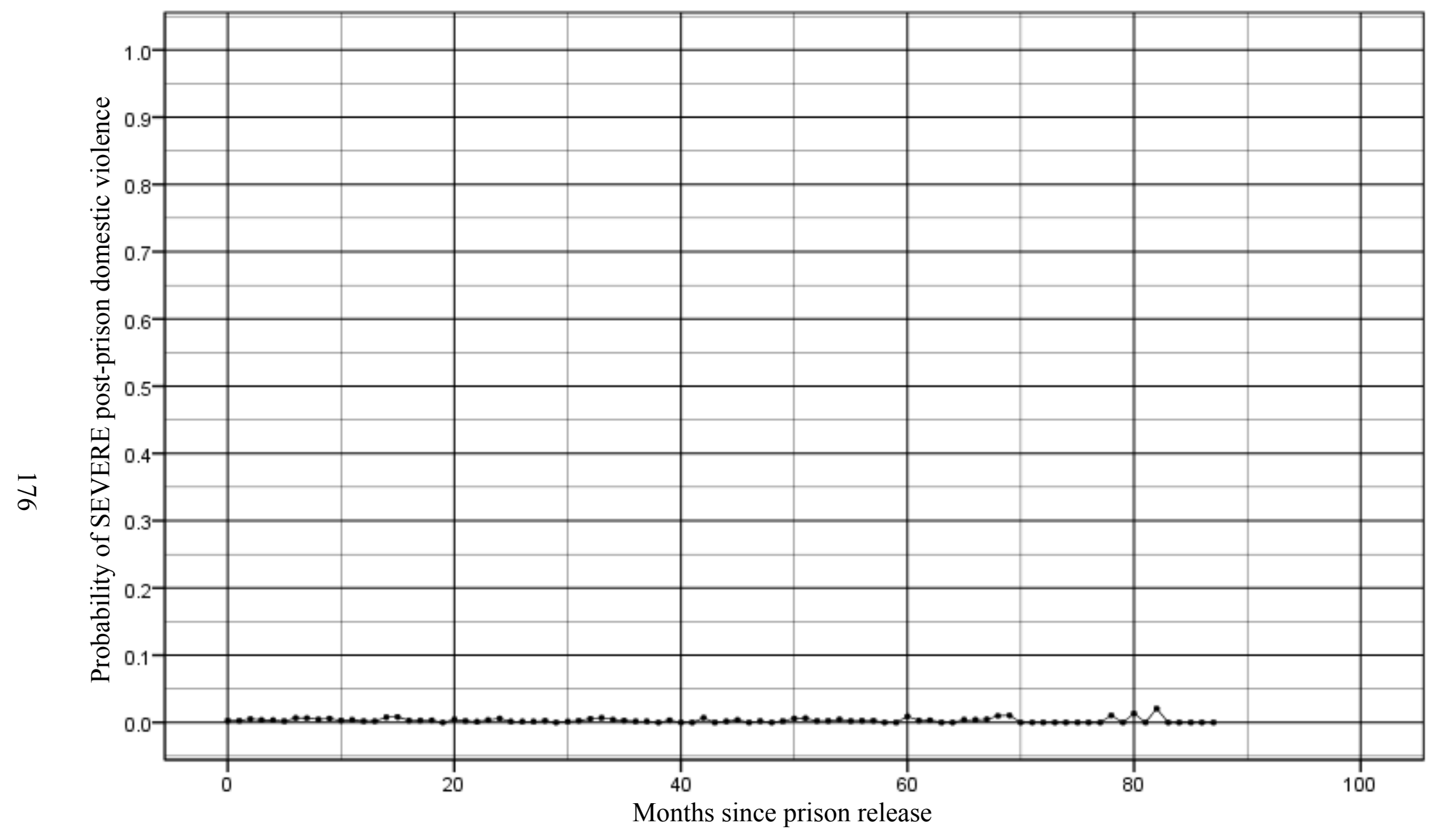

Figure 8. Estimated hazard function for severe post-prison domestic violence. 
more variables in the model were either too highly correlated or constant relative to the outcome variable. High correlations among predictors were addressed earlier during preliminary analyses, therefore a crosstabs analysis was performed to determine whether any of the predictors were constant relative to the variables representing postprison domestic violence. Crosstabs indicated that within the variable representing ethnicity, no offenders in the Asian category engaged in post-prison domestic violence. Within the variable representing marital status, no offenders in the widowed category engaged in post-prison domestic violence.

Because of this lack of variability, the variables representing ethnicity and marital status were collapsed into fewer categories. Results from the one-way ANOVA on ethnicity performed during preliminary analyses indicated no significant differences between Asian, Native American, and Latino offenders on any of the predictors of interest; therefore Asian offenders were collapsed into a single category with Native American and Latino offenders. Similarly, results from the one-way ANOVA on marital status indicated no significant differences between widowed and divorced offenders on any of the predictors of interest. Widowed offenders were therefore collapsed into a single category with divorced offenders. The remaining levels within the ethnicity and marital status variables remained intact. Cox regression analyses predicting any post-prison domestic violence incident and severe post-prison domestic violence proceeded using the new ethnicity variable containing three levels and the new marital status variable containing four categories. 
Any post-prison domestic violence incident. A sequential Cox regression survival analysis was conducted predicting any post-prison domestic violence incident from a selection of individual, situational, and social-structural variables and their interactions. Variables representing family-of-origin violence, antisocial and borderline personality, percentage of quarters worked, and neighborhood disadvantage were centered on the sample mean and entered simultaneously into the first step of the analytical model. Also entered into the first step of the analytical model were the additional demographic variables of age at release, ethnicity, crime type, marital status, number of children, length of prison stay, education need, and participation in cognitive-behavioral, substance abuse, and religious programming. Interaction terms that were created between each of the centered individual, situational, and socialstructural predictors within my ecological model were entered as a group into the second and final step of the analytical model.

Results of the first step of the sequential Cox regression survival analysis predicting any domestic violence incident from selected individual, situational, and social-structural predictors are displayed in Table 15. The overall Cox regression model significantly predicted survival time to any post-prison domestic violence incident at the first step $\left(-2 \mathrm{LL}=3598.64 ; \chi^{2}[23]=120.78, p<.001\right)$; however the strength of the association between any post-prison domestic violence incident and the predictors in the first step was relatively weak $\left(R^{2}=.09\right)$. Because all predictors were entered into the first step of the model simultaneously, each predictor is evaluated as if it was entered last. Therefore, coefficients associated with predictors reflect the unique contribution 
Table 15.

Step one of the Cox regression model predicting any post-prison domestic violence incident ( $n=1137)$.

\begin{tabular}{|c|c|c|c|c|c|c|c|}
\hline & $\beta$ & SE & $\operatorname{Exp}(B)$ & $-2 \mathrm{LL}$ & $\chi^{2}$ & $d f$ & $p$ \\
\hline Step 1 & & & & 3598.64 & 120.78 & 23 & $<.001$ \\
\hline Age at release & -.02 & .01 & $.98^{\mathrm{b}}$ & & & & \\
\hline Asian/Latino/Native American ${ }^{1}$ & .23 & .28 & 1.25 & & & & \\
\hline African American ${ }^{1}$ & .87 & .14 & $2.38^{\mathrm{a}}$ & & & & \\
\hline Moderate education need ${ }^{2}$ & -.35 & .26 & .70 & & & & \\
\hline Some education need ${ }^{2}$ & -.27 & .32 & .77 & & & & \\
\hline Minimal education need ${ }^{2}$ & -.43 & .22 & $.65^{\dagger}$ & & & & \\
\hline No education need ${ }^{2}$ & -.55 & .25 & $.58^{\mathrm{a}}$ & & & & \\
\hline Divorced /Widowed $^{3}$ & .03 & .25 & 1.03 & & & & \\
\hline Separated $^{3}$ & .18 & .29 & 1.19 & & & & \\
\hline Never married $^{3}$ & .12 & .20 & 1.13 & & & & \\
\hline Number of children & .12 & .05 & $1.13^{\mathrm{b}}$ & & & & \\
\hline Violent crime & .17 & .14 & 1.18 & & & & \\
\hline Length of incarceration (in months) & .00 & .00 & .99 & & & & \\
\hline Substance treatment & -.32 & .15 & $.72^{\mathrm{a}}$ & & & & \\
\hline Cognitive treatment & .26 & .13 & $1.30^{\mathrm{a}}$ & & & & \\
\hline Religious programs & .19 & .15 & 1.21 & & & & \\
\hline Physically abused (centered) & -.08 & .17 & .92 & & & & \\
\hline Sexually abused (centered) & -.22 & .21 & .81 & & & & \\
\hline Witnessed abuse (centered) & .30 & .13 & $1.35^{\mathrm{b}}$ & & & & \\
\hline Antisocial personality (centered) & .00 & .01 & 1.00 & & & & \\
\hline Borderline personality (centered) & .00 & .01 & 1.00 & & & & \\
\hline Percent quarters worked (centered) & .90 & .19 & $2.46^{\mathrm{c}}$ & & & & \\
\hline Neighborhood disadvantage (centered) & .07 & .04 & $1.07^{\dagger}$ & & & & \\
\hline
\end{tabular}

${ }^{1}$ Reference category $=$ Caucasian; ${ }^{2}$ Reference category $=$ Most education need $;{ }^{3}$ Reference category $=$ Married; ${ }^{\dagger} p<.10 ;{ }^{\mathrm{a}} p<.05 ;{ }^{\mathrm{b}} p<.01 ;{ }^{\mathrm{c}} p<.001$ 
each makes to the prediction of survival time over and above the contributions made by the remaining predictors. Based on this criteria, eight predictors were significantly associated with survival time to any post-prison domestic violence incident. Nonsignificant trends were also found for two additional predictors.

Among the individual-level demographic predictors, age, ethnicity, education, number of children, and treatment program attendance were significantly associated with survival time to any post-prison domestic violence incident. Regression coefficients indicated that young age significantly predicted any post-prison domestic violence incident when all other predictors were controlled $(\beta=-.02, p<.01)$. Model coefficients indicated that the odds of engaging in any post-prison domestic violence incident decreased significantly for each year increase in offenders' age $\left(\operatorname{Exp}[\mathrm{B}]_{\mathrm{Age}}=\right.$ .98). Being African American was also significantly related to engaging in any postprison domestic violence incident when all other predictors were controlled $(\beta=.87, p$ $<.05)$. Model coefficients indicated that the odds of engaging in any post-prison domestic violence incident were significantly higher for African American offenders relative to Caucasian offenders $\left(\operatorname{Exp}[\mathrm{B}]_{\text {African American }}=2.38\right)$.

Regarding education need, model coefficients indicated that the odds of engaging in any post-prison domestic violence incident were significantly lower for offenders with no education need compared to offenders with the most education need $\left(\operatorname{Exp}[\mathrm{B}]_{\text {No education need }}=.58 ; \beta=-.55, p<.05\right)$. A nonsignificant trend indicated that offenders with minimal education need were also less likely than offenders with the 
most education need to engage in any post-prison domestic violence incident when all other predictors were controlled $\left(\operatorname{Exp}[\mathrm{B}]_{\text {Minimal education need }}=.65 ; \beta=-.43, p<.10\right)$.

Regression coefficients also indicated that number of children $(\beta=.12, p<.01)$, substance abuse treatment attendance $(\beta=-.32, p<.05)$ and cognitive-behavioral treatment attendance $(\beta=.26, p<.05)$ were significant predictors of any post-prison domestic violence incident when all other predictors were controlled. Model coefficients indicated that the odds of engaging in any post-prison domestic violence incident increased significantly for each additional child $\left(\operatorname{Exp}[\mathrm{B}]_{\text {Number of children }}=1.13\right)$. The odds of engaging in any post-prison domestic violence incident were significantly lower for offenders who attended substance abuse treatment in prison relative to those who did not $\left(\operatorname{Exp}[B]_{\text {Substance treatment }}=.72\right)$. The effect of cognitive-behavioral treatment attendance was in the opposite direction, such that the odds of engaging in any postprison domestic violence incident were significantly higher among offenders who attended cognitive-behavioral treatment compared to those who did not $\left(\operatorname{Exp}[\mathrm{B}]_{\text {Substance }}\right.$ treatment $=1.30)$.

Among the predictors chosen to represent the individual, situational, and socialstructural levels of my ecological model, three were significantly associated with any post-prison domestic violence incident. Witnessing interparental violence during childhood significantly predicted survival time to any post-prison domestic violence incident in the first step of the model when all other predictors were controlled $(\beta=.30$, $p<.05)$. Model coefficients indicated that the odds of engaging in any post-prison domestic violence incident were significantly higher among offenders who reported 
witnessing interparental violence relative to those who did not witness interparental violence during childhood $\left(\operatorname{Exp}[\mathrm{B}]_{\text {Witnessed abuse }}=1.35\right)$. At the situational level, the percentage of quarters worked was also significantly associated with survival time to any post-prison domestic violence incident when all other predictors were controlled ( $\beta$ $=.90, p<.001)$. In opposition to the hypothesized direction, model coefficients indicated that the odds of engaging in any post-prison domestic violence incident increased significantly for each unit increase in the percentage of quarters worked $\left(\operatorname{Exp}[\mathrm{B}]_{\text {Percent quarters worked }}=2.46\right)$. Finally, a nonsignificant trend indicated that neighborhood disadvantage was associated with engaging in any post-prison domestic violence incident when all other predictors were controlled $(\beta=.07, p<.10)$. Coefficients indicated that the odds of engaging in any post-prison domestic violence incident tended to increase with each unit increase in neighborhood disadvantage $\left(\operatorname{Exp}[\mathrm{B}]_{\text {Neighborhood disadvantage }}=1.07\right)$.

Interactions between selected individual, situational, and social-structural variables were entered into the second step of the Cox regression model predicting any post-prison domestic violence incident. Figure 9 shows that at the mean of the predictors and interactions, the one-year survival rate to any post-prison domestic violence incident after prison release is about $92 \%$. The five-year survival rate is about $77 \%$. Regression coefficients and odds ratios associated with all predictors and interactions in the second step of the model predicting any post-prison domestic violence incident are presented in Table 16. 


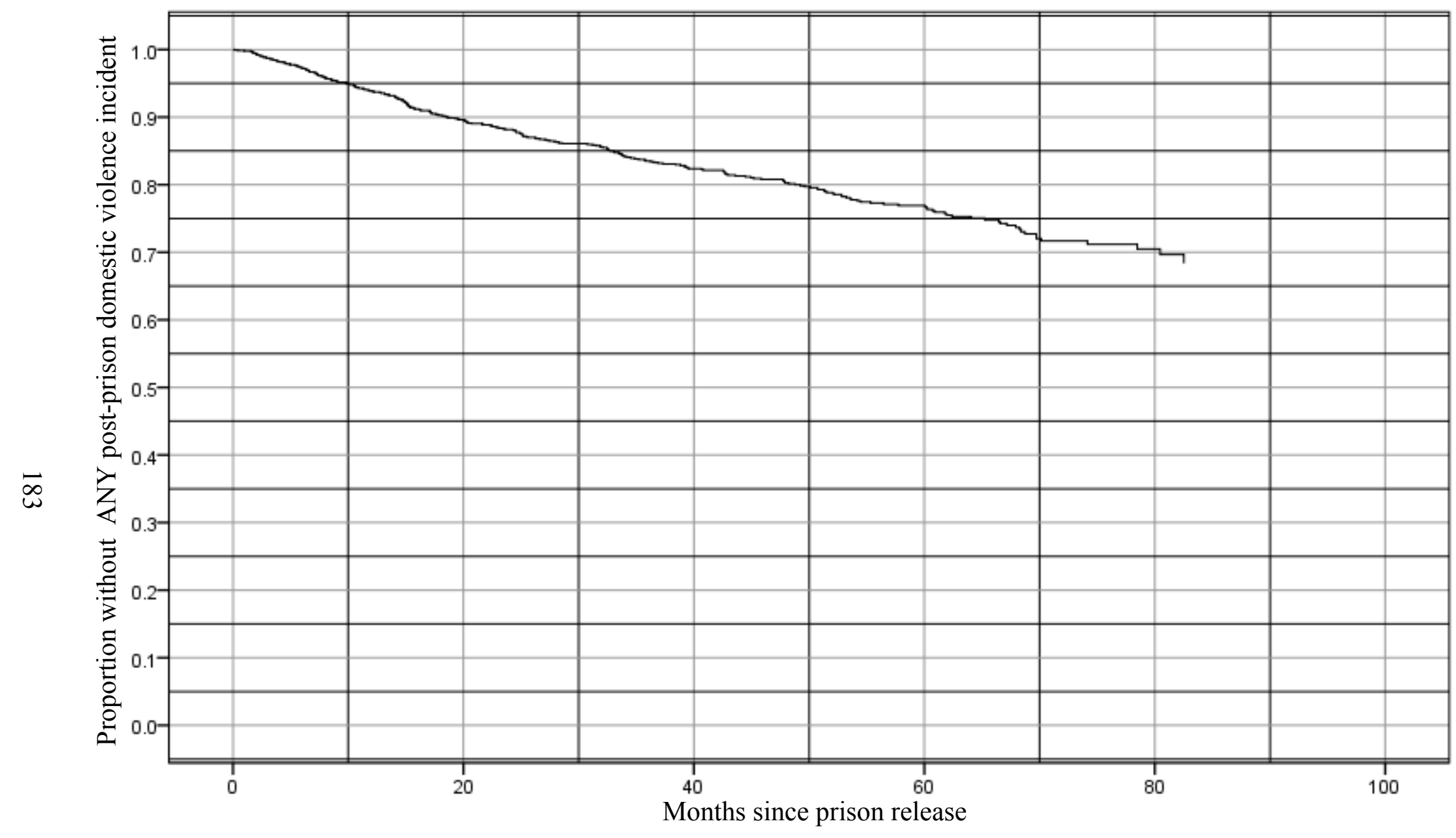

Figure 9. Survival rate to any post-prison domestic violence incident at the means of the predictors and interactions. 
Table 16.

Step two of the Cox regression model predicting any post-prison domestic violence incident ( $n=1137)$.

\begin{tabular}{|c|c|c|c|c|c|c|c|}
\hline & $\beta$ & SE & $\operatorname{Exp}(B)$ & $-2 \mathrm{LL}$ & $\chi^{2}$ & $d f$ & $p$ \\
\hline Step 2 & & & & 3575.58 & 140.48 & 40 & $<.001$ \\
\hline Age at release & -.02 & .01 & $.98^{\mathrm{a}}$ & & & & \\
\hline Asian/Latino/Native American ${ }^{1}$ & .21 & .28 & 1.23 & & & & \\
\hline African American ${ }^{1}$ & .89 & .14 & $2.44^{\mathrm{c}}$ & & & & \\
\hline Moderate education need $^{2}$ & -.39 & .27 & .68 & & & & \\
\hline Some education need ${ }^{2}$ & -.21 & .32 & .81 & & & & \\
\hline Minimal education need ${ }^{2}$ & -.47 & .22 & $.63^{\mathrm{a}}$ & & & & \\
\hline No education need ${ }^{2}$ & -.57 & .25 & $.57^{\mathrm{a}}$ & & & & \\
\hline Divorced /Widowed ${ }^{3}$ & -.03 & .24 & .97 & & & & \\
\hline Separated $^{3}$ & .25 & .29 & 1.28 & & & & \\
\hline Never married ${ }^{3}$ & .14 & .20 & 1.15 & & & & \\
\hline Number of children & .14 & .05 & $1.15^{\mathrm{b}}$ & & & & \\
\hline Violent crime & .18 & .14 & 1.20 & & & & \\
\hline Length of incarceration (in months) & .00 & .00 & .99 & & & & \\
\hline Substance treatment & -.33 & .15 & $.72^{\mathrm{a}}$ & & & & \\
\hline Cognitive treatment & .26 & .13 & $1.30^{\mathrm{a}}$ & & & & \\
\hline Religious programs & .23 & .14 & $1.26^{\dagger}$ & & & & \\
\hline Physically abused (centered) & -.06 & .19 & .95 & & & & \\
\hline Sexually abused (centered) & -.38 & .27 & .68 & & & & \\
\hline Witnessed abuse (centered) & .36 & .14 & $1.44^{\mathrm{a}}$ & & & & \\
\hline Antisocial personality (centered) & .01 & .01 & 1.01 & & & & \\
\hline Borderline personality (centered) & .00 & .01 & .99 & & & & \\
\hline Percent quarters worked (centered) & .94 & .20 & $2.56^{\mathrm{c}}$ & & & & \\
\hline Neighborhood disadvantage (centered) & .09 & .04 & $1.10^{\mathrm{a}}$ & & & & \\
\hline Physically abused*Antisocial personality & .00 & .02 & .99 & & & & \\
\hline Physically abused*Borderline personality & -.02 & .02 & .98 & & & & \\
\hline Sexually abused*Antisocial personality & .00 & .03 & 1.00 & & & & \\
\hline Sexually abused*Borderline personality & .02 & .02 & 1.02 & & & & \\
\hline Witnessed abuse*Antisocial personality & .01 & .02 & 1.01 & & & & \\
\hline Witnessed abuse*Borderline personality & .01 & .01 & 1.01 & & & & \\
\hline Physically abused*Percent quarters worked & .70 & .54 & 2.02 & & & & \\
\hline Sexually abused*Percent quarters worked & .00 & 63 & .99 & & & & \\
\hline Witnessed abuse*Percent quarters worked & -.93 & .44 & $.39^{\mathrm{a}}$ & & & & \\
\hline Physically abused*Neigh. disadvantage & .18 & .11 & 1.19 & & & & \\
\hline Sexually abused*Neigh. disadvantage & .17 & .15 & 1.18 & & & & \\
\hline Witnessed abuse*Neigh. disadvantage & .03 & .08 & 1.03 & & & & \\
\hline Antisocial personality*Percent quarters worked & -.05 & .02 & $.95^{\mathrm{a}}$ & & & & \\
\hline Borderline personality*Percent quarters worked & .04 & .02 & $1.04^{\mathrm{a}}$ & & & & \\
\hline Antisocial personality*Neigh. disadvantage & -.01 & .01 & .99 & & & & \\
\hline Borderline personality*Neigh. disadvantage & .00 & .00 & .99 & & & & \\
\hline Percent quarters worked*Neigh. disadvantage & -.11 & .11 & .89 & & & & \\
\hline
\end{tabular}

${ }^{1}$ Reference category $=$ Caucasian; ${ }^{2}$ Reference category $=$ Most education need $;{ }^{3}$ Reference category $=$ Married; ${ }^{\dagger} p<.10 ;{ }^{\mathrm{a}} p<.05 ;{ }^{\mathrm{b}} p<.01 ;{ }^{\mathrm{c}} p<.001$ 
The overall Cox regression model including all predictors and interaction terms significantly predicted survival time to any post-prison domestic violence incident at the second step $\left(-2 \mathrm{LL}=3575.58 ; \chi^{2}[40]=140.48, p<.001\right)$. The change in chi-square from the first to the second step was not significant $\left[\Delta \chi^{2}(17)=23.07, p=.147\right]$, indicating that the group of interactions did not account for a significant amount of variance in any post-prison domestic violence incident over and above the variance explained by the main effects. The strength of the association between any post-prison domestic violence incident and all predictors and interactions in the second step was also relatively weak $\left(R^{2}=.11\right)$. Interaction terms were entered into the second step of the model simultaneously, therefore each is evaluated as if it was entered into the model last. Coefficients associated with predictors and interaction terms reflect the unique contribution each makes to the prediction of survival time to any post-prison domestic violence incident.

The same predictors that were statistically significant in the first step of the model (i.e., age, ethnicity, education need, number of children, substance abuse treatment attendance, cognitive-behavioral treatment attendance, witnessing interparental violence, and percentage of quarters worked) were also significant in the second step of the model. In addition, predictors that trended toward significance in the first step became significant at the second step when the interaction terms were added to the model. The change in statistical significance of these predictors indicates that at least some of the interaction terms added in the second step accounted for unique variance in any post-prison domestic violence incident. To illustrate, the addition of 
interaction terms that accounted for unique variance in any post-prison domestic violence incident (i.e., the outcome) reduced the amount of residual or unexplained variance in the outcome. Because the total amount of unexplained variance was decreased, the standard errors for each predictor in the model were also reduced. Smaller standard errors resulted in smaller test statistics (i.e., $p$ values), which contributed to the statistical significance of these predictors.

Specifically, the nonsignificant trend for minimal education need in the first step became significant in the second step when all other predictors were controlled for $(\beta=$ $-.47, p<.05$ ), and model coefficients indicated that the odds of engaging in any postprison domestic violence incident were significantly lower for offenders with minimal education need compared to offenders with the most education need $\left(\operatorname{Exp}[\mathrm{B}]_{\text {Minimal }}\right.$ education need $=.63)$. The nonsignificant trend for neighborhood disadvantage in step one also became significant in step two when all other predictors were controlled for $(\beta=$ $.09, p<.05)$. Model coefficients indicated that the odds of engaging in any post-prison domestic violence incident were significantly higher for offenders living in more socially and economically disadvantaged neighborhoods $\left(\operatorname{Exp}[\mathrm{B}]_{\text {Neighborhood disadvantage }}=\right.$ 1.10). An additional nonsignificant trend emerged in the second step of the model and suggested that participation in religious services programming predicted any domestic violence incident when all other predictors were controlled $(\beta=.23, p<.10)$. Model coefficients indicated that the odds of engaging in any post-prison domestic violence incident tended to be higher among offenders who participated in religious services programming relative to those who $\operatorname{did} \operatorname{not}\left(\operatorname{Exp}[\mathrm{B}]_{\text {Religious programs }}=1.26\right)$. 
Three of the interactions that were entered into the second step of the Cox regression survival analysis predicting any domestic violence incident were statistically significant. All significant interactions were between variables from the individual level of my ecological model and the situational level variable of percentage of quarters worked. Regression coefficients indicated that the interaction between witnessing interparental abuse and percentage of quarters worked significantly predicted any postprison domestic violence incident when all other predictors were controlled $(\beta=-.93, p$ $<.05)$; however the interaction was not in the direction that was hypothesized. Figure 10 shows that the relationship between percentage of quarters worked and any postprison domestic violence incident was more pronounced for offenders who did not witness interparental violence compared to offenders who witnessed interparental violence during childhood. For offenders who did not witness interparental violence, a higher percentage of quarters worked was related to engaging in any post-prison domestic violence incident. Percentage of quarters worked had a more consistent relationship with any post-prison domestic violence incident for offenders who witnessed interparental violence.

The interactions between percentage of quarters worked and both antisocial and borderline personality characteristics also significantly predicted any post-prison domestic violence incident when all other predictors were controlled $(\beta=-.05, p<.05$ and $\beta=.04, p<.05)$. Figure 11 illustrates that the relationship between percentage of quarters worked and any post-prison domestic violence incident was stronger for offenders with lower scores on the measure of antisocial personality characteristics. For 


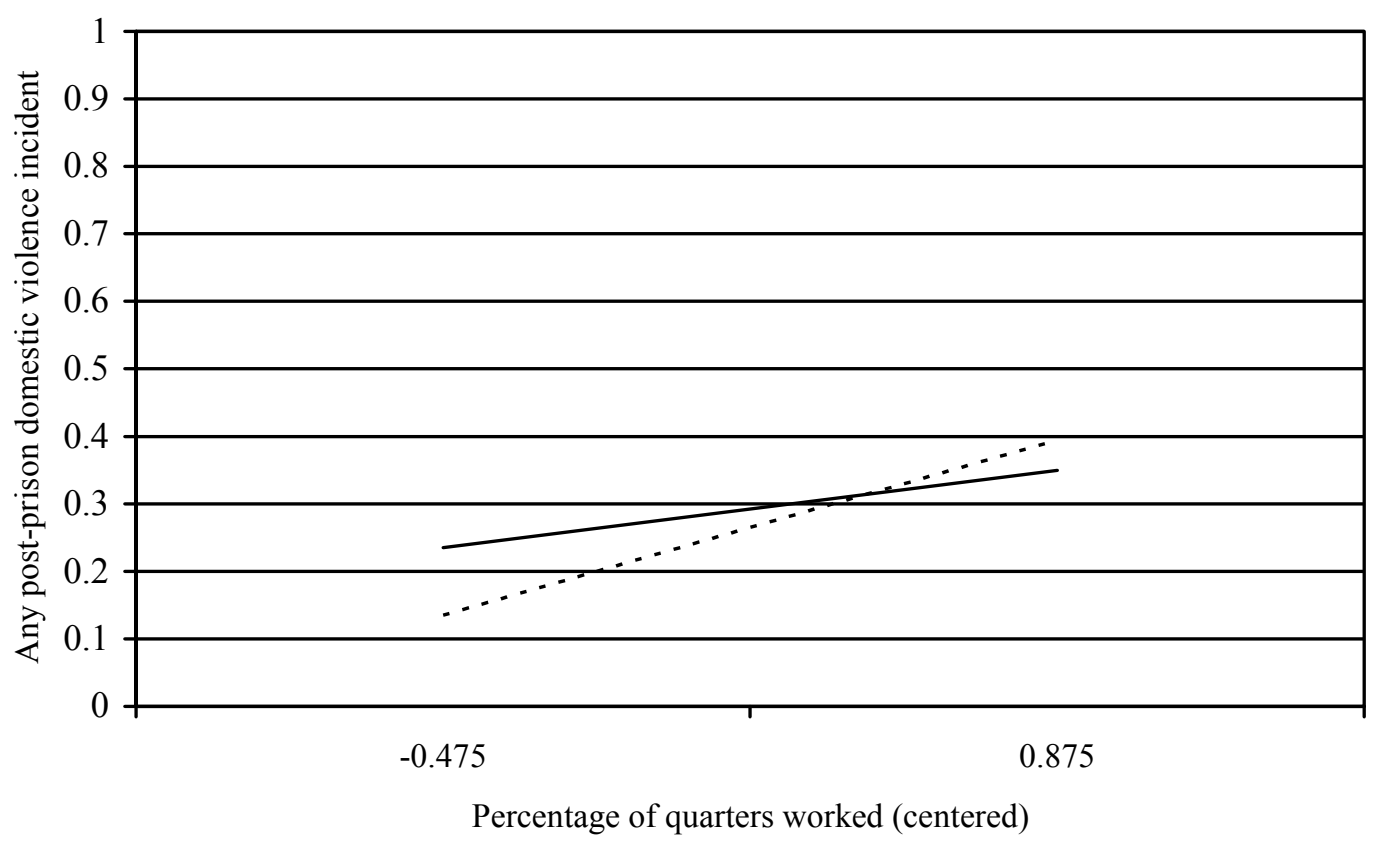

— Witnessed interparental violence $\quad$ - - . - Did not witness interparental violence

Figure 10. Interaction between witnessing interparental violence and percentage of quarters worked on any post-prison domestic violence incident. 


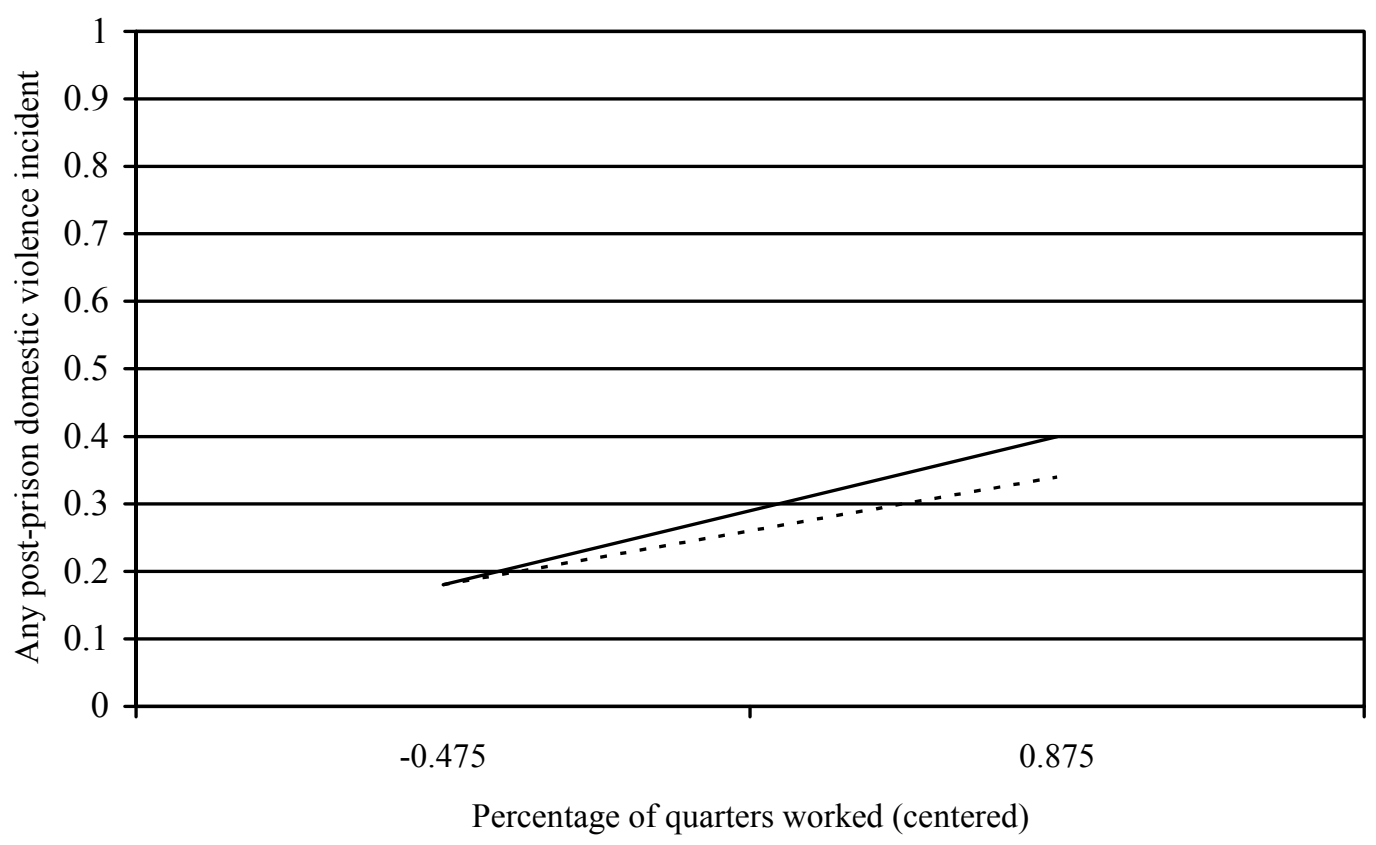

Low antisocial personality $\quad \cdots \cdot$ High antisocial personality

Figure 11. Interaction between antisocial personality characteristics and percentage of quarters worked on any post-prison domestic violence incident. 
offenders who exhibited fewer antisocial personality characteristics, a higher percentage of quarters worked was more strongly related to engaging in post-prison domestic violence. In contrast, Figure 12 shows that the relationship between the percentage of quarters worked and any post-prison domestic violence incident was stronger for offenders with higher scores on the measure of borderline personality characteristics. For offenders who exhibited more borderline personality characteristics, a higher percentage of quarters worked was related to engaging in any post-prison domestic violence incident.

Severe post-prison domestic violence. A sequential Cox regression survival analysis was conducted predicting severe post-prison domestic violence from meancentered variables representing family-of-origin violence, antisocial and borderline personality, percentage of quarters worked, and neighborhood disadvantage. Additional demographic variables of age at release, ethnicity, crime type, marital status, number of children, length of prison stay, education level, and participation in cognitivebehavioral, substance abuse, and religious programming were also entered into the model. All predictors were entered into the first step of the model simultaneously to assess the main effects of each on severe post-prison domestic violence. Interactions between each of the individual, situational, and social-structural predictors within my ecological model were entered as a group into the second and final step of the analytical model.

Results of the first step of the sequential Cox regression survival analysis predicting severe post-prison domestic violence are displayed in Table 17. The overall 


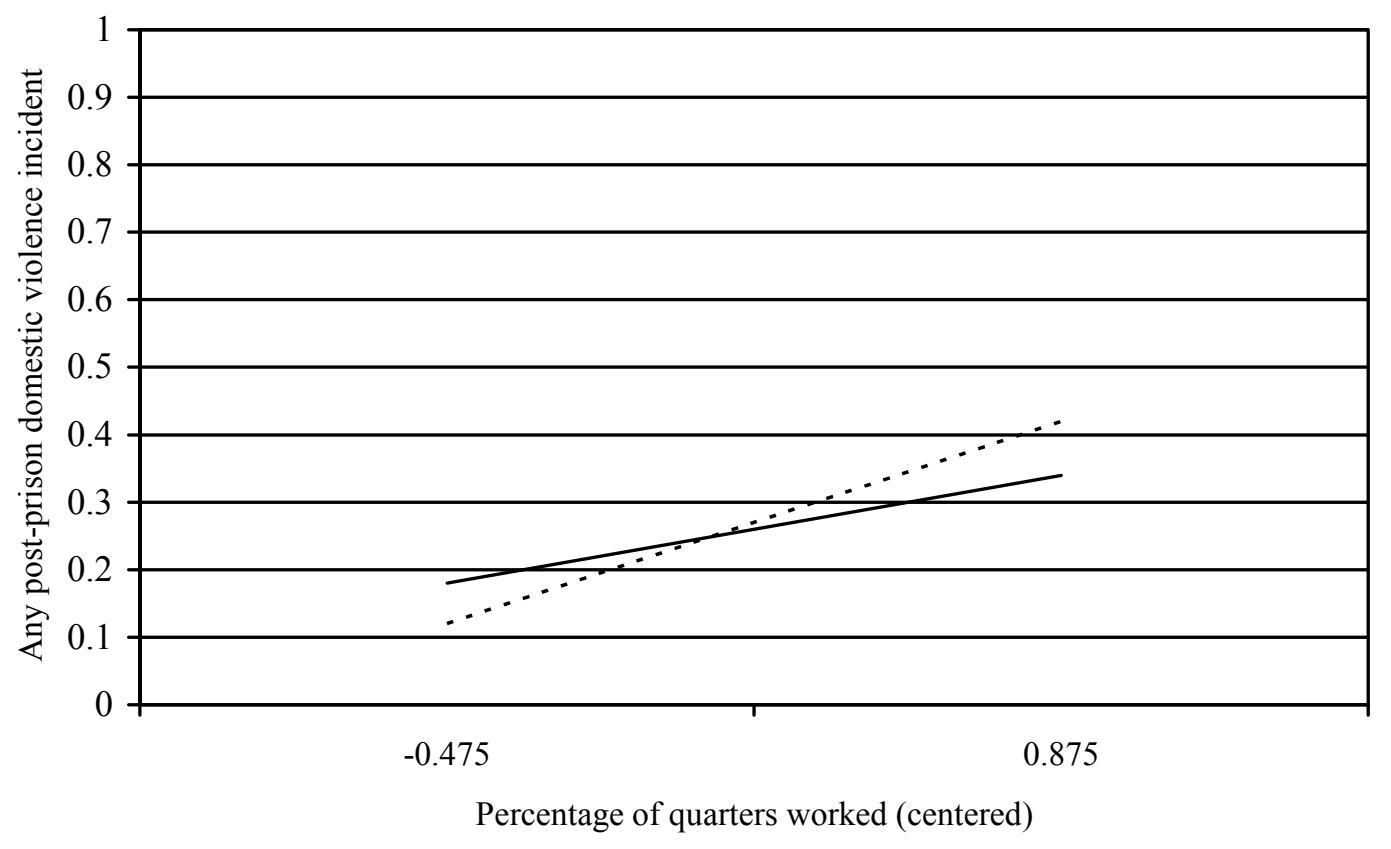

_Low borderline personality - . . - High borderline personality

Figure 12. Interaction between borderline personality characteristics and percentage of quarters worked on any post-prison domestic violence incident. 
Table 17.

Step one of the Cox regression model predicting severe post-prison domestic violence $(n=1137)$.

\begin{tabular}{|c|c|c|c|c|c|c|c|}
\hline & $\beta$ & SE & $\operatorname{Exp}(B)$ & $-2 \mathrm{LL}$ & $\chi^{2}$ & $d f$ & $p$ \\
\hline Step 1 & & & & 2046.54 & 92.86 & 23 & $<.001$ \\
\hline Age at release & -.02 & .10 & $.98^{\dagger}$ & & & & \\
\hline Asian/Latino/Native American ${ }^{1}$ & .15 & .38 & 1.16 & & & & \\
\hline African American ${ }^{1}$ & .98 & .19 & $2.67^{\mathrm{c}}$ & & & & \\
\hline Moderate education need ${ }^{2}$ & -.55 & .33 & .58 & & & & \\
\hline Some education need ${ }^{2}$ & -.31 & .39 & .73 & & & & \\
\hline Minimal education need ${ }^{2}$ & -.61 & .26 & $.54^{\mathrm{a}}$ & & & & \\
\hline No education need ${ }^{2}$ & -.80 & .31 & $.45^{\dagger}$ & & & & \\
\hline Divorced /Widowed $^{3}$ & -.02 & .32 & .98 & & & & \\
\hline Separated $^{3}$ & .38 & .37 & 1.46 & & & & \\
\hline Never married ${ }^{3}$ & .11 & .27 & 1.12 & & & & \\
\hline Number of children & .04 & .06 & 1.05 & & & & \\
\hline Violent crime & .38 & .18 & $1.46^{\mathrm{a}}$ & & & & \\
\hline Length of incarceration (in months) & .00 & .01 & .99 & & & & \\
\hline Substance treatment & -.44 & .20 & $.64^{\mathrm{a}}$ & & & & \\
\hline Cognitive treatment & .19 & .17 & 1.21 & & & & \\
\hline Religious programs & .05 & .18 & 1.05 & & & & \\
\hline Physically abused (centered) & -.14 & .22 & .87 & & & & \\
\hline Sexually abused (centered) & -.32 & .29 & .73 & & & & \\
\hline Witnessed abuse (centered) & .58 & .17 & $1.78^{\mathrm{c}}$ & & & & \\
\hline Antisocial personality (centered) & .01 & .01 & 1.01 & & & & \\
\hline Borderline personality (centered) & .00 & .01 & .99 & & & & \\
\hline Percent quarters worked (centered) & .40 & .26 & 1.49 & & & & \\
\hline Neighborhood disadvantage (centered) & .06 & .05 & 1.06 & & & & \\
\hline
\end{tabular}

${ }^{1}$ Reference category $=$ Caucasian; ${ }^{2}$ Reference category $=$ Most education need $;{ }^{3}$ Reference category $=$ Married; ${ }^{\dagger} p<.10 ;{ }^{\mathrm{a}} p<.05 ;{ }^{\mathrm{c}} p<.001$ 
Cox regression model significantly predicted survival time to severe post-prison domestic violence at the first step $\left(-2 \mathrm{LL}=2046.54 ; \chi^{2}[23]=92.86, p<.001\right)$; however the strength of the association between severe post-prison domestic violence and the predictors entered in the first step was weak $\left(R^{2}=.07\right)$. Each predictor is evaluated as if it was entered last because all predictors were entered into the model simultaneously. Coefficients associated with predictors reflect the unique contribution each makes to the prediction of survival time to severe post-prison domestic violence. Five predictors were significantly associated with survival time to severe post-prison domestic violence. Nonsignificant trends were also found for two additional predictors.

Among the individual-level demographic predictors, ethnicity, education, type of crime, and treatment program attendance were significantly associated with survival time to severe post-prison domestic violence. In addition, a nonsignificant trend indicated that age was associated with perpetrating severe post-prison domestic violence when all other predictors were controlled $(\beta=-.02, p<.10)$. Similar to the model predicting any post-prison domestic violence incident, model coefficients indicated that the odds of perpetrating severe post-prison domestic violence decreased significantly for each year increase in offender age $\left(\operatorname{Exp}[\mathrm{B}]_{\mathrm{Age}}=.98\right)$. Also identical to the model predicting any post-prison domestic violence incident, coefficients indicated that the odds of perpetrating severe post-prison domestic violence were significantly higher among African American offenders relative to Caucasian offenders $(\beta=.98, p<.001$; $\left.\operatorname{Exp}[\mathrm{B}]_{\text {African American }}=2.67\right)$. 
Education need was also associated with engaging in severe post-prison domestic violence. Model coefficients indicated that offenders with minimal education need were significantly less likely to engage in severe post-prison domestic violence than offenders with the most education need when all other predictors were controlled $\left(\operatorname{Exp}[\mathrm{B}]_{\text {Minimal education need }}=.54 ; \beta=-.61, p<.05\right)$. In addition, a nonsignificant trend indicated that offenders with no education need tended to have smaller odds of perpetrating severe post-prison domestic violence than offenders with the most education need $\left(\operatorname{Exp}[\mathrm{B}]_{\text {No education need }}=.45 ; \beta=-.80, p<.10\right)$.

Regression coefficients also indicated that type of crime conviction $(\beta=.38, p<$ $.05)$ and substance abuse treatment attendance $(\beta=-.44, p<.05)$ were significant predictors of severe post-prison domestic violence when all other predictors were controlled. Model coefficients indicated that the odds of perpetrating severe post-prison domestic violence were significantly higher for offenders who served time in prison for a violent crime compared to offenders who were incarcerated for a non-violent crime $\left.\operatorname{Exp}[\mathrm{B}]_{\text {Violent crime }}=1.46\right)$. The odds of perpetrating severe post-prison domestic violence were significantly lower for offenders who attended substance abuse treatment in prison relative to offenders who did not attend substance abuse treatment $\operatorname{Exp}[\mathrm{B}]_{\text {Substance treatment }}$ $=.64)$.

Of the predictors chosen to represent the individual, situational, and socialstructural levels of my ecological model, only one significantly predicted severe postprison domestic violence in the first step of the model. Regression coefficients indicated that witnessing interparental violence during childhood significantly predicted survival 
time to severe post-prison domestic violence when all other predictors were controlled $(\beta=.58, p<.001)$. Model coefficients indicated that the odds of perpetrating severe post-prison domestic violence were significantly higher among offenders who witnessed interparental violence during childhood relative to offenders who did not witness interparental violence $\left.\operatorname{Exp}[\mathrm{B}]_{\text {Witnessed abuse }}=1.78\right)$.

Interactions between selected individual, situational, and social-structural variables were entered as a group into the second step of the Cox regression model predicting severe post-prison domestic violence. Figure 13 shows that at the mean of the predictors and interactions, the one-year survival rate to severe post-prison domestic violence after prison release is about $97 \%$. The five-year survival rate is about $86 \%$. Regression coefficients and odds ratios associated with all predictors and interactions in the second step of the model are presented in Table 18.

The overall Cox regression model including all predictors and interaction terms significantly predicted survival time to severe post-prison domestic violence at the second step $\left(-2 \mathrm{LL}=2021.53 ; \chi^{2}[40]=116.28, p<.001\right)$. The change in chi-square from the first to the second step was not significant $\left(\Delta \chi^{2}[17]=25.01, p=.09\right)$, indicating that inclusion of the interactions between selected individual, situational, and social structural variables did not significantly improve the overall fit of the model predicting severe post-prison domestic violence. Stated differently, the group of interactions did not account for a significant amount of variance in severe post-prison domestic violence beyond what was explained by the main effects. Just as in the first step, each predictor and interaction term is evaluated as if it was entered last. Coefficients associated with 


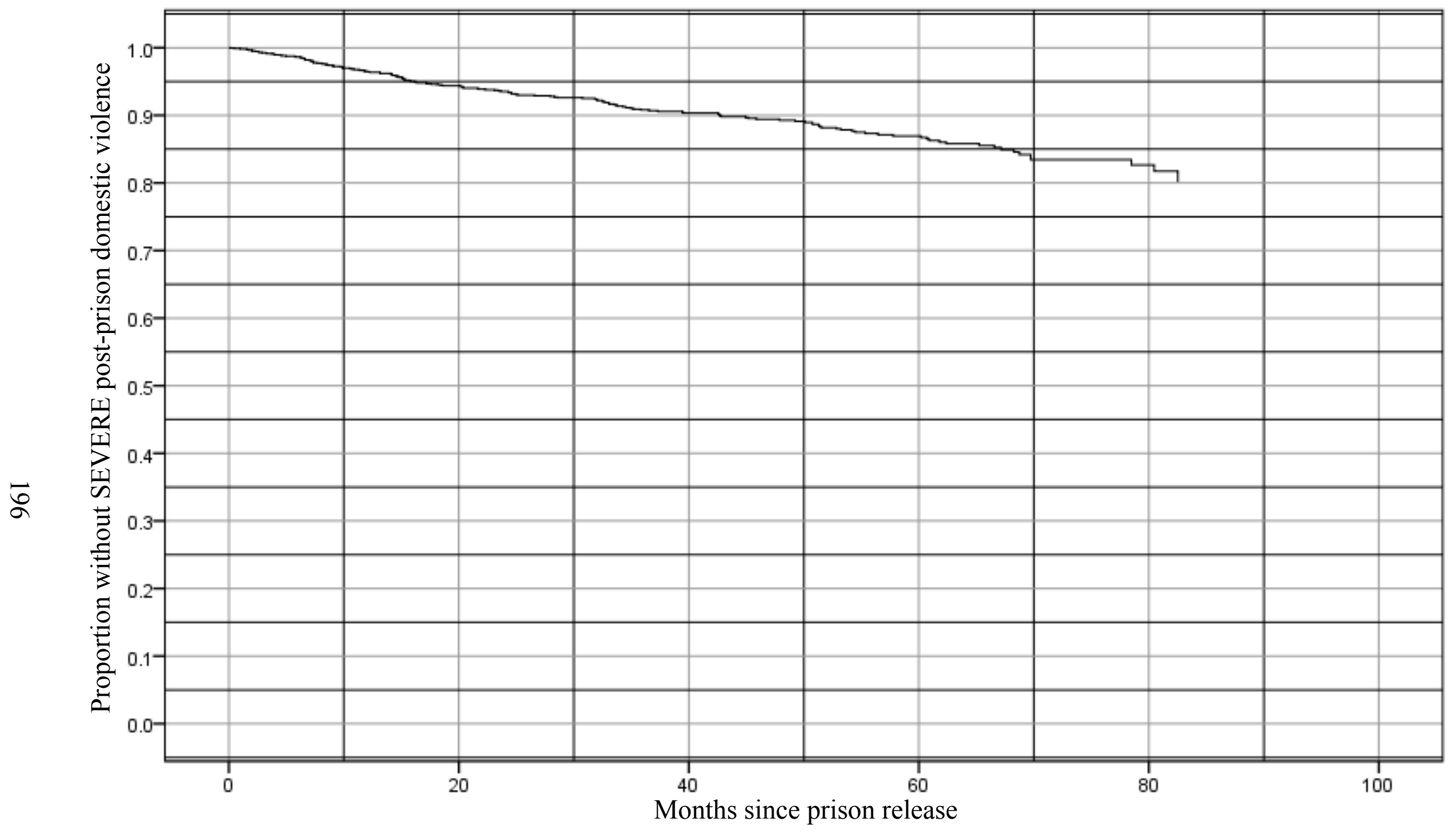

Figure 13. Survival rate to severe post-prison domestic violence at the means of the predictors and interactions. 
Table 18.

Step two of the Cox regression model predicting severe post-prison domestic violence $(n=1137)$.

\begin{tabular}{|c|c|c|c|c|c|c|c|}
\hline & $\beta$ & SE & $\operatorname{Exp}(B)$ & $-2 \mathrm{LL}$ & $\chi^{2}$ & $d f$ & $p$ \\
\hline Step 2 & & & & 2021.53 & 116.28 & 40 & $<.001$ \\
\hline Age at release & -.02 & .01 & $.98^{\dagger}$ & & & & \\
\hline Asian/Latino/Native American ${ }^{1}$ & .12 & .39 & 1.13 & & & & \\
\hline African American ${ }^{1}$ & 1.03 & .19 & $2.80^{\mathrm{c}}$ & & & & \\
\hline Moderate education need ${ }^{2}$ & -.57 & .33 & $.57^{\dagger}$ & & & & \\
\hline Some education need ${ }^{2}$ & -.19 & .39 & .83 & & & & \\
\hline Minimal education need ${ }^{2}$ & -.63 & .27 & $.53^{\mathrm{a}}$ & & & & \\
\hline No education need ${ }^{2}$ & -.77 & .32 & $.47^{\mathrm{a}}$ & & & & \\
\hline Divorced /Widowed ${ }^{3}$ & -.09 & .33 & .91 & & & & \\
\hline Separated $^{3}$ & .44 & .38 & 1.55 & & & & \\
\hline Never married ${ }^{3}$ & .14 & .27 & 1.15 & & & & \\
\hline Number of children & .05 & .06 & 1.05 & & & & \\
\hline Violent crime & .40 & .18 & $1.49^{\mathrm{a}}$ & & & & \\
\hline Length of incarceration (in months) & .00 & .01 & .99 & & & & \\
\hline Substance treatment & -.46 & .21 & $.63^{\mathrm{a}}$ & & & & \\
\hline Cognitive treatment & .21 & .17 & 1.23 & & & & \\
\hline Religious programs & .10 & .18 & 1.11 & & & & \\
\hline Physically abused (centered) & -.08 & .24 & .93 & & & & \\
\hline Sexually abused (centered) & -.42 & .34 & .66 & & & & \\
\hline Witnessed abuse (centered) & .59 & .18 & $1.80^{\mathrm{c}}$ & & & & \\
\hline Antisocial personality (centered) & .01 & .01 & 1.01 & & & & \\
\hline Borderline personality (centered) & .00 & .01 & .99 & & & & \\
\hline Percent quarters worked (centered) & .43 & .28 & 1.53 & & & & \\
\hline Neighborhood disadvantage (centered) & .08 & .06 & 1.08 & & & & \\
\hline Physically abused*Antisocial personality & .02 & .03 & 1.02 & & & & \\
\hline Physically abused*Borderline personality & -.04 & .02 & $.96^{\dagger}$ & & & & \\
\hline Sexually abused*Antisocial personality & .02 & .04 & 1.02 & & & & \\
\hline Sexually abused*Borderline personality & .01 & .03 & 1.01 & & & & \\
\hline Witnessed abuse*Antisocial personality & .01 & .02 & 1.01 & & & & \\
\hline Witnessed abuse*Borderline personality & .01 & .02 & 1.01 & & & & \\
\hline Physically abused*Percent quarters worked & 1.51 & .71 & $4.54^{\mathrm{a}}$ & & & & \\
\hline Sexually abused*Percent quarters worked & -.09 & .88 & .92 & & & & \\
\hline Witnessed abuse*Percent quarters worked & -1.02 & .59 & $.36^{\dagger}$ & & & & \\
\hline Physically abused*Neigh. disadvantage & .31 & .15 & $1.36^{\mathrm{a}}$ & & & & \\
\hline Sexually abused*Neigh. disadvantage & .02 & .21 & 1.02 & & & & \\
\hline Witnessed abuse*Neigh. disadvantage & .10 & .11 & 1.11 & & & & \\
\hline Antisocial personality*Percent quarters worked & -.05 & .03 & .95 & & & & \\
\hline Borderline personality*Percent quarters worked & .04 & .03 & 1.04 & & & & \\
\hline Antisocial personality*Neigh. disadvantage & -.01 & .01 & .99 & & & & \\
\hline Borderline personality*Neigh. disadvantage & .00 & .01 & .99 & & & & \\
\hline Percent quarters worked*Neigh. disadvantage & -.33 & .15 & $.72^{\mathrm{a}}$ & & & & \\
\hline
\end{tabular}

${ }^{1}$ Reference category $=$ Caucasian; ${ }^{2}$ Reference category $=$ Most education need $;{ }^{3}$ Reference category $=$ Married; ${ }^{\dagger} p<.10 ;{ }^{\mathrm{a}} p<.05 ;{ }^{\mathrm{b}} p<.01 ;{ }^{\mathrm{c}} p<.001$ 
predictors and interaction terms reflect the unique contribution each makes to the prediction of survival time to severe post-prison domestic violence.

The same predictors that were significant in the first step of the model (i.e., ethnicity, education need, type of crime, substance abuse treatment attendance, and witnessing interparental violence) were also significant at the $p<.05$ level in the second step of the model. The nonsignificant trend for age in the first step remained a trend in the second step $\left(\beta=-.02, p<.10 ; \operatorname{Exp}[\mathrm{B}]_{\mathrm{Age}}=.98\right)$. The nonsignificant trend for no education need became significant at step two $(\beta=-.77, p<.05)$. Model coefficients in step two indicated that the odds of perpetrating severe post-prison domestic violence were significantly lower for offenders with no education need compared to offenders with the most education need $\left(\operatorname{Exp}[\mathrm{B}]_{\text {No education need }}=.47\right)$. An additional nonsignificant trend emerged in the second step of the model and suggested that offenders with moderate education need tended to be less likely than offenders with the most education need to engage in severe post-prison domestic violence when all other predictors were controlled $\left(\beta=-.57, p<.10 ; \operatorname{Exp}[\mathrm{B}]_{\text {Moderate education need }}=.57\right)$.

Three interactions that were entered into the second step of the Cox regression survival analysis predicting severe post-prison domestic violence were statistically significant at the $p<.05$ level. Regression coefficients indicated that the interaction between physical abuse during childhood and percentage of quarters worked significantly predicted severe post-prison domestic violence $(\beta=1.51, p<.05)$. Figure 14 shows that the relationship between the percentage of quarters worked and severe post-prison domestic violence was more pronounced for offenders who experienced 


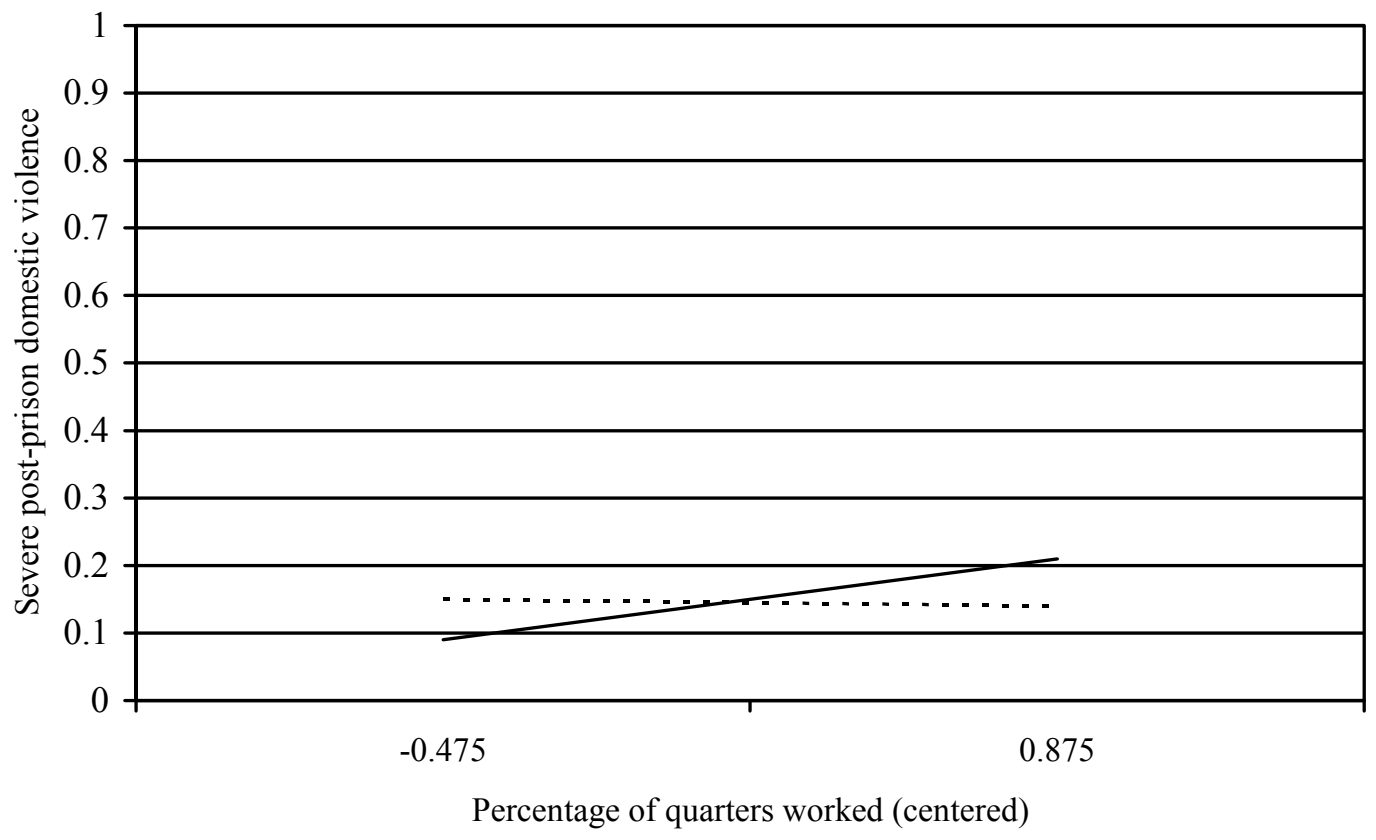

Physically abused - . . - Not physically abused

Figure 14. Interaction between physical abuse during childhood and percentage of quarters worked on severe post-prison domestic violence. 
physical abuse during childhood relative to offenders who did not experience physical abuse. For offenders who experienced physical abuse, a higher percentage of quarters worked was positively related to engaging in severe post-prison domestic violence. Percentage of quarters worked was more consistently related to severe post-prison domestic violence for offenders who were not physically abused during childhood.

The interaction between physical abuse during childhood and neighborhood disadvantage also significantly predicted severe post-prison domestic violence $(\beta=.31$, $\mathrm{p}<.05)$. Figure 15 illustrates that for offenders who were physically abused as children, higher neighborhood disadvantage was more strongly related to perpetrating severe post-prison domestic violence. Neighborhood disadvantage also interacted with percentage of quarters worked to significantly predict severe post-prison domestic violence $(\beta=-.33, p<.05)$. Figure 16 shows that the relationship between percentage of quarters worked and severe post-prison domestic violence was stronger for offenders living in less disadvantaged neighborhoods. For offenders living in less disadvantaged neighborhoods, a higher percentage of quarters worked was positively associated with perpetrating severe post-prison domestic violence. The relationship between percentage of quarters worked and severe post-prison domestic violence was more consistent for offenders living in more disadvantaged neighborhoods.

Nonsignificant trends indicated that two additional interactions were associated with severe post-prison domestic violence in the second step of the model. Physical abuse during childhood interacted with borderline personality characteristics to predict severe post-prison domestic violence $(\beta=-.04, p<.10)$. Figure 17 shows that the 
interaction was not in the direction that was hypothesized. Offenders who were physically abused and had higher scores on the measure of borderline personality characteristics were less likely to engage in severe post-prison domestic violence.

Figure 18 shows that for offenders who did not witness interparental violence, a higher percentage of quarters worked was positively related to engaging in severe post-prison domestic violence. 


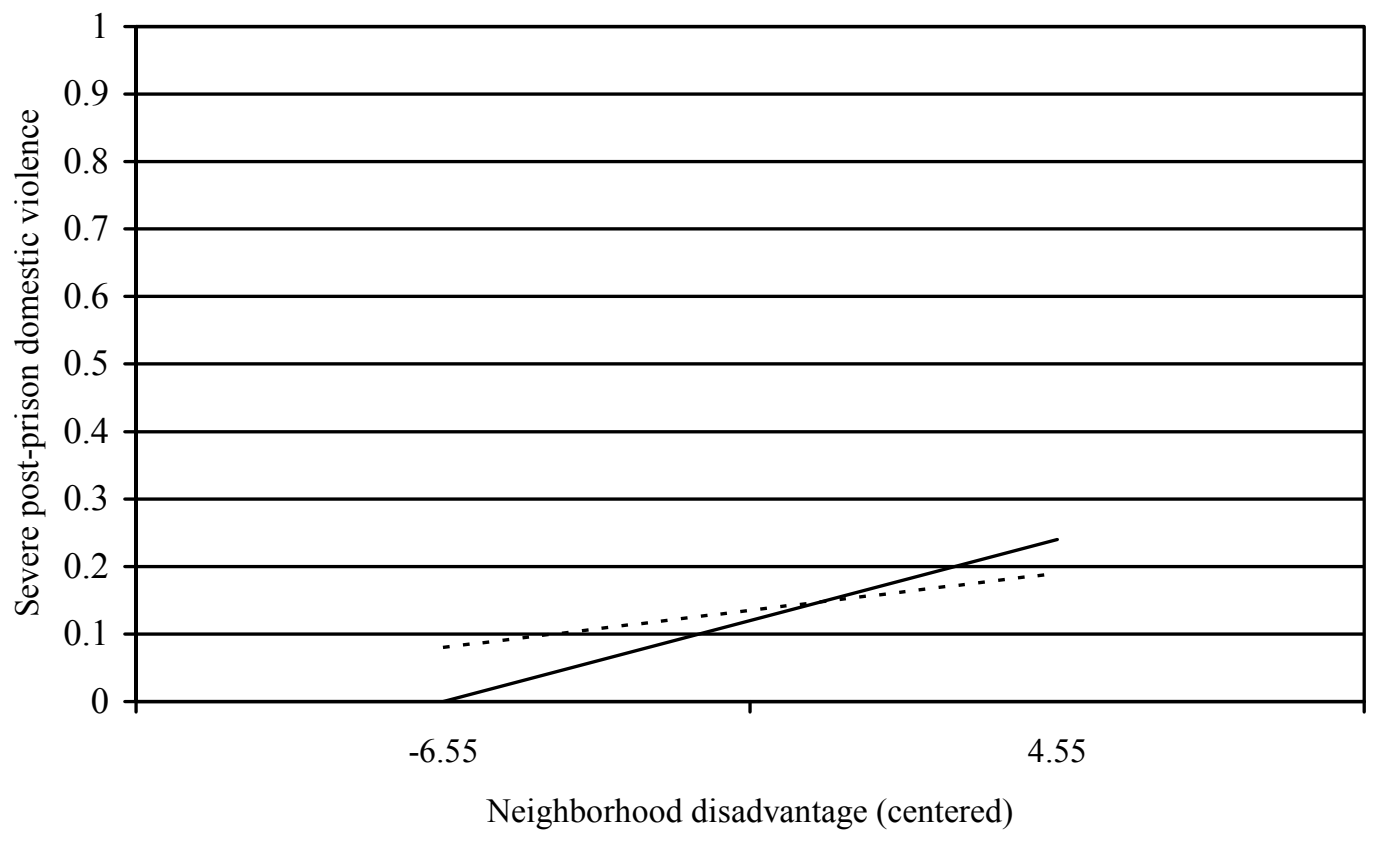

Physically abused - . . Not physically abused

Figure 15. Interaction between physical abuse during childhood and neighborhood disadvantage on severe post-prison domestic violence. 


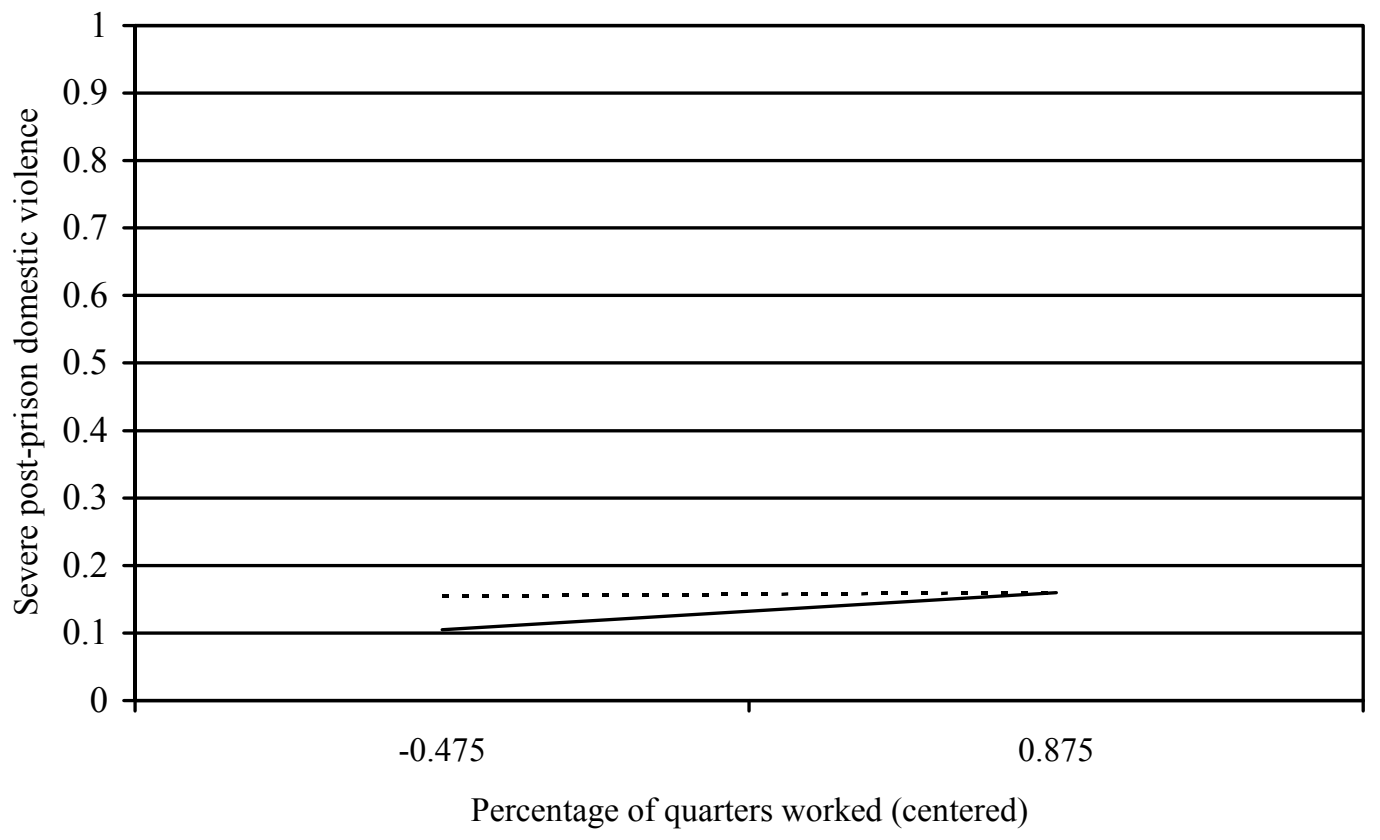

Low neighborhood disadvantage - - . - High neighborhood disadvantage

Figure 16. Interaction between neighborhood disadvantage and percentage of quarters worked on severe post-prison domestic violence. 


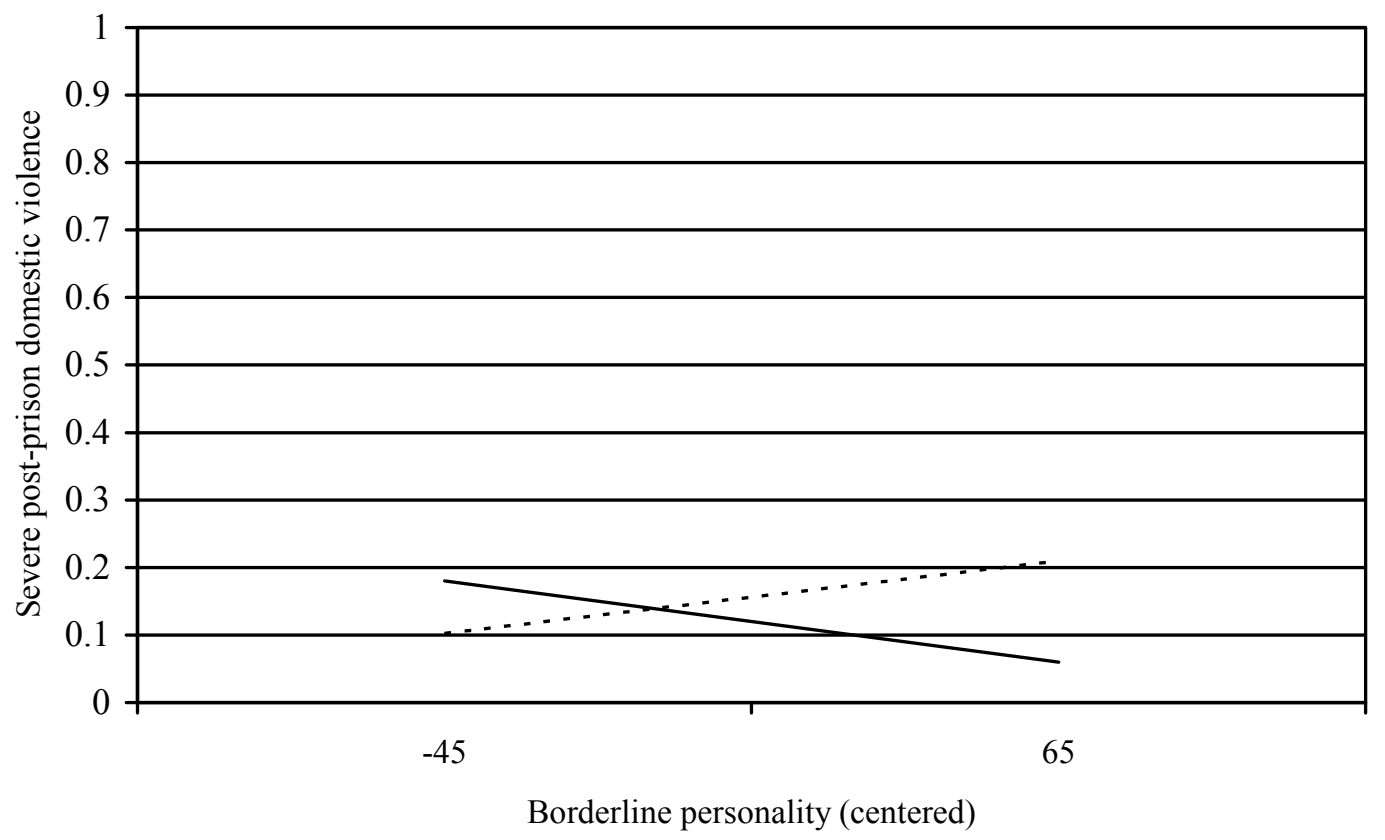

Physically abused

- . - . Not physically abused

Figure 17. Interaction between physical abuse during childhood and borderline personality on severe post-prison domestic violence. 


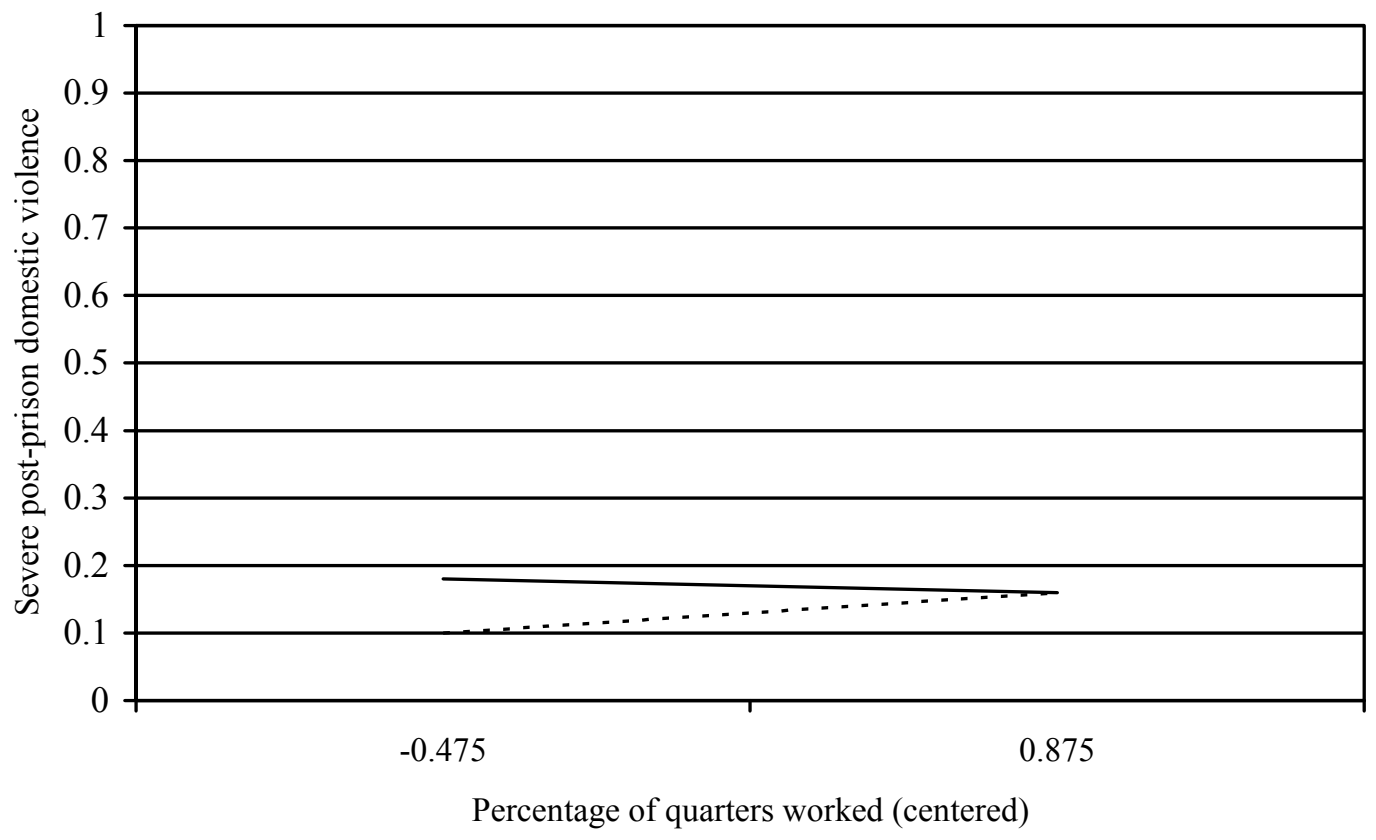

Witnessed interparental violence - . - . Did not witness interparental violence

Figure 18. Interaction between witnessing interparental violence and percentage of quarters worked on severe post-prison domestic violence. 


\section{Chapter 8: Discussion, Contributions, and Limitations}

The primary purpose of this dissertation was to examine the prevalence of domestic violence perpetrated by formerly incarcerated offenders during their transition from prison back to the community. I addressed this objective by exploring both the proportion of sampled offenders who engaged in post-prison domestic violence and the timing of these events during their transition from prison back to the community. A second goal of this dissertation was to test the independent and interactive effects of selected individual, situational, and social-structural predictors on post-prison domestic violence. Predictors were chosen from a blended ecological model of intimate partner violence and criminal risk that I proposed. The model included known predictors of both domestic violence and general criminal behavior that may also be related to the perpetration of domestic violence after prison release.

This chapter provides a more detailed discussion of the study's findings, organized by research question. Alternative interpretations of findings are discussed along with each result. Limitations of the study and contributions to the theoretical and empirical literature on intimate partner violence and social policy are also discussed along with each result.

\section{Research Question One}

My first research question addressed the primary goal of this dissertation, which was to examine the prevalence of domestic violence perpetrated by formerly incarcerated offenders during their transition from prison back to the community. This represents one of only a few analyses of intimate partner violence perpetrated by 
formerly incarcerated offenders. Previous studies of the occurrence of post-prison domestic violence have either provided only qualitative descriptions of the phenomenon (e.g., Hairston \& Oliver, 2006; Oliver \& Hairston, 2008; Oliver et al., 2004) or focused specifically on individuals who were previously identified as domestic violence offenders before their incarceration (e.g., Hilton et al., 2010). The current study is therefore the first known estimate of the prevalence of intimate partner violence perpetrated by former inmates who were not necessarily known to have engaged in previous domestic violence. Understanding the prevalence of intimate partner violence perpetrated by all types of formerly incarcerated offenders may help correctional staff determine whether soon-to-be released inmates would benefit from programming to prevent intimate partner violence during the transition from prison to the community.

To review, post-prison domestic violence was represented in the current study by two different variables: any post-prison domestic violence incident and severe postprison domestic violence. Any post-prison domestic violence incident was defined as any occurrence wherein the offender was either a suspect or taken into custody for their role in a disturbance that involved a domestic relationship (e.g., domestic problems, family disturbance, and offense versus the family). Severe post-prison domestic violence was defined as an event wherein the offender was either a suspect or taken into custody for engaging in criminal action (e.g., assault, violation of a court order, threats, or robbery) against an intimate partner. In previous studies, domestic violence has typically been assessed using either perpetrator self-reports, victim reports, and/or official criminal justice system records such as arrests. Each measure carries its own set 
of limitations. For example, perpetrators may underreport domestic violence in order to avoid criminal sanctions or other serious consequences. Victims may also underreport domestic violence out of fear of retaliation from their abuser (Tjaden \& Thoennes, 2000). Arrests represent an extremely conservative estimate of domestic violence as many incidents either go unreported or are technically not illegal (e.g., psychological abuse such as isolation, dominance, and control). The measure of domestic violence used in the current study is therefore particularly novel, in that it represents instances of domestic violence that were not necessarily self-reported by perpetrators or victims and did not always result in arrest.

The data show that 280 offenders or $25 \%$ of the sample engaged in any postprison domestic violence incident during the time that elapsed between their prison release date and the end of the study follow-up period. One-hundred-sixty-one of these offenders or $14 \%$ of the entire sample engaged in severe post-prison domestic violence after prison release and before the end of the study follow-up period. Sampled offenders had a $10 \%$ chance of engaging in any post-prison domestic violence incident by their second year in the community. The chance of engaging in severe post-prison domestic violence was $25 \%$ after offenders were in the community for approximately four years.

Timing of post-prison domestic violence. The use of survival analysis to address my first research question allowed me to explore both the proportion of offenders who engaged in post-prison domestic violence and the timing of post-prison domestic violence events. One of the more interesting findings relevant to the first research question is that survival times to both any post-prison domestic violence 
incident and severe post-prison domestic violence were somewhat lengthy relative to the duration of the follow-up period. There were a few offenders in the current sample who engaged in domestic violence within days of their release from prison; however on average, offenders who engaged in any post-prison domestic violence incident and/or severe post-prison domestic violence did not do so until more than two years after they were released from prison. In addition, hazard ratios associated with the months after prison release indicated that there was no particularly risky month during the transition from prison back to the community wherein the rate of sampled offenders' perpetration of post-prison domestic violence spiked significantly. In other words, there was no particular time wherein sampled offenders were more likely to perpetrate post-prison domestic violence relative to any of the other months during the study follow-up period.

These findings are particularly noteworthy given that they contradict prior evidence suggesting that domestic violence offenders recidivate rather quickly after experiencing criminal justice sanctions (e.g., arrest, probation, and brief incarceration; Dunford, Huizinga, \& Elliott, 1990; Klein \& Crowe, 2008; Sherman et al., 1992). For example, in their study of the effects of arrest and short-term incarceration on domestic violence recidivism, Sherman and colleagues (1992) found an average survival time of only four months before offenders perpetrated further abuse. In a similar study, Dunford et al. (1990) found that approximately 20 percent of their sample of domestic violence offenders recidivated within six months of being arrested and spending a brief time in custody. More recently, Klein and Crowe (2008) found that over half of the offenders in their study were arrested for a new domestic violence offense within six months of 
beginning a probation sentence for partner abuse. In other words, prior research on survival time to domestic violence has demonstrated considerably faster rates of recidivism compared to what I found in my analyses.

This contrast may provide important information about the impact of long-term incarceration on intimate partnerships and domestic violence. To illustrate, prior evidence and theory indicate that the arrest and brief incarceration of domestic violence offenders often exacerbates feelings of anger, resentment, and hostility directed toward intimate partners; thus potentially increasing the likelihood that the offender will retaliate as soon as he returns home (Sherman et al., 1990). Conversely, my findings may suggest that long-term incarceration either allows the offender to 'cool down' or contributes to the demise of the relationship all together; thus diminishing the likelihood of immediate recidivism after prison release. Further research is necessary to explore this interesting possibility.

These findings also add new information to environmental transition theory (e.g.,. Felner et al., 1981, 1982, 1985) regarding the timing of maladaptive adjustment after transitioning to a new environment. Specifically, Felner and colleagues (1982) assert that challenges associated with transitioning from one environment to another can lead some individuals to adjust to the new environment in maladaptive ways. These scholars, however, do not specify a particular period of time during the transition period when maladaptive adjustment typically occurs. The results of this study suggest that domestic violence may take years to manifest as a form of maladaptive adjustment to the transition from prison to the community. Alternatively, these findings may suggest 
that it could be years before an offenders' perpetration of post-prison domestic violence is reported to law enforcement.

It is worth emphasizing the finding that the rate of post-prison domestic violence perpetrated by sampled offenders is virtually the same throughout the entire follow-up period after prison release. More specifically, the rate of post-prison domestic violence appears to be the same across time regardless of how long an offender has been in the community. The risk of perpetrating post-prison domestic violence one year after prison release is the same as it is at four and five years after prison release. One possible explanation for this finding is that some offenders were more skilled at concealing domestic violence for longer periods of time and were therefore not detected by law enforcement until many years after their abusive behavior began (hypothetically upon their release from prison). Another possible explanation is that post-prison domestic violence may not be a function of the more immediate transition period between prison and the community for all offenders. For offenders whose survival time to post-prison domestic violence spans over many years, intimate partner violence may be influenced less by the challenges and stress associated with the transition between environments and more by other factors present in the dynamic context of long-term reentry (e.g., Visher \& Travis, 2003). A future prospective study could explore this possibility by closely tracking changes and challenges in offenders' lives over many years after prison release with the goal of identifying the immediate circumstances that lead up to perpetrating post-prison domestic violence. It is possible that various stressors associated with the transition from prison to the community contribute to some 
offenders' perpetration of post-prison domestic violence; however, for others it is possible that events that happen many years after the immediate transition period play a larger role in the perpetration of post-prison domestic violence.

Results indicating that the rate of post-prison domestic violence perpetrated by sampled offenders is virtually the same throughout the entire follow-up period after prison release also has important implications for policies regarding post-prison supervision sentencing. Half of sampled offenders who engaged in post-prison domestic violence did so after having been in the community for less than two years, and another quarter engaged in post-prison domestic violence three years or more after prison release. Currently, the average term of post-prison supervision in Oregon is approximately three years (J. P. Stromberg, personal communication, November, 2010). Since data indicate that many sampled offenders were either a suspect or taken into custody by police for domestic violence during the time they were on post-prison supervision, it could suggest the need for enhanced monitoring by community corrections officers of offenders' intimate relationships. Post-prison supervision sentences often involve enhanced monitoring of offenders' drug and alcohol use and other key issues that contribute to their criminality, and these data suggest that some post-prison supervision sentences should also involve enhanced monitoring of family relationships and intimate partner safety. Just as community corrections officers are required to test offenders for drug and alcohol use, officers could be required to interview offenders and their intimate partners about the offender's behavior in the home. If community corrections officers discovered that a given offender exhibited a 
number of key risk factors or was already engaging in domestic violence, he or she could direct the offender to attend a community-based domestic violence intervention program and offer appropriate services to the offender's intimate partner.

The variations in the length of sampled offenders' survival time to post-prison domestic violence support recent theory suggesting that individual pathways of inmate reentry are more varied than they are similar (i.e., Laub \& Sampson, 2003; Visher \& Travis, 2003). Some scholars recognize that the transition from prison to the community is a process that is best viewed within a longitudinal framework (Laub \& Sampson, 2003). Laub and Sampson argue that the process of inmate reintegration involves multiple challenges and changes that occur over time including replacing delinquent peers with prosocial peers and acquiring gainful employment instead of engaging in illegal activity for pay (e.g., selling drugs). Certainly findings from the current study support the notion that the theoretical transition period from prison to the community is a lengthy, dynamic process. Offenders may flounder for some time after being released from prison and it could take years to establish and maintain a stable, crime-free lifestyle. Post-prison domestic violence could therefore be a symptom of long-term instability experienced by former inmates as they reintegrate back into the community.

Alternatively, it is possible that the time to post-prison domestic violence was drawn out because most offenders did not have the opportunity (i.e., an intimate partner) for many years after they were released from prison. Data regarding sampled offenders' intimate relationships throughout the study follow-up period were not available, therefore there is no way of knowing whether variations in post-prison 
domestic violence were influenced by the presence or absence of intimate partners in sampled offenders' lives. Furthermore, some special conditions of post-prison supervision actually limit certain offenders' freedom to engage in romantic relationships. Formerly incarcerated offenders with known histories of domestic violence and child abuse are often restricted in terms of their ability to freely participate in intimate relationships (DOC, 2007). Because of these reasons, it is possible that the time that elapsed between some offenders' prison release and their perpetration of postprison domestic violence reflected a period when they were not involved with an intimate partner and therefore may not have had as great an opportunity to engage in partner abuse.

Finally, it could be that the current measure of post-prison domestic violence misrepresents sampled offenders' violent and abusive behaviors. To clarify, the measure of post-prison domestic violence used in the current study represents data collected from law enforcement records of officer responses to domestic violence calls in the community. Therefore, the current measure of post-prison domestic violence only represents incidents that were reported to law enforcement. Prior literature indicates that most cases of domestic violence are not reported, and that reported cases reflect a very small proportion of the true prevalence of intimate partner abuse (Gracia, 2004; Kaufman-Kantor \& Straus, 1990). Moreover, domestic violence that is reported to law enforcement likely represents only the most severe incidents (Gracia, 2004; KaufmanKantor \& Straus, 1990). To illustrate, in their review of national survey data KaufmanKantor and Straus (1990) estimated that less than 10 percent of all partner assaults are 
reported to law enforcement. In addition, the authors found that victims were significantly less likely to report instances of minor violence to law enforcement compared to incidents involving severe violence (Kaufman-Kantor \& Straus, 1990). Gracia (2004) refers to the small proportion of reported domestic violence incidents as the "tip of the iceberg" (p. 536), alleging that the vast majority of intimate partner violence remains hidden within the family.

Intimate partner violence is often unreported for a variety of reasons. Some theorists argue that victims may choose not to report domestic violence because of social norms that dictate a higher level of tolerance for mistreatment among family members (see Kaufman-Kantor \& Straus, 1990 for a review). Such theory states that individuals tolerate certain types of victimization at the hands of other family members in order to preserve the family and the family's privacy (Kaufman-Kantor \& Straus, 1990). Other literature suggests domestic violence victims may not report abuse because they are embarrassed, they fear retaliation, or because they are financially dependent on their abuser and cannot risk him being sent to jail and losing his job (Gracia, 2004). Similarly, partners of sampled offenders in the current study may have been reluctant to report ongoing abuse because they feared the offender would have his post-prison supervision revoked and he would be sent back to prison.

These arguments, considered together with evidence that reported cases of domestic violence represent only the most severe instances of abuse (e.g., KaufmanKantor \& Straus, 1990), suggest that the measure of domestic violence used in the current study likely limited in that it underestimates the actual prevalence of post-prison 
domestic violence perpetrated by sampled offenders. Future studies of domestic violence perpetrated by formerly incarcerated offenders should supplement law enforcement reports with offender and victim reports of physical, sexual, and psychological violence. Information regarding perpetration of intimate partner violence from all three sources is likely to provide a more accurate estimate of the prevalence of post-prison domestic violence.

\section{Research Question Two}

Research question two examined the main effects and interactions of selected individual, situational, and social-structural predictors on domestic violence perpetrated by formerly incarcerated offenders after their release from prison. All tested main effects and interactions were selected from a blended ecological model of intimate partner violence and criminal risk during the transition from prison to the community that I proposed. This is the first known analysis of the transition from prison to the community from the theoretical perspective of Bronfenbrenner's ecological approach (Bronfenbrenner, 1994; Bronfenbrenner \& Morris, 1998). The context of former inmates' transition back into society has never before been examined through the lens of an ecological model despite the inherent applicability of a multi-level analysis. Academic discourse regarding criminal risk factors asserts that offenders have multiple needs and areas of risk which, from an ecological perspective, exist on more than one level of behavioral analysis. For example, criminogenic needs identified by Andrews and Bonta (2010) represent factors that exist at the individual level (i.e., antisocial personality pattern and positive attitudes toward crime) and situational level (i.e., 
delinquent associates and family/marital circumstances). Other criminologists identify criminal risk factors at the social-structural level (e.g., neighborhoods; Lynam et al., 2000; Rose \& Clear, 1998) and the sociocultural level (e.g., lower social class origins; Braithewaite, 1981). Additional factors that are more specific to the transition from prison to the community can also be placed within the layers of an ecological framework, including the relationship between the offender and his community supervision officer (i.e., situational level) and the stigma directed toward ex-convicts from the cultural level (i.e., sociocultural level). Clearly, individual and environmental factors that shape former inmates' transition from prison to the community and influence the risk of recidivism exist at multiple levels. The ecological approach offers a theoretical framework in which these factors can be organized and tested. The analyses for my second research question represent a first attempt to do so.

In addition, the current study augments extant literature concerning ecological models of intimate partner violence and tests this theoretical framework within a sample of formerly incarcerated offenders. The ecological perspective has guided many researchers in the analysis of intimate partner violence risk factors (e.g., Carlson, 1984; Heise, 1998); however, no known ecological analyses of intimate partner violence have been tested with formerly incarcerated men. The importance of ensuring that social science research and theory are tested across multiple, heterogeneous samples is outlined elsewhere (i.e., Sears, 1986); and the current research enhances existing knowledge of ecological models of intimate partner violence within diverse populations. 
Results of the analyses for research question two indicate that a small number of hypothesized main effects were fully supported by the data and several were partially supported. About half of hypothesized relationships were not supported by the data. A summary of findings as they relate to the hypothesized main effects of selected predictors on post-prison domestic violence is presented in Table 19. The following discussion of these findings is organized by analysis level within my ecological model. Individual level main effects. Main effects on post-prison domestic violence were examined for each of the factors chosen to represent the individual level of my ecological model. I anticipated that offenders' exposure to family-of-origin violence, antisocial personality characteristics, and borderline personality characteristics would be positively related to their perpetration of post-prison domestic violence. Results indicated that exposure to family-of-origin violence was significantly related to postprison domestic violence such that offenders who reported witnessing interparental violence during childhood were significantly more likely to engage in both any postprison domestic violence incident and severe post-prison domestic violence. Data did not support the predicted relationships between physical and/or sexual victimization during childhood and either type of post-prison domestic violence. Hypotheses regarding the positive main effects of antisocial and borderline personality characteristics on post-prison domestic violence were not supported by the data.

Family-of-origin violence. The prediction that exposure to family-of-origin violence would be related to perpetrating post-prison domestic violence was partially supported. Findings indicated that exposure to family-of-origin violence predicted post- 
Table 19.

Summary of main effects.

\begin{tabular}{|c|c|c|c|c|}
\hline Level & \multirow{2}{*}{$\begin{array}{l}\text { Variable } \\
\text { Age at release }\end{array}$} & \multirow{2}{*}{$\begin{array}{l}\text { Hypothesized main effect } \\
\text { Older offenders would be less likely to perpetrate } \\
\text { domestic violence. }\end{array}$} & \multirow{2}{*}{$\frac{\text { Result }}{\text { Supported }}$} & \multirow{2}{*}{$\begin{array}{l}\text { Description } \\
\text { Younger age predicted both any domestic violence } \\
\text { incident and severe domestic violence. }\end{array}$} \\
\hline \multirow[t]{10}{*}{ Individual } & & & & \\
\hline & Ethnicity & $\begin{array}{l}\text { Ethnic minority offenders would be more likely to } \\
\text { perpetrate domestic violence. }\end{array}$ & $\begin{array}{l}\text { Partially } \\
\text { supported }\end{array}$ & $\begin{array}{l}\text { African Americans were more likely to engage in any } \\
\text { domestic violence incident and severe domestic } \\
\text { violence. }\end{array}$ \\
\hline & Education need & $\begin{array}{l}\text { Offenders with more education need would be more } \\
\text { likely to perpetrate domestic violence. }\end{array}$ & Supported & $\begin{array}{l}\text { Offenders with more need for education were more } \\
\text { likely to engage in any domestic violence incident } \\
\text { and severe domestic violence. }\end{array}$ \\
\hline & Marital status & $\begin{array}{l}\text { Married offenders would be less likely to perpetrate } \\
\text { domestic violence. }\end{array}$ & $\begin{array}{l}\text { Not } \\
\text { supported }\end{array}$ & \\
\hline & $\begin{array}{l}\text { Number of } \\
\text { children }\end{array}$ & $\begin{array}{l}\text { Offenders with more children would be more likely } \\
\text { to engage in domestic violence. }\end{array}$ & Supported & $\begin{array}{l}\text { Offenders with more children were more likely to } \\
\text { engage in any domestic violence incident. }\end{array}$ \\
\hline & Type of crime & $\begin{array}{l}\text { Offenders incarcerated for a violent crime would be } \\
\text { more likely to perpetrate domestic violence. }\end{array}$ & Supported & $\begin{array}{l}\text { Incarceration for a violent crime was related to } \\
\text { perpetrating severe domestic violence. }\end{array}$ \\
\hline & $\begin{array}{l}\text { Length of } \\
\text { incarceration }\end{array}$ & $\begin{array}{l}\text { Length of incarceration would be positively related to } \\
\text { perpetrating domestic violence. }\end{array}$ & $\begin{array}{l}\text { Not } \\
\text { supported }\end{array}$ & \\
\hline & $\begin{array}{l}\text { Correctional } \\
\text { programs }\end{array}$ & $\begin{array}{l}\text { Offenders who participated in correctional programs } \\
\text { would be less likely to perpetrate domestic violence. }\end{array}$ & $\begin{array}{l}\text { Partially } \\
\text { supported }\end{array}$ & $\begin{array}{l}\text { Offenders who participated in substance abuse } \\
\text { treatment were less likely to engage in any domestic } \\
\text { violence incident and severe domestic violence. }\end{array}$ \\
\hline & $\begin{array}{l}\text { Family-of- } \\
\text { origin violence }\end{array}$ & $\begin{array}{l}\text { Exposure to family-of-origin violence would be } \\
\text { related to perpetrating domestic violence. }\end{array}$ & $\begin{array}{l}\text { Partially } \\
\text { supported }\end{array}$ & $\begin{array}{l}\text { Offenders who witnessed interparental violence during } \\
\text { childhood were more likely to engage in any domestic } \\
\text { violence incident and severe domestic violence. }\end{array}$ \\
\hline & $\begin{array}{l}\text { Personality } \\
\text { characteristics }\end{array}$ & $\begin{array}{l}\text { Antisocial and borderline personality characteristics } \\
\text { would be related to perpetrating domestic violence. }\end{array}$ & $\begin{array}{l}\text { Not } \\
\text { supported }\end{array}$ & \\
\hline Situational & Employment & $\begin{array}{l}\text { Employed offenders would be less likely to } \\
\text { perpetrate domestic violence. }\end{array}$ & $\begin{array}{l}\text { Not } \\
\text { supported }\end{array}$ & \\
\hline $\begin{array}{l}\text { Social- } \\
\text { structural }\end{array}$ & $\begin{array}{l}\text { Neighborhood } \\
\text { disadvantage }\end{array}$ & $\begin{array}{l}\text { Residing in disadvantaged neighborhoods would be } \\
\text { related to domestic violence. }\end{array}$ & Supported & $\begin{array}{l}\text { Offenders who resided in more disadvantaged } \\
\text { neighborhoods were more likely to engage in any } \\
\text { domestic violence incident. }\end{array}$ \\
\hline
\end{tabular}


prison domestic violence such that the odds of engaging in any post-prison domestic violence incident were nearly one and a half times greater for offenders who witnessed interparental violence relative to those who did not witness interparental violence during childhood. The odds of perpetrating severe post-prison domestic violence were almost two times greater for offenders who witnessed interparental violence during childhood. Contrary to what was predicted, experiencing family-of-origin violence in the form of physical and/or sexual victimization was not related to perpetrating postprison domestic violence.

The significant relationship between witnessing interparental violence and perpetrating domestic violence found in the current study is in line with previous literature (Carlson, 1984; Delsol \& Margolin, 2004; Dutton \& Hart, 1992; Heise, 1998; Malamuth et al., 1991; Stith et al., 2000). Past studies have found significant moderate associations between witnessing interparental violence and perpetrating domestic violence as an adult, and the current study is no exception. The finding that witnessing interparental violence had a stronger effect on post-prison domestic violence than offenders' own physical and sexual victimization is also in line with previous research (Delsol \& Margolin, 2004; Stith et al., 2000). In their meta-analysis of the intergenerational transmission of domestic violence, Stith and colleagues (2000) found that the strength of the relationship between witnessing interparental violence and perpetrating domestic violence was stronger than the relationship between one's own physical victimization and perpetrating domestic violence. Among males, Stith et al. (2000) found a moderate overall effect size for the relationship between witnessing interparental violence during childhood and perpetrating domestic violence as a adult ( $r$ 
$=.21$ ) and a slightly smaller effect size for the relationship between childhood victimization and perpetrating domestic violence as an adult $(r=.19)$. The difference in effect size for each relationship within clinical samples was larger $(r=.35$ for witnessing interparental violence and $r=.27$ for experiencing victimization; Stith et al., 2000).

Among sampled offenders in the current study who witnessed interparental violence during childhood, the slightly greater likelihood of engaging in severe postprison domestic violence versus any post-prison domestic violence incident is particularly interesting. Recall that sampled offenders' exposure to interparental violence was assessed via a single question: "when you were growing up, did you ever see the people who raised you hit or strike one another?" This question asks specifically about offenders' witnessing of assault which qualifies as severe domestic violence according to the definition used in the current study. Therefore, offenders who reported witnessing their parents engage in severe domestic violence were more likely to engage in severe domestic violence themselves. This finding provides support for a social learning theory explanation of the intergenerational transmission of domestic violence (e.g., Bandura, 1974, 1977). Social learning theory asserts that children create schemas of family relationships by observing their parents' behaviors and the consequences of those behaviors. Children are likely to imitate behaviors that are positively rewarded and initiated by the parent with whom they identify strongly. Following this line of reasoning, it is possible that sampled offenders who perpetrated severe post-prison domestic violence witnessed a male caregiver (i.e., the parent with whom they likely identified) engage in severe domestic violence (e.g., assault) against a female caregiver 
without negative consequences. As a result, these offenders may have learned to accept severe domestic violence as part of their schema of family relationships and therefore became more likely to imitate those behaviors with their own intimate partners.

The current study represents only the second known examination of the relationship between exposure to family-of-origin violence and perpetration of domestic violence within an incarcerated or formerly incarcerated sample. Results of the other known study indicated that male offenders who were incarcerated for domestic violence offenses were significantly more likely to report physical abuse, sexual abuse, and witnessing interparental abuse during childhood compared to offenders incarcerated for non-domestic violence offenses (Dutton \& Hart, 1992). Specifically, 55 percent of domestic violence offenders reported physical abuse, sexual abuse, and/or witnessing interparental abuse during childhood compared to only 39 percent of offenders incarcerated for other violent offenses and 20 percent of offenders incarcerated for nonviolent offenses (Dutton \& Hart, 1992). The similarity between findings from the current study of formerly incarcerated offenders and Dutton and Hart's (1992) study of currently incarcerated offenders suggests a need for further research focused on the predictors of domestic violence within these types of samples.

Personality characteristics. The prediction that formerly incarcerated offenders' antisocial and borderline personality characteristics would be positively related to their perpetration of post-prison domestic violence was not supported by the data. This finding was surprising given the extent to which prior literature confirms the relationship between these specific personality characteristics and intimate partner 
violence $^{1}$ (Dutton, 1994, 1995, 1998; Dutton \& Hart, 1992; Ehrensaft, Cohen, Brown, Smailes, Chen, \& Johnson, 2003; Edwards et al., 2003; Hamberger \& Hastings, 1986; Holtzworth-Munroe \& Stuart, 1994; White et al., 2002).

One possible reason for the lack of relationship between post-prison domestic violence and antisocial and borderline personality characteristics is that scores on the personality assessment used in the current study may not accurately reflect offenders' personality characteristics at the time they engaged in post-prison domestic violence. Measures of antisocial and borderline personality characteristics used in the current study were derived from personality assessment measures that were administered to sampled offenders during the Intake process - within the first 30 days of their incarceration. In other words, the length of time between the point at which offenders completed their personality assessment and the point at which they perpetrated domestic violence could have been quite long. To illustrate, offenders in the current study were incarcerated for an average of two years; and the average survival time to a post-prison domestic violence event was another two years. A given offender could have had a

\footnotetext{
${ }^{1}$ Because my findings contradicted decades of research on the association between borderline and antisocial personality characteristics and domestic violence perpetration, I was motivated to re-examine sampled offenders' PAI data within the context of the four validity scales that are built into the measurement tool. The PAI validity scales include Inconsistency (INC), which detects inconsistent response patterns; Infrequency (INF), which identifies random or careless responding; Positive Impression Management (PIM), which senses whether a respondent is reluctant to admit minor flaws; and Negative Impression Management (NIM), which detects malingering (i.e., "faking bad"). Scores above a certain threshold on any validity scale are indicators of "probable distortion" or "marked distortion" depending on the threshold that is reached. Upon reexamining the PAI profiles of the offenders in my sample I found that over 50 percent met criteria for "probable distortion" and about 16 percent met criteria for "marked distortion" on one or more of the four validity subscales. Consistent with Edens' (2009) research examining the validity of PAI profiles within criminal offender samples, I used the "marked distortion" threshold as an indicator of an invalid PAI within my sample. I then performed my statistical models again using the subset of sampled offenders who did not meet criteria for marked distortion on one or more validity scales $(n=959)$ and compared them to the models I estimated using the full sample $(\mathrm{n}=1137)$. The models were virtually identical, therefore my interpretation of findings is not affected by sampled offenders' scores on the validity subscales of the PAI.
} 
variety of experiences in the years since their personality assessment that may have decreased the influence of certain personality characteristics on their risk of perpetrating of post-prison domestic violence. Future studies should attempt to minimize the time that lapses between offenders' personality assessments and measurement of the study outcome.

Future studies that examine the relationship between personality characteristics and post-prison domestic violence should also account for any kind of treatment in which an offender participated after his personality assessment in order to more effectively isolate the influence of personality characteristics on intimate partner violence. For example, over half of the offenders in the current sample engaged in cognitive-behavioral treatment programs during their incarceration wherein they may have learned better coping skills and how to regulate their emotions. In addition, some offenders may have been prescribed medication while incarcerated which helped them regulate behaviors associated with borderline and/or antisocial personality characteristics (e.g., violence). It is possible that offenders' participation in treatment programs and/or taking of medication explains why the current study failed to find a relationship between antisocial/borderline personality characteristics and post-prison domestic violence.

Another possible reason why there was no significant relationship between antisocial/borderline personality characteristics and post-prison domestic violence is that the personality measure used in the current study may not have been sufficiently sensitive. To review, borderline and antisocial personality characteristics were measured with the Personality Assessment Inventory (PAI; Morey, 1991, 2007). Use of 
the PAI is rare in domestic violence research, which has relied almost exclusively on personality measures like the MMPI (Hathaway \& McKinley, 1943) and MCMI (Millon, 1983) despite criticism that both tools may be overly sensitive to the presence and diagnosis of pathology (Groth-Marnat, 1997). The decision to use the PAI instead of the MMPI or MCMI in the current study was based in part on Chambers and Wilson's (2007) argument that personality measurement tools used in domestic violence research need to be sensitive to both pathological characteristics and nonpathological characteristics. However, the lack of a relationship between antisocial/borderline personality and domestic violence in the current study could suggest that the PAI is not sensitive enough to the presence of these characteristics. Future studies that examine the relationship between certain personality characteristics and post-prison domestic violence should utilize the PAI and other personality measures like the MCMI and MMPI and compare the results. This kind of study may provide evidence suggesting that one of these measures is well-suited for use in offender populations.

When interpreting findings related to the PAI in the current study, it is important to consider the possibility that sampled offenders were not completely honest when they responded to questions on the measure. The PAI (and nearly all other assessments of constructs in the current study) was given to sampled offenders in self-administered survey format and therefore represents self-reported data. Given the somewhat sensitive nature of questions asking about personal characteristics, there is a chance that offenders were not completely honest when responding to the self-administered surveys. Self-reported information regarding personal information is inherently threatened by research participants' willingness to be honest, and the threat is somewhat 
pronounced when sensitive information is gathered via self-administered surveys that are not anonymous (Gribble, Miller, Rogers, \& Turner, 1999). Unfortunately, the threat of biased responses on the PAI and other measures used in the current study are a small but inherent limitation to the interpretation of the findings.

Additional individual-level demographic variables. Main effects on post-prison domestic violence were also examined for the additional individual-level demographic variables that were considered within my model. These included offender age, ethnicity, education need, marital status at the time of arrest, number of children, type of crime, length of incarceration, and participation in correctional rehabilitation programs. Of these variables, age, ethnicity, education need, number of children, and participation in correctional rehabilitation programs were significantly related to engaging in any postprison domestic violence incident and severe post-prison domestic violence.

Age. The prediction that age would be negatively related to offenders' likelihood of perpetrating post-prison domestic violence was supported. Results indicated that the odds of engaging in any post-prison domestic violence incident and severe post-prison domestic violence decreased for each additional year of age. This finding corroborates years of research and meta-analyses showing that age consistently predicts intimate partner violence within both the general community (Hotaling \& Sugarman, 1986; Schumacher et al., 2000; Stith et al., 2003) and offender populations (Hilton et al., 2010). The magnitude of the effect of age on domestic violence found in the current study is similar to what has been found previously (e.g., Kantor, Jasinski, \& Aldarondo, 1994; Pan, Neidig, \& O’Leary, 1994). 
Very little research sufficiently addresses the occurrence of both domestic violence and criminal behavior in general over the life course - likely because this type of longitudinal research requires a tremendous amount of time and resources. As a result, theory regarding the actual mechanism(s) though which aging decreases the risk of domestic violence and criminal behavior is lacking. One exception is Laub and Sampson's (2003) study of criminal conduct over the life course of male juvenile offenders until the age of 70. In their work, Laub and Sampson (2003) focused predominantly on the internal and external circumstances offenders experienced over the life course that contributed to both persistence in a life of crime and desistance from crime. Most of their observations regarding the reasons why offenders desist from crime seem to reflect a theory of "turning points." More specifically, Laub and Sampson (2003) observed that most of the participants in their research were able to identify turning points or specific points in their lives at which they began desisting from crime. For example, offenders in their research identified such events as enlisting in the military, getting married, and finding a satisfying career (Laub \& Sampson, 2003).

What is important to notice is that each of these "turning points" are often standard functions of aging. As an individual ages, he theoretically takes on more responsibility (e.g., a spouse and children), becomes more settled and stable (e.g., through finding a job or career), and therefore has more to lose if he were to reengage in criminal activity. Aging, and the maturational progression that naturally occurs with it, could be considered a source of informal social control that often results in desistance from crime. In other words, one must consider that the relationship between aging and desistance from criminal behavior - specifically domestic violence in the case of the 
current findings - may be moderated by other life events that are highly correlated with age (e.g., stability through jobs and relationships). Additional research regarding the occurrence of domestic violence over the life course is needed to explore this line of reasoning.

Ethnicity. The prediction that ethnic minority offenders would be more likely to perpetrate post-prison domestic violence was partially supported. Results showed that African American offenders were significantly more likely than Caucasian offenders to engage in both any post-prison domestic violence incident and severe post-prison domestic violence. Relative to Caucasian offenders, African American offenders' odds of being named as a suspect or taken into custody were nearly two and a half times greater for any post-prison domestic violence incident and nearly three times greater for severe post-prison domestic violence. The odds of Asian, Native American, and Latino offenders engaging in either type of post-prison domestic violence were not significantly different from Caucasian offenders in the current study.

Although data indicated that African American offenders were significantly more likely than Caucasian offenders to perpetrate post-prison domestic, I caution the reader from interpreting this finding without considering other findings from the current study. Specifically, the current analysis only examined the main effects of ethnicity on post-prison domestic violence despite prior evidence suggesting that the effect of ethnicity on domestic violence is often mediated by other variables such as socioeconomic characteristics and alcohol use (e.g., Field \& Caetano, 2004; Straus \& Smith, 1990). Therefore, it is important that the reader consider the effects of ethnicity 
on post-prison domestic violence found in the current study within the context of the remaining significant effects discussed throughout the rest of this chapter.

The finding that African American offenders in the current study were more likely to engage in post-prison domestic violence provides support for theory regarding the purportedly increased risk of domestic violence during the transition from prison to the community among African American offenders (Hairston \& Oliver, 2006; IDVAAC, 2008; Oliver \& Hairston, 2008; Oliver et al., 2004). Given the relatively higher risk of both domestic violence and incarceration within the African American community, male African American former inmates have been identified as a particularly high risk group for perpetrating post-prison domestic violence (Hairston \& Oliver, 2006; Oliver \& Hairston, 2008). Up until this point, all previous research regarding domestic violence perpetrated by African American males after prison release has been qualitative and exploratory in nature; and no direct comparisons have been made between African American offenders and other ethnic groups in terms of postprison domestic violence. The current results which indicate that African American offenders were between two and a half to three times more likely than Caucasian offenders to engage in post-prison domestic violence represent the first known quantifiable evidence supporting the claim that African American former inmates are more likely to perpetrate post-prison domestic violence compared to other offender ethnic groups.

Scholars have proposed a number of different theoretical explanations for the higher occurrence of intimate partner violence in the African American community that could also be applied to the current findings. For example, Hampton, Oliver, and 
Magarian (2003) argue that relative to Caucasian men, African American men generally experience more frequent and severe environmental stressors which may create conditions that are conducive to intimate partner abuse (IDVAAC, 2008). Hampton and colleagues (2003) assert that the largest potential motivator of intimate partner violence perpetrated by African American men is their experience of institutional racial oppression which categorically prevents them from achieving equality with Caucasian men. Historical patterns of institutional discrimination against African American men in the US have led to significant racial inequality in employment, income, and education. These economic disparities are a source of anger and frustration that can sometimes be projected onto female partners in the form of domestic violence (Hampton et al., 2003; Majors \& Billson, 1992).

The connection between African American men's frustration in response to economic inequality and intimate partner violence is reasonable from a masculinity theory perspective. Western society endorses a limited number of avenues through which men can achieve masculinity—some of which are employment, financial independence, and providing for one's family (Harway \& O’Neil, 1999; Kilmartin, 2000; Moore \& Stuart, 2005). Men who fall short of meeting masculine gender role expectations experience stress, anger, and frustration which may lead to the expression of other, often dysfunctional behaviors that reassert masculinity, including violence and interpersonal aggression (Majors \& Billson, 1992; Messerschmidt, 1993, 2005; Moore \& Stuart, 2005). Due in part to historical patterns of institutional discrimination and oppression, African American men are essentially prevented from achieving economic equality and fulfilling masculine gender role expectations through the same channels as 
Caucasian men (Majors \& Billson, 1992). As a result, scholars such as Majors and Billson (1992) argue that African American men are more likely to view violence as "a resource that can be used to achieve desired goals and status when other routes to achievement are blocked" (p.33). Therefore it is reasonable to imagine that African American men might be more likely than Caucasian men to engage in violence against an intimate partner in order to meet masculine gender role expectations.

The extent to which economic disparities brought on by racial oppression contribute to higher rates of domestic violence among African American men relative to Caucasian men was not examined in the current study. Given the apparent intersection between incarceration and domestic violence in the African American community (e.g., Oliver \& Hairston, 2008) and the higher rate of post-prison domestic violence perpetrated by African American offenders in the current study, exploring the interactive effects of ethnicity and economic factors on post-prison domestic violence is an important avenue for future research.

Alternatively, the significant difference between African American and Caucasian offenders' likelihood of perpetrating post-prison domestic violence in the current study could be due to differential law enforcement responses based on ethnicity. To illustrate, perpetration of post-prison domestic violence by offenders in the current study was measured using law enforcement records of officer responses to domestic violence calls in the community. Offenders whose records indicated that they were either a suspect or taken into custody for a domestic violence event during the study follow-up period were considered to have perpetrated post-prison domestic violence for purposes of the study. It is possible that law enforcement officers were more likely to 
name African American offenders as suspects and/or take them into custody for domestic violence events compared to Caucasian offenders. In other words, it could be that law enforcement officers responded to a proportionally equal number of Caucasian and African American domestic violence calls, but that they were more likely to name African American offenders as suspects in their reports and/or take them into custody. This explanation is in line with previous literature suggesting that law enforcement decisions to make arrests are significantly influenced by offender ethnicity (e.g., Avakame \& Fyfe, 2001; Black \& Reiss, 1970; Smith, Visher, \& Davidson, 1984; Kochel, Wilson, \& Mastrofski, 2011). In a recent meta-analysis of 27 studies from this extensive body of research, Kochel and colleagues (2011) found that African American offenders and other ethnic minorities were between 1.3 and 1.5 times more likely than Caucasian offenders to be arrested during interactions with law enforcement. The magnitude of the effect of ethnicity on the probability of arrest remained the same even when factors such as offense severity, quantity of evidence at the scene, and criminal history of the offender were statistically controlled (Kochel et al., 2011). Such strong evidence suggests that the significant differences found between African American and Caucasian offenders in the current study could be a reflection of biases in law enforcement responses to domestic violence in the community.

Education need. The prediction that offenders with more need for education would be more likely to perpetrate post-prison domestic violence was also supported. The odds of engaging in any post-prison domestic violence incident and severe postprison domestic violence among offenders with minimal or no education need at the time of their release from prison were approximately half the size of the odds of 
offenders with the most education need. This finding is in line with extant literature on domestic violence and general criminality which indicates that individuals with less education (i.e., individuals with more education need) are more likely to engage in domestic violence and criminal activity (e.g., Andrews \& Bonta, 2010; Laub \& Sampson, 2003; Sherman et al., 1992; Stith et al., 2004).

Many of the theories that haven been put forth to explain the link between education and domestic violence are based on the notion that one's educational level contributes to one's social status, which acts as a source of informal social control that guides behavior (e.g., Sherman et al., 1992). Generally, social control theorists argue that individuals with higher social status due to higher education, employment, wealth, and/or social background are less likely to engage in deviant behaviors that would jeopardize that social status (Hirschi \& Gottfredson, 1988; Sherman et al., 1992). Accordingly, men who are highly educated and employed - and therefore have more to lose in terms of their social status - are considered less likely to engage in intimate partner violence (Pate \& Hamilton, 1992; Sherman et al., 1992).

As an extension of informal social control theory, Sherman and colleagues $(1984,1992)$ posit that domestic violence may be more effectively deterred by the interaction of informal and formal social controls. In a study of the deterrent effects of arrest on perpetrating domestic violence, Sherman and Berk (1984) found that being arrested for domestic violence only prevented future incidents for certain types of offenders. In a follow-up study, Sherman et al. (1992) found that arrest (a source of formal control) worked best for offenders with higher social statuses due to ethnicity, employment, and marriage (sources of informal control). Therefore, Sherman and 
colleagues (1992) were able to conclude that the implementation of formal controls (e.g., arrest or other sanctions) works best to deter intimate partner violence among men with high levels of informal social control.

Sherman and colleagues' (1992) explanation for the connections between informal control, formal control, and domestic violence prevention may apply to the results of the current study. Formerly incarcerated offenders in Oregon are monitored under post-prison supervision for an average of three years after prison release (J. P. Stromberg, personal communication, November, 2010). Although post-prison supervision was not examined among offenders in the current study, it is reasonable to assume that all sampled offenders were sentenced to some term of post-prison supervision. Given the finding that offenders with more education were significantly less likely to engage in any post-prison domestic violence incident and severe postprison domestic violence, it is certainly possible that the influence of offenders' education level was moderated by the formal control of post-prison supervision. Future studies should test for this potential interaction to confirm whether informal and formal sources of social control work together to influence former inmates' perpetration of domestic violence after prison release.

Another possible explanation for the relationship between education and postprison domestic violence in the current study is that sampled offenders' education level may have been different than their partners', thus creating "status incompatibility" (Carlson, 1984, p. 572). Theoretically, status incompatibility arises when a man perceives that his dominant position in the family is threatened by his partner's superior personal resources (e.g., more education or a higher-paying job). Allen and Straus 
(1980) posit that, when a man's dominant status within the family is threatened, he may resort to using violence against his partner to reclaim his position of power. Findings from Anderson's (1997) analysis of national survey data support this theory. Specifically, Anderson (1997) found that men whose education level was lower than their female partners' were significantly more likely to engage in partner assault than men whose education level was the same as their female partners. Discrepancies between the education levels of sampled offenders and their partners were not measured in the current study, therefore no assumptions can be made about the potential relationship between status incompatibility and post-prison domestic violence. Future research should involve data from both the offender and his intimate partner so a more complete picture of the context of post-prison domestic violence can be used to draw conclusions about study results.

Marital status. The prediction that married offenders would be less likely to perpetrate post-prison domestic violence relative to separated or divorced offenders was not supported by the data. There were no significant differences between married, single, divorced, or separated offenders' likelihood of engaging in any post-prison domestic violence incident or severe post-prison domestic violence. This finding is not entirely surprising, given that the measure used in the current study represented sampled offenders' marital status at the time of their arrest—-before they were incarcerated. Sampled offenders' marital status may have changed during the years between their arrest, release from prison, and the study follow-up period. Recent evidence indicates that incarcerated men's risk for divorce is three times that of men who are not incarcerated (Apel, Blokland, Nieuwbeerta, \& van Schellen, 2010; Massoglia, Remster, 
\& King, 2011), therefore it is quite possible that sampled offenders who were married at the time of their arrest divorced during their incarceration or after their release. It is also reasonable to suppose that some offenders married while they were incarcerated (e.g., Comfort, 2007; Hairston, 1995), or after they were released from prison during the study follow-up period. Future studies should measure participants' marital status at the time of the domestic violence offense to more accurately estimate the role of the couple's relationship in former inmates' perpetration of post-prison domestic violence.

Moreover, the marital status variable used in the current study did not include an important relationship category: cohabiting. Research on the relationship between marital status and intimate partner violence indicates that cohabiting couples report different rates of intimate partner violence than married and dating couples (see Johnson \& Ferraro, 2000, for a review). For example, Stets and Straus (1990) found that cohabitation accounted for a significant amount of the variance in intimate partner violence after controlling for other key factors including age, education, and career. Stets and Straus (1990) argue that cohabiting couples are more socially isolated than married couples and experience less social support and social control, which creates more opportunities for violence and abuse.

Alternatively, Johnson and Ferraro (2000) attribute the relationship between cohabiting and intimate partner violence to lower levels of commitment among unmarried couples. This interpretation brings up an important point-namely that the differences in domestic violence due to marital status may represent differences in the level of satisfaction and/or commitment in the relationship. Several individual studies and meta-analyses indicate that marital satisfaction may play an essential role in men's 
perpetration of partner violence (Henning \& Connor-Smith, 2011; Hotaling \& Sugarman, 1986; Stith et al., 2004; Stith et al., 2008). Ideally, future research should include measures of both marital status and marital satisfaction in order to gain a more precise understanding of their relationship to intimate partner violence perpetrated by former inmates after their release from prison.

Number of children. The prediction that offenders who had more children would be more likely to engage in post-prison domestic violence than offenders with fewer children was supported. Results indicated that the odds of engaging in any post-prison domestic violence incident increased significantly with each additional child offenders reported $\left(\operatorname{Exp}[\mathrm{B}]_{\text {Number of children }}=1.15\right)$. The odds of engaging in severe post-prison domestic violence also increased with each additional child, but this increase was not statistically significant. This finding is consistent with previous literature (Hotaling \& Sugarman, 1986; Szinovacz \& Egley, 1995).

Some evidence indicates that the relationship between the number of children and intimate partner violence is moderated by low marital satisfaction (Henning \& Connor-Smith, 2011). The number of children a couple has is negatively correlated with marital satisfaction (Twenge et al., 2003), which is associated with domestic violence (Stith et al., 2008). Given the findings of the current study it is possible that each additional child reported by sampled offenders contributed to low marital satisfaction which led to post-prison domestic violence; but because marital satisfaction was not measured, this explanation cannot be backed by evidence. The relationship between number of children and marital satisfaction and its impact on post-prison domestic violence is a possible avenue for future research. 
Type of crime. The hypothesis that offenders who were incarcerated for a violent crime would be more likely than those who were incarcerated for a non-violent crime to perpetrate post-prison domestic violence was supported. The odds of perpetrating severe post-prison domestic violence among offenders who were incarcerated for a violent crime (e.g., assault, robbery, and rape) were nearly one and a half times the odds of offenders who were incarcerated for a non-violent crime (e.g., theft, drug offenses, and burglary). Violent crime offenders also had slightly higher odds of engaging in any post-prison domestic violence incident, but the relationship was not statistically significant.

This finding is consistent with prior literature on the prediction of future violent behavior from past violent behavior (e.g., Harris et al., 1993; Hilton et al., 2004; Rice, 1997). Violent offense history plays an important role in the calculation of violent recidivism risk and is assessed by several actuarial risk tools in the extant literature (i.e., VRAG, Harris et al., 1993; ODARA, Hilton et al., 2004). For example, Harris and colleagues (1993) found that men with extensive histories of violent offending were significantly more likely to engage in further violent crime than men with little to no violent past. In addition, Hilton et al. (2004) found that men with histories of violent assaults against individuals outside the family were significantly more likely to commit violent forms of domestic abuse (e.g., assault) against their wives. Findings from the current study directly confirm those of Hilton and colleagues (2004) in that violent crime history predicted severe post-prison domestic violence (e.g., assault).

Length of incarceration. The prediction that the length of time offenders were incarcerated would be positively related to post-prison domestic violence was not 
supported by the data. There was no significant difference in the odds of perpetrating post-prison domestic violence based on the length of time sampled offenders were incarcerated. This finding conflicts with the principles of prisonization theory (e.g., Clemmer, 1940) and prior evidence indicating that longer prison sentences are related to significant increases in the probability of recidivism (Gendreau et al., 1999; Gendreau, Goggin, Cullen, \& Andrews, 2000). However, the current finding may be in line with research indicating that the effect of incarceration length on general recidivism varies from offender to offender (DeJong, 1997; Song \& Lieb, 1993).

For example, based on their review of the literature Song and Lieb (1993) concluded that the effects of incarceration length on recidivism were offender-specific. Length of time served increased the chance of recidivism for some offenders (as I had predicted for my sample), but either decreased or had no effect on the chance of recidivism for other offenders (Song \& Lieb, 1993). Similarly, DeJong (1997) found that the effect of prison sentence length on future criminal behavior is different based on offenders' ties to conventional society. Specifically, offenders who had fewer ties to society were more likely to recidivate after serving shorter periods in prison and less likely to recidivate if their prison sentences were somewhat long. For offenders with strong ties to society, length of time served in prison had no significant effect on recidivism (DeJong, 1997). These findings suggest that offenders in the current study may have had stronger ties to conventional society and, as a result, were not significantly influenced by the length of time served in prison. Future research on the relationship between length of incarceration and post-prison domestic violence should explore the extent to which the effect varies between offenders. 
Correctional rehabilitation program attendance. The prediction that offenders who participated in correctional rehabilitation programs would be less likely to perpetrate post-prison domestic violence was partially supported. Results indicated that offenders who attended substance abuse treatment while incarcerated had significantly smaller odds of engaging in any post-prison domestic violence incident and severe postprison domestic violence. This finding suggests that offenders with substance abuse problems who participated in treatment during their incarceration may have been less likely to perpetrate post-prison domestic violence because of a reduction in their use and potential abuse of drugs and alcohol. This line of reasoning corresponds with previous research suggesting that domestic violence offenders who participate in substance abuse treatment are less likely to engage in partner violence (e.g., Easton, Mandel, Hunkele, Nich, Rounsaville, \& Carroll, 2007). In fact, substance abuse and domestic violence co-occur so frequently that domestic violence offenders in the community are often mandated to attend substance abuse treatment programs along with domestic violence intervention programs (Bennett \& Bland, 2008; Easton et al., 2007). The practice of referring domestic violence offenders to separate treatment programs for substance abuse demonstrates the frequency with which these two problems co-occur (Bennett \& Bland, 2008). However, there are a number of caveats to the data that warrant interpreting this finding with caution. Specifically, substance abuse treatment attendance was measured with a single, dichotomous, "dummy" variable indicating only that a given sampled offender attended at least one substance abuse treatment session. The extent to which offenders complied with, engaged in, and/or completed treatment was not measured. In addition, because sampled offenders were 
not randomly assigned to attend substance abuse treatment I cannot rule out the possibility of a selection bias. Despite these exceptions, this finding provides modest additional evidence confirming the relationship between substance abuse and domestic violence and may suggest that substance abuse treatment could be part of a comprehensive solution to prevent former inmates' perpetration of post-prison domestic violence. Contrary to my hypothesis, offenders who participated in religious services programming during their incarceration tended to have greater odds of engaging in any post-prison domestic violence incident although the relationship only approached statistical significance $(p=.09)$. This trend is contrary to prior research indicating that religious involvement decreases the risk of domestic violence (Ellison, Trinitapoli, Anderson, \& Johnson, 2007). However, it may provide modest support for speculation regarding the relationship between men's perpetration of violence against women and the advancement of traditional and patriarchal ideology within some religious doctrine (e.g., Clark, 2008; Nason-Clark, 2000). It is possible that offenders in the current study who participated in religious programming during their incarceration tended to be slightly more likely to perpetrate post-prison domestic violence because of patriarchal and traditional values learned in religious programs. Research has yet to provide irrefutable evidence indicating a strong relationship between patriarchal religious ideology and domestic violence (Ellison et al., 2007); therefore such an interpretation of the trend found in this study must be approached with caution. Certainly, more research concerning the mechanisms through which religiosity and religious program participation may shape men's perpetration of post-prison domestic violence is needed. 
Finally, results indicated that sampled offenders who participated in cognitivebehavioral treatment programs during their incarceration had significantly greater odds of engaging in any post-prison domestic violence incident. This finding is contrary to my prediction and to previous literature demonstrating the small but overall positive impact of cognitive-behavioral treatment on domestic violence recidivism (Babcock, Green, \& Robie, 2004). However, the same caveats that applied to the current measure of substance abuse treatment also apply here. Specifically, like substance abuse treatment attendance, cognitive-behavioral program participation was measured using a dichotomous "dummy" variable indicating whether a sampled offender had or had not participated in this type of programming at any time during their incarceration. Such a simple categorization of program participation does not indicate the extent to which a given offender engaged with the program material or understood the program message. Moreover, the dummy variable does not indicate the number of times a given offender attended the program (i.e., program exposure or dose) or whether the offender completed the requirements of the program curriculum. Program attendance, compliance, and completion are three factors that are related to the effectiveness of other intervention programs (i.e., domestic violence intervention programs; Bennett, Stoops, Call, \& Flett, 2007; Feder \& Wilson, 2005; Gondolf, 2002); therefore future research on the relationship between cognitive-behavioral program participation and post-prison domestic violence should include information regarding more specific features of program engagement. In addition, following Andrews and colleagues' (1990) guidelines for evidence-based correctional rehabilitation, only offenders who are moderate or high risk to recidivate are given the opportunity to participate in cognitive- 
behavioral programming in Oregon prisons. Because of this built-in bias toward selecting riskier offenders, the positive relationship I found between cognitivebehavioral treatment participation and post-prison domestic violence is less surprising.

Situational-level main effect. The situational level of my ecological model of post-prison domestic violence was represented by sampled offenders' post-prison employment. The prediction that offenders who were employed after prison release would be less likely to engage in post-prison domestic violence was not supported by the data. Unexpectedly, post-prison employment was significantly related to offenders' perpetration of post-prison domestic violence in the opposite direction of what was anticipated. Results indicated that the odds of engaging in any post-prison domestic violence incident were two and a half times greater among offenders who were employed for a larger percentage of calendar quarters during the study follow-up period. The odds of perpetrating severe post-prison domestic violence were one and a half times greater among offenders who were employed for a larger percentage of quarters as well, although the relationship was not statistically significant $(p=.13)$. This finding contradicts much of the previous literature on the relationship between men's employment status and perpetrating domestic violence (see Schumacher et al., 2008 and Stith et al., 2003 for reviews).

There are several possible reasons why post-prison employment was positively related to engaging in any post-prison domestic violence incident. First, the measure of post-prison employment may have been flawed. Post-prison employment was represented by the percentage of calendar quarters during which a given offender was employed. The percentage of quarters worked was calculated by taking the number of 
quarters during which the offender was employed and dividing it by the number of quarters that were available to work between his prison release date and study exit date. For example, say an offender was released from prison on December 1, 2006 and exited the study on July 20, 2010 because he engaged in post-prison domestic violence. This offender had 15 calendar quarters between his prison release and study exit dates during which he could have worked. If the offender worked during all 15 quarters, his percentage of quarters worked (and therefore his 'score' on the employment variable) was $100 \%$. However, say that this offender-who worked consistently after prison release - was laid off or fired during the quarter in which he engaged in domestic violence and exited the study. Prior literature indicates that his perpetration of postprison domestic violence could have been related to the stress of losing his job (e.g., Catalano, Novaco, \& McConnell, 1997; Johnson \& Indvik, 1994; McCloskey, 1996). Unfortunately, data that were used to calculate post-prison employment in the current study did not allow for tracking of sampled offenders' employment patterns (i.e., hiring and firing); therefore this explanation for the positive relationship between employment and post-prison domestic violence cannot be confirmed. Future studies should include an expanded measure of employment wherein more accurate patterns of employment and unemployment can be used to predict domestic violence perpetrated by former inmates after prison release.

Another possible explanation for the positive association between offenders' employment and post-prison domestic violence is that it may reflect the presence of an unmeasured mediating construct or variable. In statistical analyses, a mediator variable is one that explains or accounts for some or all of relationship between two other 
variables. If a given variable perfectly mediates the relationship between two other variables, the relationship between the two variables disappears when the effect of the mediator is removed (Baron \& Kenny, 1986).

One potential variable or construct that may explain the positive relationship between employment and post-prison domestic violence in the current study is that of sampled offenders' conditions of employment relative to their female partners'. To illustrate, the current findings suggest that offenders who were employed after prison release were more likely to engage in any post-prison domestic violence incident; however sampled offenders' employment may have been mediocre in terms of pay, stability, and status compared to that of their female partners'. As mentioned earlier in this chapter, there is some evidence to support the theory that intimate partner violence can be triggered by status incompatibility, or men's perception that their dominant status within the family is threatened by their female partner's resources (Carlson, 1984, p. 572). Evidence indicates that domestic violence is more likely to occur in partnerships where the male's employment status, income, and education level are inferior to his partner's (Allen \& Straus, 1980; Anderson, 1997). For example, Anderson (1997) found that men who earned less than their female partners were between three and five times more likely to engage in partner assault than men who earned the same amount as their partners. Because status incompatibility was not measured in the current study, the degree to which the construct explains the positive relationship between employment and post-prison supervision is unknown. However, the current findings coupled with those of Anderson (1997) and status incompatibility theory in general suggest that studies on the relationship between intimate partner 
violence and employment should measure the income and employment status of both perpetrators and partners/victims. Male domestic violence offenders' employment status and income are somewhat meaningless outside the context of their female partners' employment status and income.

A third possible explanation for the positive association between post-prison employment and post-prison domestic violence found in the current study can be derived from previous research on work-related stress and its relationship to intimate partner violence. Specifically, prior literature indicates that men who engage in partner abuse report significantly more stressful work experiences and less job satisfaction than non-abusive men (Barling \& Rosenbaum, 1986; VanBuren-Trachtenberg, Anderson, \& Sabatelli, 2009). For example, VanBuren-Trachtenberg and colleagues (2009) found that low job satisfaction among men was significantly related to work-family conflict, which predicted both physical and psychological partner abuse. In Barling and Rosenbaum's (1986) study comparing abusive and non-abusive husbands, the authors found that abusive husbands reported a higher frequency of stressful work events than non-abusive husbands. Abusive husbands also indicated that stressful work events had significantly more negative impact on their lives than non-abusive husbands (Barling \& Rosenbaum, 1986). Given the findings of these previous studies, it is certainly possible that sampled offenders in the current study who spent more time working after prison release may have experienced more work-related stress, which contributed to their perpetration of domestic violence.

Alternatively, it is possible that the stress of having a job at all contributed to sampled offenders' perpetration of post-prison domestic violence in the current study. 
For example, it could be that many sampled offenders never maintained consistent employment before their incarceration, and that the stress of holding a steady job led them to engage in post-prison domestic violence. To illustrate, employment can certainly decrease stress to the extent that it provides ex-offenders with a sense of purpose, income, and stability (e.g., Laub \& Sampson, 2003); however, for former inmates, maintaining a steady job could represent a dramatic shift from previous life patterns which may have included chronic unemployment and/or illegal employment (e.g., selling drugs). As Felner et al. (1989) theorize, individuals undergoing significant life transitions are required to navigate new social roles and expectations which may create stress in the form of role strain. The stress experienced during the transition from one set of roles to another may cause individuals to adjust to the new set of roles in maladaptive ways. In view of this theory, it is reasonable to speculate that offenders in the current study who engaged in post-prison domestic violence despite their consistent post-prison employment may have done so in reaction to stress brought on by the role requirements of their post-prison employment. This line of thinking is a possible avenue for further exploration.

Social-structural level main effect. The social-structural level of my ecological model was represented by the social and economic characteristics of neighborhoods where offenders lived after prison release (i.e., neighborhood disadvantage). The prediction that neighborhood disadvantage would be positively related to offenders' perpetration of post-prison domestic violence was supported. Offenders who lived in more socially and economically disadvantaged neighborhoods after prison release had significantly greater odds of engaging in any post-prison domestic violence incident 
$\left(\operatorname{Exp}[\mathrm{B}]_{\text {Neighborhood disadvantage }}=1.10\right)$. Offenders who lived in more disadvantaged neighborhoods were also had slightly greater odds of perpetrating severe post-prison domestic violence, but the relationship was not statistically significant $(p=.16)$. These findings are consistent with previous research on the relationship between intimate partner violence and the level of social and economic disadvantage associated with perpetrators' neighborhood contexts (Benson \& Fox, 2004; Benson et al., 2004; Heise, 1998).

There are a number of different theoretical explanations that may help describe the nature of the relationship between neighborhood disadvantage and post-prison domestic violence found in the current study. For instance, social disorganization theory asserts that social and economic disadvantage in neighborhoods generate weak social bonds among residents. This lack of social cohesion is associated with isolation of the family and low levels of informal social control for perpetrators - two factors that are known predictors of intimate partner violence (Moe \& Bell, 2004; Rose \& Clear, 1998; Sherman et al., 1992; Stets, 1991). Applied to the current study, this theory suggests that sampled offenders who lived in more socially and economically disadvantaged neighborhoods were more likely to engage in post-prison domestic violence because of a lack of informal social control and cohesion that they would have experienced had they lived in more economically and socially advantaged neighborhoods.

On the other hand, a social disorganization theoretical explanation of the link between domestic violence and neighborhood disadvantage also implies that residents are likely to be apathetic to other residents' problems; and therefore the likelihood of law enforcement being called to respond to domestic violence in these neighborhoods is 
relatively low (Benson et al., 2004). However, the measure of domestic violence used in the current study was collected from records of law enforcement responses to domestic violence calls in the community. Because of the nature of the domestic violence measure, results of the current study suggest that police may have been more likely to respond to domestic violence calls in disadvantaged neighborhoods. Therefore, social disorganization theory may not provide the most accurate explanation of the link between neighborhood disadvantage and post-prison domestic violence for all offenders in the current study.

Then again, for offenders in the current study with multiple post-prison addresses, the variable of neighborhood disadvantage represented the average level of neighborhood disadvantage experienced by the offender throughout the study follow-up period. In other words, some sampled offenders' 'score' on the measure of neighborhood disadvantage did not necessarily signify the level of social and economic disadvantage associated with the neighborhood in which they were living at the time they engaged in the post-prison domestic violence incident. It is possible that some offenders were living in more socially and economically advantaged neighborhoods at the time they engaged in post-prison domestic violence despite their score on the measure of neighborhood disadvantage. Future researchers should score variables differently so that offenders' perpetration of domestic violence can be predicted from their immediate neighborhood circumstances.

The positive relationship between neighborhood disadvantage and post-prison domestic violence has important implications for policies regarding offender housing. In Oregon, formerly incarcerated offenders are often required to live in the county in 
which they resided when they committed the crime that led to their imprisonment for at least six months after prison release. Theoretically, this residency requirement compels offenders to live either in or near the same community and/or neighborhood in which they resided before going to prison. For offenders who lived in economically and socially disadvantaged neighborhoods before going to prison, the results of the current study suggest that the residency requirement may increase the chance that they will engage in post-prison domestic violence. In an effort to prevent post-prison domestic violence, it may be prudent for correctional staff to more carefully consider the neighborhood context in which the offender is directed to reside, and reflect on whether it may increase the risk that they will engage in post-prison domestic violence. Ideally, policy would dictate that formerly incarcerated offenders be released to the types of communities that would facilitate successful transition out of prison and decrease the chance of post-prison domestic violence, regardless of whether the offender lived in that community at the time of their offense. Fortunately, there are already policies in place that allow offenders to be released to a different county if they can provide evidence that they will be more likely to succeed as a result (e.g., because of the presence of supportive family and/or friends in that county). Given the findings from the current study, perhaps correctional staff would be more inclined to consider alternative placements for formerly incarcerated offenders so that their chances for a successful transition are increased and the risk of post-prison domestic violence is decreased.

One thing to consider when interpreting the current findings regarding neighborhood disadvantage is that the measure itself is not void of limitations. For example, one of the factors used to calculate the neighborhood disadvantage index was 
the percentage of families living in a given zip code who were receiving public assistance. Current laws often prevent individuals who have been convicted of certain crimes (e.g., manufacture and sale of illegal drugs) from obtaining public assistance (e.g., subsidized housing; US Department of Housing and Urban Development, 2011). Therefore, the percentage of families who are currently receiving public assistance does not necessarily reflect the need for public assistance. It could be that the need is significantly greater, but that some individuals who need public assistance are not allowed to receive it. If the percentage of families in need for public assistance is much greater than the percentage receiving public assistance, it is reasonable to imagine that the actual level of neighborhood disadvantage, or at least perceived disadvantage, would be higher.

Chronosystem effect. Up to this point I have addressed predictors of intimate partner violence during the transition from prison to the community that exist at the individual, situational, and social-structural levels of ecological analysis. One of the levels that I have not addressed is the chronosystem. Bronfenbrenner (1986) added the chronosystem to his conceptualization of the ecological model to represent the impact of time on factors and processes that exist at the other levels of contextual analysis. More specifically, chronosystem research models examine the influence of time "on the person's development of changes (and continuities)...in the environments in which the person is living" (Bronfenbrenner, 1986, p. 724). The chronosystem level also represents the cumulative effects of life experiences and developmental changes on behavior over time (Bronfenbrenner, 1986). 
Analysis of the chronosystem level allows domestic violence researchers in particular to examine the continuity of violence over the life course, and provides a framework for theorizing about the trajectory of violent behavior and its consequences over time (e.g., Campbell, Dworkin, \& Cabral, 2009; Graham-Bermann \& Gross, 2008). The current study of domestic violence perpetrated by formerly incarcerated offenders over time (i.e., the transition from prison to the community) provides evidence for at least one chronosystem effect. Specifically, although I discussed the construct of witnessing interparental violence during childhood at the individual level of analysis, results suggest that it could also be considered an effect of the chronosystem. The finding that sampled offenders who witnessed interparental violence during childhood were more likely to perpetrate post-prison domestic violence suggests that this early experience influenced their development over time and contributed to the likelihood of perpetrating post-prison domestic violence during adulthood. In other words, this finding supports the notion that domestic violence perpetration may result from the cumulative effects of certain developmental experiences over time. More importantly, it demonstrates the need for longitudinal research designs that follow individuals over time (ideally from childhood to adulthood) so that other potential chronosystem effects on domestic violence perpetration can be identified and addressed.

Interactions. This research is informed by an ecological theoretical perspective; thus, in addition to identifying the main effects of variables on the outcome of interest, the current study was also concerned with identifying effects caused by interactions. From the onset, I argued that statistically significant interaction effects between predictors that I selected to represent each level of analysis would provide support for 
my ecological model of post-prison domestic violence. Regrettably, results indicated that the tested interaction effects as a whole did not account for a significant amount of the variance in post-prison domestic violence. Furthermore, interpretation of each separate interaction effect revealed that only the interaction between the individual-level variable of family-of-origin violence and the social-structural variable of neighborhood disadvantage was significantly related to post-prison domestic violence in the predicted direction. All other predicted interaction effects were not supported by the data. A summary of findings as they relate to the hypothesized interaction effects on post-prison domestic violence is presented in Table 20.

Individual-level interactions. The prediction that exposure to family-of-origin violence would moderate the effects of borderline and antisocial personality characteristics on post-prison domestic violence was not supported. Results indicated that the effects of borderline and antisocial personality characteristics on post-prison domestic violence were not stronger for offenders who reported witnessing interparental violence, physical abuse during childhood, or sexual abuse during childhood. In fact, a nonsignificant trend suggested that offenders who were physically abused and had higher scores on the measure of borderline personality characteristics tended to be less likely to engage in severe post-prison domestic violence $(p=.07)$. This trend was in the opposite direction of what was predicted.

These findings are somewhat contrary to previous evidence and theoretical work regarding the possible mechanisms through which exposure to family-of-origin violence during childhood shapes domestic violence perpetration in adulthood (e.g., Delsol \& Margolin, 2004). Based on their summary of theory and evidence, Delsol and Margolin 
Table 20.

Summary of interaction effects.

\begin{tabular}{|c|c|c|c|c|}
\hline Level & Variables & Hypothesized interaction & Result & Description \\
\hline $\begin{array}{l}\text { Individual* } \\
\text { Individual }\end{array}$ & $\begin{array}{l}\text { Family-of-origin } \\
\text { violence* } \\
\text { Personality } \\
\text { characteristics }\end{array}$ & $\begin{array}{l}\text { Positive main effects of } \\
\text { antisocial and borderline } \\
\text { personality characteristics on } \\
\text { domestic violence would be } \\
\text { stronger for offenders exposed } \\
\text { family-of-origin violence. }\end{array}$ & $\begin{array}{l}\text { Not } \\
\text { supported }\end{array}$ & \\
\hline \multirow[t]{2}{*}{$\begin{array}{l}\text { Individual* } \\
\text { Situational }\end{array}$} & $\begin{array}{l}\text { Family-of-origin } \\
\text { violence* } \\
\text { Employment }\end{array}$ & $\begin{array}{l}\text { Positive main effects of } \\
\text { exposure to family-of-origin } \\
\text { violence on domestic violence } \\
\text { would be weaker for offenders } \\
\text { who were employed. }\end{array}$ & $\begin{array}{l}\text { Not } \\
\text { supported }\end{array}$ & \\
\hline & $\begin{array}{l}\text { Personality } \\
\text { characteristics* } \\
\text { Employment }\end{array}$ & $\begin{array}{l}\text { Positive main effects of } \\
\text { antisocial and borderline } \\
\text { personality characteristics on } \\
\text { domestic violence would be } \\
\text { weaker for offenders who } \\
\text { were employed. }\end{array}$ & $\begin{array}{l}\text { Not } \\
\text { supported }\end{array}$ & \\
\hline \multirow[t]{2}{*}{$\begin{array}{l}\text { Individual* } \\
\text { Social- } \\
\text { structural }\end{array}$} & $\begin{array}{l}\text { Family-of-origin } \\
\text { violence* } \\
\text { Neighborhood } \\
\text { disadvantage }\end{array}$ & $\begin{array}{l}\text { Positive main effects of } \\
\text { exposure to family-of-origin } \\
\text { violence on domestic violence } \\
\text { would be stronger for } \\
\text { offenders living in } \\
\text { disadvantaged neighborhoods. }\end{array}$ & $\begin{array}{l}\text { Partially } \\
\text { supported }\end{array}$ & $\begin{array}{l}\text { Physical abuse during } \\
\text { childhood and } \\
\text { neighborhood } \\
\text { disadvantage predicted } \\
\text { violent post-prison } \\
\text { domestic violence. }\end{array}$ \\
\hline & $\begin{array}{l}\text { Personality } \\
\text { characteristics* } \\
\text { Neighborhood } \\
\text { disadvantage }\end{array}$ & $\begin{array}{l}\text { Positive main effects of } \\
\text { antisocial and borderline } \\
\text { personality characteristics on } \\
\text { domestic violence would be } \\
\text { stronger for offenders living in } \\
\text { disadvantaged neighborhoods. }\end{array}$ & $\begin{array}{l}\text { Not } \\
\text { supported }\end{array}$ & \\
\hline $\begin{array}{l}\text { Situational* } \\
\text { Social- } \\
\text { structural }\end{array}$ & $\begin{array}{l}\text { Employment* } \\
\text { Neighborhood } \\
\text { disadvantage }\end{array}$ & $\begin{array}{l}\text { Negative main effect of } \\
\text { employment on domestic } \\
\text { violence would be weaker for } \\
\text { offenders living in } \\
\text { disadvantaged neighborhoods. }\end{array}$ & $\begin{array}{l}\text { Not } \\
\text { supported }\end{array}$ & \\
\hline
\end{tabular}


(2004) posit that exposure to family-of-origin violence contributes to the development of both antisocial and borderline personality characteristics, which are related to the perpetration of domestic violence. Specifically, children who are exposed to interparental violence, physical abuse, and/or sexual abuse are at a greater risk to develop borderline personality characteristics including extreme anxiety, unstable sense of self, and the inability to regulate one's emotions (Dutton, 1998). Oftentimes these characteristics consequently play a role in the formation of insecure adult attachments characterized by fear of abandonment, jealousy, distrust, and anger, which are known predictors of intimate partner violence (Dutton, 1998). Other studies have found that interparental violence is often associated with poor parenting ability and harsh treatment during childhood, which may lead to antisocial personality traits and the perpetration of domestic violence in adulthood (Simons, Wu, Johnson, \& Conger, 1995). Given this prior literature, I expected to find significant interactions between family-of-origin violence and personality characteristics among offenders in the current study.

However, other research has shown that different forms of family-of-origin violence have strong main effects on the perpetration of domestic violence and do not interact with abusers' personality characteristics. For example, Ehrensaft and colleagues (2003) found that antisocial behavior interacted with physical abuse during childhood to predict domestic violence perpetration, but did not interact with witnessing interparental violence. Interestingly, the only statistically significant interaction between personality and family-of-origin violence found in the current study also involved physical abuse 
during childhood, but the direction of the interaction was opposite to what was predicted.

Finally, as I discussed earlier, it could be that the measure of personality used in the current study did not adequately assess offenders' antisocial and borderline personality characteristics. Put simply, if the tool used to measure one of the variables in an interaction term did not accurately assess that variable, one should not expect the interaction to be significantly related to the outcome. Future studies on the relationship between personality characteristics, family-of-origin violence, and post-prison domestic violence should involve the use of PAI along with other personality assessment tools in order to determine whether the PAI is an appropriate measure to use among formerly incarcerated offenders.

Individual and situational level interactions. The prediction that employment would moderate the effects of family-of-origin violence on post-prison domestic violence was not supported by the data. Results indicated that the positive main effects of exposure to family-of-origin violence were not weaker for offenders who were employed after prison release. A few significant interactions and one trend between family-of-origin violence variables and employment did emerge, however all were in the opposite direction of what was predicted. Specifically, for offenders who did not witness interparental violence, a higher percentage of calendar quarters worked was positively related to engaging in any post-prison domestic violence incident. A nonsignificant trend indicated these offenders also tended to be more likely to engage in severe post-prison domestic violence. Similarly, for offenders who were physically 
abused as children, a higher percentage of quarters worked was positively related to engaging in severe post-prison domestic violence.

In addition, the prediction that employment would moderate the positive main effects of antisocial and borderline personality characteristics on post-prison domestic violence was not supported. Findings indicated that the effects of antisocial and borderline personality characteristics on post-prison domestic violence were not weaker for offenders who were employed after their release from prison. A few statistically significant interactions between personality variables and employment emerged but all were in the opposite direction of what was predicted. For offenders who exhibited fewer antisocial personality characteristics, a higher percentage of quarters worked was related to engaging in any post-prison domestic violence incident. For offenders who exhibited more borderline personality characteristics, a higher percentage of quarters worked was related to engaging in any post-prison domestic violence incident.

Given that none of the anticipated interaction effects with employment were supported by the data and that several significant interaction effects emerged in the opposite direction of what was hypothesized, either the measure of employment used in the current study was flawed or the positive relationship between employment and postprison domestic violence can be explained by the presence of mediating construct that was not measured (e.g., job stress and status incompatibility between male offenders' employment and their female partners' employment). Earlier in this chapter I discussed several reasons why the measure of employment might have been flawed, including the fact that it did not allow for tracking of employment patterns that may be associated 
with perpetrating post-prison domestic violence (i.e., hiring and firing). I also discussed reasons why the positive relationship between post-prison employment and post-prison domestic violence might have been mediated by an unmeasured construct. Future studies should use a more accurate and detailed measure of offenders' post-prison employment that captures a broader scope of information including employment patterns and other job-related characteristics that are linked to intimate partner violence (e.g., status incompatibility).

Individual and social-structural level interactions. The prediction that neighborhood disadvantage would moderate the positive effects of exposure to familyof-origin violence on post-prison domestic violence was partially supported by the data. Results indicated that for offenders who were physically abused during childhood, a higher level of neighborhood disadvantage was related to perpetrating severe postprison domestic violence. This is the only interaction effect that significantly predicted former inmates' perpetration of post-prison domestic violence in the direction that was hypothesized. Contrary to what was anticipated, neighborhood disadvantage did not moderate the effects of the remaining family-of-origin variables on post-prison domestic violence. Neighborhood disadvantage also did not moderate the effects of antisocial or borderline personality characteristics on post-prison domestic violence.

The finding that offenders who were physically abused as children were more likely to engage in severe post-prison domestic violence if they were also exposed to a high level of neighborhood disadvantage is in line with social learning theory (Bandura, 1974, 1977) and with theory proposed by Sampson and Wilson (1995). To illustrate, 
from the perspective of social learning theory one could argue that sampled offenders who were physically abused as children were more likely to perpetrate post-prison domestic violence because they learned that physical violence was an accepted method of exerting power and control over an inferior member of the family (i.e., a child). As an apparent extension of social learning theory, Sampson and Wilson (1995) suggest that individuals who experience socially and economically deprived neighborhoods characterized by high levels of violence and instability may learn that violence is an accepted method of coping with interpersonal conflict. Therefore, sampled offenders who were physically abused as children and exposed to neighborhood-level social and economic disadvantage theoretically received messages condoning the use of violence both from their family-of-origin and from their neighborhood, making them significantly more likely to perpetrate post-prison domestic violence. This finding provides support for an ecologically-informed theory of the predictors of post-prison domestic violence in that it demonstrates the simultaneous effects of multiple risk factors from multiple levels of context.

Situational and social-structural level interactions. The prediction that neighborhood disadvantage would moderate the effect of employment on post-prison domestic violence was not supported by the data. Results indicated that the main effect of employment on post-prison domestic violence was not weaker for offenders who resided in socially and economically disadvantaged neighborhoods. Contrary to what was hypothesized, offenders who were exposed to less neighborhood disadvantage and 
worked for a higher percentage of quarters were significantly more likely to perpetrate violent post-prison domestic violence.

Employment and neighborhood social and economic characteristics are considered indicators of socioeconomic status (Braveman, Cubbin, Egerter, Chideya, Marchi, Metzler, \& Posner, 2005); therefore this finding may suggest that offenders belonging to a relatively higher socioeconomic class (characterized by more stable employment and neighborhood advantage) were more likely to engage in post-prison domestic violence relative to offenders who were part of a lower socioeconomic class. This contradicts a good deal of previous literature that demonstrates a positive relationship between indicators of lower socioeconomic status and perpetrating domestic violence (Hotaling \& Sugarman, 1986; Schumacher et al., 2001; Stith et al., 2004).

However, while domestic violence might be more prevalent among individuals of lower socioeconomic status, it is important to emphasize that domestic violence has been found to occur among all groups of people regardless of socioeconomic status (Garcia-Moreno, Jansen, Ellsberg, Heise, \& Watts, 2005). Indeed, evidence suggests that relationship violence is often reported among couples seeking marital therapy who, traditionally, are more likely to be from a higher social class (Ehrensaft \& Vivian, 1996; Simpson, Doss, Wheeler, \& Christensen, 2007). For example, Simpson and colleagues (2007) found that 40 percent of couples from high socioeconomic backgrounds who were seeking marital therapy reported experiencing moderate to severe psychological and physical aggression in their marriage. In another study of married couples from 
high socioeconomic backgrounds, Lorber and O'Leary (2004) found that 41 percent of couples reported husband-to-wife physical aggression that began before couples were married and lasted into the first three years of marriage. Considering that a higher percentage of quarters worked and exposure to less neighborhood disadvantage may be indicative of higher socioeconomic status among offenders in the current study, these results are in line with those of Garcia-Moreno et al. (2005), Lorber and O'Leary (2004), and Simpson and colleagues (2007).

Of course, my interpretation of the interaction between neighborhood disadvantage and employment is based on the assumption that the measure of employment used in the current study was not flawed. I have presented arguments throughout the chapter suggesting both the possibility that the measure was flawed and the possibility that measure was not flawed and that employment was positively related to post-prison domestic violence because of status incompatibility and/or work-related stress. Since the measure of employment used in the current study may have been flawed, I interpret all significant interactions involving the employment variable with caution.

\section{Final Thoughts}

Without a doubt the current study demonstrates that ecological theoretical models of social phenomena are difficult to test empirically. Much of this difficulty is driven by the notion that there are an infinitude of different variables a researcher could choose to test within any given ecological theoretical model; but the realities of applied research and limited sample sizes compel investigators to restrict the number of tested 
effects through the use of prior evidence and informed decision-making. This inherently limits the scope of tested effects and may leave investigators with more questions than answers. Despite the limited amount of variance in post-prison domestic violence that was explained by the variables I tested, this study represents an important step forward in the application of ecological theory to the prediction of intimate partner violence during the transition from prison to the community. The use of ecological theory in the current study demonstrates that predictors of real-life behavior and social phenomena can be organized into a manageable, testable framework wherein the effects of multiple features of contexts can be examined simultaneously. That some of the variance in postprison domestic violence (albeit a very small amount) was explained by selected variables from my ecological conceptual model is encouraging in that it provides preliminary support for the utility of ecological frameworks in applied settings.

Certainly, more research is needed to fully identify and understand potential causes, correlates, and predictors of intimate partner violence perpetrated by former inmates during the transition from prison to the community. To facilitate further study of this phenomenon using an ecological theoretical framework, I offer two key recommendations. My first recommendation concerns the ideal research methodology and the predictors that I suggest future researchers include in their investigations. Perhaps most importantly, future researchers should consider a prospective approach that involves multiple waves of data collection over time. To illustrate, such an approach could include a preliminary survey of soon-to-be-released incarcerated offenders as well as structured follow-up interviews addressing an expanded set of 
constructs from the ecological model of intimate partner violence and general criminal risk used in the current study (see Figure 3). Not only would this approach facilitate the study of a greater number of constructs (i.e., there would be no need to rely on existing data), but it would also allow for tracking and collection of information about these constructs as they develop over time. This approach would permit researchers to examine offender trajectories as they transition from prison back to the community and document the sequencing of constructs and events that influence post-prison domestic violence behavior. For example, if the current study involved a prospective approach I would have been able to confirm whether or not the unanticipated positive relationship between the post-prison employment and post-prison domestic violence was due to changes in offenders' employment status (i.e., being fired) that were not captured by the retrospective measure of employment (i.e., percentage of quarters worked during the study follow-up period).

Future studies applying the current ecological model should ideally address some of the same variables that I tested as well as additional constructs that were not included in this analysis. A significant amount of variance in post-prison domestic violence was not explained by the predictors I tested, therefore additional predictors from one or more levels of ecological analysis are needed. At the individual/ontogeniclevel, I propose future researchers test sampled offenders' histories of substance abuse, masculine gender role conflict and/or conformity to masculine norms, and attitudes toward crime in general. I also recommend that researchers continue to investigate the effects of exposure to family-of-origin violence given the positive relationship between 
witnessing interparental violence and post-prison domestic violence found in the current study. Investigators should also consider further exploration of the relationship between borderline and antisocial personality characteristics and post-prison domestic violence. Previous studies have demonstrated significant relationships between histories of perpetrating intimate partner violence and both borderline and antisocial personality characteristics among incarcerated samples (Dutton \& Hart, 1992; White et al., 2002); therefore the lack of findings between the same personality constructs and post-prison domestic violence in the current study was unexpected.

At the situational/microsystem level, future researchers should use an enhanced measure of post-prison employment that includes data on income and employment patterns (i.e., hiring, firing, and number of hours worked) so that a more detailed and potentially accurate picture of the relationship between post-prison employment and post-prison domestic violence can be tested. Also at the situational/microsystem level, I propose future researchers explore the effects of intimate partner characteristics on postprison domestic violence. Intimate partners represent an important microsystem within offenders' social contexts, and prior evidence suggests that certain partner characteristics may contribute to the immediate risk of domestic violence occurring (e.g., substance abuse problems; Hilton et al., 2004).

At the social-structural/exosystem level I propose that future investigators explore the relationship between post-prison domestic violence and factors that were not included in the current analysis such as the community response to intimate partner violence. This construct could be represented by the number of resources that are 
available in the community for perpetrators and victims (e.g., domestic violence intervention programs and women's shelters). I also recommend further investigation of the relationship between post-prison domestic violence and neighborhood social and economic disadvantage. Current findings indicated a positive relationship between neighborhood disadvantage and post-prison domestic violence, which has important implications for offender placement and housing after prison release.

Lastly, in order to capture the impact of sociocultural/macrosystem variables such as culturally idealized masculinity and tolerance of violence against women, I recommend that studies of former inmates' perpetration of intimate partner violence be conducted with samples from a diverse assortment of countries and cultures. The current study was conducted in the US with a relatively homogenous sample, therefore significant sociocultural/macrosystem effects were not tested. Differences in the rates and predictors of post-prison domestic violence perpetrated by offenders from varied cultural backgrounds would provide evidence that sociocultural factors shape the effects of variables that exist within all other contextual levels.

My second and final recommendation concerns the potential implications that could be associated with the use of an ecological theoretical framework to study formerly incarcerated offenders' perpetration of domestic violence. Specifically, there is a tension between ecological models of intimate partner violence that emphasize context, and feminist (i.e., power and control) theories of domestic violence that focus exclusively on the individual responsibility of the abusive man. On the one hand, ecological models consider the effects of multiple factors and contexts and their impact 
on men's perpetration of intimate partner violence. In other words, ecological models consider the relationship between perpetrating domestic violence and individual characteristics such as personality and exposure to interparental violence; situational characteristics like the offender-partner microsystem; social-structural features such as neighborhood qualities; and sociocultural factors like cultural norms that are tolerant of partner abuse. On the other hand, feminist theories of domestic violence are fixed on the notion that men who perpetrate domestic violence do so for virtually no other reason than to maintain power and control over women. In other words, power and control theories of domestic violence do not incorporate other factors (e.g., situational factors like the offender- partner relationship) into the explanation for or treatment of domestic violence behavior. In fact, any observation that certain characteristics or behaviors of the victim may play a role in domestic violence is generally considered victim blaming (see Oregon Administrative Rules 137-087-0045 and 137-087-0050).

The tension between power and control theory and ecological theories of intimate partner violence exists in that the former is the predominant conceptual framework used to inform most state-sanctioned batterer intervention program standards (Maiuro \& Eberle, 2008) and corresponding curricula (i.e., the Duluth curriculum; Pence \& Paymar, 1993). In other words, batterer intervention programs who seek to be endorsed and potentially funded by the state are generally required to adopt curricula and practices that are informed by power and control theory. This means that factors like partner characteristics — which inherently shape the context of the offender-partner microsystem — cannot be addressed by batterer intervention programs 
adhering to state standards. Therefore, while it may be appropriate theoretically to consider the impact of variables present within the offender-partner microsystem as I suggest (e.g., the partner's substance abuse problems), doing so may be less appropriate politically. If future researchers find that partner characteristics account for significant variance in ecological frameworks of post-prison domestic violence, such findings could be misconstrued as victim blaming. Using this example, I caution against failing to consider the professional risk and political ramifications of exploring the relationships between certain variables and domestic violence, even though doing so would be appropriate from an ecological theoretical perspective. 


\section{References}

Allison, P. D. (1995). Survival analysis using the SAS system: A practical guide. Cary, NC: SAS Institute Inc.

American Psychiatric Association (1994). Diagnostic and statistical manual of mental disorders (Fourth ed.). Washington, DC: American Psychiatric Association.

Andrews, D. A. (1995). The psychology of criminal conduct. In J. McGuire (Ed.) What Works: Reducing Reoffending-Guidelines from Research and Practice (pp. 3562). New York, NY: John Wiley \& Sons, Ltd.

Andrews, D. A., \& Bonta, J. (2010). The Psychology of Criminal Conduct, $5^{\text {th }}$ Edition. New Providence, NJ: Anderson Publishing.

Andrews, D. A., \& Bonta, J., \& Hoge, R. D. (1990). Classification for effective rehabilitation: Rediscovering psychology. Criminal Justice and Behavior, 17(1), $19-52$.

Andrews, D. A., \& Wormith, J. S. (1984). Criminal Sentiments and Criminal Behavior. Program Branch User Report. Ottawa: Solicitor General Canada.

Andrews, D. A., Zinger, I., Hoge, R. D., Bonta, J., Gendreau, P., \& Cullen, F. T. (1990). Does correctional treatment work? A clinically relevant and psychologically informed meta-analysis. Criminology, 28(3), 369-404.

Apel, R., Blokland, A. A. J., Nieuwbeerta, P., \& van Schellen, M. (2010). The impact of imprisonment on marriage and divorce: A risk set matching approach. Journal of Quantitative Criminology, 26(2), 269-300.

Avakame, E. F., \& Fyfe, J. J. (2001). Differential police treatment of male-on-female spousal violence: Additional evidence on the leniency thesis. Violence Against Women, 7(1), 22-45.

Babcock, J. C., Green, C. E., \& Robie, C. (2004). Does batterers' treatment work? A meta-analytic review of domestic violence treatment. Clinical Psychology Review, 23(8), 1023-1053.

Bahr, S. J., Armstrong, A. H., Gibbs, B. G., Harris, P. E., \& Fisher, J. K. (2005). The reentry process: How parolees adjust to release from prison. Fathering, 3, $243-$ 265.

Bakker, L. J., Morris, B. A., Janus, L. M. (1978). Hidden victims of crime. Social Work, 23, 143-148. 
Bandura, A. (1974). Behavior theories and the models of man. American Psychologist, 29(12), 859-869.

Bandura, A. (1977). Social Learning Theory. Englewood Cliffs, NJ: Prentice Hall.

Barling, J., \& Rosenbaum, A. (1986). Work stressors and wife abuse. Journal of Applied Psychology, 71(2), 346-348.

Baron, R. M., \& Kenny, D. A. (1986). The moderator-mediator variable distinction in social psychological research: Conceptual, strategic, and statistical considerations. Journal of Personality and Social Psychology, 51(6), 1173-1182.

Bates, R. E., Lawrence-Wills, S., \& Hairston, C. F. (Summer, 2003). Children and families of incarcerated parents: A view from the ground. (Children, Families, and the Criminal Justice System Research Brief). Chicago, IL: Jane Addams Center for Social Policy and Research, University of Illinois at Chicago.

Belsky, J. (1980). Child maltreatment: An ecological integration. American Psychologist, 35(4), 320-335.

Bennett, L., W., \& Bland, P. (2008). Substance abuse and intimate partner violence. Harrisburg, PA: National Online Resource Center on Violence Against Women. Retrieved October 8, 2011 from http://vawnet.org/applied-research-papers/ summary.php?doc_id $=1324 \&$ find_type $=$ web_desc_AR

Bennett, L. W., Stoops, C., Call, C., \& Flett, H. (2007). Program completion and rearrest in a batterer intervention system. Research on Social Work Practice, $17(1), 42-54$.

Bennett, L., Tolman, R. M., Rogalski, C. J., \& Srinivasaraghavan, J. (1994). Domestic abuse by male alcohol and drug addicts. Violence and Victims, 9(4), 359-368.

Bennett, L., \& Williams, O. J. (2003). Substance abuse and men who batter. Violence Against Women, 9, 558-575.

Benson, M. L. \& Fox, G. L. (2004, September). When violence hits home: How economics and neighborhood play a role (National Institute of Justice Research in Brief). Retrieved November 1, 2010 from http://www.ncjrs.gov/ pdffiles1/nij/205004.pdf

Benson, M. L., Fox. G. L., DeMaris, A., \& Van Wyk, J. (2003). Neighborhood disadvantage, individual economic distress, and violence against women in intimate relationships. Journal of Quantitative Criminology, 19(3), 207-235. 
Black, D. J., \& Reiss, A. J. (1970). Police control of juveniles. American Sociological Review, 35(1), 63-77.

Boone, D. (1998). Internal consistency reliability of the Personality Assessment Inventory with psychiatric inpatients. Journal of Clinical Psychology, 54(6), 839-843.

Braithewaite, J. (1981). The myth of social class and criminality reconsidered. American Sociological Review, 46, 36-47.

Braithwaite, J., \& Daly, K. (1994). Masculinities, violence, and communitarian control. In T. Newburn \& B. Stanko (Eds.), Just Boys doing Business: Men, Masculinities, and Crime (pp. 189-213). London, England: Routledge.

Braveman, P. A., Cubbin, C., Egerter, S., Chideya, S., Marchi, K. S., Metzler, M., \& Posner, S. (2005). Socioeconomic status in health research: One size does not fit all. Journal of the American Medical Association, 294(22), 2879-2888.

Bronfenbrenner, U. (1977). Toward an experimental ecology of human development. American Psychologist, 32, 513-503.

Bronfenbrenner, U. (1986). Ecology of the family as a context for human development: Research perspectives. Developmental Psychology, 22(6), 723-742.

Bronfenbrenner, U. (1994). Ecological models of human development. In T. Husen \& T. N. Postlethwaite (Eds.), International Encyclopedia of Education ( $2^{\text {nd }} \mathrm{ed}$.) (Vol. 3, pp. 1643-1647). Oxford, England: Pergamon Press/Elsevier Science.

Bronfenbrenner, U., \& Morris, P. A. (1998). The ecology of developmental processes. In W. Damon \& R. M. Lerner (Eds.), Handbook of Child Psychology $5^{\text {th }}$ Ed., Vol. 1, Theoretical Issues (pp. 993-1028). New York, NY: Wiley.

Buzawa, E. S. \& Buzawa, C. G. (2003). Domestic Violence: The Criminal Justice Response, $3^{\text {rd }}$ Edition. Thousand Oaks, CA: Sage.

Caetano, R., Cundradi, C. B., Schafer, J., \& Clark, C. L. (2000). Intimate partner violence and drinking patterns among White, Black, and Hispanic couples in the US. Journal of Substance Abuse, 11(2), 123-138.

Campbell, J. C. (1995). Prediction of homicide of and by battered women. In J. C. Campbell (Ed.), Assessing Dangerousness: Violence by Sexual Offenders, Batterers, and Child Abusers (pp. 96-113). Thousand Oaks, CA: Sage. 
Campbell, R., Dworkin, E., \& Cabral, G. (2009). An ecological model of the impact of sexual assault on women's mental health. Trauma, Violence, \& Abuse, 10(3), 225-246.

Carlson, B. E. (1984). Causes and maintenance of domestic violence: An ecological analysis. Social Service Review, 58(4), 569-587.

Carlson, B. E., \& Cervera, N. (1991). Inmates and their families: Conjugal visits, family contact, and family functioning. Criminal Justice and Behavior, 18(3), 318-331.

Casey, E. A., \& Beadnell, B. (2010). The structure of male adolescent peer networks and risk for intimate partner violence perpetration: Findings from a national sample. Journal of Youth and Adolescence, 39(6), 620-633.

Catalano, R., Novaco, R., \& McConnell, W. (1997). A model of the net effect of job loss on violence. Journal of Personality and Social Psychology, 72(6), 14401447.

Check, J. V. P., Malamuth, N. M., Elias, B., \& Barton, S. A. (1985). On hostile ground. Psychology Today, 4, 56-61.

Chodorow, N. J. (1978). The reproduction of mothering: Psychoanalysis and the sociology of gender. Berkeley, CA: University of California Press.

Chonco, N. R. (1989). Sexual assaults among male inmates: A descriptive study. The Prison Journal, 69(1), 72-82.

Clark, R. (2008, January-February). The dilemma of anger, aggression, and intimate partner violence. New Wineskins, 70. Retrieved from http://www.wineskins.org/ filter.asp?SID=2\&fi_key $=172 \&$ co_key $=1500$

Clemmer, D. (1940). The Prison Community. New York, NY: Holt, Rinehart, \& Winston.

Codd, H. (2007). Prisoners' families and resettlement: A critical analysis. Howard Journal of Criminal Justice, 46(3), 255-263.

Cohen, J. (1992). A power primer. Psychological Bulletin, 112(1), 155-159.

Coker, A. L., Smith, P. H., McKeown, R. E., \& King, M. J. (2000). Frequency and correlates of intimate partner violence by type: physical, sexual, and psychological battering. American Journal of Public Health, 90(4), 553-559. 
Comfort, M. L. (2003). 'Papa's house': The prison as domestic and social satellite. Ethnography, 3(4), 467-499.

Cook, S. L. (2002). Self-reports of sexual, physical, and nonphysical abuse perpetration: A comparison of three measures. Violence Against Women, 8(5), 541-565.

Copenhaver, M. M., Lash, S. J., \& Eisler, R. M. (2000). Masculine gender-role stress, anger, and male intimate abusiveness: Implications for men's relationships. Sex Roles: A Journal of Research, 42(5/6), 405-414.

Coser, R. L. (1990). Reflections on Merton's role-set theory. In J. Clack, C. Modgil, \& S. Modgil (Eds.), Robert K. Merton: Consensus and Controversy (pp. 159-174). London: Falmer Press, Taylor \& Francis Group.

Cowburn, M. (1998). A man's world: Gender issues in working with male sex offenders in prison. The Howard Journal, 37(3), 234-251.

Cox., D. (1972). Regression models and life tables. Journal of the Royal Statistical Society, Series B (Methodological), 34(2), 187-220.

Cullen, F. T., \& Gilbert, K. E. (1982). Reaffirming Rehabilitation. Cincinnati, OH: Anderson.

Cunningham, A., Jaffe, P. G., Baker, L., Dick, T., Malla, S., Mazaheri, N., \& Poisson, S. (1998). Theory-derived explanations of male violence against female partners: Literature update and related implications for treatment and evaluation. Retrieved February 26, 2010 from Centre for Children and Families in the Justice System website: http://www.lfcc.on.ca/male violence.html

Dallao, M. (1997). Coping with incarceration. Corrections Today, 59(6), 96-99.

DeJong, C. (1997). Survival analysis and specific deterrence: Integrating theoretical and empirical models of recidivism. Criminology, 35(4), 561-575.

Delsol, C., \& Margolin, G. (2004). The role of family-of-origin violence in men's marital violence perpetration. Clinical Psychology Review, 24(1), 99-122.

Delsol, C., Margolin, G., \& John, R. S. (2003). A typology of martially violent men and correlates of violence in a community sample. Journal of Marriage and Family, 65, 635-651. 
DeKeseredy, W., \& Kelly, K. (1993). Woman abuse in university and college dating relationships: The contribution of the ideology of family patriarchy. The Journal of Human Justice, 4(2), 25-52.

Dhami, M. K., Ayton, P., \& Loewenstein, G. (2007). Adaptation to imprisonment: Indigenous or imported? Criminal Justice and Behavior, 34(8), 1085-1100.

Dobash, R. E., \& Dobash, R. P. (1979). Violence Against Wives: A Case Against the Patriarchy. New York, NY: Free Press.

Draine, J., \& Wolff, N. (2009, September). Social capital and reentry to the community from prison (Center for Behavioral Health Services and Criminal Justice Research Brief). New Brunswick, NJ: Center for Behavioral Health Services and Criminal Justice Research, Rutgers University.

Dumond, R. W. (1992). The sexual assault of male inmates in incarcerated settings. The International Journal of the Sociology of Law, 20(2), 135-157.

Dunford, F. W., Huizinga, D., \& Elliott, D. S. (1990). The role of arrest in domestic assault: The Omaha police experiment. Criminology, 28(2), 183-206.

Dutton, D. G. (1994). The origin and structure of the abusive personality. Journal of Personality Disorders, 8(3), 181-191.

Dutton, D. G. (1998). The Abusive Personality: Violence and Control in Intimate Relationships. New York: Guilford Press.

Dutton, D. G., \& Corvo, K. (2006). Transforming a flawed policy: A call to revive psychology and science in domestic violence research and practice. Aggression and Violent Behavior, 11, 457-483.

Dutton, D. G., \& Corvo, K. (2007). The Duluth model: A data-impervious paradigm and a failed strategy. Aggression and Violent Behavior, 12, 658-667.

Dutton, D. G., \& Hart, S. D. (1992). Risk markers for family violence in a federally incarcerated population. International Journal of Law and Psychiatry, 15, 101112.

Easton, C. J., Mandel, D. L., Hunkele, K. A., Nich, C., Rounsaville, B. J., \& Carroll, K. M. (2007). A cognitive behavioral therapy for alcohol-dependent domestic violence offenders: An integrated substance abuse-domestic violence treatment approach (SADV). The American Journal on Addictions, 16(1), 24-31. 
Edens, J. F. (2009). Interpersonal characteristics of male criminal offenders: Personality, psychopathological, and behavioral correlates. Psychological Assessment, 21(1), 89-98.

Edens, J. F., Cruise, K. R., \& Buffington-Vollum, J. K. (2001). Forensic and correctional applications of the Personality Assessment Inventory. Behavioral Sciences and the Law, 19, 519-543.

Edens, J. F., \& Ruiz, M. A. (2005). PAI interpretive report for correctional settings. Lutz, FL:. Psychological Assessment Resources.

Edleson, J. L., \& Tolman, R. M. (1992). A comprehensive ecological approach. In J. L. Edelson \& R. M. Tolman (Eds.), Intervention for Men who Batter: An Ecological Approach (pp. 11-25). Newbury Park, CA: Sage.

Edwards, D. W., Scott, C. L., Yarvis, R. M., Paizis, C. L., \& Panizzon, M. S. (2003). Impulsiveness, impulsive aggression, personality disorder, and spousal violence. Violence and Victims, 18(1), 3-14.

Ehrensaft, M. K., Cohen, P., Brown, J., Smailes, E., Chen, H., \& Johnson, J. G. (2003). Intergenerational transmission of partner violence: A 20-year prospective study. Journal of Consulting and Clinical Psychology, 71(4), 741-753.

Ehrensaft, M. K., \& Vivian, D. (1996). Spouses' reasons for not reporting existing marital aggression as a marital problem. Journal of Family Psychology, 10(4), 443-453.

Eisikovits, Z. C., Edleson, J. L., Guttman, E., \& Sela-Amit, M. (1991). Cognitive styles and socialized attitudes of men who batter: Where should we intervene? Family Relations, 40, 72-77.

Ellison, C. G., Trinitapoli, J. A., Anderson, K. L., \& Johnson, B. R. (2007). Race/Ethnicity, religious involvement, and domestic violence. Violence Against Women, 13(11), 1094-1112.

Epstein, D., Bell, M. E., \& Goodman, L. A. (2003). Transforming aggressive prosecution policies: Prioritizing victims' long term safety in the prosecution of domestic violence cases. Journal of Gender, Social Policies, and the Law, 11(2), 465-498.

Erdfelder, E., Faul, F., \& Buchner, A. (1996). GPOWER: A general power analysis program. Behavior Research Methods, Instruments, \& Computers, 28, 1-11. 
Faulkner, R. A., Davey, M., \& Davey, A. (2005). Gender-related predictors of change in marital satisfaction and marital conflict. The American Journal of Family Therapy, 33, 61-83.

Fazel, S., Bains, P., \& Doll, H. (2006). Substance abuse and dependence in prisoners: A systematic review. Addiction, 101, 181-191.

Fazel, S., \& Danesh, J. (2002). Serious mental disorder in 23,000 prisoners: A systematic review of 62 surveys. The Lancet, 359, 545-550.

Feder, L., \& Wilson, D. B. (2005). A meta-analytic review of court-mandated batterer intervention programs: Can courts affect abusers' behavior? Journal of Experimental Criminology, 1, 239-262.

Felner, R. D., Aber, M. S., Primavera, J., \& Cauce, A. M. (1985). Adaptation and vulnerability in high-risk adolescents: An examination of environmental mediators. American Journal of Community Psychology, 13(4), 365-379.

Felner, R. D., Ginter, M., \& Primavera, J. (1982). Primary prevention during school transitions: Social support and environmental structure. American Journal of Community Psychology, 10(3), 277-290.

Felner, R. D., Primavera, J., \& Cauce, A. M. (1981). The impact of school transitions: A focus for preventive efforts. American Journal of Community Psychology, 9, 449-459.

Fenzel, L. M. (1989). Role strains and the transition to middle school: Longitudinal trends and sex differences. Journal of Early Adolescence, 9(3), 211-226.

Field, C. A., \& Caetano, R. (2004). Ethnic differences in intimate partner violence in the US general population: The role of alcohol use and socioeconomic status. Trauma, Violence, \& Abuse, 5(4), 303-317.

Fishman, L.T. (1990). A study of prisoners' wives doing time on the outside. Albany, NY: State University of New York.

Fiske, A. P., Kitayama, S., Markus, H. R., \& Nisbett, R. E. (1998). The cultural matrix of social psychology. In D. T. Gilbert, S. T. Fiske, \& G. Lindzey, The Handbook of Social Psychology: Vol. 2 (4 ${ }^{\text {th }}$ ed., pp. 915-981). Boston, MA: McGraw-Hill.

Fowler, F. J. (1995). Improving Survey Questions: Design and Evaluation. Thousand Oaks, CA: Sage. 
Fox, G. L., Benson, M. L., DeMaris, A. A., \& Van Wyk, J. (2002). Economic distress and intimate partner violence: Testing family stress and resources theories. Journal of Marriage and the Family, 64(3), 793-807.

Freedman, B. J., \& Rice, D. G. (1977). Marital therapy in prison: One-partner "couple therapy". Psychiatry, 40, 175-183.

Gadsen, V. L. (2003). Heading Home: Offender Reintegration into the Family. Lanham, MD: American Correctional Association.

Garcia-Moreno, C., Jansen, H., Ellsberg, M., Heise, L., \& Watts, C. (2005). WHO Multi-county study on women's health and domestic violence against women: Initial results on prevalence, health outcomes, and women's responses. Geneva, Switzerland: WHO Press.

Gatz, N., \& Vito, G. F. (1982). The use of the determinate sentence-an historical perspective: A research note. Journal of Criminal Justice, 10, 323-329.

Gelles, R. J. (1999). Male offenders. In M. Harway \& J. M. O’Neil (Eds.), What Causes Men's Violence Against Women? (pp. 36-48). Thousand Oaks, CA: Sage.

Gelles, R. J., \& Straus, M. A. (1979a). Violence in the American family. Journal of Social Issues, 35, 15-39.

Gelles, R. J., \& Straus, M. A. (1979b). Determinants of violence in the family: Toward a theoretical integration. In W. R. Burr, R. Hill, F. I., Nye, \& I. Reiss (Eds.), Contemporary Theories about the Family (pp. 549-579). New York, NY: Free Press.

Gelles, R. J., \& Straus, M. A. (1988). Intimate Violence: The Causes and Consequences of Abuse in the American Family. New York, NY: Simon \& Schuster, Inc.

Gendreau, P. (1996). The principles of effective intervention with offenders. In A.T. Harland (Ed.), Choosing Correctional Options that Work: Defining the Demand and Evaluating the Supply (pp. 117-130). Thousand Oaks, CA: Sage.

Gendreau, P., \& Goggin, C., \& Cullen, F. T. (1999). The Effects of prison sentences on recidivism. Ottawa: Solicitor General Canada.

Gendreau, P., \& Goggin, C., Cullen, F. T., \& Andrews, D. A. (2000). The effects of community sanctions and incarceration on recidivism. Forum on Corrections Research, 12(2), 10-13. 
Gendreau, P., Little, T., \& Goggin, C. (1996). A meta-analysis of the predictors of adult offender recidivism: What works! Criminology, 34, 575-607.

Gillespie, W. (2004). The context of imprisonment. In S. Stanko, W. Gillespie, \& G. A. Crews (Eds.), Living in Prison: A History of the Correctional System with an Insider's View (pp. 63-88). Westport, CT: Greenwood Press.

Glaze, L. E., \& Maruschak, L. M. (2008). Parents in prison and their minor children. (Report No. NCJ 222984). Retrieved September 30, 2011 from Bureau of Justice Statistics: http://bjs.ojp.usdoj.gov/content/pub/pdf/pptmc.pdf

Glover, A. J. J., Nicholson, D. E., Hemmati, T., Bernfeld, G. A., \& Quinsey, V. L. (2002). A comparison of predictors of general and violent recidivism among high-risk federal offenders. Criminal Justice and Behavior, 29(3), 235-249.

Goldstein, D., \& Rosenbaum, A. (1985). An evaluation of the self-esteem of martially violent men. Family Relations, 34, 425-428.

Gondolf, E. W. (1988). Who are those guys? Toward a behavioral typology of batterers. Violence and Victims, 3, 187-203.

Gondolf, E. W. (2002). Batterer Intervention Systems: Issues, outcomes, and recommendations. Thousand Oaks, CA: Sage.

Gondolf, E. W. (2007). Theoretical and research support for the Duluth Model: A reply to Dutton and Corvo. Aggression and Violent Behavior, 12, 644-657.

Good, G.E., \& Wood, P.K. (1995). Male gender role conflict, depression, and help seeking: Do college men face double jeopardy? Journal of Counseling and Development, 74, 70-75.

Gottschalk, M. (2009). Money and mass incarceration: The bad, the mad, and penal reform. Criminology \& Public Policy, 8(1), 97-109.

Gracia, E. (2004). Unreported cases of domestic violence against women: towards an epidemiology of social silence, tolerance, and inhibition. Journal of Epidemiological Community Health, 58, 536-537.

Graham-Bermann, S., \& Gross, M. (2008). Ecological models of violence. In C. M. Renzetti \& J. L. Edleson (Eds.) Encyclopedia of Interpersonal Violence, Vol. 2 (pp. 212-214). Thousand Oaks, CA: Sage.

Greenfeld, L. A., \& Henneberg, M. A. (2001). Victim and offender self-reports of alcohol involvement in crime. Alcohol Research \& Health, 25(1), 20-31. 
Gribble, J. N., Miller, H. G., Rogers, S. M., \& Turner, C. F. (1999). Interview mode and measurement of sexual behaviors: Methodological issues. Journal of Sex Research, 36(1), 16-24.

Griffin, D., \& Bartholomew, K. (1992). Testing a two dimensional model of adult attachment: A latent variable approach. Waterloo, Ontario, Canada: University of Waterloo Department of Psychology.

Groth-Marnat, G. (1997). Handbook of psychological assessment, $3^{\text {rd }}$ Edition. New York: Wiley.

Hairston, C. F. (1995). Fathers in prison. In K. Gabel \& D. Johnston (Eds.) Children of Incarcerated Parents (pp. 31-40). New York, NY: Lexington Books.

Hairston, C. F., \& Oliver, W. (2006). Domestic Violence and Prisoner Reentry: Experiences of African American Women and Men. New York: Vera Institute of Justice. Retrieved August 29, 2009 http://www.dvinstitute.org/current/ pdfs/367_660.pdf

Hamberger, L. K. (2009). Risk factors for intimate partner violence perpetration: Typologies and characteristics of batterers. In C. Mitchell \& D. Anglin (Eds.), Intimate Partner Violence: A Health-Based Perspective (pp. 115-131). New York, NY: Oxford University Press.

Hamberger, L. K., \& Hastings, J. E. (1986). Personality correlates of men who abuse their partners: A cross validation study. Journal of Family Violence, 1, 323-341.

Hamberger, L. K., Lohr, J. M., Bonge, D., \& Tolin, D. F. (1996). A large empirical typology of male spouse abusers and its relationship to dimensions of abuse. Violence and Victims, 11, 277-292.

Hamilton, L. C. (2009). Statistics with STATA: Updated for Version 10. Belmont, CA: Brooks/Cole.

Hampton, R. L., \& Gelles, R. J. (1994). Violence toward Black women in a nationally representative sample of Black families. Journal of Comparative Family Studies, 25, 105-119.

Hampton, R., Oliver, W., \& Magarian, L. (2003). Domestic violence in the African American community: An analysis of social and structural factors. Violence Against Women, 9(5), 533-557. 
Haney, C. (2008). The consequences of prison life: Notes on the new psychology of prison effects. In D. Carter \& R. Žukanskiené (Eds.), Psychology and the Law: Bridging the Gap (pp. 143-166). Burlington, VT: Ashgate Publishing Company.

Hannon, G. Martin, D., \& Martin, M. (1984). Incarceration in the family: Adjustment to change. Family Therapy, 11, 253-260.

Hanson, R. K., Helmus, L., \& Bourgon, G. (2007). The validity of risks assessments for intimate partner violence: A meta-analysis. Ottawa, ON: Public Safety Canada.

Harding, D. J. (2003). Jean val Jean's dilemma: The management of ex-convict identity in the search for employment. Deviant Behavior, 24, 571-595.

Hare, R. D. (1991). Manual for the Hare Psychopathy Checklist-Revised. Toronto, Canada: Multi-Health Systems.

Harford, T. C., Grant, B. F., Yi, H., \& Chen, C. M. (2005). Patterns of DSM-IV alcohol abuse and dependence criteria among adolescents and adults: Results from the 2001 National Household Survey on Drug Abuse. Alcoholism: Clinical and Experimental Research, 29(5), 810-828.

Harlow, C. W. (2003). Education and Correctional Populations. (Report No. NCJ 195670). Retrieved December 10, 2009 from the US Department of Justice Office of Justice Programs: http://www.ojp.usdoj.gov/bjs/abstract/ecp.htm

Harman, J. J., Smith, V. E., \& Egan, L. C. (2007). The impact of incarceration on intimate relationships. Criminal Justice and Behavior, 34(6), 794-815.

Harrell, W. A. (1990). Husband's masculinity, wife's power, and marital conflict. Social Behavior and Personality, 18(2), 207-216.

Harrell, A., \& Smith, B. E. (1996). Effects of restraining orders on domestic violence victims. In E. S. Buzawa \& C. G. Buzawa (Eds.), Do Arrests and Restraining Orders Work? (pp. 214-242). Thousand Oaks, CA: Sage.

Harris, G. T., Rice, M. E., \& Quinsey, V. L. (1993). Violent recidivism of mentally disordered offenders: The development of a statistical prediction instrument. Criminal Justice and Behavior, 20, 315-335.

Harrison, P. M., \& Beck, A. J. (2003). Prisoners in 2002. Washington, DC: U.S. Department of Justice.

Harway, M., \& O’Neil, J. M. (1999). What Causes Men’s Violence Against Women? Thousand Oaks, CA: Sage Publications. 
Hathaway, S. R., \& McKinley, J. C. (1943). The Minnesota Multiphasic Personality Inventory. Minneapolis, MN: University of Minnesota Press.

Healey, K., Smith, C., \& O’Sullivan, C. (1998). Batterer intervention: Program approaches and criminal justice strategies. Issues and Practice in Criminal Justice (Report No. OJP-94-C-007). Washington, DC: National Institute of Justice.

Heise, L. L. (1998). Violence against women: An integrated, ecological framework. Violence Against Women, 4(3), 262-290.

Henning, K., \& Connor-Smith, J. (2011). Why doesn't he leave? Relationship continuity and satisfaction among male domestic violence offenders. Journal of Interpersonal Violence, 26(7), 1366-1387.

Henning, K., Martinsson, R., \& Holdford, R. (2009). Gender differences in risk factors for intimate partner violence recidivism. Journal of Aggression, Maltreatment, \& Trauma, 18(6), 623-645.

Hensley, C., Koscheski, M., \& Tewksbury, R. (2005). Examining the characteristics of male sexual assault targets in a southern maximum-security prison. Journal of Interpersonal Violence, 20(6), 667-679.

Hensley, C., Tewksbury, R., \& Castle, T. (2003). Characteristics of prison sexual assault targets in male Oklahoma correctional facilities. Journal of Interpersonal Violence, 18(6), 595-606.

Hemann, L. K. (2007). A multivariate analysis of masculine gender role strain and its relationship to degrees of substance dependence and degrees of violence in an adult incarcerated population (Doctoral dissertation). Available from ProQuest Dissertations and Theses database. (UMI No. 3260872)

Herman-Stahl, M., \& Kan, M. L., \& McKay, T. (2008). Incarceration and the family: A review of research and promising approaches for serving fathers and families. Washington, DC: US Department of Health and Human Services. Retrieved October 21, 2009 from http://aspe.hhs.gov/hsp/08/MFSIP/ Incarceration\&Family/report.pdf

Hilton, N. Z., \& Harris, G. T. (2005). Predicting wife assault: A critical review and implications for policy and practice. Trauma, Violence, \& Abuse, 6(1), 3-23.

Hilton, N. A., Harris, G. T., Popham, S., \& Lang, C. (2010). Risk assessment among incarcerated male domestic violence offenders. Criminal Justice and Behavior, 37(8), 815-832. 
Hilton, N. Z., Harris, G. T., Rice, M. E., Lang, C., \& Cormier, C. A. (2004). A brief actuarial assessment for the prediction of wife assault recidivism: The ODARA. Psychological Assessment, 16(3), 267-275.

Hirschi, T., \& Gottfredson, M. (1988). Towards a general theory of crime. In W. Buikhuisen \& S. A. Mednick (Eds.), Explaining Criminal Behaviour (pp. 8-26). Leiden, The Netherlands: E. J. Brill.

Holtzworth-Munroe, A. (2000). A typology of men who are violent toward their female partners: Making sense of the heterogeneity in husband violence. Current Directions in Psychological Science, 9(4), 140-143.

Holtzworth-Munroe, A., Meehan, J. C., Herron, K., Rehman, U., \& Stuart, G. L. (2000). Testing the Holtzworth-Munroe and Stuart (1994) batterer typology. Journal of Consulting and Clinical Psychology, 68(6), 1000-1019.

Holtzworth-Munroe, A., \& Stuart, G. L. (1994). Typologies of male batterers: Three subtypes and the differences among them. Psychological Bulletin, 116(3), 476497.

Horowitz, J. (2010, February). Containing crime and prison costs: A Look at innovative solutions. In B. Renauer (Chair), Containing Crime and Prison Costs. Forum conducted at the Portland State University Hatfield School of Government Second Annual Criminal Justice Forum, Portland, OR.

Hosmer, D. W. (2000). Applied Logistic Regression (2 ${ }^{\text {nd }}$ Edition). New York, NY: John Wiley \& Sons.

Hotaling, G. T., \& Sugarman, D. B. (1986). An analysis of risk markers in husband to wife violence: The current state of knowledge. Violence \& Victims, 1, 101-124.

Hotaling, G. T., \& Sugarman, D. B. (1990). A risk marker analysis of assaulted wives. Journal of Family Violence, 5(1), 1-13.

Howell, D. C. (2009). Treatment of missing data. Retrieved May 18, 2011 from http://www.uvm.edu/ dhowell/StatPages/More_Stuff/Missing_Data/ Missing.html

Hughes, M. (1998). Turning points in the lives of young inner-city men forgoing destructive criminal behaviors: A qualitative study. Social Work Research, 22(3), 143-151. 
Institute on Domestic Violence in the African American Community (2008). Safe Return Initiative. Retrieved October 15, 2009 from http://www.dvinstitute.org/ Currentinitiatives/safereturninitiative.html

Jakupcak, M., Lisak, D., \& Roemer, L. (2002). The role of masculine ideology and masculine gender role stress in men's perpetration of relationship violence. Psychology of Men and Masculinity, 3, 97-106.

Jennings, J. L. \& Murphy, C. M. (2000). Male-male dimensions of male-female battering: A new look at domestic violence. Psychology of Men and Masculinity, 1(1), 21-29.

Jezl, D. R., Molidor, C. E., \& Wright, T. L. (1996). Physical, sexual, and psychological abuse in high school dating relationships: Prevalence rates and self-esteem issues. Child and Adolescent Social Work Journal, 13(1), 69-87.

Johnson, M. P., \& Ferraro, K. J. (2000). Research on domestic violence in the 1990s: Making distinctions. Journal of Marriage and the Family, 62(4), 948-963.

Johnson, P. R., \& Indvik, J. (1994). Workplace violence: An issue of the nineties. Public Personnel Management, 23(4), 515-523.

Kantor, G. K., Jasinski, J. L., \& Aldarondo, E. (1994). Sociocultural status and incidence of marital violence in Hispanic families. Special issue: Violence against women of color. Violence and Victims, 9, 207-222.

Kaplan, E. L., \& Meier, P. (1958). Nonparametric estimation from incomplete observations. Journal of the American Statistical Association, 53, 457-481.

Kaufman, M. (1994). Men, feminism, and men's contradictory experiences of power. In H. Brod \& M. Kaufman (Eds.) Theorizing Masculinities (pp. 142-164). Thousand Oaks, CA: Sage Publications.

Kaufman-Kantor, G., \& Straus, M. A. (1990). Response of victims and the police to assaults on wives. In M. A. Straus \& R. J. Gelles (Eds.). Physical Violence in American Families: Risk Factors and Adaptations to Violence in 8,145 Families (pp. 473-487). New Brunswick, NJ: Transaction Publishers.

Kaufman-Kantor, G. \& Straus, M. A. (2003). The "drunken bum" theory of wife beating. In J. D. Orcutt \& D. R. Rudy (Eds.), Drugs, Alcohol, and Social Problems (pp. 219-238). Lanham, MD: Rowman \& Littlefield. 
Kazemain, L., \& LeBlanc, M. (2004). Exploring patterns of perpetration of crime across the life course: Offense and offender-based viewpoints. Journal of Contemporary Criminal Justice, 20(4), 393-415.

Kelly, J. G. (1966). Ecological constraints on mental health services. American Psychologist, 21(6), 535-539.

Kelly, J. G. (1968). Toward an ecological conception of preventive interventions. In J. W. Carter, Jr. (Ed.), Research Contributions from Psychology to Community Mental Health (pp. 75-99). New York, NY: Behavioral Publications.

Kilmartin, C. T. (2000). The Masculine Self, $2^{\text {nd }}$ Edition. Boston, MA: The McGrawHill Companies, Inc.

Kimmel, M. S. (1994). Masculinity as homophobia: Fear, shame, and silence in the construction of gender identity. In H. Brod \& M. Kaufman (Eds.), Theorizing Masculinities (pp. 119-141). Thousand Oaks, CA: Sage.

Kite, M. E., Deaux, K., \& Haines, E. L. (2008). Gender stereotypes. In F. L. Denmark \& M. A. Paludi (Eds.) Psychology of Women: A Handbook of Issues and Theories (pp. 205-236). Westport, CT: Praeger Publishers.

Kochel, T. R., Wilson, D. B., \& Mastrofski, S. D. (2011). Effect of suspect race on officers' arrest decisions. Criminology, 49(2), 473-512.

Koss, M. P., \& Dinero, T. E. (1989). Discriminant analysis of risk factors for sexual victimization among a national sample of college women. Journal of Consulting and Clinical Psychology, 57, 242-250.

Koss, M. P., Gidycz, C. A., \& Wisniewski, N. (1987). The scope of rape: Incidence and prevalence of sexual aggression and victimization in a national sample of higher education students. Journal of Consulting and Clinical Psychology, 55, 162-170.

Knight, K., Simpson, D. D., \& Hiller, J. T. (2002). Screening and referral for substanceabuse treatment in the criminal justice system. In C.G. Leukefeld, F. M. Tims, \& D. Farabee (Eds.), Treatment of drug offenders: Policies and Issues (pp. 259272). New York, NY: Springer.

Kropp, P. R. (2009). Intimate partner violence risk assessment. In J. L. Ireland, C. A. Ireland, \& P. Birch (Eds.), Violent and Sexual Offenders: Assessment, Treatment, and Management (pp. 43-67). 
Kropp, P. R., Hart, S. D., Webster, C. D., \& Eaves, D. (1995). Manual for the Spousal Assault Risk Assessment Guide, $2^{\text {nd }}$ Ed. Vancouver, BC: British Columbia Institute on Family Violence. Portland, OR: Willan Publishing.

Kropp, P. R., Hart, S. D., Webster, C. D., \& Eaves, D. (1999). Spousal Assault Risk Assessment Guide (SARA). Toronto, ON: Multi-Health Systems, Inc.

Laub, J. H., \& Sampson, R. J. (2003). Shared beginnings, divergent lives: Delinquent boys to age 70. Cambridge, MA: Harvard University Press.

Lazarus, R. S. (2006). Emotions and interpersonal relationships: Toward a personcentered conceptualization of emotions and coping. Journal of Personality, 74(1), 9-46.

Lerman, A. E. (2009). The people prisons make: Effects of incarceration on criminal psychology. In S. Raphael \& M. A. Stoll (Eds.), Do Prisons make us Safer? The Benefits and Costs of the Prison Boom (pp. 151-176). New York, NY: Russell Sage Foundation.

Liang, B., Goodman, L., Tummala-Marra, P., \& Weintraub, S. (2005). A theoretical framework for understanding help-seeking processes among survivors of intimate partner violence. American Journal of Community Psychology, 36(1/2), 71-84.

Lipsey, M. W., Wilson, D. B., Cohen, M. A., \& Derzon, J. H. (1997). Is there a causal relationship between alcohol use and violence? A synthesis of evidence. In M. Galanter (Ed.), Recent Developments in Alcoholism, Vol 13: Alcoholism and Violence. New York, NY: Plenum Press.

Lisak, D., Hopper, J., \& Song, P. (1996). Factors in the cycle of violence: Gender rigidity and emotional constriction. Journal of Traumatic Stress, 9(4), 721-743.

Little, T. D., Bovaird, J. A., \& Card, N. A. (2007). Modeling Contextual Effects in Longitudinal Studies. Mahwah, NJ: Lawrence Erlbaum Associates, Inc.

Logan, T. K., Walker, R., Staton, M., \& Leukefeld, C. (2001). Substance use and intimate violence among incarcerated males. Journal of Family Violence, 16(2), 93-114.

Lohr, J. M., Bonge, D., Witte, T. H., Hamberger, L. K., \& Langhinrichsen-Rohling, J. (2005). Consistency and accuracy of batterer typology identification. Journal of Family Violence, 20(4), 253-258. 
Loo, R., \& Thorpe, K. (2000). Confirmatory factor analyses of the full and short versions of the Marlowe-Crowne Social Desirability Scale. Journal of Social Psychology, 140(5), 628-635.

Lorber, M. F., \& O'Leary, K. D. (2004). Predictors of the persistence of male aggression in early marriage. Journal of Family Violence, 19(6), 329-338.

Luke, D. A. (1993). Charting the process of change: A primer on survival analysis. American Journal of Community Psychology, 21(2), 203-246.

Lutze, F. E., \& Murphy, D. W. (1999). Ultramasculine prison environments and inmates' adjustment: It's time to move beyond the "boys will be boys" paradigm. Justice Quarterly, 16(4), 709-733.

Lynam, D. R., Caspi, A., Moffitt, T. E., Wikström, P. O. H., Loeber, R., \& Novak, S. (2000). The interaction between impulsivity and neighborhood context on offending: The effects of impulsivity in poorer neighborhoods. Journal of Abnormal Psychology, 109, 563-574.

Maiuro, R. D., Cahn, T. S., Vitaliano, P. P., Wagner, B. C., \& Zegree, J. B. (1988). Anger, hostility, and depression in domestically violent versus generally assaultive men and nonviolent control subjects. Journal of Consulting and Clinical Psychology, 45, 247-255.

Maiuro, R. D., \& Eberle, J. A. (2008). State standards for domestic violence perpetrator treatment: Current status, trends, and recommendations. Violence and Victims, 23(2), 133-155.

Majors, R., \& Billson, J. M. (1992). Cool pose: The dilemmas of Black manhood in America. New York, NY: Lexington.

Malamuth, N. M., Sockloskie, R. J., Koss, M. P. \& Tanaka, J. S. (1991). Characteristics of aggressors against women: Testing a model using a national sample of college students. Journal of Consulting and Clinical Psychology, 59(5), 670681 .

Mankowski, E. S., Silvergleid, C. S., \& Abassi, B. (2001). Correlates of Men's physical and psychological abuse: Results of a survey of clients at the Men's Resource Center. Unpublished manuscript, Portland State University, Portland, OR.

Manstead, A. S. R. (1996). Attitudes and behavior. In G.R. Semin \& K. Fiedler (Eds.), Applied Social Psychology (pp. 3-29). Thousand Oaks, CA: Sage. 
Marin, A. J., \& Russo, N. F. (1999). Feminist perspectives on male violence against women. In M. Harway \& J. M. O’Neil (Eds.), What Causes Men’s Violence Against Women? (pp. 18-35). Thousand Oaks, CA: Sage Publications.

Marshall, L. L. (1992). Development of the severity of violence against women scales. Journal of Family Violence, 7, 103-121.

Marshall, W. L., \& Moulden, H. (2001). Hostility toward women and victim empathy in rapists. Sexual Abuse: A Journal of Research and Treatment, 13(4), 249-255.

Maruna, S. (2001). Making Good: How Ex-Convicts Reform and Rebuild their Lives. Washington, DC: American Psychological Association.

Maruna, S., \& Immarigeon, R. (2004). After Crime and Punishment: Pathways to ExOffender Reintegration. Cullompton, Devon, UK: Willan Books.

Mauer, M., \& King, R. S. (2007). Uneven justice: State rates of incarceration by race and ethnicity. Washington, DC: The Sentencing Project. Retrieved December 30, 2009 from The Sentencing Project: http:/www.sentencingproject.org/doc/ publications/rd_stateratesofincbyraceandethnicity.pdf

McCaffrey, B. (1998). Drug Treatment in the Criminal Justice System. Washington, DC: Office of National Drug Control Policy.

McCarroll, J. E., Ursano, R. J., Liu, X., Thayer, L. E., Newby, J. H., Norwood, A. E., \& Fullerton, C. S. (2010). Deployment and the probability of spousal aggression by US Army soldiers. Military Medicine, 175(5), 352-356.

McCloskey, L. A. (1996). Socioeconomic and coercive power within the family. Gender \& Society, 10(4), 449-463.

Messerschmidt, J. W. (1993). Masculinities and Crime: Critique and Reconceptualization of Theory. Lanham, MD: Rowman \& Littlefield.

Messerschmidt, J. W. (2005). Men, masculinities, and crime. In M. S. Kimmel, J. Hearn, \& R. W. Connell (Eds.), Handbook of Studies on Men \& Masculinities (pp. 196-212). Thousand Oaks, CA: Sage.

Millon, T. (1983). Millon Clinical Multiaxial Inventory Manual, $3^{\text {rd }}$ Edition. Minneapolis, MN: Interpretive Scoring System.

Mills, A., \& Codd, H. (2008). Prisoners' families and offender management: Mobilizing social capital. Probation Journal: The Journal of Community and Criminal Justice, 55(1), 9-24. 
Mitchell, R. E., \& Hodson, C. A. (1986). Coping and social support among battered women: An ecological perspective. In S. E. Hobfoll (Ed.), Stress, Social Support, and Women (pp. 153- 169). New York, NY: Hemisphere Publishing Corporation.

Moe, A., \& Bell, M. (2004). Abject economics: The effects of battering and violence on women's work and employability. Violence Against Women, 10(1), 29-55.

Moore, T. M., \& Stuart, G. L. (2005). A review of the literature on masculinity and partner violence. Psychology of Men \& Masculinity, 6, 46-61.

Morey, L. C. (1991). The Personality Assessment Inventory professional manual. Odessa, FL: Psychological Assessment Resources.

Morey, L. C. (2007). The Personality Assessment Inventory professional manual $\left(2^{\text {nd }}\right.$ ed.). Lutz, FL: Psychological Assessment Resources.

Morris, N. (1974). The Future of Imprisonment. Chicago, IL: University of Chicago Press.

National Commission for the Protection of Human Subjects of Biomedical and Behavioral Research (1979). Belmont Report: Ethical principles and guidelines for the protection of human subjects of research. Washington, DC: U.S. Government Printing Office.

Nason-Clark, N. (2000). Making the sacred safe: Woman abuse and communities of faith. Sociology of Religion, 61(4), 349-368.

Nelson, M., Deess, P., \& Allen, C. (1999). The First Month Out: Post-Incarceration Experiences in New York City. New York: Vera Institute. Retrieved May 6, 2010 from http://www.vera.org/content/first-month-out-post-incarcerationexperiences-new-york-city

Neufeld, J., McNamara, J. R., \& Ertl, M. (1999). Incidence and prevalence of dating partner abuse and its relationship to dating practices. Journal of Interpersonal Violence, 14(2), 125-137.

Nurse, A. (2002). Fatherhood arrested: Parenting from within the juvenile justice system. Nashville, TN: Vanderbilt University Press.

O'Brien, P., \& Bates, R. (2003). Negotiating the waves: Challenges of conducting inprison and follow-up research with women. Affilia, 18(2), 210-225. 
Ogloff, J. R. P. (2006). Psychopathy/antisocial personality disorder conundrum. Australian and New Zealand Journal of Psychiatry, 40(6-7), 519-528.

O’Leary, K. D. (1999). Psychological abuse: A variable deserving critical attention in domestic violence. Violence and Victims, 14(1), 3-23.

O'Leary, K. D., \& Schumacher, J. A. (2003). The association between alcohol use and intimate partner violence: Linear effect, threshold effect, or both? Addictive Behaviors, 28, 1575-1585.

O’Leary, K. D., Smith Slep, A. M., \& O’Leary, S. G. (2007). Multivariate models of men's and women's partner aggression. Journal of Consulting and Clinical Psychology, 75(5), 752-764.

Oliver, W., \& Hairston, C. F. (2008) Intimate partner violence during the transition from prison to the community: Perspectives of incarcerated African American men. Journal of Aggression, Maltreatment, and Trauma, 16(3), 258-276.

Oliver, W., Williams, O. J., Hairston, C. F., \& Crowder, L. (2004). Prisoner reentry and intimate partner violence in the African American community: The case for culturally competent interventions. Journal of the Institute of Justice and International Studies, 4, 147-156.

O’Neil, J. M. (2008). Summarizing 25 years of research on men's gender role conflict using the Gender Role Conflict Scale: New research paradigms and clinical implications. The Counseling Psychologist, 36(3), 358-445.

O'Neil, J. M., Helms, B., Gable, R., David, L., \& Wrightsman, L. (1986). Gender role conflict scale (GRCS): College men's fear of femininity. Sex Roles, 14, 335-350.

O'Neil, J. M. \& Nadeau, R.A. (1999). Men's gender role conflict, defense mechanisms, and self-protective defensive strategies: Explaining men's violence against women from a gender role socialization perspective. In M. Harway \& J. O'Neil (Eds.) What causes men's violence against women? (pp. 89-116). Thousand Oaks, CA: Sage Publications.

Oregon Criminal Justice Commission (2010). The Public Safety Checklist for Oregon. Retrieved February 3, 2011 from Oregon Criminal Justice Commission website: http://risktool.ocjc.state.or.us/psc/

Oregon Department of Corrections (1991). Oregon Case Management System. Retrieved February 3, 2011 from National Institute of Corrections website: http://nicic.gov/Library/009279 
Oregon Department of Corrections (2007). Local Supervisory Authority Procedure Manual. Retrieved October 4, 2011 from Oregon Department of Corrections Community Corrections website: http://www.oregon.gov/DOC/TRANS/CC/ docs/pdf/Local_Supervisory_Authority_Procedures_Manual.pdf?ga=t

Oregon Department of Corrections (2011). Offender demographics [Data file]. Retrieved January 31, 2011 from Oregon Department of Corrections' Corrections Management Information System: http://cmis/CMIS/CMIS/ cmisportal.jsp

Pan, H. S., Neidig, P. H., \& O’Leary, K. D. (1994). Predicting mild and severe husband-to-wife physical aggression. Journal of Consulting and Clinical Psychology, 62, 975-981.

Parrott, D. J., \& Zeichner, A. (2003). Effects of hypermasculinity on physical aggression against women. Psychology of Men \& Masculinity, 4(1), 70-78.

Pate, A. M., \& Hamilton, E. E. (1992). Formal and informal deterrents to domestic violence: The Dade county spouse assault experiment. American Sociological Review, 57(5), 691-697.

Paterline, B. A., \& Petersen, D. M. (1999). Structural and social psychological determinants of prisonization. Journal of Criminal Justice, 27(5), 427-441.

Pence, E., \& Paymar, M. (1993). Education Groups for Men who Batter: The Duluth Model. New York, NY: Springer.

Petersilia, J. (2001). When prisoners return to the community: Political, economic, and social consequences. In A. R. Roberts \& D. W. Springer (Eds). Social Work in Juvenile and Criminal Justice Settings (pp. 400-407). Springfield, IL: Charles C Thomas.

Petersilia, J. (2009). When Prisoners Come Home: Parole and Prisoner Reentry. New York, NY: Oxford University Press.

Piotrowski, C. (2000). How popular is the Personality Assessment Inventory in practice and training? Psychological Reports, 86, 65-66.

Pleck, J. H. (1995). The gender role strain paradigm: An update. In R. F. Levant \& W. S. Pollack (Eds.), A new psychology of men (pp. 11-32). New York, NY: Basic Books.

Porporino, F. J. (1990). Difference in response to long-term imprisonment: Implications for the management of long-term offenders. The Prison Journal, 70(1), 35-45. 
Raphael, S. (2009). Explaining the rise in US incarceration rates. Criminology \& Public Policy, 8(1), 87-95.

Rappaport, J. (1981). In praise of paradox: A social policy of empowerment over prevention. American Journal of Community Psychology, 9(1), 1-25.

Rice, M. E. (1997). Violent offender research and implications for the criminal justice system. American Psychologist, 52(4), 414-423.

Rice, M. E., \& Harris, G. T. (1995). Violent recidivism: Assessing predictive validity. Journal of Consulting and Clinical Psychology, 63(5), 737-748.

Riesch Toepell, A., \& Greaves, L. (2001). Experience of abuse among women visiting incarcerated partners. Violence Against Women, 7(1), 80-109.

Roberston, K. \& Murachver, T. (2007). Correlates of partner violence for incarcerated women and men. Journal of Interpersonal Violence, 22(5), 639-655.

Rose, D. (2001). Masculinity, offending, and prison-based work. In B. Pease and P. Camilleri (Eds.), Working with Men in the Human Services (pp. 147-158). St. Crows Nest, New South Wales, Australia: Allen \& Unwin.

Rose, D. R., \& Clear, T. R. (1998). Incarceration, social capital, and crime: Implications for social disorganization theory. Criminology, 36(3), 441-479.

Rose, D. R., \& Clear, T. R. (2003). Incarceration, reentry, and social capital: Social networks in the balance. In J. Travis \& M. Waul (Eds.), Prisoners Once Removed: The Impact of Incarceration and Reentry on Children, Families, and Communities (pp. 313-341). Washington, DC: The Urban Institute.

Rosenbaum, A., Hoge, S. K., Adelman, S. A., Warnken, W. J., Fletcher, K. E., \& Kane, R. L. (1994). Head injury in partner-abusive men. Journal of Consulting and Clinical Psychology, 62(6), 1187-1193.

Rowe, D. C., \& Osgood, D. W. (1984). Heredity and sociological theories of delinquency: A reconsideration. American Sociological Review, 49(4), 526-540.

Rummel, R. J. (1970). Applied factor analysis. Evanston, IL: Northwestern University Press.

Sabol, W. J., West, H. C., \& Cooper, M. (2009). Prisoners in 2008. (Report No. NCJ 228417). Retrieved October 29, 2010 from Bureau of Justice Statistics: http://bjs.ojp.usdoj.gov/content/pub/pdf/p08.pdf 
Sampson, R. J., \& Wilson, W. J. (1995). Toward a theory of race, crime, and urban inequality. In J. Hagan \& R. D. Peterson (Eds.), Crime and Inequality (pp. 3754). Stanford, CA: Stanford University Press.

Saunders, D. G. (1992). A typology of men who batter women: Three types derived from cluster analysis. American Orthopsychiatry, 62, 264-275.

Schumacher, J. A., Feldbau-Kohn, S., Smith Slep, A. M., \& Heyman, R. E. (2001). Risk factors for male-to-female partner physical abuse. Aggression and Violence Behavior, 6, 281-352.

Schwartz, J. P., Buboltz, W. C., Seemann, E., \& Flye, A. (2004). Personality styles: Predictors of masculine gender role conflict in male prison inmates. Psychology of Men \& Masculinity, 5(1), 59-64.

Scully, D. (1990). Understanding Sexual Violence: A Study of Convicted Rapists. Cambridge, MA: Unwin Hyman.

Sears, D. O. (1986). College sophomores in the laboratory: Influences of a narrow data base on social psychology's view of human nature. Journal of Personality and Social Psychology, 51(3), 515-530.

Seymour, K. (2003). Imprisoning masculinity. Sexuality \& Culture, 7(4), 27-55.

Sherman, L. W., \& Berk, R. A. (1984). The specific deterrent effects of arrest for domestic assault. American Sociological Review, 49(2), 261-272.

Sherman, L. W., Smith, D. A., Schmidt, J. D., \& Rogan, D. P. (1992). Crime, punishment, and stake in conformity: Legal and informal control of domestic violence. American Sociological Review, 57, 680-690.

Showalter, D., \& Williams-Jones, C. (1980). Marital and family counseling in prisons. Social Work, 25, 224-228.

Sim, J. (1994). Tougher than the rest? Men in prison. In T. Newburn \& B. Stanko (Eds.), Just Boys doing Business? Men, Masculinities, and Crime. London, England: Routledge.

Simons, R. L., Wu, C., Johnson, C., \& Conger, R. D. (1995). A test of various perspectives on the intergenerational transmission of domestic violence. Criminology, 33(1), 141-172.

Simourd, D. J., \& Olver, M. E. (2002). The future of criminal attitudes research and practice. Criminal Justice and Behavior, 29(4), 427-446. 
Simpson, L. E., Doss, B. D., Wheeler, J., \& Christensen, A. (2007). Relationship violence among couples seeking therapy: Common couple violence or battering? Journal of Marital and Family Therapy, 33(2), 270-283.

Singh, V. (2009). Academic men's health: Case studies in clinical practice: Intimate partner violence perpetration. Journal of Men's Health, 6(4), 383-392.

Smith, D. A., Visher, C. A., \& Davidson, L. A. (1984). Equity and discretionary justice: The influence of race on police arrest decisions. The Journal of Criminal Law \& Criminology, 75(1), 234-249.

Snider, L. (1998). Feminism, punishment, and the potential of empowerment. In K. Daly \& L. Maher (Eds.), Criminology at the Crossroads (pp. 75-104). New York, NY: Oxford University Press.

Song, L., \& Lieb, R. (1993). Recidivism: The effect of incarceration and length of time served (Document No. 93-09-1201). Retrieved from Washington State Institute for Public Policy website: http://www.wsipp.wa.gov/rptfiles/IncarcRecid.pdf

South, C. R., \& Wood, J. (2006). Bullying in prisons: The importance of perceived social status, prisonization, and moral disengagement. Aggressive Behavior, 32(5), 490-501

Stets, J. E., (1991). Cohabiting and marital aggression: The role of social isolation. Journal of Marriage and Family, 53(3), 669-680.

Stets, J. E., \& Straus, M. A. (1990). The marriage license as hitting license: A comparison of assaults in dating, cohabitating, and married couples. In M. A. Straus \& R. J. Gelles (Eds.), Physical Violence in American Families: Risk Factors and Adaptations to Violence in 8,145 Families (pp. 227-244). New Brunswick, NJ: Transaction Publishers.

Steurer, S. J., Smith, L., \& Tracy, A. (2001). Three state recidivism study. Retrieved from Correctional Education Association: http://www.ceanational.org/PDFs/ 3StateFinal.pdf

Stevens, J. (1992). Applied multivariate statistics for the social sciences ( $2^{\text {nd }}$ Edition). Hillsdale, NJ: Lawrence Erlbaum Associates.

Stith, S. M., Green, N. M., Smith, D. B., \& Ward, D. B. (2008). Marital satisfaction and marital discord as risk markers for intimate partner violence: A meta-analytic review. Journal of Family Violence, 23, 149-160. 
Stith, S. M., Rosen, K. H., Middleton, K. A., Busch, A. L., Lundeberg, K., \& Carlton, R. P. (2000). The intergenerational transmission of spouse abuse: A metaanalysis. Journal of Marriage and the Family, 62, 640-654.

Stith, S. M., Smith, D. B., Penn, C. E., Ward, D. B., \& Tritt, D. (2004). Intimate partner physical abuse perpetration and victimization risk factors: A meta-analytic review. Aggression and Violent Behavior, 10(1), 65-98.

Straus, M. A. (1979). Measuring intrafamilial conflict and violence: The conflict tactics (CT) scale. Journal of Marriage and the Family, 45, 75-78.

Straus, M. A. (2004). Conflict Tactics Scales (CTS) Sourcebook: Scoring the CTS2 and CTSPC. Los Angeles, CA: Western Psychological Services.

Straus, M. A., Gelles, R. J., \& Steinmetz, S. K. (1980). Behind closed doors: Violence in the American Family. New York, NY: Doubleday.

Straus, M. A., Hamby, S. L., Boney-McCoy, S., \& Sugarman, D. B. (1996). The revised conflict tactics scales (CTS2): Development and preliminary psychometric data. Journal of Family Issues, 17(3), 283-316.

Straus, M. A., \& Smith, C. (1990). Violence in Hispanic families in the United States: Incidence rates and structural interpretations. In M. A. Straus and R. J. Gelles (Eds.) Physical Violence in American Families: Risk Factors and Adaptations in Violence in 8,145 Families (pp. 341-363). New Brunswick, NJ: Transaction Books.

Substance Abuse and Mental Health Services Administration (2005). Overview of findings from the 2004 National Survey on Drug Use and Health. Retrieved September 27, 2010 from the National Criminal Justice Reference Service: http://www.ncjrs.gov/App/publications/Abstract.aspx?id=232793

Sugarman, D. B., \& Frankel, S. L. (1996). Patriarchal ideology and wife-assault: A meta-analytic review. Journal of Family Violence, 11(1), 13-40.

Swanberg, J. E., Logan, T. K., \& Macke, C. (2005). Intimate partner violence, employment, and the workplace: Consequences and future directions. Trauma, Violence, \& Abuse, 6(4), 286-312.

Sykes, G. (1958). Society of Captives: Study of a Maximum Security Prison. Princeton, NJ: Princeton University Press. 
Szinovacz, M. E., \& Egley, L. C. (1995). Comparing one-partner and couple data on sensitive marital behaviors: The case of marital violence. Journal of Marriage and Family, 57(4), 995-1010.

Tabachnick, B. G., \& Fidell, L. S. (2001). Using Multivariate Statistics, $4^{\text {th }}$ Ed. Needham Heights, MA: Allyn \& Bacon.

Tatman, A. W., Swogger, M. T., Love, K., \& Cook, M. D. (2009). Psychometric properties of the Marlowe-Crowne Social Desirability Scale with adult male sexual offenders. Sexual Abuse: A Journal of Research and Treatment, 21(1), 21-34.

Terry, C. M. (2003). The Fellas: Overcoming Prison and Addiction. Toronto, Ontario: Wadsworth/Thomson Learning.

Tittle, C. R., Villimez, W. J., \& Smith, D. A. (1978). The myth of social class and criminality: An empirical assessment of the empirical evidence. American Sociological Review, 43, 643-656.

Tjaden, P., \& Thoennes, N. (2000). Prevalence and causes of male-to-female and female-to-male intimate partner violence as measured by the National Violence against Women Survey. Violence Against Women, 6(2), 142-161.

Toch, H. (1992). Living in Prison: The Ecology of Survival (pp. 185-234). Hyattsville, MD: American Psychological Association.

Tolman, R. M. (1999). The validation of the psychological maltreatment of women inventory. Violence and Victims, 14(1), 25-37.

Tonry, M. (1999). Why are US incarceration rates so high? Crime \& Delinquency, 45(4), 419-437.

Travis, J., \& Petersilia, J. (2001). Reentry reconsidered: A new look at an old question. Crime \& Delinquency, 47(3), 291-313.

Travis, J., \& Waul, M. (2004). Prisoners Once Removed: The Impact of Incarceration and Reentry on Children, Families, and Communities. Washington, DC: The Urban Institute.

Trickett, E. J. (1984). Towards a distinctive community psychology: An ecological metaphor for training and the conduct of research. American Journal of Community Psychology, 12, 261-279. 
Trickett, E. J. (1995). The community context of disaster and traumatic stress: An ecological perspective from community psychology. In S. E. Hobfoll \& M. W. de Vries (Eds.), Extreme Stress and Communities: Impact and Intervention (pp. 11-26). AH Dordrecht, The Netherlands: Kluwer Academic Publishers

Trickett, E. J. (1996). A future for community psychology: The contexts of diversity and the diversity of contexts. American Journal of Community Psychology, 24, 209-234.

Trickett, E. J., \& Birman, D. (1989). Taking ecology seriously: A community development approach to individually based preventive interventions in schools. In L. Bond \& B. Compas (Eds.), Primary Prevention and Promotion in the Schools (pp. 361-389). Hanover, NH: University of New England Press.

Trickett, E. J., \& Buchanan, R. M. (2001). The role of personal relationships in transitions: Contributions of an ecological perspective. In B. R. Sarason \& S. Duck (Eds.), Personal Relationships: Implications for Clinical and Community Psychology (pp. 141-157). New York, NY: Wiley.

Trickett, E. J., Kelly, J. G., \& Todd, D. M. (1972). The social environment of the high school: Guidelines for individual change and organizational development. In S. E. Golann and C. Eisdorfer (Eds.), Handbook of Community Mental Health (pp. 331-406). New York, NY: Appleton-Century-Crofts.

Trickett, E. J., Kelly, J. G., \& Vincent, T. A. (1985). The spirit of ecological inquiry in community research. In E. Susskind \& D. Klein (Eds.), Community Research: Methods, Paradigms, and Applications (pp. 283-333). New York, NY: Praeger.

Trickett, E. J., \& Todd, D. M. (1972). The high school culture: An ecological perspective. Theory into Practice, 11(1), 28-37.

Tripp, B. (2003). Incarcerated African American fathers: Exploring changes in family relationships. In O. Harris \& R. Miller (Eds.), Impacts of Incarceration on the African American Family (pp. 17-31). New Brunswick, NJ: Transaction Publishers.

Tuomi Jones, N., Ji, P., Beck, M., \& Beck, N. (2002). The reliability and validity of the Revised Conflict Tactics Scale (CTS2) in a female incarcerated population. Journal of Family Issues, 23(3), 441-457.

Twenge, J. M., Campbell, W. K., \& Foster, C. A. (2003). Parenthood and marital satisfaction: A meta-analytic review. Journal of Marriage and Family, 65(3), 574-583. 
US Department of Housing and Urban Development (2011). Housing vouchers fact sheet. Retrieved May 26, 2011, from http://portal.hud.gov/hudportal/HUD?src=/ program_offices/public_indian_housing/programs/hcv/about/fact_sheet\#2

VanBuren-Trachtenberg, J., Anderson, S. A., \& Sabatelli, R. M. (2009). Work-home conflict and domestic violence: A test of a conceptual model. Journal of Family Violence, 24,471-483.

Versola-Russo, J. M., \& Russo, F. (2009). When domestic violence turns into workplace violence: Organizational impact and response. Journal of Police Crisis Negotiations, 9(2), 141-148.

Visher, C. A. \& Travis, J. (2003). Transitions from prison to community: Understanding individual pathways. Annual Review of Sociology, 29, 89-113.

Waldfogel, J. (2001). The effect of criminal conviction on income and the trust "reposed in the workmen." The Journal of Human Resources, 29(1), 62-81.

Waltz, J., Babcock, J. C., Jacobson, N. S., \& Gottman, J. M. (2000). Testing a typology of batterers. Journal of Consulting and Clinical Psychology, 68, 658-669.

Warnken, W. J., Rosenbaum, A., Fletcher, K. E., Hoge, S. \& Adelman, S. A. (1994). Head-injured males: A population at risk for relationship aggression? Violence and Victims, 9(2), 153-166.

Warren, J., Gelb, A., Horowitz, J., \& Riordan, J. (2008). One in 100: Behind bars in America, 2008. Washington, DC: The PEW Center on the States.

Webster, C. D., Douglas, K. S., Eaves, D., \& Hart, S. D. (1997). HCR-20: Assessing risk for violence (version 2). Burnaby, British Columbia: Mental Health Law \& Policy Institute, Simon Fraser University.

Western, B. Kling, J. R., \& Weiman, D. F. (2001). The labor market consequences of incarceration. Crime and Delinquency, 47(3), 410-427.

Wetzler, S. (1990). The Millon Clinical Multiaxial Inventory (MCMI): A review. Journal of Personality Assessment, 55, 445-464.

White, R. J., Gondolf, E. W., Robertson, D. U., Goodwin, B. J., \& Caraveo, L. E. (2002). Extent and characteristics of woman batterers among federal inmates. International Journal of Offender Therapy and Comparative Criminology, 46(4), 412-426. 
Williams, K. R., \& Houghton, A. B. (2004). Assessing the risk of domestic violence reoffending: A validation study. Law and Human Behavior, 28(4), 437-455.

Wooldredge, J. (2007). Convicting and incarcerating felony offenders of intimate assault and the odds of new assault charges. Journal of Criminal Justice, 35, 379-389.

Yllö, K. A., \& Straus, M. A. (1990). Patriarchy and violence against wives: The impact of structural and normative factors. In M. A. Straus \& R. J. Gelles (Eds.), Physical Violence in American Families: Risk Factors and Adaptations to Violence in 8,145 Families (pp. 383-399). New Brunswick, NJ: Transaction Publishers.

Zamble, E., \& Porporino, F. J. (1990). Coping, imprisonment, and rehabilitation: Some data and their implications. Criminal Justice and Behavior, 17(1), 53-70.

Zamble, E. \& Quinsey, V. L. (1997). The criminal recidivism process. Cambridge, MA: Cambridge University Press.

Zhang, Z. (2003). Drug and alcohol use and related matters among arrestees. Retrieved September 27, 2010 from the National Institute of Justice: http://www.ojp.usdoj.gov/nij/topics/drugs/adam.htm 